LEANDRO SAITO

\title{
Antitruste e novos negócios na Internet. Condutas anticompetitivas ou exercício regular de poder econômico?
}

Dissertação apresentada à Banca Examinadora do Programa de Pós-Graduação em Direito, da Faculdade de Direito da Universidade de São Paulo, como exigência parcial para obtenção do título de Mestre em Direito, na área de concentração Direito Comercial, sob orientação da Professora titular Paula A. Forgioni.

Universidade de São Paulo

FaCuldade de Direito

São Paulo - SP 
Catalogação da Publicação Serviço de Biblioteca e Documentação Faculdade de Direito da Universidade de São Paulo

\section{Saito, Leandro}

Antitruste e novos negócios na Internet. Condutas anticompetitivas ou exercício regular de poder econômico? / Leandro Saito ; orientadora Paula A. Forgioni -- São Paulo, 2016.

236

Dissertação (Mestrado - Programa de Pós-Graduação em Direito Comercial) - Faculdade de Direito, Universidade de São Paulo, 2016.

1. Antitruste. 2. Internet. 3. Condutas Anticompetitivas. 4. Mercados de Preco Zero. I. Forgioni, Paula A., orient. II. Título. 
"We must merely recognize that capitalism must live within certain rules. Indeed our whole view of the economy, with all of those animal spirits, indicates why the government must set those rules."

George A. Akerlof (Animal Spirits: How Human Psychology Drives the Economy, and Why It Matters for Global Capitalism) 
Autor: Leandro Saito. Título: Antitruste e novos negócios na Internet. Condutas anticompetitivas ou exercício regular de poder econômico? 2016. 236 p. Mestrado Faculdade de Direito, Universidade de São Paulo, São Paulo, 2016.

\section{RESUMO}

As profundas mudanças trazidas pela sociedade da informação, em especial o advento da Internet, tiveram enorme impacto sobre as interações humanas, modificando a forma como as pessoas se relacionam e consomem bens e serviços. Nesse contexto, surgem inúmeros serviços prestados por empresas baseadas na rede mundial de computadores. Características destes novos mercados como o uso de plataformas de múltiplos lados, o uso intensivo de novas tecnologias, a presença de efeitos ou externalidades de rede, a interligação entre serviços distintos, o oferecimento de serviços de forma gratuita ao consumidor e o entrelaçamento entre os diversos serviços prestados, desafiam conceitos tradicionais do direito concorrencial como mercado relevante, poder de mercado e venda casada. Faz-se necessária, assim, a adaptação da metodologia de análise antitruste, por meio da analise dos fundamentos teóricos que dão suporte à sua aplicação, considerando-se as particularidades presentes nesses mercados. O presente estudo tem por objetivo analisar o controle de condutas nesses novos setores de Internet por meio da análise das particularidades econômicas desses novos setores e as consequências desse enfoque sobre a análise antitruste.

Palavras-chave: Antitruste, Internet, Condutas Anticompetitivas, Mercados de Preço Zero. 
Author: Leandro Saito. Title: Antitrust and Internet new business. Anticompetitive conducts or regular exercise of economic power? 2016. 236 p. Master - Law School, University of São Paulo, São Paulo, 2016.

\begin{abstract}
The deep changes brought by the information society, especially the rising of the Internet, caused an enormous impact over human interactions, changing the way people relate and the way people consume goods and services. As a consequence of this new reality, services provided by web based companies emerged. Some characteristics of those new markets, such as the use of multiple side platforms, the intensive use of new technologies, the existence of network effects or network externalities, the connection of distinct services, the offer of zero price services and the deep connection between the services, challenge traditional concepts of antitrust law, like relevant market, market power and tying. Therefore, traditional antitrust analysis and its theoretical foundations must be reviewed, considering the particularities of those markets. The main objective of this study is to analyze the conduct control on these new Internet sectors, considering its economic particularities and the consequences of these view on antitrust analysis.
\end{abstract}

Keywords: Antitrust, Internet, Anticompetitive Conducts, Zero-price markets. 


\section{SUMÁRIO}

INTRODUÇÃO.

\section{CAPÍTULO I - FUNDAMENTOS ECONÔMICOS DAS POLÍTICAS DE DEFESA} DA CONCORRÊNCIA ........................................................................................11

I.1 Fundamentos econômicos da defesa da concorrência ..................................................13

I.1.1 Conceitos econômicos fundamentais ............................................................17

I.1.1.1 Mercado perfeitamente competitivo ………………..................................17

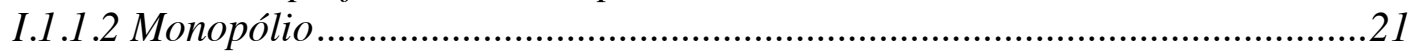

I.1.1.2.1 Os custos sociais do Monopólio ...........................................................22

I.1.1 .3 Poder de Mercado ou Poder de Monopólio .................................................24

I.1.2 O tradicional debate entre Escola de Chicago e Escola de Harvard......................31

I.1.3 Direito antitruste e eficiências dinâmicas ..................................................................35

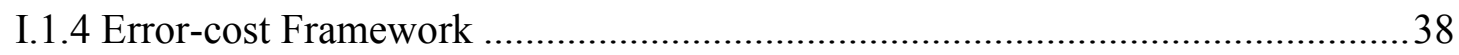

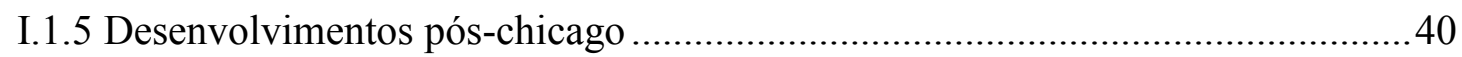

I.1.6 A influência da escola comportamental .............................................................4

\section{CAPÍTULO II - PRINCIPAIS CARACTERÍSTICAS DOS SETORES}

"PONTOCOM" .........................................................................................................................48

II.1 A criação da Internet e desenvolvimentos recentes .................................................49

II.2 Desenvolvimentos recentes e tendências futuras da internet.................................55

II.3 Governança e regulação da Internet.............................................................................59

II.4 Principais características dos setores pontocom ...........................................................61

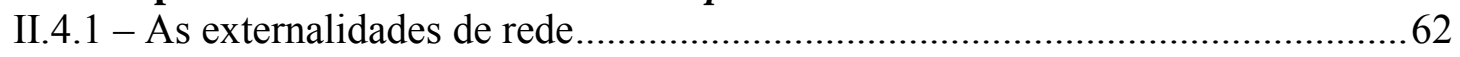

II.4.2 - Mercados de múltiplos lados ("multi-sided platforms") ........................................

II.4.3 - Mercados baseados em plataformas de software ………………………….....

II.4.3.1 - Algoritmos inteligentes ou Clever Algorithms ..........................................81

II.4.3.2 - Estrutura de governança em plataformas de software .............................86

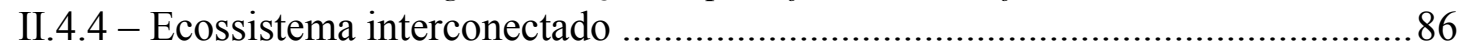

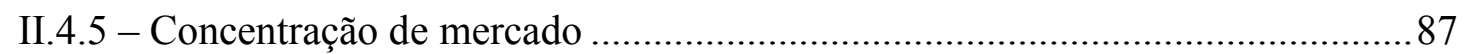

II.4.6 - Ausência de lucro por longos períodos ......................................................... 89

II.4.7 - Mercados com estrutura de preço "zero" ............................................................99

II.4.7.1 - Estrutura de preços em mercados de preço zero ......................................91

II.4.7.2 - A evolução da publicidade e os mercados de múltiplos lados ..................95

II.4.7.3 - Contribuições da Economia Comportamental para análise dos setores de

preço zero .............................................................................................96

II.4.7.4 - Contribuições da Economia dos Custos de Transação (ECT) para análise dos setores de preço zero ................................................................................99

II.4.8 - Possibilidade de customização da experiência do usuário ...............................105

II.4.9 - Elevado potencial para experimentação e inovação..........................................107

\section{CAPÍTULO III - CONDUTAS ANTICOMPETITIVAS EM SETORES}

"PONTOCOM" ..............................................................................................................110

III.1 - Intervenção antitruste sobre mercados de preço zero ......................................112

III.2 - Poder de mercado e delimitação de mercado relevante nos setores pontocom

.

III.2.1 - Delimitação do mercado relevante ...............................................................118

III.2.1.1 - Competição por atenção ......................................................................130 
III.2.1.2 - Mercado relevante nos setores pontocom ….......................................135

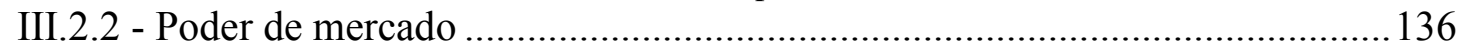

III.2.2.1 - Substituição no mercado de atenção .................................................140

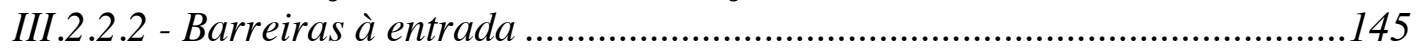

III.2.2.3 - Poder de mercado nos novos setores de Internet .................................146

III.3 - Bem estar social nos setores pontocom..............................................................149

III.4 - Condutas exclusionárias ...............................................................................................152

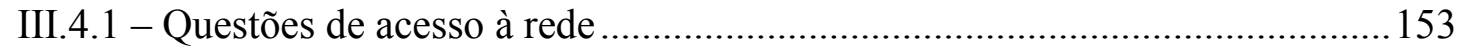

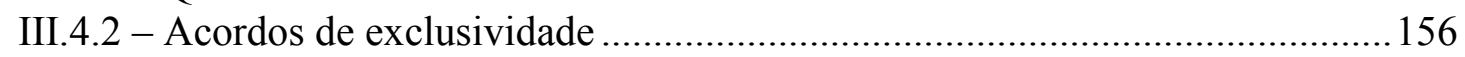

III.4.3 - Venda casada e integração de serviços ..................................................... 157

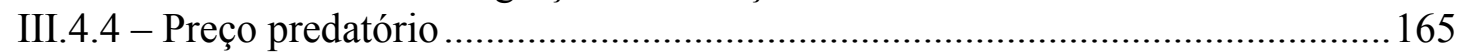

III.5 - Bases de dados e uso de informações de navegação .....................................166

III.6 - Condutas colusivas ......................................................................................167

III.7 - Regulação de setores pontocom, eficiência dinâmica e inovação ...................178

III.8 - Análise do caso Google..............................................................................................183

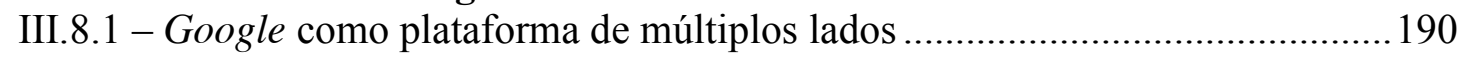

III.8.2 - Análise do poder de mercado do Google ..................................................... 195

III.8.3 - Barreiras à entrada no mercado de buscadores ............................................203

III.8.4 - Análise da conduta .................................................................................204

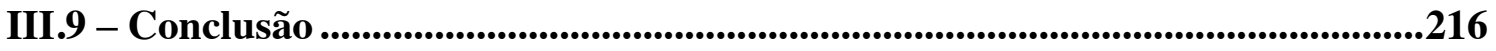

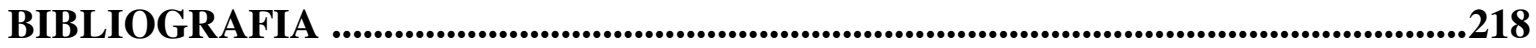




\section{INTRODUÇÃO}

A Revolução Tecnológica e o surgimento da Economia da Informação foram responsáveis por profundas mudanças sobre a sociedade e sobre as formas de interação humana. Inúmeros debates tem se travado no tocante à intervenção antitruste nos diversos setores da nova economia, que, por suas particularidades, como a existência de modestos investimentos de capital, elevadíssimas taxas de inovação, entrada e saída frequente de novos players, e economias de escala no consumo ${ }^{1}$, acabam trazendo complicações à tradicional análise antitruste de cunho neoclássico. ${ }^{2}$

Dentre os setores da nova economia, um setor que desponta como gerador de preocupações de cunho concorrencial são os novos negócios baseados em plataformas de Internet, também conhecidos como setores web-based ou setores "pontocom". Sua principal distinção em relação aos outros setores está no fato de seu modelo de negócios se basear exclusivamente, ou quase exclusivamente, em serviços providos por meio de sites hospedados na Internet. ${ }^{3}$

1 As indústrias tradicionais, por outro lado, seriam caracterizadas pela: dispersão da produção entre diversas unidades fabris e diversas firmas, mercados estáveis, elevados investimentos de capital, taxas modestas de inovação, e entrada lenta e não-frequente de novos players (RICHARD A. POSNER, Antitrust law, $2^{\text {nd }}$ ed., Chicago, The University of Chicago Press, 2001, pp. 245-246).

2 Tradicionalmente, políticas antitruste tem como base a teoria neoclássica dos mercados, sendo esta baseada na noção ortodoxa de que seu objetivo é evitar que estratégias empresariais impeçam o adequado funcionamento das forças invisíveis de mercado (JORGE FAGUNDES, Fundamentos econômicos das políticas de defesa da concorrência - Eficiência econômica e distribuição de renda em análises antitruste, São Paulo, Singular, 2003, p. 12) A aplicação destas teorias vem sofrendo inúmeras críticas, sendo sua aplicação relativizada pelas autoridades antitruste. Sua inadequação atinge a análise de quaisquer mercados, sendo, porém, patentes nos mercados de alta tecnologia. Por esta razão alguns, como CALIXTO SALOMÃO FILHO e LUIZ FERNANDO SCHUARTZ, defendem que o advento dos estudos da Economia da Informação, baseados nas teorias da hard uncertainty, proposta por KEYNES, levam a uma crise de justificação do direito concorrencial e a uma paralisia do direito antitruste (CALIXTO SALOMÃO FILHO, A paralisia do antitruste, In EDUARDO MOLAN GABAN; JULIANA OLIVEIRA DOMINGUES (coord.), Estudos de direito econômico e economia da concorrência em homenagem ao Prof. Dr. Fábio Nusdeo, Curitiba, Juruá, 2009, pp. 15-31; e LUIZ FERNANDO SCHUARTZ, Mercados de Novas Tecnologias Crise Anunciada do Direito da Concorrência?, In MARCO AURÉLIO GRECO, IVES GANDRA DA SILVA MARTINS, (Org.), Direito e Internet - Relações Jurídicas na Sociedade Informatizada, São Paulo, Revistas dos Tribunais, 2001).

Isso não impede, evidentemente, que estas empresas estabeleçam escritórios físicos para gerenciamento e desenvolvimento destas atividades, como podemos constatar nos enormes escritórios espalhados ao redor do mundo de empresas como Google e Facebook. 
O surgimento destes novos serviços teve um boom ao longo dos últimos anos, fazendo surgir uma verdadeira febre de startups que tinham como principal objetivo se tornar o novo Facebook ${ }^{4}$. A pujança e o enorme crescimento destes setores, aliados à enorme complexidade ligada ao seus detalhes de funcionamento e aos seus modelos de negócio, levaram ao surgimento de práticas anticompetitivas extremamente sofisticadas, que, constantemente, desafiam a análise das autoridades antitruste em diferentes países. Exemplos destes questionamentos foram os inúmeros processos abertos contra empresas como Google e Facebook. ${ }^{5}$

A origem destes novos setores, porém, remonta à criação da Internet e de sua abertura à exploração comercial no ano de 1998. Já neste período inicial, o Departamento de Justiça dos EUA demonstrou sérias preocupações quando determinou a abertura de processo contra a empresa Microsoft por práticas anticoncorrenciais relacionadas aos navegadores de internet (browsers). ${ }^{6} \mathrm{O}$ enorme crescimento do setor nos últimos anos, bem como o crescimento exponencial de importância destas empresas na nova economia trazem consigo um aumento de preocupação das autoridades regulatórias e, consequentemente, dos casos envolvendo condutas anticompetitivas praticados por estas empresas. $^{7}$

Características destes mercados como o uso de plataformas de múltiplos lados, o uso intensivo de novas tecnologias, a presença de efeitos ou externalidades de rede, a interligação entre serviços distintos, o oferecimento de serviços de forma gratuita ao consumidor e o entrelaçamento entre os diversos serviços prestados, desafiam conceitos

\footnotetext{
$4 \quad$ Fundada em 2004 pelo jovem MARK ZUCKERBERG (então com 19 anos) com outros estudantes da Universidade de Harvard, o que começou como um experimento universitário baseado em um pequeno site em curto período de tempo se tornou uma das maiores empresas do mundo, alcançando receitas brutas superiores a 7,8 bilhões de dólares em 2013 (Conforme dados disponíveis em: http://bit.ly/1a3qoRJ, acesso no dia 29, jun., 2014).

5 Os casos da empresa Google serão analisados com maiores detalhes no CAPÍTULO III.

6 Para maiores detalhes sobre o caso vide LEANDRO SAITO, A “propriedade" intelectual como barreira à entrada de novos players no mercado de softwares, IBPI. 2012. Disponível em: http://bit.ly/1MQEGIp, acesso no dia 8, nov., 2015.

7 Conforme aponta DAVID S. EVANS, "The internet economy is likely to raise antitrust concerns and possibly demands for regulation - for years to come. Gargatuan global firms have emerged, which will likely attract scrutiny by competition authorities and by policymakers concerned with competition issues." (DAVID S. EVANS, Antitrust issues raised by the emerging global internet economy, In Northwestern University Law Review, vol. 102, n.4, 2008, p. 2).
} 
tradicionais do direito concorrencial como mercado relevante, poder de mercado e venda casada.

Um exemplo dessa inadequação pode ser vista no caso da tradicional delimitação de mercado relevante nas análises antitruste. Tradicionalmente, processos de análise de condutas e extruturas se iniciam com a delimitação dos mercados relevantes geográfico e material, com o objetivo de delimitar os market shares das empresas que atuam no setor analisado, para com tais medidas se inferir o poder de mercado da empresa. Porém, o que notamos em casos de empresas pontocom é que tal delimitação se mostra inadequada uma vez que, conforme demonstraremos, estas novas empresas muitas vezes concorrem com empresas que oferecem serviços completamente diferentes e que, segundo esta metodologia estariam em mercados relevantes distintos.

Como consequência da inadequação do conceito tradicional de mercado relevante surge um descompasso com relação à definição de poder de mercado e de poder de monopólio, uma vez que uma definição de market share superestimada pode levar à atribuição de poder de mercado a um agente que não possui tal característica. Nota-se, assim, que a análise da autoridade concorrencial deve passar por diversas adaptações de seus conceitos com o objetivo de se adequar a realidade destes novos mercados.

Neste ponto podemos delimitar a questão central do presente trabalho: a análise das condutas anticompetitivas praticadas por empresas dos novos setores surgidos com o advento da Internet (empresas pontocom ou web-based). Como corte metodológico decidiu-se por estudar apenas o controle de condutas, uma vez que a análise do controle de estruturas destes setores acabaria por tornar o trabalho demasiado extenso. Além disso, decidiu-se por analisar apenas condutas praticadas por empresas cujas atividades surgem, justamente, com o advento da Internet, tendo seus modelos de negócios baseados exclusivamente ou quase exclusivamente em web. Dessa forma, não constitui objeto do presente estudo a análise de setores tradicionais que estenderam suas atividades para a Internet ao longo dos últimos anos ou que passaram a utilizá-la como nova plataforma de venda de seus bens e serviços. ${ }^{8}$

Desta forma, este trabalho tem como objetivos principais sistematizar a literatura econômica sobre a concorrência nos setores “pontocom”, analisar os fundamentos teóricos

\footnotetext{
8 Como exemplo podemos citar o e-commerce, que nada mais é do que a extensão da atividade de empresas varejistas para as vendas on-line, em substituição ou complementação a venda em lojas físicas.
} 
que dão suporte à aplicação do direito antitruste quando confrontados com esta nova realidade, e, por fim, consolidar novos parâmetros de aplicação do direito concorrencial nestes setores.

A escolha do presente tema se justifica pela baixa disponibilidade de pesquisas e trabalhos acadêmicos publicados sobre o assunto, bem como pela importância que estes setores vem desempenhando na moderna economia. O risco de aplicação de sanções ineficazes, ou mesmo da desconsideração da real extensão de algumas práticas nestas indústrias levam a uma necessidade urgente de revisão da literatura antitruste tradicional.

O Capítulo I iniciará com uma breve exposição dos fundamentos teóricos da economia neoclássica que dão suporte à aplicação do direito concorrencial, para depois serem analisados os atuais desenvolvimentos da matéria, com os recentes questionamentos das teorias pós-chicago, como a economia dos custos de transação, a teoria dos mercados contestáveis e a teoria dos jogos, sendo, por fim, analisadas as recentes influências da escola da Economia Comportamental.

O Capítulo II tratará das principais características dos mercados de Internet. Partiremos de um breve histórico da criação da Internet, desde seu surgimento como projeto estatal até sua abertura comercial e posterior explosão do surgimento de empresas pontocom a partir dos anos 90 . Em seguida serão analisados os fundamentos econômicos que dão suporte à análise destes setores, como a problemática dos efeitos de rede, dos mercados de múltiplos lados, a estrutura de mercados de preço zero e a questão da eficiência dinâmica.

O Capítulo III trará uma análise pormenorizada das condutas anticompetivas praticadas por empresas deste setor, buscando enfrentar as principais questões relacionadas à aplicação da metodologia antitruste tradicional diante das particularidades dos setores pontocom. Como casos exemplificativos serão analisados os casos da empresa Google que vem já vem sendo analisados pelas principais autoridades antitruste do mundo, inclusive pelo Sistema Brasileiro de Defesa da Concorrência. 


\section{CAPÍTULO I - FUNDAMENTOS ECONÔMICOS DAS POLÍTICAS DE DEFESA DA CONCORRÊNCIA}

A partir dos escritos de Adam Smith, no século XVIII, tornou-se senso comum a noção de que a livre concorrência e a liberdade dos agentes econômicos levariam à eficiência econômica do sistema, ao aumento do bem estar e ao desenvolvimento econômico. Tais ideias partem do princípio de que o bem estar econômico geral é atingido não pela benevolência dos agentes, mas sim pela busca do auto interesse, uma vez que a mão invisível dos mercados gera um resultado ótimo. ${ }^{9}$ Com base nestas concepções, o capitalismo moderno tomaria a livre concorrência e a livre iniciativa como principais fundamentos para o desenvolvimento econômico e incremento do bem estar geral. ${ }^{10}$

Nos anos que se seguiram, porém, o desenvolvimento econômico viria demonstrar que o sistema capitalista contém imperfeições cujos efeitos autodestrutivos poderiam leválo ao colapso. ${ }^{11}$ A teoria econômica passou então a estudar as chamadas falhas de mercado: situações em que os mecanismos de mercado não funcionam adequadamente, por conta de imperfeições como a existência de informação assimétrica, custos de transação e externalidades, além da ocorrência de estruturas de mercado de concorrência imperfeita. Diante destas falhas, as teorias normativas de regulamentação passaram a defender que o

9 Conforme famosa frase de ADAM SMITH em seu livro seminal A Riqueza das Nações: "It is not from the benevolence of the butcher the brewer, or the baker that we expect our dinner, but from their regard to their own interest" (ADAM SMITH, An inquiry into the nature and causes of the wealth of nations, edição eletrônica, disponível em: http://bit.ly/1dPsCAF, acesso no dia 27/06/2014, p. 19).

10 Segundo ROBERT PITOFSKY: "for most of our history, a free market and free trade have been central characteristics of the United States economy", sendo esta uma das principais razões para a eficiência no uso dos recursos de que gozou a economia do país. "Toward the end of the nineteenth century, however, people began to realize that absolute free market opportunities could be abused by giant corporations, and indirectly by the concentration of economic power, and that some limits on private sector behavior had to be established" (ROBERT PITOFSKY, Introduction: Setting the stage, In ROBERT PITOFSKY, How the Chicago school overshot the mark - The effect of conservative economic analysis on U.S. antitrust, Oxford University Press, 2008, p.3).

11 Conforme aponta VINICIUS MARQUES DE CARVALHO, o próprio papel do Estado sofre alterações quando passa a exercer papéis positivos de atuação: "No sistema de economia política clássico, reservava-se ao Estado funções negativas em relação ao bem-estar social. O interesse público decorria da capacidade do Estado para realizar a missão de garantir o sistema de livre concorrência, cuja prevalência asseguraria o equilíbrio econômico e social. Já no Estado pós-liberal, o principal objetivo da política econômica era a expansão da renda nacional e o desenvolvimento das forças produtivas por meio da ação propulsive do Estado." (VINICIUS MARQUES DE CARVALHO, Poder Econômico e Defesa da Concorrência: reflexões sobre a realidade brasileira, In GUEDES, Jefferson Carús; NEIVA, Juliana Sahione Mayrink (org.), Publicações da Escola da AGU: Debates em Direito da Concorrência, Brasília, Advocacia Geral da União, 2011, p. 297). 
Estado deve intervir quando o sistema de preços falha ${ }^{12}$, de modo a garantir o adequado funcionamento dos mercados. Da mesma forma, ao final do século XIX e especialmente ao longo do século XXI, cresce a consciência de que o enorme poder exercido pelas grandes corporações deveria ser de alguma forma limitado. ${ }^{13}$

Diversos instrumentos seriam dados ao Estado para limitação deste poder e para formatação do mercado. Enquanto as externalidades e a informação assimétrica deveriam ser objeto de regulamentação social $^{14}$, a regulamentação econômica ${ }^{15}$ teria lugar nas situações de monopólio natural; a política industrial ${ }^{16}$ atuaria nas falhas intertemporais de mercado e a política antitruste teria como função controlar o poder de mercado decorrente

12 ELIZABETH M. M. Q. FARINA, ET. AL., Competitividade: Mercado, Estado e organizações, São Paulo, Singular, 1997, p. 115.

13 "Quanto mais atomizado o poder econômico, mais espaço para uma ação coordenada macroeconômica, na medida em que maior poder se confere ao centro decisório nacional e mais distante essa racionalidade fica da soma das racionalidades individuais. Por outro lado, quanto maior a concentração de poder econômico, maior o espaço influência dos agentes na racionalidade macroeconômica, mais próxima ela se torna da soma das racionalidades microeconômicas. Enfim, o poder econômico concentrado pode limitar a capacidade de o Estado ordenar variáveis macroeconômicas, e de formular e implementar um conjunto coerente de diretrizes chamado política econômica." (VINICIUS MARQUES DE CARVALHO, Poder Econômico e Defesa da Concorrência: reflexões sobre a realidade brasileira, In GUEDES, Jefferson Carús; NEIVA, Juliana Sahione Mayrink (org.), Publicações da Escola da AGU: Debates em Direito da Concorrência, Brasília, Advocacia Geral da União, 2011, p. 302).

14 As externalidades se referem às situações em que o cálculo privado for distinto do cálculo social da produção, ou seja, nos casos em que os bens não possam ser inseridos dentro da lógica de mercados competitivos que atribuam preços aos bens, ou nos casos em que estes custos não sejam internalizados nos preços dos bens. A informação assimétrica, por sua vez, também impede que o sistema de preços opere de forma correta, uma vez que os consumidores não terão consciência completa dos efeitos associados ao consumo de determinados produtos, ao mesmo tempo em que os produtores não terão informações completas sobre os seus consumidores (ELIZABETH M. M. Q. FARINA, ET. AL., Competitividade: Mercado, Estado e organizações, São Paulo, Singular, 1997, pp. 115-117).

15 O poder de monopólio ocorre as situações em que um único produtor (ou um pequeno grupo) tenha a capacidade de restringir a oferta, elevando os preços acima do nível de concorrência. Tal situação não é eficiente, uma vez que a quantidade ofertada não estará no ponto de ótimo. O monopólio natural, por sua vez, ocorre nas situações em que o número de empresas que minimiza o custo total de uma indústria é de apenas um agente. A teoria econômica prevê que, nestas situações, as forças de mercado devem ser substituídas pela regulamentação ou pela prestação dos serviços pelo próprio estado (ELIZABETH M. M. Q. FARINA, ET. AL., Competitividade: Mercado, Estado e organizações, São Paulo, Singular, 1997, p. 118-120). GESNER OLIVEIRA aponta que a regulação econômica surge justamente nestas situações de falha de mercado, nas quais o monopólio estatal foi substituído pela privatização seguido da forte regulamentação através da criação de diversas agências reguladoras (GESNER OLIVEIRA; JOÃO GRANDINO RODAS, Direito $e$ economia da concorrência, 2a ed., São Paulo, Revista dos Tribunais, 2013, p. 144-149).

16 A política industrial, inicialmente associada a ideia de eliminação da concorrência internacional com o fim de permitir e estimular o desenvolvimento da indústria doméstica, após o declínio das teorias de desenvolvimento, passam a ser associadas às necessidades de manutenção da competitividade de nações já desenvolvidas (ELIZABETH M. M. Q. FARINA, ET. AL., Competitividade: Mercado, Estado e organizações, São Paulo, Singular, 1997, p. 123-124). 
de estruturas oligopolizadas. ${ }^{17}$

Cumpre ressaltar que a regulação antitruste é residual, uma vez que tem como propósito promover a competição nas situações em que as escolhas de mercado já não tenham sido moldadas por outras intervenções regulatórias. Por esta razão, HOVENKAMP afirma que o antitruste tem como preocupação "the proper allocation of regulatory power between the antitrust laws and other legal regimes, such as the intellectual property laws, federal telecommunications law, state regulation of public utilities, or municipal regulation of land use". ${ }^{18}$

É importante destacar que não há consenso acerca da conceituação do direito antitruste, ou de defesa da concorrência, ou mesmo quanto a definição de seu objeto de estudo. GESNER OLIVEIRA e JOÃO GRANDINO RODAS buscam traçar uma definição geral da disciplina como o "conjunto de regras jurídicas destinadas a apurar, reprimir e prevenir as várias modalidades de abuso do poder econômico, com o intuito de impedir a monopolização de mercados e favorecer a livre iniciativa, em favor da coletividade". ${ }^{19}$ Outra definição geral é feita a partir do objeto da disciplina: harmonizar o interesse público com os desejos privados de maximização de lucros, enfrentando-se para tanto o poder de monopólio, seja através do controle de estruturas, buscando aproximá-las de características que se espera levem a resultados desejados, seja através da punição de condutas indesejadas praticadas pelas firmas. ${ }^{20}$

\section{$\underline{\text { I.1 Fundamentos econômicos da defesa da concorrência }}$}

O fim da Guerra de Secessão norte-americana no século XIX e o enorme crescimento econômico vivenciado por setores como a siderurgia, as ferrovias e o petróleo,

17 EliZABETH M. M. Q. FARINA, ET. AL., Competitividade: Mercado, Estado e organizações, São Paulo, Singular, 1997, p. 115.

18 Ainda, conforme o autor, o direito antitruste entende que os mercados funcionam bem e, por esta razão, seu papel é o de criar incentivos de segunda ordem que desenvolvam estruturas de mercado adequadas e desencorajem condutas anticompetitivas. É por esta razão que este é reativo, ou seja, ele não deve definir quais estratégias empresariais as firmas podem adotar, mas apenas julgar sua legalidade na medida em que estas realizem tais estratégias (HERBERT HOVENKAMP, The antitrust enterprise - Principle and execution, Cambridge, Harvard University, 2005, p. 13-15).

19 GESNER OLIVEIRA; JOÃO GRANDINO RODAS, Direito e economia da concorrência, 2a ed., São Paulo, Revista dos Tribunais, 2013, p. 43-44.

20 ELIZABETH M. M. Q. FARINA, ET. AL., Competitividade: Mercado, Estado e organizações, São Paulo, Singular, 1997, p. 120. Esta é a clássica divisão do direito concorrencial entre o controle de estruturas, também chamado de controle dos atos de concentração, e o controle de condutas. 
levaram a um intenso processo de concentração econômica nos Estados Unidos, com a caraterização de condutas anticompetitivas que tinham por intuito principal prejudicar os concorrentes. Neste contexto de enorme poder dos trusts foram criadas as primeiras leis de regulamentação e contenção do poder destes conglomerados, como é o caso do famoso Sherman Act, editado em 1890, que tinha o objetivo de limitar tentativas de restrição do comércio e monopolização, por meio da proibição de qualquer forma de truste ou similar. ${ }^{21}$

Importante ressaltar que o surgimento de regras disciplinadoras de condutas de agentes econômicos remonta à disciplina da repressão de monopólios da antiguidade clássica. Porém, é certo que o uso técnico da palavra concorrência, ligada ao sentido de regulação de mercado, tem origem no século XVIII. Por este motivo, a noção de defesa da concorrência como entendemos hoje surge apenas no final do século XIX com o Sherman Act. $^{22}$

No Brasil, a disciplina tem suas raízes nas leis de proteção da economia popular da década de 1930, que já traziam implícita a noção de proteção dos mercados para garantia do bem estar dos consumidores. A ideia de proteção institucional da concorrência, porém, surge apenas com o Decreto Lei no 7666 de 1945, conhecido como Lei Malaia e considerado por muitos como nossa primeira Lei Antitruste. O Decreto foi responsável por criar a Comissão Administrativa de Defesa Econômica, que anos depois viria a ter seu nome modificado para Conselho Administrativo de Defesa Econômica (CADE), órgão cuja competência principal consiste na prevenção e a repressão de infrações contra a ordem econômica. $^{23}$

Ainda que seja perigoso tentarmos traçar uma definição geral dos objetivos da lei antitruste $^{24}$, uma vez que estes decorrem da interpretação de uma série de princípios

21 Tradicionalmente credita-se ao Canadá a elaboração da primeira lei concorrencial da história, uma vez que seu Act for the Prevention and Suppression of Combinations formed in Restraint of Trade foi editado em 1889. Entretanto, apenas um ano mais tarde, surge nos Estados Unidos o Sherman Act. (GESNER OLIVEIRA; JOÃO GRANDINO RODAS, Direito e economia da concorrência, 2 ed., São Paulo, Revista dos Tribunais, 2013, pp. 17-20).

22 PAUlA A. FORGIONI, Os fundamentos do antitruste, 6 ed., São Paulo, Revista dos Tribunais, 2013, pp. 34-37.

23 Para mais informações relacionadas à evolução da defesa da concorrência no Brasil consultar VICENTE BAGNOLI, Introdução ao Direito da Concorrência: Brasil, Globalização, União Européia, Mercosul, Alca, São Paulo, Singular, 2005, pp. 67-98.

$24 \quad$ Uma vez que a lei antitruste desempenhará em cada local e de acordo com cada momento histórico um papel diferente, além de não haver um único objetivo a ser perseguido, como fazem crer as escolas 
econômicos definidos pelos sistemas legais de cada país, é possível afirmar, de um modo amplo, que o principal objetivo da política de defesa da concorrência é a proteção do processo competitivo, ou a defesa da concorrência, enquanto instituição. ${ }^{25}$ Não se tem como objeto, portanto, a proteção dos concorrentes individualmente considerados, mas sim a garantia do processo competitivo que levará a sociedade a um aumento de eficiência econômica, com melhor qualidade dos produtos, menores preços e incentivos à inovação. ${ }^{26-27}$

$\mathrm{O}$ argumento econômico que dá fundamento para aplicação das políticas antitruste está na possibilidade de acúmulo assimétrico de poder de mercado, o qual pode levar os agentes a manipularem as condições de concorrência a seu favor. A consequência desta assimetria seria a redução da eficiência de Pareto $^{28}$ e dos níveis de bem estar, decorrentes da elevação dos preços. De certa forma, podemos dizer que o objetivo "geral" da defesa da concorrência seria a promoção do bem estar social, através da busca por um subconjunto de objetivos particulares. ${ }^{29}$

Conforme destacamos, porém, não se trata de definir um único objetivo a ser perseguido pelo Direito Concorrencial, uma vez que, segundo aponta PAULA A. FORGIONI, a lei Antitruste "é instrumental a uma determinada política econômica,

econômicas associadas à linha de pensamento da Escola de Chicago (PAULA A. FORGIONI, Os fundamentos do antitruste, 6 ed., São Paulo, Revista dos Tribunais, 2013, p. 160-164).

25 HERBERT HOVENKAMP aponta que as leis antitruste tem como principal objetivo a manutenção da competição nos mercados, sendo esta entendida como o estado em que os preços não sejam excessivos mas sejam suficientes para cubrir os custos das empresas, mantendo-se os adequados incentivos para inovação (HERBERT HOVENKAMP, The antitrust enterprise - Principle and execution, Cambridge, Harvard University, 2005, p. 13).

26 JULIANA OLIVEIRA DOMINGUES, Concorrência e defesa comercial, In PEDRO ZANOTTA; PAULO BRANCHER, Desafios atuais do direito da concorrência, São Paulo, Singular, 2008, p. 150.

27 A defesa da concorrência geralmente é associada aos três componentes básicos do conceito de eficiência: (i) eficiência produtiva; (ii) eficiência alocativa; e (iii) eficiência na inovação. (ANDRÉA PEREIRA MACERA; CARMEN DIVA BELTRÃO MONTEIRO, Antitruste versus Antidumping: reconciliando políticas através da Cláusula do Interesse Nacional, In Revista de Políticas Públicas e Gestão Governamental, vol. 7, n. 1, 2008, p. 32).

28 "A state of the economy is said to be Pareto optimal if no consumer can be made better off by reallocating productive resources and engaging in mutually beneficial trades without making another consumer worse off; Pareto optimality thus represents a state of maximal consumer welfare." (YOON-HO ALEX LEE; DONALD J. BROWN, Competition, consumer welfare, and the social cost of monopoly, In Yale Law School legal scholarship repository, disponível em: http://bit.ly/20EUPEX, acesso no dia 8, nov., 2015, p. 8).

29 JORGE FAGUNDES, Fundamentos econômicos das políticas de defesa da concorrência Eficiência econômica e distribuição de renda em análises antitruste, São Paulo, Singular, 2003, p. 12. 
possuindo, por consequência, objetivos bem próprios, diversos daqueles das demais leis antitruste." 30 Basta lembrarmos que a base normativa das políticas de defesa da concorrência, diferentemente de outras políticas econômicas, é a Lei, sendo esta distinta nos diferentes países. Além disso, a própria definição de conceitos como "maximização do bem estar" traz poucas respostas em relação à definição de regras de aplicação do direito antitruste. $^{31}$

Os princípios positivados nas legislações antitrustes dependem em grande medida da teoria econômica para que sejam adequadamente interpretados pelo jurista. Dessa forma, a base normativa tradicional das políticas de defesa da concorrência é a teoria neoclássica dos mercados, e a sua missão, segundo tal escola, consiste em evitar estratégias empresariais que tragam desequilíbrios às forças de mercado. Por esta razão, afirma-se que o pilar fundamental das políticas antitruste é a proteção da concorrência contra alguns efeitos criados pelo próprio sistema. A busca do lucro pelos agentes privados, ao mesmo tempo em que poderia levar à maximização do bem estar, poderia, também, em algumas situações, levar ao acúmulo assimétrico de poder econômico e, consequentemente, ao seu abuso. $^{32}$

Afirma-se, então, que o argumento fundamental a favor da implementação de políticas antitruste consiste na visão da concorrência como um processo em que a mão invisível dos mercados levaria ao bem estar máximo.

A escola econômica neoclássica, vale ressaltar, surge após a revolução marginalista da economia, que teve como seus primeiros teóricos WILLIAM JEVONS, CARL MENGER e LÉON WALRAS. A principal mudança proposta por tais pensadores consiste na introdução da Teoria da Utilidade Marginal, da qual derivam os conceitos de escolha marginal e curva de custo marginal. Ao contrário da escola clássica, que partia da noção de valor como a quantidade de trabalho incorporado em uma mercadoria, os teóricos marginalistas passaram a sustentar que o valor depende inteiramente da utilidade. Além disso, a escola marginalista passa a defender que mais importante do que o grau total de

30 PAUla A. FORGIONI, Os fundamentos do antitruste, 6 ed., São Paulo, Revista dos Tribunais, 2013, p. 163.

31 HERBERT HOVENKAMP, The antitrust enterprise - Principle and execution, Cambridge, Harvard University, 2005, p. 14.

32 JORGE FAGUNDES, Fundamentos econômicos das políticas de defesa da concorrência: Eficiência econômica e distribuição de renda em análises antitruste, São Paulo, Singular, 2003, p. 12. 
utilidade extraída de um bem seria o grau final de utilidade, ou seja, sua utilidade marginal. ${ }^{33}$

Tais proposições afetaram profundamente a teoria do valor da escola clássica, especialmente no tocante a noção de valor subjetivo, porquanto a escola clássica entendia que o valor seria objetivamente mensurado enquanto os marginalistas irão defender que sua mensuração seria subjetiva. Tais postulados trariam profundo impacto sobre todo pensamento econômico da época, estendendo-se tal influência até os dias de hoje. Assim, para que possamos compreender os fundamentos econômicos que dão base para a aplicação do direito antitruste na atualidade, cumpre realizarmos uma melhor explicação de alguns conceitos microeconômicos decorrentes da teoria neoclássica.

\section{I.1.1 Conceitos econômicos fundamentais}

O modelo econômico neoclássico trouxe ao antitruste uma série de princípios econômicos fundamentais. A noção marginalista levou à constatação de que a curva de demanda é negativamente inclinada, uma vez que unidades adicionais do bem levam a diminuição de sua utilidade para o indivíduo, consequentemente levando a uma menor disposição deste para adquiri-lo. Conforme veremos, tal modelo demonstrou que a situação de concorrência perfeita maximiza o bem estar geral, porque o volume produzido é o maior possível, enquanto os preços são os mais baixos.

\section{I.1.1.1 Mercado perfeitamente competitivo}

Um primeiro modelo teórico que se desenvolve para fins de análise econômica é o do mercado perfeitamente competitivo ou de concorrência perfeita. O mercado competitivo geralmente é associado à ocorrência de duas características fundamentais: (i) os bens são comercializados ao seu preço de custo (no caso, ao Custo Marginal de produção da mercadoria $^{34}$ ); e (ii) todas as pessoas que estão dispostas a pagar determinado preço por

33 E. K. HUNT, História do pensamento econômico - Uma perspectiva crítica, tradução da 2 ed., Rio de Janeiro, Elsevier, 2005, pp. 236 e ss.

34 Se considerarmos $p$ o preço dado em determinado mercado, a receita para uma quantidade $q$ será dada por: " $R(q)=p . q$ ". A Receita Marginal nessa situação será dada por: " $R M g(q)=p \cdot(q+1)-p . q=q$ ". Nessa situação percebemos que o preço será igual à Receita Marginal. Se lembrarmos que no ponto de maximização de lucro o produtor iguala a Receita Marginal ao Custo Marginal, teremos que, nessa situação o preço será igual à Custo Marginal. É por esta razão que se afirma que no mercado de concorrência perfeita o preço tende a se igualar ao Custo Marginal de produção (BERNARDO GUIMARÃES; CARLOS EDUARDO GONÇALVES, Introdução à economia, Rio de Janeiro, Elsevier, 2010, p. 44). 
um bem podem adquiri-lo. ${ }^{35}$ As condições que geralmente levam à concorrência perfeita, por sua vez, são: existência de bens homogêneos, ausência de barreiras à entrada e à saída, amplo acesso a informação (informação perfeita), ausência de custos de transação, presença de ofertantes como tomadores de preços (price takers) e ausência de externalidades. ${ }^{36}$

Em um mercado perfeitamente competitivo, as firmas maximizam lucro igualando o custo marginal à receita marginal, que nesta situação será igual ao preço. Por conta disso, tais mercados apresentam três grandes resultados: (i) a condição de lucro econômico zero; (ii) o equilíbrio de mercado e (iii) a maximização do bem estar social. ${ }^{37}$

Os mercados competitivos tendem ao equilíbrio por conta da lei da oferta e da demanda, segundo a qual os preços no mercado serão uma função da relação entre a disponibilidade de um produto no mercado e a disposição dos consumidores, na margem, de arcar com aqueles preços para adquiri-los. A demonstração gráfica desta lei demonstra que a curva de demanda será decrescente com o aumento da quantidade ao passo que a curva de oferta será crescente com o aumento da quantidade. Tal evidência decorre da noção marginalista de que o aumento da quantidade de um bem faz com que o consumidor tenha cada vez menor satisfação e, portanto, esteja disposto a arcar com um valor cada vez menor para adquiri-lo. ${ }^{38}$ Da mesma forma, os produtores, ao aumentarem as quantidades

35 HERBERT HOVENKAMP, Federal antitrust policy - The law of competition and its practice, $2^{\text {nd }}$ ed., St. Paul, West Group, 1999, p. 3.

36 HERBERT HOVENKAMP, Federal antitrust policy - The law of competition and its practice, $2^{\text {nd }}$ ed., St. Paul, West Group, 1999, p. 3. Geralmente o mercado competitivo se associa a existência de inúmeros pequenos compradores adquirentes de produtos homogêneos, ausência de barreiras à entrada e à saída, e empresas como price takers (ROGER D. BLAIR; CELESTE K. CARRUTHERS, The economies of monopoly power in antitrust, In KEITH N. HILTON, Antitrust law and economics, Encycplopedia of law and economics, 2 ed., Northhampton, MPG Books, 2010, p. 65). Ainda em sentido semelhante: "A perfectly competitive market is on that obeys the following assumptions: 1) There are a large number of firma, each producing the same homogenous product; 2) Each firm attempts to maximize profits; 3) Each firm is a pricetaker: It assumes that its actions have no effect on market price; 4) Prices are assumed to be known by all market participant - information is perfect; 5) Transactions are costless: Buyers and sellers incur no costs in making exchanges" (CHRISTOPHER SNYDER; WALTER NICHOLSON, Microeconomic theory: Basic principles and extensions, 11 ed., Cengage Learning, 2012, p. 371).

37 ROGER D. BLAIR; CELESTE K. CARRUTHERS, The economies of monopoly power in antitrust, In KEITH N. HILTON, Antitrust law and economics, Encycplopedia of law and economics, 2 ed., Northhampton, MPG Books, 2010, p. 65.

38 Conforme BERNARDO GUIMARÃES e CARLOS EDUARDO GONÇALVES, a utilidade marginal de um bem é decrescente com o aumento da quantidade demandada: "É comum em economia trabalharmos com a hipótese de que o benefício marginal das coisas reduz-se à medida que as possuímos em maior abundância. Comer o primeiro pedaço de bolo me gera enorme prazer, comer o segundo ainda é bom, mas já um pouco menos prazeroso; o terceiro ainda vai, mas já desce sem aquela alegria; no quarto eu paro, pois o benefício marginal, ou adicional já é pequeno". Sendo esta a razão para que a curva de demanda seja 
produzidas, incorrem em custos de produção cada vez maiores (uma vez que deverá aumentar o tamanho de sua indústria, de funcionários, de custos de fiscalização e supervisão, dentre outros), e, por isso, o preço que ele estará disposto a receber para produzir uma unidade adicional será cada vez maior.

Do equilíbrio entre estas duas forças contrapostas surge o preço de equilíbrio, o qual, na ausência de possibilidade de discriminação de preços, será o mesmo para todos os consumidores. Isso faz com que surja o chamado excedente do consumidor (consumer surplus), que consiste justamente na diferença entre o preço que os consumidores estão dispostos a pagar e o preço que efetivamente pagam. ${ }^{39}$ Por outro lado, os produtores também possuem custos de produção diferentes entre si, e isso faz com que alguns estejam dispostos a vender seu produto por um preço menor do que o preço de mercado. A diferença entre o preço que o produtor recebe e o que ele está disposto a receber é chamado de excedente do produtor (producers surplus). ${ }^{40-41}$

Outro conceito fundamental é o de elasticidade, que consiste na variação percentual da quantidade em relação à variação percentual do preço $^{42}$. A elasticidade pode se referir à demanda, quando relaciona a quantidade demandada de um bem " $x$ " à variação percentual do preço do bem " $x$ ", ou se referir à oferta, quando relaciona os preços de um bem " $\mathrm{x}$ " com a quantidade ofertada deste bem. Nos casos em que a variação da quantidade em relação ao preço é substancial, dizemos que a demanda ou a oferta é elástica (em termos matemáticos, a elasticidade depende de seu valor ser maior do que 1); já quando ocorre pouca variação de quantidade com o aumento do preço, dizemos que a demanda ou oferta

negativamente inclinada, ou seja, decresça de acordo com o aumento da quantidade demandada. (BERNARDO GUIMARÃES; CARLOS EDUARDO GONÇALVES Introdução à economia, Rio de Janeiro, Elsevier, 2010, pp. 12-13).

39 "Consumer surplus is the difference between market price and the minimum price at which a given quantity would be produced" (ROGER D. BLAIR; CELESTE K. CARRUTHERS, The economies of monopoly power in antitrust, In KEITH N. HILTON, Antitrust law and economics, Encycplopedia of law and economics, 2 ed., Northhampton, MPG Books, 2010, p. 65).

$40 \quad$ "Producer surplus is the aggregate difference between market price and the minimum price at which a given quantity would be produced." (ROGER D. BLAIR; CELESTE K. CARRUTHERS, The economies of monopoly power in antitrust, In KEITH N. HILTON, Antitrust law and economics, Encycplopedia of law and economics, 2 ed., Northhampton, MPG Books, 2010, p. 65)

41 HERBERT HOVENKAMP, Federal antitrust policy - The law of competition and its practice, $2^{\text {nd }}$ ed., St. Paul, West Group, 1999, pp. 4-5.

42 O conceito de elasticidade decorre da própria noção matemática de "derivada". A derivada nada mais é do que a fórmula de cálculo da variação percentual de "x" em relação a variação percentual de "y". 
é inelástica (em termos matemáticos, a inelasticidade depende de seu valor ser menor do que 1).

Para a política antitruste, mais do que os valores absolutos das elasticidades, o importante será a análise do tempo em que ocorrerá a variação da oferta diante das mudanças nos preços. Nas hipóteses em que o aumento da oferta depende de substanciais investimentos de tempo e de recursos como, por exemplo, a instalação de novas unidades fabris, o agente pode ser estimulado a adotar comportamentos estratégicos de modo a impedir que a concorrência faça frente a aumentos de preços do seu produto. $\mathrm{O}$ mesmo ocorre em relação a variação de preços no lado da demanda: em muitos casos, os custos de mudança de um bem para outro são elevados, ou o consumidor se encontra em uma situação de lock-in que o impede de migrar para outro produtor concorrente. ${ }^{43}$ É por esta razão que as análises econômicas diferenciam o curto prazo do longo prazo. ${ }^{44}$

Em uma situação de competição perfeita, a curva de demanda será horizontal, já que o preço será dado pelo mercado. Neste cenário, a elasticidade da oferta é extremamente alta, uma vez que uma pequena variação do preço leva a enormes variações das quantidades ofertadas. Além disso, sendo o preço de mercado estabelecido pelo equilíbrio de mercado, a empresa, para maximizar seu lucro, irá adequar a quantidade de produção de modo que seu Custo Marginal fique igual ao preço. Por isso, pode-se afirmar que o mercado competitivo é o arranjo mais eficiente: nesta situação, os bens são ofertados por seus preços de custo, ao mesmo tempo em que nenhuma firma individualmente possui poder de mercado. ${ }^{45}$

Devemos ressaltar que tal modelo não encontra paralelo no mundo real, sendo, portanto, meramente teórico. A existência de diversas falhas de mercado como a

\footnotetext{
43 '“Lock-in' is defined as switching costs that are sufficiently high so that buyers stay with a current supplier rather than switch to a supplier whose product they consider to be preferable (or, alternatively, that the costs of switching suppliers exceed the benefits of switching)." (AARON S. EDLIN e ROBERT G. HARRIS, The role of switching costs in antitrust analysis: A comparison of Microsoft and Google, In Yale Journal of Law and Technology, n. 169, v. 15, 2013, p. 176).

44 HERBERT HOVENKAMP, Federal antitrust policy - The law of competition and its practice, $2^{\text {nd }}$ ed., St. Paul, West Group, 1999, pp. 6-7.

45 "Em um processo competitivo, o preço de um produto tende a igualar-se ao seu custo marginal. Nessa caso, os produtores são remunerados por seus esforços à taxa de mercado (sendo que os mais eficientes lucram a taxa superior), e os consumidores têm suas necessidades satisfeitas ao preço de equilíbrio (sendo que uma parcela substancial deles goza de excedente, pois seu preço de reserva é superior ao preço de mercado). (IVO TEIXEIRA GICO JUNIOR, Cartel - Teoria unificada da colusão, São Paulo, Lex Editora, 2007, p. 75).
} 
informação imperfeita e a ocorrência de outros fatores como as economias de escala impedem qualquer mercado de operar sob as condições de concorrência perfeita. ${ }^{46}$ No entanto, seu estudo proporciona um ferramental importante (ainda que imperfeito e sujeito a adaptações), munindo o agente de políticas públicas de um mínimo de instrumentos analíticos aptos a indicar as consequências de determinadas escolhas.

\section{I.1.1.2 Monopólio}

O monopólio, por sua vez, situa-se no lado oposto do espectro competitivo. Nesta situação, ao invés de inúmeros pequenos vendedores teremos um único vendedor, ${ }^{47} \mathrm{o}$ monopolista, que tem o poder de reduzir a oferta total do mercado em razão de ser o único produtor. ${ }^{48}$ No entanto, ele não será capaz de aumentar seu preço infinitamente, pois os consumidores não estarão dispostos a pagar um preço muito elevado, podendo migrar para alternativas melhores. Assim como na situação de competição perfeita, o monopolista também maximiza seu lucro no ponto da curva de demanda em que o Custo Marginal do bem for igual a sua Receita Marginal. Contudo, diferentemente do competidor em concorrência perfeita, a Receita Marginal do monopolista não coincide com a curva de demanda, sendo a Receita Marginal sempre inferior a demanda. O poder de mercado, agora, vai depender da elasticidade da demanda para seu produto: quanto maior a elasticidade, menor o poder de mercado de um monopolista. ${ }^{49}$

Vale ressaltar que monopólios podem ou não gerar receitas positivas. O grande prejuízo, no caso, consiste na ocorrência de níveis de produção inconsistentes com a maximização do bem estar social. A possibilidade de ajustar os níveis de produção ao longo da curva de demanda faz com que o monopolista produza no nível que garanta sua

46 HERBERT HOVENKAMP, Federal antitrust policy - The law of competition and its practice, $2^{\text {nd }}$ ed., St. Paul, West Group, 1999, pp. 8-11.

$47 \quad$ "A monopoly is a single supplier to the market. This firm may choose to produce at any point on the market demand curve" (CHRISTOPHER SNYDER; WALTER NICHOLSON, Microeconomic theory: Basic principies and extensions, 11 ed., Cengage Learning, 2012, p. 449).

48 É comum encontrarmos a associação do monopólio com a capacidade de aumentar preços, no entanto, na realidade o monopolista tem a capacidade de estabelecer os preços ou as quantidades em que pretende ofertar, mas não ambos concomitantemente. É por esta razão que o conceito técnico associa o monopólio à capacidade de estabelecer a quantidade ofertada, que será igual ao valor que maximiza seu lucro. (CHRISTOPHER SNYDER; WALTER NICHOLSON, Microeconomic theory: Basic principies and extensions, 11 ed., Cengage Learning, 2012, p. 449).

49 HERBERT HOVENKAMP, Federal antitrust policy - The law of competition and its practice, $2^{\text {nd }}$ ed., St. Paul, West Group, 1999, pp. 12-13. 
maximização de lucros (ponto em que a receita marginal é igual ao custo marginal). Porém, nesta situação, o preço será superior ao do mercado competitivo e a quantidade produzida será menor que a socialmente desejada, e neste ponto reside o principal prejuízo do monopólio. ${ }^{50}$

Devemos lembrar que monopólios com total controle da oferta por um único produtor são quase impossíveis de existirem no mundo real, salvo nos casos de monopólios naturais $^{51}$, que são objeto de intensa regulação pela autoridade regulatória. Na maioria dos casos, notamos a ocorrência dos chamados monopólios de facto, nos quais o controle da quase totalidade da oferta se dá por um único produtor, que age como um monopolista. Estes monopolistas de facto utilizam sua posição para agir estrategicamente e eliminar competidores ou potenciais competidores do mercado. Grande parte das preocupações antitruste relaciona-se a decisões estratégicas de monopolistas de facto, que buscam aumentar ou proteger sua posição de monopólio. Nestes casos, ainda que não haja exercício de monopólio puro como o descrito, o exercício deste poder tende a elevar os preços para níveis supra competitivos e a diminuir os níveis de produção. ${ }^{52}$

\section{I.1.1.2.1 Os custos sociais do Monopólio}

Os primeiros custos associados ao monopólio são os sociais, ou seja, aqueles relacionados aos prejuízos que a sociedade sofre por conta do preço de monopólio. Conforme aponta HOVENKAMP, para o Antitruste, o custo social do monopólio consiste

50 ROGER D. BLAIR; CELESTE K. CARRUTHERS, The economies of monopoly power in antitrust, In KEITH N. HILTON, Antitrust law and economics, Encycplopedia of law and economics, 2 ed., Northhampton, MPG Books, 2010, p. 66. Devemos lembrar que, ao contrário do que muitas vezes se defende, o grande prejuízo do monopólio não decorre dos maiores preços cobrados, mas sim da quantidade produzida ser inferior à quantidade socialmente desejada. No mercado competitivo todos os consumidores dispostos a comprar um bem o farão, diferentemente da situação de monopólio, em que os consumidores deverão optar pelo seu second best.

51 Monopólios naturais ocorrem nas situações em que os bens apresentam custos marginais decresentes com o aumento do nível de produção e custos baixos apenas com produção em larga escala. Nestas situações uma empresa que produza baixas quantidades destes bens enfrenta elevados custos médios, o que inviabiliza sua produção em baixa escala. (CHRISTOPHER SNYDER; WALTER NICHOLSON, Microeconomic theory: Basic principies and extensions, 11 ed., Cengage Learning, 2012, p. 449).

52 ROGER D. BLAIR; CELESTE K. CARRUTHERS, The economies of monopoly power in antitrust, In KEITH N. HILTON, Antitrust law and economics, Encycplopedia of law and economics, 2 ed., Northhampton, MPG Books, 2010, p. 68. 
na diferença entre a perda decorrente do preço de monopólio e do comportamento monopolista, menos os benefícios associados a esta situação. ${ }^{53}$

Devemos, ainda, diferenciar o monopólio enquanto processo e enquanto situação. Para o Direito Concorrencial, são mais relevantes os processos que levam a sua formação e manutenção. Os monopólios criados sem a prática de condutas anticompetitivas não são objeto do antitruste, pois este está mais preocupado com os resultados destes monopólios do que propriamente com sua existência. ${ }^{54}$

Em termos econômicos, os principais custos do monopólio estão associados: (i) à criação de peso morto (deadweight loss), (ii) ao comportamento rent seeking e (iii) à perda do investimento.

Os monopólios levam as pessoas a escolher uma segunda melhor opção, se comparada à hipótese de concorrência perfeita. A ocorrência de monopólios, entretanto, não significa que a sociedade esteja em uma situação pior: um mercado monopolizado é melhor que a inexistência de mercado por conta de falta de incentivos para sua a existência. ${ }^{55} \mathrm{O}$ principal custo associado ao monopólio é o chamado deadweight loss (peso morto), que corresponde ao excedente social adicional que poderia ser realizado caso o preço de mercado fosse igual ao custo marginal. ${ }^{56}$ Importante destacar que o peso morto não surge por conta dos maiores preços pagos pelo consumidor, mas sim porque o monopólio incentiva o consumidor a procurar bens alternativos, ou seja, ele acaba por

53 HERBERT HOVENKAMP, Federal antitrust policy - The law of competition and its practice, $2^{\text {nd }}$ ed., St. Paul, West Group, 1999, pp. 17-18.

54 Conforme aponta HERBERT HOVENKAMP: "Antitrusters often say that their principal concern is monopoly, but that is not quite true. Their principal concern is monopoly created by certain means. Indeed the costs of the means by which monopoly is created and preserved may dwarf the costs of any misallocation caused by the monopoly pricing and output reduction themselves." (HERBERT HOVENKAMP, Federal antitrust policy - The law of competition and its practice, $2^{\text {nd }}$ ed., St. Paul, West Group, 1999, p. 19).

$55 \quad$ "Although monopoly imposes a social cost, society is not necessarily poorer because the monopolist exists. For example, society was clearly better off because Alcoa existed than if no aluminum producer existed at all, even for many years Alcoa was a monopolist. Monopolist Alcoa produced more than the cost of producing it. Otherwise there would have been no market for aluminum." (HERBERT HOVENKAMP, Federal antitrust policy - The law of competition and its practice, $2^{\text {nd }}$ ed., St. Paul, West Group, 1999, p 19).

56 YOON-HO ALEX LEE; DONALD J. BROWN, Competition, consumer welfare, and the social cost of monopoly, , In Yale Law School legal scholarship repository, disponível em: http://bit.ly/20EUPEX, acesso no dia 8, nov., 2015, p. 4. IVO TEIXEIRA GICO JUNIOR se refere ao peso morto como o resultado do "desalojamento de recursos" causado pelo monopolista (IVO TEIXEIRA GICO JUNIOR, Cartel - Teoria unificada da colusão, São Paulo, Lex Editora, 2007, pp. 79-80). 
escolher a segunda melhor opção em detrimento daquela que seria sua preferência original. $^{57}$

Um segundo custo associado ao monopólio é o do comportamento rent seeking. Uma vez estabelecido o monopólio, a firma monopolista possui incentivos para empreender estratégias visando a manter tal estrutura. ${ }^{58-59}$ Algumas destas práticas podem ser eficientes, como no caso de investimentos em pesquisa e desenvolvimento que permitam à empresa manter-se no state-of-art da inovação. Porém, muitas vezes a empresa pode adotar condutas prejudiciais ao bem estar social, buscando a mera exclusão de concorrentes, como ocorre no preço predatório e na shame litigation. ${ }^{60}$

Por fim, um terceiro custo associado ao monopólio são aqueles diretamente impostos por condutas exclusionárias dirigidas aos concorrentes da empresa dominante. $\mathrm{O}$ investimento realizado pelas empresas excluídas é perdido com sua saída do mercado, o que cria mais um efeito negativo ao bem estar social. ${ }^{61}$

\section{I.1.1.3 Poder de Mercado ou Poder de Monopólio}

A conceituação do poder econômico apresenta inúmeras dificuldades, ${ }^{62}$ razão pela qual se costuma optar pela análise das condições para o seu exercício e dos critérios utilizados para verificar sua licitude.

57 HERBERT HOVENKAMP, Federal antitrust policy - The law of competition and its practice, $2^{\text {nd }}$ ed., St. Paul, West Group, 1999, pp. 19-20.

58 HERBERT HOVENKAMP, Federal antitrust policy - The law of competition and its practice, $2^{\text {nd }}$ ed., St. Paul, West Group, 1999, pp. 20-21.

59 "Uma vez que o status de monopólio proprociona a oportunidade de obtenção de lucro econômico, o poder monopolístico encerra em si mesmo valor econômico, o que gera incentivos para que agentes econômicos tentem se tornar monopolistas e cria incentivos para aqueles que já o são utilizem recursos reais para manter a posição dominante" (IVO TEIXEIRA GICO JUNIOR, Cartel - Teoria unificada da colusão, São Paulo, Lex Editora, 2007, p. 83).

60 HERBERT HOVENKAMP, The antitrust enterprise - Principle and execution, Cambridge, Harvard University, 2005, p. 20. Um exemplo citado por HOVENKAMP de empresa que manteve sua posição dominante com investimentos agressivos em R\&D foi a IBM nos anos de 1970. Exemplos de práticas que aumentam os custos sociais do monopólio citadas pelo autor são o preço predatório, sabotagem, espionagem, e litigância vexatória. (HERBERT HOVENKAMP, Federal antitrust policy - The law of competition and its practice, $2^{\text {nd }}$ ed., St. Paul, West Group, 1999, p. 20).

61 HERBERT HOVENKAMP, Federal antitrust policy - The law of competition and its practice, $2^{\text {nd }}$ ed., St. Paul, West Group, 1999, p. 23-26.

62 Conforme aponta CALIXTO SALOMÃO FILHO, o poder de mercado constitui um daqueles conceitos que são "de tal maneira fundamentais e constitutivos para uma ciência que sua definição é 
A teoria neoclássica frequentemente associa a noção de poder de mercado à capacidade de aumentar preços por meio da redução de oferta de um bem. ${ }^{63}$ Tal conceito, porém, mostra-se simplista, na medida em que a capacidade de aumentar preços é condição não necessária e não suficiente para a existência do poder de mercado. Em muitos casos a empresa com poder de mercado não se encontra em situação de aumentar preços, seja por já estar cobrando preços acima dos preços de monopólio, seja por estar adotando a estratégia de cobrar preços mais baixos com o objetivo de excluir concorrentes do mercado. Por estas razões, CALIXTO SALOMÃO FILHO afasta a conceituação ligada à capacidade de aumentar preços para relacionar o poder de mercado à "possibilidade de escolher entre essas diferentes alternativas: grande participação no mercado e menor lucratividade, ou pequena participação e maior lucratividade". ${ }^{4}$

O direito antitruste se utiliza de dois instrumentos para limitação do poder de mercado: o controle de estruturas e o controle de condutas. O fundamento econômico do controle de estruturas baseia-se na hipótese da concentração-coalizão, derivada do modelo de oligopólio de COURNOT, segundo o qual o resultado do monopólio depende diretamente do número de participantes no mercado. Ou seja, quanto menor o número de participantes maior será o poder de monopólio, e, de maneira inversa, quanto maior o número de participantes menor o poder de monopólio. Assim, o Estado passa a ter o papel, justamente, de evitar a concentração econômica e o poder de monopólio. ${ }^{65}{ }^{66}$

O problema, contudo, não é a concentração econômica, mas sim a possibilidade de exercício arbitrário conferida pela posição de monopólio. A medida de mensuração desta

axiomática", ou seja, "deve-se indagar de suas formas de revelação, ao invés de procurar defini-los" (CALIXTO SALOMÃO FILHO, Direito concorrencial, São Paulo, Malheiros, 2013, pp. 141-142).

63 "A monopolist differs from a perfectly competitiva firm in its ability to raise price above marginal cost by restricting output. This is the essence of monopoly power: the ability to deviate from the competitive price (i.e., marginal cost) by restricting the quantity produced" (ROGER D. BLAIR; CELESTE K. CARRUTHERS, The economies of monopoly power in antitrust, In KEITH N. HILTON, Antitrust law and economics, Encycplopedia of law and economics, 2 ed., Northhampton, MPG Books, 2010, p. 68).

64

CALIXTO SALOMÃO FILHO, Direito concorrencial, São Paulo, Malheiros, 2013, pp. 142-143.

65

ELIZABETH M. M. Q. FARINA, ET. AL., Competitividade: Mercado, Estado e organizações, São Paulo, Singular, 1997, pp. 120-121.

66 Interessante notar que, mesmo após mais de 150 anos, o modelo de Cournot continua sendo o paradigma de análise para formação de preços em situações de oligopólio. Conforme aponta SALIL K. MEHRA, o modelo de BERTRAND aponta resultados duvidosos ao afirmar que, se as empresas selecionarem preços, serão necessárias apenas duas para atingir o nível de preços de competição perfeita (SALIL K. MEHRA, Antitrust and the Robo-Seller: Competition in the time of algorithms, disponível em: http://bit.ly/1kZQtrk, acesso no dia 16, nov., 2015, p. 23). 
distorção é a perda líquida do bem estar, ou peso morto (deadweight loss). Conforme observamos acima, o peso morto surge nas situações em que a transferência do excedente do produtor para o excedente do consumidor não ocorre de forma completa, ocasionando perdas. $^{67}$

O poder de monopólio, por sua vez, depende do controle de parcela significativa do mercado, razão pela qual as análises antitruste geralmente apontam as participações de mercado como indicadoras de poder de monopólio. ${ }^{68}$ Por meio do exercício deste poder as empresas auferem lucros econômicos no curto prazo e podem realizar condutas de exclusão de concorrentes ou de fechamento de mercado. Dessa forma, é o poder de mercado decorrente de estruturas concentradas que faz surgir as chamadas condutas anticompetitivas.

Verifica-se, assim, que os dois instrumentos de defesa da concorrência guardam estreita relação entre si, uma vez que a prática de condutas anticompetitivas depende, justamente, do poder de monopólio decorrente de estruturas concentradas. Por meio do controle de condutas, o Estado se utiliza de ameaças de punição com a finalidade de inibir condutas que possam levar à restrição da ação dos concorrentes, limitação da concorrência por meio de condutas colusivas, imposição de condições desfavoráveis de aquisição aos compradores, dentre outras. ${ }^{69}$

Devemos lembrar que, independentemente da divisão entre controle de condutas e estruturas, o objetivo das políticas de defesa da concorrência, em última instância, "tem como alvo todo e qualquer tipo de estratégia empresarial que tenha como efeito - ou possa vir a ter - a redução da efíciência econômica e, portanto, potencialmente a diminuição do bem estar social", independentemente da forma que se revestirem tais estratégias (aquisições, cartéis, contratos de exclusividade, etc.). ${ }^{70}$

67 ELIZABETH M. M. Q. FARINA, ET. AL., Competitividade: Mercado, Estado e organizações, São Paulo, Singular, 1997, pp. 120-121.

68 ELIZABETH M. M. Q. FARINA, ET. AL., Competitividade: Mercado, Estado e organizações, São Paulo, Singular, 1997, pp. 120-121.

69 JORGE FAGUNDES, Fundamentos econômicos das políticas de defesa da concorrência Eficiência econômica e distribuição de renda em análises antitruste, São Paulo, Singular, 2003, pp. 12-13.

70 JORGE FAGUNDES, Fundamentos econômicos das políticas de defesa da concorrência Eficiência econômica e distribuição de renda em análises antitruste, São Paulo, Singular, 2003, p. 13. 
Para compreender a questão do poder econômico, é preciso relembrar alguns conceitos microeconômicos fundamentais. Conforme observamos, a maximização do lucro, em situação de concorrência perfeita, ocorre quando o agente iguala o preço ao custo marginal $^{71}$. Por outro lado, na situação em que o mercado não esteja em concorrência perfeita e algumas empresas detenham poder de mercado, estas terão influência sobre o preço, sendo a curva de demanda decrescente e a receita marginal sempre inferior ao preço. Nesta situação, ao maximizar o seu lucro (igualando o seu custo marginal à receita marginal) o agente com poder de mercado irá estabelecer preços superiores à receita marginal, e, portanto, superiores ao preço da situação de concorrência perfeita. ${ }^{72}$ Tal explicação demonstra a ocorrência de sobrepreço em condições em que há o exercício de poder de mercado por parte de uma ou mais empresas. No entanto, devemos notar que a elevada participação, por si só, não comprova a existência de poder de mercado, uma vez que este dependerá de diversos fatores como a elasticidade da demanda e da oferta, além da existência de barreiras à entrada no mercado em que a empresa atua.

Uma empresa com elevada participação de mercado (market share) pode não possuir qualquer poder de elevar preços quando houver substitutos para seu produto (ou seja, elevada elasticidade cruzada da demanda) ${ }^{73}$ ou quando existir possibilidade de entrada de novos concorrentes (elevada elasticidade cruzada da oferta). ${ }^{74}$ Assim, a elasticidade cruzada da oferta depende da existência de barreiras à entrada neste setor. Ou seja, a ocorrência destas barreiras impede a entrada de concorrentes, tornando a elasticidade cruzada da oferta baixa.

Por esta razão, as barreiras à entrada se tornam importante fator para manutenção do poder de mercado, ${ }^{75}$ e podem ser definidas como um custo que apenas os entrantes

71 Isso ocorre porque, até este ponto, a unidade adicional produzirá maior receita, ao passo que, a partir deste ponto, a produção de uma unidade adicional implicará receita decrescente, uma vez que o custo marginal será maior que o preço.

72 CALIXTO SALOMÃO FILHO, Direito concorrencial, São Paulo, Malheiros, 2013, pp. 144-145.

73 A elasticidade sempre se refere à variação percentual (em termos matemáticos, se refere à derivada) de um bem em relação à variação do preço. No caso da elasticidade cruzada da demanda a relação ocorre entre a variação percentual da quantidade de um bem $\mathrm{B}$ em relação à variação do preço de um bem $\mathrm{A}$ (substituto do bem B). Quanto maior a variação, maior o grau de substitutibilidade entre os bens.

74

CALIXTO SALOMÃO FILHO, Direito concorrencial, São Paulo, Malheiros, 2013, p. 146.

75 "Consequently, for monopoly power to be more than a temporary bump in an otherwise competitive road, there must be some barriers to entry. [...] high barriers mean that monopoly (or market) power will persist, as will its exercise and its effect on social welfare" (ROGER D. BLAIR; CELESTE K. 
estão sujeitos a enfrentar, ou, então, como uma vantagem competitiva que uma firma estabelecida possui em relação aos potenciais entrantes. Diversas espécies de vantagens podem constituir barreiras à entrada, como, por exemplo, elevados custos de capital, fornecimento limitado de insumos importantes, contratos de fornecimento de longa duração, licenças legais, efeitos de rede e propriedade intelectual. ${ }^{76}$

A respeito do exercício do poder de mercado, a teoria econômica marginalista apresenta uma análise que é alvo de inúmeras críticas. Conforme sustentam seus teóricos, não há poder de mercado que não seja exercido pelos seus detentores. Segundo tal raciocínio, não existiria a possibilidade de uma empresa com poder de mercado não cobrar preços de monopólio. Logo, se uma empresa com suposto poder de mercado estiver praticando preços concorrenciais, não há que poder de mercado. ${ }^{77}$ Esta conclusão, entretanto, mostra-se equivocada em diversas situações.

Em alguns casos, a estratégia de cobrar preços abaixo dos preços de monopólio pode ser condizente com o interesse em aumentar participação de mercado ou mesmo com o receio de intervenção governamental em caso de preços considerados abusivos. Além disso, a ocorrência de falhas como informação imperfeita pode levar o agente a não atuar conforme descrito pela teoria neoclássica. ${ }^{78}$ Conclui-se, portanto, que os insights oferecidos pelo modelo teórico constituem importante indicativo de prováveis condutas de agentes racionais, não devendo, por outro lado, servir como presunções absolutas a serem transportadas acriticamente para o direito antitruste. ${ }^{79}$

Assim, se para a teoria econômica o poder de mercado se refere à capacidade de uma firma cobrar preços superiores ao preço competitivo, para o direito concorrencial outros critérios devem ser utilizados para demonstrar sua real existência. ROGER D. BLAIR e CELESTE K. CARRUTHERS dividem as evidências da existência de poder de

CARRUTHERS, The economies of monopoly power in antitrust, In KEITH N. HILTON, Antitrust law and economics, Encycplopedia of law and economics, 2 ed., Northhampton, MPG Books, 2010, p. 75).

76 ROGER D. BLAIR; CELESTE K. CARRUTHERS, The economies of monopoly power in antitrust, In KEITH N. HILTON, Antitrust law and economics, Encycplopedia of law and economics, 2 ed., Northhampton, MPG Books, 2010, pp. 75-75.

77 CALIXTO SALOMÃO FILHO, Direito concorrencial, São Paulo, Malheiros, 2013, pp. 147-148.

78 Conforme veremos adiante, além da questão das falhas de mercado, contribuições da economia comportamental vem demonstrando diversas outras situações em que os agentes econômicos não agiriam segundo a racionalidade ilimitada maximizadora de lucro descrita pela teoria neoclássica. 
mercado em diretas e circunstanciais. As evidências diretas estariam na comprovação quanto a cobrança de preços acima do nível competitivo ou a exclusão de competidores, ao passo que as evidências indiretas estariam na constatação de elevadas parcelas de market share. $^{80}$

A verificação de tais evidências é feita a partir de vários métodos para aferição do poder de mercado. CALIXTO SALOMÃO FILHO divide estes critérios em dois grandes grupos: os não baseados na definição do mercado e os baseados na definição do mercado. ${ }^{81}$

Os métodos não baseados na definição de mercado buscam a verificação de preços de monopólio para caracterização do poder de mercado. Sua limitação está, justamente, no fato de serem úteis apenas nas situações em que há efetivo sobrepreço de monopólio, sendo de pouca utilidade em outras hipóteses. Dentre estes métodos podemos destacar o Lerner Index ${ }^{82}$, que procura realizar uma mensuração direta do sobrepreço monopolista valendo-se de um cálculo que relaciona preço e custo marginal para o monopolista; o método da "curva de demanda residual", que procura estimar a curva de demanda de todos os concorrentes da empresa investigada; o método de avaliação do poder de mercado não por dados quantitativos, mas por meio da análise de condutas típicas de agentes com poder de mercado; e, por fim, o método do lucro excessivo. ${ }^{83}$

Todos estes métodos possuem suas limitações seja pela dificuldade de obtenção de dados ou de cálculo das estimativas, seja pela insuficiência destes dados para a constatação do poder de mercado. O Lerner Index, por exemplo, falha como uma medida monotônica de poder de mercado, uma vez que seu valor depende dos custos e das preferências dos consumidores, não considerando o grau com que uma empresa pode excluir suas

\footnotetext{
80 ROGER D. BLAIR; CELESTE K. CARRUTHERS, The economies of monopoly power in antitrust, In KEITH N. HILTON, Antitrust law and economics, Encycplopedia of law and economics, 2 ed., Northhampton, MPG Books, 2010, pp. 73-74.

$82 \quad$ Para o Lerner Index o grau de poder de monopólio é igual a margem que o preço monopolista excede o Custo Marginal (ROGER D. BLAIR; CELESTE K. CARRUTHERS, The economies of monopoly power in antitrust, In KEITH N. HILTON, Antitrust law and economics, Encycplopedia of law and economics, 2 ed., Northhampton, MPG Books, 2010, p. 69).
} 
concorrentes. Apesar destes problemas, o Lerner Index ainda se mostra como uma importante ferramenta para apurar a existência de poder de mercado. ${ }^{84}$

As inúmeras dificuldades associadas aos métodos supra descritos fazem com que o método atualmente dominante seja o baseado na definição do mercado, ou da delimitação dos mercados relevantes. ${ }^{85}$ Este método, que é adotado pela legislação nacional, perpassa a delimitação do mercado relevante sob os pontos de vista geográfico ${ }^{86}$ e do produto ${ }^{87}$, para em seguida definir as participações de mercado das empresas. O uso deste instrumento é importante tanto nas análises de condutas anticompetitivas, como na análise dos atos de concentração econômica, uma vez que é capaz de medir tanto o poder presente quanto estimar o possível poder de monopólio gerado pela concentração de empresas. ${ }^{88} \mathrm{~A}$ definição do tamanho dos mercados relevantes traz consequências diretas sobre a consideração do poder de mercado, uma vez que uma definição muito restrita do mercado pode transformar uma empresa com pouca participação de mercado em um monopolista, ao passo que uma definição muito abrangente pode fazer com que uma empresa com substancial poder de mercado aparente não possui-lo. ${ }^{89}$

Tanto sob o aspecto geográfico como sob o ponto de vista material, o método neoclássico tradicional envolve a análise de substitutibilidade pelo lado da demanda e pelo

84 ROGER D. BLAIR; CELESTE K. CARRUTHERS, The economies of monopoly power in antitrust, In KEITH N. HILTON, Antitrust law and economics, Encycplopedia of law and economics, 2 ed., Northhampton, MPG Books, 2010, pp. 69-70.

85 O mercado relevante, conforme definição de PAULA A. FORGIONI: "é aquele em que se travam as relações de concorrência ou atua o agente econômico cujo comportamento esta sendo analisado" (PAULA A. FORGIONI, Os fundamentos do antitruste, 6 ed., São Paulo, Revista dos Tribunais, 2013, pp. 212-213).

86 Ainda conforme PAULA A. FORGIONI, o mercado relevante geográfico constitui: "o espaço físico onde se desenvolvem as relações de concorrência que são consideradas. Pode ser compreendido como a área na qual o agente econômico é capaz de aumentar os preços que pratica sem (i) perder um grande número de clientes, que passariam a utilizar-se de um fornecedor alternativo situado fora da mesma área ou (ii) provocar imediatamente a inundação da região por bens de outros fornecedores que, situados fora dela, produzem bens similares." (PAULA A. FORGIONI, Os fundamentos do antitruste, 6 ed., São Paulo, Revista dos Tribunais, 2013, pp. 214-215).

87 O mercado relevante material (ou do produto), "é aquele em que o agente econômico enfrenta a concorrência, considerado o bem ou serviço que oferece. Sua delimitação, a exemplo do mercado relevante geográfico, parte da identificação das relações de concorrência" (PAULA A. FORGIONI, Os fundamentos do antitruste, 6 ed., São Paulo, Revista dos Tribunais, 2013, p. 219). Northhampton, MPG Books, 2010, pp. 76-77. 
lado da oferta. Para isso, realiza-se uma projeção dos efeitos de determinado aumento de preços para se estimar o percentual de substituição (as elasticidades cruzadas) por parte dos consumidores (lado da demanda) ou o percentual de entrada de novos produtores (lado da oferta). ${ }^{90} \mathrm{O}$ método utilizado nos Estados Unidos e no Brasil é o chamado "teste do monopolista hipotético" (SSNIP) ${ }^{91}$, segundo o qual se estima a área ou o grupo de produtos sobre os quais o monopolista poderia impor um "pequeno porém significativo e não transitório" aumento de preços.

Diversas críticas podem ser apontadas com relação à metodologia de delimitação dos mercados relevantes. Em geral elas se direcionam às dificuldades de aferição do preço competitivo de determinado setor, de definição do nível de aumento de preços a ser aplicado, de demonstração da existência efetiva de substituição, e do montante a ser incluído do produto para cálculo do volume de substituição. ${ }^{92}$

A questão da delimitação dos mercados relevantes se mostra ainda mais complexa nos setores de Internet. Tanto é assim que vem surgindo nos últimos anos inúmeras dúvidas quanto à aplicação dos tradicionais métodos de aferição de poder de mercado e de definição de market shares nestes setores. Conforme veremos no CAPÍTULO III adiante, a redefinição dos mercados pontocom a partir da noção de "competição por atenção" faz com que, nestes mercados, serviços completamente distintos acabem pertencendo ao mesmo mercado relevante.

\section{I.1.2 O tradicional debate entre Escola de Chicago e Escola de Harvard}

Durante o período do entreguerras, as políticas antitruste exerceram um papel secundário, uma vez que os esforços de guerra e a enorme crise do sistema capitalista em 1929 não criavam um ambiente propício para a emergência destas ideias. Porém, esta situação muda no pós segunda guerra mundial. ${ }^{93}$

\footnotetext{
90 CALIXTO SALOMÃO FILHO, Direito concorrencial, São Paulo, Malheiros, 2013, pp. 155-156.

91 PAUlA A. FORGIONI, Os fundamentos do antitruste, 6 ed., São Paulo, Revista dos Tribunais, 2013, p. 236. A sigla SSNIP vem do termo inglês "Small Small but significant and non-transitory increase in price".

92 CALIXTO SALOMÃO FILHO, Direito concorrencial, São Paulo, Malheiros, 2013, pp. 158-161.

93 ROBERT PITOFSKY, Introduction: Setting the stage, In ROBERT PITOFSKY, How the Chicago school overshot the mark - The effect of conservative economic analysis on U.S. antitrust, Oxford University Press, 2008, pp. 4-5.
} 
Nessa época, iniciativas das autoridades concorrenciais, apoiadas pelo Congresso norte-americano, introduzem um dos programas mais agressivos de aplicação do direito antitruste da história dos Estados Unidos. No entanto, especialmente entre os anos de 1960 e 1970, as premissas adotadas pelas autoridades concorrenciais se baseavam fortemente em valores sócio-políticos que tinham como norte um alto grau de desconfiança em relação às grandes empresas e uma preocupação em definir regras justas para o jogo competitivo. Tais ideias desconsideravam a questão da eficiência econômica associada a muitas operações e condutas. ${ }^{94}$

Nese período, as posições da autoridade antitruste estavam imersas sob a influência da chamada Escola de Harvard, ou escola estruturalista. A base conceitual desta escola econômica repousa no modelo de estrutura-conduta-desempenho (ECD). Tal modelo desenvolvido por AREEDA, TURNER e SULLIVAN, tem como objetivo obter conclusões em relação ao desempenho de determinadas indústrias com base nas estruturas de mercado do setor em que estas empresas atuam. Sua base normativa remonta aos modelos de equilíbrio geral e parcial competitivo, segundo os quais as eficiências decorrem diretamente de condições estruturais, ou seja, da existência de grande número de vendedores e compradores nos mercados e da ausência de barreiras significativas à entrada. ${ }^{95}$ Seguindo esta linha de raciocínio, a escola estruturalista apontava o controle prévio de estruturas como mecanismo hábil para evitar condutas anticompetitivas por parte das empresas, uma vez que a prática dessas condutas dependia do poder de mercado fruto de estruturas concentradas. ${ }^{96}$

Ao fim dos anos de 1960 e início dos anos de 1970 as preocupações desta escola evoluem para objetivos mais amplos, passando a abarcar também o estudo de condutas exclusionárias, o que leva a um direcionamento de sua atenção às condutas empresariais e seus efeitos sobre a estrutura de mercado. Esta mudança de enfoque, porém, não faz com que seus teóricos abandonem a visão de multiplicidade de objetivos da política antitruste

$94 \quad$ ELIZABETH M. M. Q. FARINA, ET. AL., Competitividade: Mercado, Estado e organizações, São Paulo, Singular, 1997, pp. 131-132.

95 JORGE FAGUNDES, Fundamentos econômicos das políticas de defesa da concorrência Eficiência econômica e distribuição de renda em análises antitruste, São Paulo, Singular, 2003, pp. 190-191.

96 "Under structuralism, the competitive assessment was firmly grounded in the goal of preserving competition by protecting a competitive market structure to guarantee good market performance" (ROGER VAN DEN BERGHPP, Behavioral antitrust: Not ready for the main stage, In Journal of Competition Law \& Economics, vol. 9 (1), 2013, p. 207). 
com ênfase no controle do poder econômico, na distribuição de renda e na concentração do poder econômico. ${ }^{97}$

Tais teorias aplicadas ao direito concorrencial pela autoridade dos Estados Unidos nesta época resultaram em forte intervenção estatal sobre práticas e estruturas empresariais, com total desconsideração de qualquer argumento de eficiência, e a introdução de uma série de normas contendo proibições per se. ${ }^{98}$ ROBERT PITOFSKY aponta que este período, conhecido como Warren Era, trouxe não apenas uma série de decisões hoje consideradas indefensáveis, mas também deu subsídios para que acadêmicos fossem incentivados pelo setor privado a estudar os impactos que a aplicação excessiva de direito antitruste poderia trazer para a economia. ${ }^{99}$

O questionamento dessas teorias por parte de acadêmicos, em especial aqueles ligados de alguma forma à Universidade de Chicago, aliado à depressão da economia americana e à crise do sistema capitalista ao final dos anos $70^{100}$ levou a uma completa revisão dos fundamentos teóricos da política antitruste dos Estados Unidos. Nesse momento ganha enorme relevo a análise econômica de questões concorrenciais ${ }^{101} \mathrm{e}$ as

97 JORGE FAGUNDES, Fundamentos econômicos das políticas de defesa da concorrência Eficiência econômica e distribuição de renda em análises antitruste, São Paulo, Singular, 2003, pp. 193-194.

$98 \quad$ "During the 1950s and 1960s, tiny mergers that could not seriously be viewed as challenges to a competitive market were consistently blocked, abbreviated (so-called per se) rules were introduced to outlaw behavior that rarely produced anticompetitive or anticonsumer effects, and licensing practices were challenged, which were little more than efforts to engage in aggressive innovation. All of this was accompanied by an almost total disregard for business claims of efficiency." (ROBERT PITOFSKY, Introduction: Setting the stage, In ROBERT PITOFSKY, How the Chicago school overshot the mark - The effect of conservative economic analysis on U.S. antitrust, Oxford University Press, 2008, pp. 4-5). Em sentido semelhante afirma HOVENKAMP: "Indeed, many Warren-Era decisions condemned conduct precisely because it reduced costs or generated more desirable products. 2 Such practices harm rivals unable to match them, but they benefit consumers. On top of that, Warren Court antitrust was highly distrustful of markets, suspicious of innovation and the intellectual property laws, and convinced that aggressive antitrust remedies would make the economic world a better place." (HERBERT HOVENKAMP, The antitrust enterprise - Principle and execution, Cambridge, Harvard University, 2005, p. 1).

99 ROBERT PITOFSKY, Introduction: Setting the stage, In ROBERT PITOFSKY, How the Chicago school overshot the mark - The effect of conservative economic analysis on U.S. antitrust, Oxford University Press, 2008, pp. 4-5.

100 Como lembra ERIC HOBSBAWM o final da década de 1970 e o início dos anos de 1980 marcam o final da chamada "Era de Ouro do Capitalismo" (ERIC HOBSBAWM, Era dos extremos: O breve século $X X$, São Paulo, Companhia das Letras, 1995, pp. 393-421).

101 A naturalidade com que se utilizam as análises econômicas e os estudos econométricos nas discussões de direito concorrencial na atualidade nos faz parecer que sempre foi assim. No entanto, o uso de ferramental matemático e econométrico ganham importância em processos concorrenciais apenas nos últimos 20 anos. 
ideias comumente atribuídas à chamada Escola de Chicago, baseada na noção de eficiência econômica como norte do sistema.

O problema central na hipótese anteriormente aventada de que estruturas concentradas levariam necessariamente a distorções na alocação de recursos está na ausência de fundamentação teórica para corroborar tal tese, bem como na dificuldade empírica em se definir o nível ótimo de concentração que seja compatível com a eficiência. ${ }^{102} \mathrm{O}$ questionamento das teorias baseadas na relação entre estrutura e desempenho foi feito a partir de modelos de teoria dos jogos que apontavam para inúmeras situações de equilíbrio em diversas estruturas possíveis, e a partir de trabalhos realizados nos anos 60 e 70, que demonstravam como estruturas oligopolizadas podem ter variados desempenhos econômicos. ${ }^{103}$ Por fím, a teoria dos mercados contestáveis também contribui para a superação destas visões ao defender que estruturas concentradas podem apresentar desempenho competitivo desde que os mercados possuam baixas barreiras à entrada e sejam perfeitamente contestáveis. ${ }^{104}$

As preocupações da Escola de Harvard com relação aos efeitos das concentrações sobre a distribuição de renda parecem apontar para o sentido correto. O problema desta Escola, no entanto, está na excessiva ênfase sobre a questão da eficiência econômica da produção agregada. Isso porque "não somente o objetivo de se evitar o surgimento e/ou aumento do poder de mercado é consistente tanto com a meta de maximizar o excedente do consumidor (critério do price standard), quanto com a de maximizar a eficiência potencial de Pareto (critério de Chicago-Williamson), aferida pelas variações no excedente agregado de Marshall’"105 como também não há razões para que a autoridade antitruste desconsidere outras eficiências associadas à conduta.

102 ELIZABETH M. M. Q. FARINA, ET. AL., Competitividade: Mercado, Estado e organizações, São Paulo, Singular, 1997, p. 133.

103 "Antitrust writers belonging to the latter school [Chicago School] powerfully argued that the structure of a particular market does not allow conclusions on the conduct of firm in that market and its ultimate economic performance" (ROGER VAN DEN BERGH, Behavioral antitrust: Not ready for the main stage, In Journal of Competition Law \& Economics, vol. 9 (1), 2013, p. 207).

104 ELIZABETH M. M. Q. FARINA, ET. AL., Competitividade: Mercado, Estado e organizações, São Paulo, Singular, 1997, pp. 134-135.

105 JORGE FAGUNDES, Fundamentos econômicos das políticas de defesa da concorrência Eficiência econômica e distribuição de renda em análises antitruste, São Paulo, Singular, 2003, pp. 194-195. 
Assim, as inconsistências desta teoria decorrem da tentativa de criar uma relação entre redistribuição de renda e aumento do poder de mercado. A teoria aponta para a possibilidade de determinadas estratégias reduzirem o nível de competição e ao mesmo tempo aumentarem o poder de mercado e os ganhos de eficiência de Pareto, sem que haja redistribuição de renda para o produtor. ${ }^{106}$

A superação do embate entre Escola de Harvard e Escola de Chicago nos anos de 1970 levou a prevalência da maior parte dos postulados da Escola de Chicago. Devemos lembrar, porém, que tal embate se dava no campo do controle de estruturas, uma vez que ambas tinham como objeto de análise a área da economia chamada de organização industrial. Por outro lado, nos últimos anos outra área que vem ganhando maior relevo e que ainda permanece pouco estudada pela doutrina nacional é o do chamado controle de condutas anticompetitivas ou anticoncorrenciais. ${ }^{107}$ Neste campo, diversas teorias comportamentais, também chamadas de escolas "pós-Chicago", vem trazendo questionamentos sobre os postulados da Escola de Chicago.

\section{I.1.3 Direito antitruste e eficiências dinâmicas}

A eficiência dinâmica se relaciona aos efeitos das políticas antitruste sobre o processo de inovação. A busca por maiores lucros é o fator que move as empresas a investirem no desenvolvimento de novos processos e de novos produtos. Conforme a teoria desenvolvida pelo economista JOSEPH A. SCHUMPETER, a possibilidade de surgimento de concorrentes potenciais a qualquer momento faz com que as firmas invistam em inovação, com o intuito de criar a tecnologia que irá dominar os mercados futuros. ${ }^{108}$

As políticas antitruste, na medida em que sancionam concentrações empresariais e acordos entre concorrentes, em muitos casos podem acabar desestimulando a inovação. Por isso, as considerações de SCHUMPETER no tocante a inovação nos mercados traz importantes reflexões quanto ao papel do direito antitruste sobre os mercados. As grandes

\footnotetext{
106 JORGE FAGUNDES, Fundamentos econômicos das políticas de defesa da concorrência Eficiência econômica e distribuição de renda em análises antitruste, São Paulo, Singular, 2003, pp.195-196.

107 CALIXTO SALOMÃO FILHO, Direito concorrencial, São Paulo, Malheiros, 2013, pp. 383-385.

108 "Entretanto, o que impede que o monopolista deite sua cabeça em uma almofada e descanse, para usar a expressão de Schumpeter, é a presença incessante de concorrentes potenciais. A concorrência é responsável não somente por preços competitivos, mas pela busca incessante do poder de monopólio por meio da inovação!” (ELIZABETH M. M. Q. FARINA, ET. AL., Competitividade: Mercado, Estado e organizações, São Paulo, Singular, 1997, p. 139).
} 
dificuldades que se afiguram, porém, decorrem do fato de não existir consenso teórico com relação ao nível de concorrência adequado para estimular a inovação, da mesma forma que não há consenso quanto à definição do próprio conceito de eficiência dinâmica.

O pensamento de SCHUMPETER muda radicalmente as concepções tradicionais de concorrência e eficiência baseadas em modelos de equilíbrio geral e parcial, cujo norte é o conceito de eficiência de Pareto. É dos trabalhos de SCHUMPETER que surge a noção da eficiência dinâmica, que se associa à redução de custos através de inovações ao longo do tempo e ao surgimento de novos produtos e processos produtivos. ${ }^{109}$ Conforme sua teoria, a concorrência ocorreria em ciclos de inovação e não por meio de concorrência estática de preços, como defendiam os modelos anteriores. As firmas concorreriam pela introdução de inovações que suplantassem a tecnologia existente e levassem à dominação temporária daquele setor, de modo que a competição entre as empresas não ocorreria por fatias do mercado, mas antes pela dominação do mercado como um todo. ${ }^{110}$

Decorre desta visão que a competição não gera necessariamente um equilíbrio competitivo. A concorrência entre as empresas estimula um esforço de diferenciação e busca pela criação de vantagens competitivas com o objetivo de criar um monopólio temporário que permitisse aos agentes receberem lucros extraordinários. ${ }^{111}$ Estes ciclos, portanto, não conduziriam ao equilíbrio de mercado, mas sim à formação de uma série de monopólios temporários consecutivos ao longo dos tempos. Nesta situação, a instabilidade, e não o equilíbrio, será a característica fundamental do sistema.

Da mesma forma, o monopólio não representaria a ausência de concorrência, mas seria o próprio resultado temporário do processo competitivo. Ou seja, a criação do monopólio depende da intensa concorrência e dos investimentos em inovação das firmas. Os lucros extraordinários de monopólio também não seriam objeto de preocupação, uma vez que o processo constante de investimento em P\&D e a consequente destruição das

\footnotetext{
109 JORGE FAGUNDES, Fundamentos econômicos das políticas de defesa da concorrência Eficiência econômica e distribuição de renda em análises antitruste, São Paulo, Singular, 2003, p. 83.

110 MICHAEL L. KATZ; HOWARD A SHELANSKI, Schumpeterian competition in high-tech markets, disponível em: http://bit.ly/1NqgTMw, acesso no dia 16, jul, 2014, p. 4.

111 JORGE FAGUNDES, Fundamentos econômicos das políticas de defesa da concorrência Eficiência econômica e distribuição de renda em análises antitruste, São Paulo, Singular, 2003, p. 84.
} 
estruturas econômicas existentes, chamada por SCHUMPETER de destruição criativa ${ }^{112}$, seriam responsáveis por impedir que tal situação perdurasse por longos períodos. ${ }^{113}$

As observações apontadas pela teoria Schumpeteriana trazem importantes consequências para o direito concorrencial. Segundo a visão estruturalista, firmas em competição perfeita possuem incentivos de curto prazo para reduzirem seus custos, porém não possuem recursos necessários para aplicar em investimentos que trarão resultados apenas a longo prazo. Por isso, estruturas concentradas criariam um ambiente propício à inovação. $^{114}$

É por esta razão que teorias baseadas nas ideias de SCHUMPETER indicam que a concentração empresarial e a existência de grandes monopólios seriam essenciais para o progresso técnico e a inovação. No entanto, as dificuldades de comprovação empírica desta tese fizeram com que surgisse uma abordagem mais complexa, que considera diversos outros elementos como grau de oportunidade e apropriabilidade da tecnologia para análise das estruturas. Assim, segundo estes critérios, algumas situações tornam estruturas difusas mais eficientes para estímulo da inovação ao passo que outras situações demandariam estruturas concentradas. $^{115}$

Por um lado, então, a teoria Schumpeteriana demonstra como o uso de instrumentos tradicionais baseados em análise de market share podem apresentar sérios problemas quando confrontados com mercados de inovação, porquanto nestes setores não vale a regra de que as concentrações sempre irão desestimular a inovação. Por outro lado, a teoria

\footnotetext{
112 Conforme aponta SCHUMPETER, a abertura de novos mercados e os desenvolvimentos organizacionais introduzidos pelas inovações "incessantly revolutionizes the economic structure from within, incessantly destroying the old one, incessantly creating a new one. This process of Creative Destruction is the essential fact about capitalism. It is what capitalism consists in and what every capitalist concern has got to live in." (JOSEPH A. SCHUMPETER, Capitalism, socialism and democracy, New York, Harper Perennial Modern Though, 1975, p. 83).
}

113 A introdução de inovações cria vantagens competitivas que são suplantadas pelos concorrentes na medida em que estes passam a também se valer destas inovações. Assim, o autor divide os ciclos de desenvolvimento em quatro fases: (i) prosperidade; (ii) recessão; (iii) depressão; e (iv) recuperação. (PAULO MARCOS RODRIGUES BRANCHER, Direito da concorrência e propriedade intelectual - Da inovação tecnológica ao abuso de poder, Tese de Doutorado, PUC-SP, p. 29).

114 HERBERT HOVENKAMP, The antitrust enterprise - Principle and execution, Cambridge, Harvard University, 2005, p. 25.

115 JORGE FAGUNDES, Fundamentos econômicos das políticas de defesa da concorrência Eficiência econômica e distribuição de renda em análises antitruste, São Paulo, Singular, 2003, pp. 92-93. 
Schumpeteriana também se mostra equivocada quando defende que concentração e poder de mercado sempre irão estimular a inovação. ${ }^{116}$

Dados empíricos comprovam a enorme ambiguidade das situações apresentadas. Segundo JORGE FAGUNDES, estatísticas apontam que grandes empresas não seriam necessariamente mais progressivas em matéria de investimento em P\&D do que empresas médias e pequenas. Inclusive, em muitos casos são as pequenas empresas que atuam no desenvolvimento da maior parte das inovações radicais. Soma-se a isso o fato de que a relação entre concentração econômica e investimentos em $\mathrm{P} \& \mathrm{D}$ apresenta grandes diferenças quando comparadas a indústrias com diferentes características de grau de apropriabilidade e de oportunidade tecnológica. ${ }^{117}$

Dessa forma, verifica-se que não há uma relação clara entre concorrência, estrutura de mercado e progresso técnico, razão pela qual não se pode concluir que concentrações econômicas levariam ao maior investimento em inovações. Por isso, é importante observar com cautela as análises que apontam a teoria Schumpeteriana como fundamento para defender concentrações econômicas, cartéis ou condutas anticompetitivas. O que percebemos é: a pressão competitiva aliada à promessa de lucros extraordinários constitui o maior incentivo para que as empresas invistam em estratégias de inovação. ${ }^{118}$

\section{I.1.4 Error-cost Framework}

Desenvolvida originalmente por FRANK EASTERBOOK, expoente da Escola de Chicago, em seu livro The limits of Antitrust a teoria da moldura de custo-erro tem por objetivo criar uma estrutura de análise que permita aos juízes refletirem sobre o melhor desenho das regras de direito antitruste diante da inevitabilidade dos erros de análise. Suas três principais assunções são: (i) erros de falso positivo (Tipo I), bem como erros de falso negativo (Tipo II) são inevitáveis por conta da dificuldade em distinguir eficiência de

\footnotetext{
116 MICHAEL L. KATZ; HOWARD A SHELANSKI, Schumpeterian competition in high-tech markets, disponível em: http://bit.ly/1NagTMw, acesso no dia 16, jul, 2014, pp. 19-20.

117 JORGE FAGUNDES, Fundamentos econômicos das políticas de defesa da concorrência Eficiência econômica e distribuição de renda em análises antitruste, São Paulo, Singular, 2003, p. 94.

118 Conforme conclui JORGE FAGUNDES, “o aspecto central a ser ressaltado se encontra no fato de que as pressões competitivas - efetivas ou potenciais - são, juntamente com a promessa de lucros extraordinários prospectivos, a mais importante fonte de incentivos ao comportamento e estratégias inovativas por parte das firmas." (JORGE FAGUNDES, Fundamentos econômicos das políticas de defesa da concorrência - Eficiência econômica e distribuição de renda em análises antitruste, São Paulo, Singular, 2003, p. 98).
} 
condutas anticompetitivas; (ii) os custos sociais de falso positivos costumam ser superiores aos custos de falsos negativos; e (iii) regras de direito antitruste devem minimizar os erros ao dar preferência a regras de fácil aplicação e que não levem em conta todas as particularidades e complexidades da situação. ${ }^{119}$

A metodologia se baseia em um modelo de decisão Bayesiano, desenvolvido para tomada de decisões em situação de incerteza. ${ }^{120}$ Segundo essa abordagem, o regulador parte apenas da possibilidade de que uma prática seja anticompetitiva, e a atualiza continuamente com evidências e informações específicas do caso, de modo que a intervenção ocorra apenas quando se constatar com sólidas evidências que a prática seja anticompetitiva. Ao deixar de lado complexas análises baseadas em econometria e modelos de teoria dos jogos e economia comportamental, o julgador evita selecionar uma teoria que se enquadre em sua impressão inicial do caso, moldando os dados colhidos para justificar sua decisão. ${ }^{121}$

No caso de setores com profunda inovação os erros podem ser ainda maiores, uma vez que a literatura ainda não se encontra madura o suficiente para determinar em que medida determinadas políticas concorrenciais estimulariam a inovação e aumentariam o bem estar geral. Por conta disso, segundo esta moldura teórica, a postura ideal do agente regulador seria a de não intervir diante de supostas condutas competitivas até que haja evidência empírica robusta. ${ }^{122}$

119 GEOFFREY A. MANNE; JOSHUA D. WRIGHT, Google and the limits of antitrust: The case against the case against Google, In Harvard Journal of Law \& Public Policy, vol. 34, disponível em: http://bit.ly/1hHH4TR, acesso em 17, ago., 2015, p. 179.

120 Segundo a Stanford Encyclopedia of Philosophy: "Bayes' Theorem is a simple mathematical formula used for calculating conditional probabilities. It figures prominently in subjectivist or Bayesian approaches to epistemology, statistics, and inductive logic. [...] 'Bayes' Theorem relates the 'direct' probability of a hypothesis conditional on a given body of data, $\mathrm{PE}(\mathrm{H})$, to the 'inverse' probability of the data conditional on the hypothesis, PH(E)." (disponível em: http://stanford.io/1RG0dVu, acesso no dia 23, dez., 2015).

121 Conforme aponta MANNE e WRIGHT, "a fundamental challenge for antitrust is the existence of too many theories without methodological commitments from regulators and courts on how to select among them." (GEOFFREY A. MANNE; JOSHUA D. WRIGHT, Google and the limits of antitrust: The case against the case against Google, In Harvard Journal of Law \& Public Policy, vol. 34, disponível em: http://bit.ly/1hHH4TR, acesso em 17, ago., 2015, p. 182).

122 GEOFFREY A. MANNE; JOSHUA D. WRIGHT, Google and the limits of antitrust: The case against the case against Google, In Harvard Journal of Law \& Public Policy, vol. 34, disponível em: http://bit.ly/1hHH4TR, acesso em 17, ago., 2015, pp. 184-187. 


\section{I.1.5 Desenvolvimentos pós-chicago}

$\mathrm{O}$ advento das ideias da Escola de Chicago para análise antitruste tiveram um profundo impacto sobre o pensamento dos anos de 1970, tendo se tornado mainstream durante os anos que se seguiram. No entanto, sua ênfase na eficiência econômica como único valor e na desconsideração de valores não econômicos tem sido fortemente contestada em inúmeras situações. Atualmente, há um claro consenso entre acadêmicos ligados a diferentes escolas econômicas de que a aplicação destas ideias vem gerando dúvidas, especialmente com relação à prevalência de modelos econômicos em relação aos fatos, à tendência de assumir que o livre mercado vai resolver todas as imperfeições, bem como à crença de que apenas a eficiência seria relevante. ${ }^{123}$

Diante desta constatação, novas teorias buscam reformular alguns postulados da teoria econômica então dominante, de modo a adequá-los à realidade. O pensamento econômico pós-chicago se divide entre três vertentes principais: (i) teoria dos mercados contestáveis; (ii) teoria dos jogos; e (iii) teoria dos custos de transação. ${ }^{124}$

A teoria dos mercados contestáveis (contestable markets) tem como base a linha de pensamento clássica da organização industrial, com foco na análise da estrutura de mercado como um todo. Assim, segundo esta teoria, a estrutura de mercado é determinada de forma endógena e concomitante à determinação dos preços, quantidades, dentre outras decisões da firma. Parte, portanto, de uma visão dinâmica, segundo a qual a contestabilidade $^{125}$ de um mercado determinará o comportamento das empresas. Assim, diferentemente da teoria neoclássica, a teoria dos mercados contestáveis afirma que o mercado não deve se aproximar da concorrência perfeita para funcionar de forma eficiente, bastando para tanto a sua contestabilidade. ${ }^{126}$

123 ROBERT PITOFSKY, Introduction: Setting the stage, In ROBERT PITOFSKY, How the Chicago school overshot the mark - The effect of conservative economic analysis on U.S. antitrust, Oxford University Press, 2008, p. 5.

124 ROGER VAN DEN BERGHPP, Behavioral antitrust: Not ready for the main stage, In Journal of Competition Law \& Economics, vol. 9 (1), 2013, p. 207.

125 A contestabilidade do mercado dependerá da possibilidade de livre entrada e saída de players. Nas palavras de BAUMOL: "A contestable market is one into which entry is absolutely free, and exit is absolutely costless." (WILLIAM J. BAUMOL, Contestable markets: An uprising in the theory of industry structure, In The American Economic Review, vol. 72, N. 1, 1982, p. 3. 
A teoria dos jogos, por sua vez, tem como objeto de estudos as estratégias racionais dos jogadores por meio de modelos matemáticos que estudam sua interação estratégica. Sua aplicação no direito antitruste ocorre em grande medida no estudo da motivação dos agentes econômicos, especialmente no tocante às práticas colusivas. Sua grande contribuição nesta área se deu pela identificação, sistematização e descrição dos requisitos para que o comportamento paralelo dos oligopolistas ocorra. ${ }^{127}$

Por fim, a teoria dos custos de transação surge como ramo da Nova Economia Institucional tendo como foco de análise os custos associados a negociação e aquisição de bens no mercado. Sua elaboração original ocorreu com os trabalhos de RONALD COASE, sendo posteriormente desenvolvida por OLIVER WILLIAMSON, que deu à teoria seus contornos atuais.

Segundo a teoria dos custos de transação, a racionalidade limitada e o oportunismo presentes nas relações faz com que surjam diversos custos relacionados às negociações entre os agentes econômicos. ${ }^{128}$ Diante da constatação da existência destes custos, os agentes passam a buscar formas de minimizá-los por meio da estruturas de governança, que podem se revestir de três tipos básicos: (i) o mercado; (ii) as hierarquias; e (iii) as formas híbridas. Tais estruturas mostram-se mais ou menos eficientes a depender das condições e das características das relações nas quais elas são implementadas. ${ }^{129}$

A eficiência analisada sob o enfoque desta teoria permite examinar as circunstâncias em que integrações ou restrições verticais, bem como outras formas contratuais que tragam restrições à concorrência, teriam como objetivo principal gerar ganhos de eficiências que suplantariam os possíveis prejuízos à concorrência. Tal enfoque traz importantes reflexões com relação a análise de restrições verticais, uma vez que tais eficiências deveriam, conforme defende WILLIAMSOM, ser contrabalanceadas com os eventuais aumentos de poder de mercado decorrentes destas operações. ${ }^{130}$

127 CALIXTO SALOMÃO FILHO, Direito concorrencial, São Paulo, Malheiros, 2013, pp. 388-390.

128 Os custos de transação podem ser divididos em quatro grupos: (i) custos de elaboração e negociação dos contratos; (ii) custos de mensuração e fiscalização dos direitos de propriedade; (iii) custos de monitoramento do desempenho e (iv) custos de organização das atividades (ELIZABETH M. M. Q. FARINA, ET. AL., Competitividade: Mercado, Estado e organizações, São Paulo, Singular, 1997, p. p. 57).

129 JORGE FAGUNDES, Fundamentos econômicos das políticas de defesa da concorrência Eficiência econômica e distribuição de renda em análises antitruste, São Paulo, Singular, 2003, pp. 99-103.

130 JORGE FAGUNDES, Fundamentos econômicos das políticas de defesa da concorrência Eficiência econômica e distribuição de renda em análises antitruste, São Paulo, Singular, 2003, pp. 104-107. 
A Economia dos Custos de Transação (ECT) analisa as circunstâncias em que os contratos se mostram incompletos, fazendo com que as partes se adaptem a estas circunstâncias imprevisíveis. Dessa forma, os custos de transação se dividem entre custos ex-ante e ex-post. Os custos ex-ante consistem nos custos para elaborar, negociar e salvaguardar um acordo, ao passo que os custos ex-post consistem nos custos decorrentes da execução dos contratos. Segundo a ECT esses custos são distintos dos custos de produção, sendo estas contribuições importantes para a análise das situações em que os preços aparentam ser iguais a zero. ${ }^{131}$

Segundo esta escola, os agentes atuam de forma racional, porém não tem capacidade para antecipar tudo que pode ocorrer durante a execução do contrato. Surgem, assim, diversas possibilidades de lacuna, erros e omissões no contrato original que levam a necessidade de adaptações. Por essa razão, as partes devem acompanhar e verificar a conduta da outra parte ex-post. A possibilidade de comportamento oportunístico e estratégico, aliado à incapacidade de previsão de todas as situações, resultam na inevitável incompletude contratual. ${ }^{132}$

Neste cenário, conclui-se que apenas estruturas de governança são capazes de reduzir estes custos de transação, levando a resultados mais eficientes. As características presentes na relação, por sua vez, tem influência sobre a capacidade das estruturas e das partes se adaptarem às situações imprevistas. Alguns desses atributos são a incerteza, a complexidade, o número de competidores, e a informação assimetricamente distribuída. Estes fatores apresentam riscos para essas relações, e WILLIAMSON conclui que a presença destes riscos leva a elaboração de contratos mais complexos.

Além disso, alguns fatores podem gerar situações de dependência entre as partes. $\mathrm{O}$ desenvolvimento de ativos como a experiência, a informação e os investimentos por vezes aumentam o grau de dependência entre as partes. O termo cunhado por WILLIAMSON para descrever o grau em que um ativo perde valor produtivo ao ser direcionado para outro uso alternativo é a especificidade de ativos. Esta especificidade de ativos cria uma dependência bilateral que pode levar a situações semelhantes a do monopólio bilateral. $\mathrm{O}$ aumento causado por estes riscos é mitigado por meio de incentivos, controles

131 CHRIS JAY HOOFNAGLE; JAN WHITTINGTON, Free - Accounting for the costs of the Internet's most popular price, In UCLA Law Review, n. 61, vol. 3, 2014, pp. 614-615.

132 CHRIS JAY HOOFNAGLE; JAN WHITTINGTON, Free - Accounting for the costs of the Internet's most popular price, In UCLA Law Review, n. 61, vol. 3, 2014, pp. 615-616. 
administrativos e outras salvaguardas, remédios que podem ser contratuais ou parte de um aparato institucional. ${ }^{133}$

Inúmeras dúvidas surgem quanto a sua aplicabilidade ao direito antitruste, uma vez que a criação de eficiências sob a forma de economia dos custos de transação podem trazer consigo efeitos anticompetitivos, decorrentes da menor rivalidade e menor concorrência entre as empresas. Somam-se a isto as dificuldades de mensuração dos trade-offs, dentre outros problemas de operacionalização destas teorias. Por estas razões, a teoria dos custos de transação deve ser analisada com o devido cuidado para que não aponte para resultados prejudiciais à concorrência. ${ }^{134}$

Por outro lado, conforme veremos, a aplicação da teoria dos custos de transação aos mercados de preço zero pode auxiliar na compreensão de algumas de suas particularidades. Muitas vezes, as estruturas de governança permitem que as firmas ignorem as preferências dos consumidores em relação a privacidade e volume das informações pessoais coletadas gerando incentivos aos comportamento oportunístico por parte das empresas. ${ }^{135}$

\section{I.1.6 A influência da escola comportamental}

Os questionamentos relacionados à aplicação das teorias neoclássicas ao direito da concorrência fizeram com que outras escolas econômicas também fossem aplicadas a esta área. Uma das mais recentes vertentes que vem sendo desenvolvida é a da chamada economia comportamental.

A economia comportamental é a ciência que busca aplicar teorias do campo da psicologia ao estudo da economia com objetivo de analisar a escolha dos consumidores, trazendo inúmeras críticas aos modelos de escolha racional da teoria neoclássica, segundo a qual os agentes econômicos sempre teriam informação completa, agiriam de forma racional e com o intuito de maximização dos seus lucros. Nos últimos anos, estudos vem questionando a afirmação de que os indivíduos sempre agem de forma racional e buscando

\footnotetext{
133 CHRIS JAY HOOFNAGLE; JAN WHITTINGTON, Free - Accounting for the costs of the Internet's most popular price, In UCLA Law Review, n. 61, vol. 3, 2014, pp. 618-619.

134 JORGE FAGUNDES, Fundamentos econômicos das políticas de defesa da concorrência Eficiência econômica e distribuição de renda em análises antitruste, São Paulo, Singular, 2003, pp. 107-108.

135 CHRIS JAY HOOFNAGLE; JAN WHITTINGTON, Free - Accounting for the costs of the Internet's most popular price, In UCLA Law Review, n. 61, vol. 3, 2014, p. 609.
} 
o auto interesse, ${ }^{136}$ e demonstram que em diversas situações os indivíduos acabam agindo de forma previsivelmente irracional. ${ }^{137}$

Ao questionar o paradigma dos agentes econômicos racionais, a economia comportamental provoca profundas mudanças em relação às duas teorias dominantes no direito antitruste, a escola de Harvard e a escola de Chicago, e aos desdobramentos posteriores das teorias pós-Chicago, uma vez que todas tem a racionalidade dos agentes como pressupostos, e a Microeconomia e a Price Theory como ferramental de análise e interpretação. ${ }^{138}$ Inúmeras dúvidas ainda persistem no tocante à aplicabilidade destas teorias ao direito concorrencial, porém, este debate é fundamental para que se compreenda melhor a aplicação das normas antitruste.

A ciência econômica tradicional se baseia em grande medida no método indutivo inferencial, por meio do qual se utilizam observações empíricas não experimentais para realizar previsões sobre o futuro. A partir de alguns axiomas a respeito do comportamento humano (como, por exemplo, a racionalidade e a aversão ao risco), e por meio do uso de dados pretéritos coletados sobre eventos ocorridos, formulam-se diversos modelos matemáticos que identificam relações de causa e consequência sobre os eventos. Dessa forma, o uso de experimentos em ambientes controlados se mostra extremamente raro e controvertido neste campo da ciência. ${ }^{139}$

O uso da psicologia e do experimentalismo nos estudos econômicos surge com os Utilitaristas Marginais (em especial JEVONS, que buscou estabelecer uma escala contínua

136 AMANDA P. REEVES, Behavioral antitrust: Unanswered questions on the horizon, In The antitrust source, jun., 2010, p. 1.

137 Conforme termo cunhado por DAN ARIELY, os indivíduos agem de forma previsivelmente irracional: "my further observation is that we are not only irrational, but predictably irrational - that our irrationality happens the same way, again and again". E continua o autor: "we are really far less rational than standard economic theory assumes. Moreover, these irrational behaviors of ours are neither random nor senseless. They are systematic, and since we repeat them again and again, predictable." (DAN ARIELY, predictably irrational, New York, Harper Collins, 2009, p. xviii).

138 ROGER VAN DEN BERGHPP, Behavioral antitrust: Not ready for the main stage, In Journal of Competition Law \& Economics, vol. 9 (1), 2013, pp. 204-205. Ainda AMANDA P. REEVES: “Judge Bork's Antitrust Paradox, along with the work of Judge Richard Posner, and Professors Donald Turner and Phillip Areeda, brought these ideas to the forefront of modern antitrust analysis during the 1970s and early $1980 \mathrm{~s}$. Collectively, their work demonstrated that all of antitrust analysis could be viewed 'through the lens of price theory." (AMANDA P. REEVES, Behavioral antitrust: Unanswered questions on the horizon, In The antitrust source, jun., 2010, p. 2). de psicologia, Vol. 46, n. 2, 2012, p. 318. 
no qual de um lado estaria o prazer e do outro lado a dor) e a noção de utilidade e saciedade. O desenvolvimento da economia e sua tendência de aproximação com a matemática fez com que esta ciência se distanciasse da psicologia e se aproximasse das ciências exatas. ${ }^{140}$ Deste processo surge o conceito de "Homem Econômico", que incorporava uma série de pressupostos de racionalidade ao comportamento dos indivíduos quando analisado pela economia.

A reaproximação das áreas ocorre apenas na metade do século $\mathrm{XX}$, quando evidências empíricas começam a contrariar as condições sine qua non e os axiomas adotados pela teoria econômica dominante. Já na década de 1950, estudiosos como HERBERT SIMON iniciam a noção de racionalidade limitada, criando os primeiros alicerces teóricos do behaviorismo. ${ }^{141}$

Os primeiros economistas comportamentais, por sua vez, surgem na década de 1970, trazendo uma série de contribuições para o questionamento da noção de informação completa, por meio do uso da heurística e de métodos experimentais. ${ }^{142}$ Este ramo inicia seus estudos com a observação de que as tendências comportamentais relacionadas aos riscos, custos e benefícios, em situações de incerteza, desviam-se sistematicamente do comportamento racional. Nestes casos, os atores tendem a agir com aversão à perda e até com propensão ao risco quando confrontados com uma possível perda. DANIEL KAHNEMAN e AMOS TVERSKY, precursores deste ramo, identificaram o chamado "framing effect", segundo o qual as decisões dos indivíduos são afetadas diretamente pela

140 Uma das teorias que levou a esse distanciamento foi a noção das "preferências reveladas" desenvolvida por PARETO, que sustentava que os "prazeres internos" não poderiam ser quantificados, bastando a ordenação entre cestas diferentes de bens. O Behaviorismo Econômico se distancia da economia por uma série de razões, dentre elas podemos apontar sua preferência por temas distintos, os sujeitos de análise e o método experimental (ANA CAROLINA TROUSDELL FRANCESCHINI; DIOGO CONQUE SECO FERREIRA, Economia Comportamental: uma introdução para analistas do comportamento, In Revista interamericana de psicologia, Vol. 46, n. 2, 2012, p. 320-321).

141 ROGER VAN DEN BERGHPP, Behavioral antitrust: Not ready for the main stage, In Journal of Competition Law \& Economics, vol. 9 (1), 2013, pp. 208-209. "Nobel Laureate Herbert Simon first introduced the idea of 'bounded rationality' in the 1950s" (AMANDA P. REEVES, Behavioral antitrust: Unanswered questions on the horizon, In The antitrust source, jun., 2010, p. 3).

142 Os precursores da economia comportamental foram autores como DANIEL KAHNEMAN e AMOS TVERSKY, que desenvolveram a chamada "prospect theory" (teoria da perspectiva), como substituta para a teoria da escolha racional (ROGER VAN DEN BERGHPP, Behavioral antitrust: Not ready for the main stage, In Journal of Competition Law \& Economics, vol. 9 (1), 2013, p. 207). As principais obras sobre o assunto são DANIEL KAHNEMAN, Thinking, fast and slow, New York, Farrar, Straus and Giroux, 2011; DAN ARIELY, Predictably irrational: The hidden forces that shape our decisions, New York, Harper Perennial, 2010; RICHARD H. THALER, CASS R. SUNSTEIN, Nudge: Improving decisions about health, wealth, and happiness, London, Penguin Books, 2008; e CHARLES DUHIGG, The power of habit: Why we do what we do in life and business, New York, Random House, 2012. 
forma como as informações são apresentadas. Por esta razão, quando os indivíduos são confrontados com uma idêntica gama de opções, mas em ambientes distintos, suas decisões tendem a ser diferentes. ${ }^{143}$

A partir dos anos de 1990 tais teorias passam a ser estudadas e aplicadas por pesquisadores de diversas áreas do conhecimento. A crise de 2008 e as discussões relacionadas à necessidade de regulamentação dos mercados por meio de instrumentos de economia comportamental fizeram com que estas discussões ganhassem enorme relevo. ${ }^{144}$

A economia comportamental questiona a noção de racionalidade maximizadora ao sustentar que as limitações cognitivas do ser humano impedem que as informações sejam processarem perfeitamente. Desenvolve-se, portanto, a noção de racionalidade limitada (bounded rationality), que leva os indivíduos a agirem com tendências comportamentais que desviam seu comportamento do padrão de racionalidade. ${ }^{145}$

A aplicação destas teorias ao direito antitruste, no entanto, é extremamente recente, motivo pelo qual ainda persistem inúmeras dúvidas quanto à sua aplicabilidade. ${ }^{146} \mathrm{~A}$ economia comportamental aponta para um série de escolhas irracionais por parte dos consumidores, tendo enorme capacidade de influência sobre políticas relacionadas às leis de defesa do consumidor. No entanto, o foco do direito antitruste não é sobre o comportamento do consumidor, mas sim das firmas. Dessa forma, a grande contribuição

$143 \quad$ "Framing effects: Different ways of presenting the same information often evoke different emotions. The statement that 'the odds of survival one month after surgery are $90 \%$ ' is more reassuring than the equivalent statement that 'mortality within one month of surgery is $10 \%$.' Similarly, cold cuts described as ' $90 \%$ fat-free' are more attractive than when they are described as ' $10 \%$ fat'. The equivalence of alternative formulations is transparent, but an individual normally sees only one formulation, and what she sees is all there is." (DANIEL KAHNEMAN, Thinking fast and slow, New York, Farrar, Straus and Giroux, 2011, p. 88). ROGER VAN DEN BERGHPP, Behavioral antitrust: Not ready for the main stage, In Journal of Competition Law \& Economics, vol. 9 (1), 2013, pp. 208-209.

144 Nos últimos anos inúmeros livros relacionados à economia comportamental vem ganhando enorme espaço na mídia e se tornando best sellers, como por exemplo as obras de DAN ARIELY, JUSTIN FOX, GEORGE AKERLOF e ROBERT SHILLER, DANIEL KAHNEMAN, dentre outros (AMANDA P. REEVES, Behavioral antitrust: Unanswered questions on the horizon, In The antitrust source, jun., 2010, p. 3).

145 AMANDA P. REEVES, The antitrust source, In The antitrust source, jun., 2010, pp. 2-3.

146 Um dos primeiros trabalhos que analisam a aplicabilidade da economia comportamental ao direito antitruste é feito por AVISHALOM TOR, em seu artigo The fable of entry - Bounded rationality, market discipline, and legal policy. O autor defende que "behavioral insights are highly applicable do those numerous areas in the law addressing nonmarket behaviors" e "highlights how competitive forces unexpectedly facilitate bounded rationality in the market. The profound role of boundedly rational action in markets therefore renders its understanding supremely important for the legal regulation of economic phenomena" (AVISHALOM TOR, The fable of entry - Bounded rationality, market discipline, and legal policy., In Michigan Law Review, Vol. 101, 2002, p. 485). 
que tais teorias poderiam fornecer está na influência da irracionalidade sobre decisões tomadas no nível da firma. ${ }^{147}$

O comportamento das firmas se difere dos consumidores na medida em que aquelas atuam profissionalmente na aquisição e venda de bens e serviços, tendo incentivos para investir em busca de informações; possuem setores especializados; sofrem a todo momento pressão da concorrência; e são players frequentes. Por esta razão, suas escolhas tendem a ser mais racionais do que as dos consumidores individuais. No entanto, as empresas não estão isentas de irracionalidade. Basta pensarmos que as decisões internas das firmas são tomadas por indivíduos sujeitos às mais diversas influências, sejam elas pessoais ou frutos do ambiente em que se tomam as decisões. Muitas vezes a busca por promoção profissional ou maior remuneração leva ao comportamento irracional ou risk-seeking. ${ }^{148}$

Apesar das dúvidas quanto à aplicabilidade da economia comportamental ao Direito Concorrencial, ao invés de configurar uma completa contraposição às teorias econômicas pós-Chicago, tais teorias poderiam ser de certo modo conciliadas. O conceito de racionalidade limitada exposto pela Nova Economia Institucional, por exemplo, poderia ser aperfeiçoado com as contribuições da economia comportamental. ${ }^{149}$

Conforme veremos, a insuficiência da economia neoclássica para explicar alguns comportamentos de mercado, especialmente diante de situações de preço zero, faz com que a economia comportamental ofereça importantes considerações com relação ao comportamento do consumidor nestes setores. ${ }^{150}$

147 ROGER VAN DEN BERGHPP, Behavioral antitrust: Not ready for the main stage, In Journal of Competition Law \& Economics, vol. 9 (1), 2013, p. 209.

148 "Also, managers of firms may want to maximize their profits relative to that of their peers. Managers may also be vulnerable to cognitive biases and framing effects. In striving for future promotion, managers may be overconfident about profitability of a certain action." (ROGER VAN DEN BERGHPP, Behavioral antitrust: Not ready for the main stage, In Journal of Competition Law \& Economics, vol. 9 (1), 2013, p. 211).

149 ROGER VAN DEN BERGHPP, Behavioral antitrust: Not ready for the main stage, In Journal of Competition Law \& Economics, vol. 9 (1), 2013, p. 215.

150 JOHN M. NEWMAN, Antitrust in zero-price markets: Foundations, In University of Pennsylvania Law Review, Vol. 164, disponível em: http://bit.ly/1jEUMaX, acesso no dia 15, out., 2015, p. 32. 


\section{CAPÍTULO II - PRINCIPAIS CARACTERÍSTICAS DOS SETORES "PONTOCOM"}

O primeiro registro que se tem notícia relacionado a uma interação social por meio de uma rede se encontra em memorandos escritos por JOSEPH LICKLIDER, do MIT, discorrendo sobre o conceito de "Galactic Network" em 1962. Já nesse momento o pesquisador vislumbrava a possibilidade de interligar uma série de computadores por meio de conexões de rede, permitindo o acesso de dados e de programas de qualquer lugar do mundo. $^{151}$

O surgimento da Internet remonta aos projetos desenvolvidos pela ARPA (Advanced Research Projects Agency do Department of Justice dos Estados Unidos) nos anos de 1960, durante o auge da Guerra Fria, quando as duas potências mundiais da época, Estados Unidos e União Soviética, buscavam aumentar seu poderio geopolítico através do desenvolvimento de sistemas de comunicação mais eficientes. Entre os anos de 1960 e 1980, os computadores sofrem profundas alterações, passando de meros instrumentos de cálculo para verdadeiras ferramentas de comunicação. A princípio, ninguém poderia imaginar que estas ferramentas enormes e extremamente caras se tornariam instrumentos comunicativos tão acessíveis e disseminados. ${ }^{152}$ Basta lembrarmos que, antes do advento das redes de computadores, era necessário o uso de meios físicos como fitas magnéticas ou cartões perfurados para o transporte de informação. ${ }^{153}$ A introdução dos primeiros modems

151 BARRY M. LEINER; ET. AL., Brief history of the Internet, Internet Society, 2012, disponível em: http://bit.ly/1S9Zoks, acesso no dia 8, nov., 2015, p. 2.

152 "The transcendence of geographical distance has come to seem an inherent part of computer technology. But in the early 1960s, when computers were scarce, expensive, and cumbersome, using a computer for communication was almost unthinkable." (JANET ABBATE, Inventing the internet, Cambridge, MIT, 1999, Kindle Edition, p. 1).

153 Os computadores evoluem do uso de elementos mecânicos (como válvulas e cartões perfurados) para os circuitos eletrônicos. A mudança dos elementos utilizados trouxe enorme ganho de velocidade das operações realizadas pelos computadores. A substituição de elementos mecânicos, para circuitos transistorizados para o uso de chips de silício e microprocessadores trouxe aumentos exponenciais de velocidade de processamento (MANOEL JOAQUIM PEREIRA DOS SANTOS, A proteção autoral de programas de computador, Rio de Janeiro, Lumen Iuris, 2008, p. 26). 
ocorre apenas no final da década de 1950, quando ainda apresentavam diversos problemas de compatibilidade e comunicação. ${ }^{154}$

A Internet se desenvolveu ao longo de inúmeros anos por meio de alianças entre órgãos militares dos Estados Unidos, universidades americanas e diversas entidades localizadas em outros países. É importante notar que seus usos, seu valor e sua própria essência sofreram transformações radicais ao longo dos anos. No início, seu principal objetivo era permitir o uso de programas por cientistas localizados em diferentes partes do mundo por meio de acesso remoto. O uso como meio de comunicação interpessoal surge posteriormente, após um longo processo de reestruturação técnica, política e organizacional. $^{155}$

Vale ressaltar que a criação da Internet não decorreu do esforço individual e isolado de algumas pessoas, mas sim da atuação colaborativa de uma série de agências e indivíduos. Em muitos casos, como na criação do e-mail e da World Wide Web, a capacidade de usuários independentes criarem informalmente aplicações que se adequassem às suas necessidades foi até preponderante em comparação à criação por agências e órgãos centralizados. ${ }^{156}$

\section{II.1 A criacão da Internet e desenvolvimentos recentes}

O surgimento da Internet remonta aos trabalhos com sistemas de transmissão de dados por meio do chamado "packet switching" (comutação de pacotes) pelas agências $A R P A$ e RAND nos Estados Unidos, pela NPL na Inglaterra, e pela CYCLADES na França. ${ }^{157}$ Devemos lembrar que o desenvolvimento inicial destas tecnologias ocorre em meio à Guerra Fria, período em que o desenvolvimento de sistemas confiáveis e seguros de comunicação era fundamental para as potências hegemônicas. Com o objetivo de

\footnotetext{
154 As dificuldades eram tamanhas que, conforme aponta JANET ABBATE, “A scientist who needed to use a distant computer might find it easier to get on a plane and fly to the machine's location to use it in person" (JANET ABBATE, Inventing the internet, Cambridge, MIT, 1999, Kindle Edition, p. 1).

155 JANET ABBATE, Inventing the internet, Cambridge, MIT, 1999, Kindle Edition, p.2.

156

JANET ABBATE, Inventing the internet, Cambridge, MIT, 1999, Kindle Edition, p. 5.

157 O packet switching foi criado de forma independente por dois pesquisadores: PAUL BARAN da agência RAND nos Estados Unidos e DONALD DAVIES da NPL (National Physical Laboratory) na Inglaterra (JANET ABBATE, Inventing the internet, Cambridge, MIT, 1999, Kindle Edition, p. 8). O primeiro paper a tratar o packet switching foi escrito por LEONARD KLEINROCK do MIT, em 1961 (BARRY M. LEINER; ET. AL., Brief history of the Internet, Internet Society, 2012, disponível em: http://bit.ly/1S9Zoks, acesso no dia 8, nov., 2015, p. 2).
} 
desenvolve-los, a partir de 1965, ocorre intenso investimento governamental nas universidades e centros de pesquisa dos Estados Unidos. Nesse momento, cria-se a rede ARPANET com o fim de permitir que os computadores localizados nas diferentes universidades fossem utilizados por pesquisadores de forma conjunta, estimulando o uso compartilhado e a programação cooperativa entre os diferentes usuários. ${ }^{158} \mathrm{Um}$ dos pontos centrais da cultura organizacional da $A R P A$ era justamente a descentralização e a informalidade, o que estimulava a participação e a cooperação de todos os colaboradores. $^{159}$

Os primeiros quatro pontos de conexão da rede foram estabelecidos na Universidade da Califórnia em Santa Barbara (UCSB), Universidade de Stanford, Universidade de Utah e Universidade da Califórnia em Los Angeles (UCLA), além da interligação com uma firma de consultoria $(B B N) .{ }^{160} \mathrm{~A}$ infraestrutura do sistema se utilizava de conexões por linhas de telefonia instaladas pela $A T \& T$. Ao longo de seu desenvolvimento, novas universidades foram incorporadas à rede, o que levou ao aumento do número de colaboradores. Devemos lembrar, porém, que o projeto da $A R P A$, apesar do intenso envolvimento com o meio acadêmico e sua orientação para a pesquisa, ainda era um projeto militar de grande importância estratégica para o governo norte-americano. ${ }^{161}$

Ao longo dos anos, as funcionalidades da ARPANET passam a se diversificar. Seu uso como ferramenta de comunicação, com o desenvolvimento do e-mail em $1972^{162}$, leva

158 Devemos lembrar que, ao final da década de 1960, as incompatibilidades entre os diversos tipos e marcas de computadores traziam inúmeras dificuldades para a realização de trabalho conjunto entre os diferentes centros de pesquisa. A superação destes obstáculos envolveu uma série de mudanças de software e de hardware nos sistemas da época (JANET ABBATE, Inventing the internet, Cambridge, MIT, 1999, Kindle Edition, pp. 46-49).

159 Conforme aponta JANET ABBATE, "The lack of established authorities and the newness of the field meant that the NWG's participants had to formulate technical problems and propose solutions on their own." (JANET ABBATE, Inventing the internet, Cambridge, MIT, 1999, Kindle Edition, p. 73).

160 DAVID C. MOWERY; TIMOTHY SIMCOE, Is the Internet a U.S. invention? - An economic and technological history of computer networking, In Research Policy, n. 31, Elsevier, 2002, p. 1373. A ligação entre os primeiros quatro pontos foi realizada em 1969, sendo que nos anos que se seguiram diversos novos computadores foram adicionados à rede (BARRY M. LEINER; ET. AL., Brief history of the Internet, Internet Society, 2012, disponível em: http://bit.ly/1S9Zoks, acesso no dia 8, nov., 2015, p. 3).

161 JANET ABBATE ressalta que: "although Principal Investigators at universities acted as buffers between their graduate students and the Department of Defense, thus allowing students to focus on the research without necessarily having to confront its military implications, this only disguised and did not negate the fact that military imperativas drove the research" (JANET ABBATE, Inventing the internet, Cambridge, MIT, 1999, Kindle Edition, p. 73).

162 "It was also in 1972 that the initial 'hot' application, eletronic mail, was introduced" (BARRY M. LEINER; ET. AL., Brief history of the Internet, Internet Society, 2012, disponível em: http://bit.ly/1S9Zoks, 
a uma completa redefinição de sua essência, migrando de um sistema de compartilhamento de recursos para um verdadeiro sistema de comunicação. ${ }^{163-164}$ Sua transição para a abertura comercial passa ainda por um novo período de intenso controle militar, a partir de 1975, e um retorno ao domínio acadêmico nos anos de $1980 .{ }^{165-166}$ A popularização da rede se deu em grande medida pela popularização do computador pessoal no final da década de $1970 .{ }^{167}$

Apesar da enorme descentralização e da ausência de controles centrais no funcionamento da Internet, uma função essencial que precisava ser centralizada era a atribuição de nome e endereço aos hosts, de modo que cada um pudesse ser identificado, evitando conflitos. Dessa forma, criou-se um sistema de atribuição de um nome e um endereço (numérico) para cada host conectado à rede. Este mecanismo funcionaria,

acesso no dia 8, nov., 2015, p. 3). Interessante notar que quando a ARPANET foi projetada seus desenvolvedores não viam a capacidade de troca de mensagens como algo relevante para uma rede de computadores científicos (JANET ABBATE, Inventing the internet, Cambridge, MIT, 1999, Kindle Edition, p. 108). Um estudo realizado pela ARPA aponta que, após um ano de sua criação, o e-mail já gerava $73 \%$ de todo tráfego da ARPANET (DAVID C. MOWERY; TIMOTHY SIMCOE, Is the Internet a U.S. invention? An economic and technological history of computer networking, In Research Policy, n. 31, Elsevier, 2002, p. 1372).

163 "In the process of using the network, the ARPANET community developed a new conception of what networking meant. [...] By embracing email, ARPANET users gave the network a new purpose and initiated a significant change in the theory and practice of networking" (JANET ABBATE, Inventing the internet, Cambridge, MIT, 1999, Kindle Edition, pp. 111-112).

${ }^{164} \mathrm{O}$ desenvolvimento da tecnologia Ethernet, a partir dos trabalhos de ROBERT METCALFE no aprimoramento do método de transmissão por rádio desenvolvido na Universidade do Hawaii, chamado de Alohanet, foi o primeiro passo fundamental para o surgimento da Internet. Foi, no entanto, o trabalho de KAHN e VINTON CERF no ano de 1973 que trouxe o primeiro desenho do que viria a ser a Internet. Outras definições importantes ocorreriam com o estabelecimento do TCP/IP (Transmission Control Protocol/ Internetwork Protocol), que tinha por base a noção de arquitetura aberta de KAHN, como protocolo padrão de transmissão de dados e a criação dos chamados gateways, computadores responsáveis pela transmissão de dados entre duas redes. O desenvolvimento destas tecnologias, porém, enfrentou inúmeros obstáculos nos anos que se seguiram. Podemos afirmar que o marco inicial da Internet ocorre com a interligação da ARPANET com a PRNET e a SATNET, três redes experimentais da ARPA que utilizavam o packet switching (BARRY M. LEINER; ET. AL., Brief history of the Internet, Internet Society, 2012, disponível em: http://bit.ly/1S9Zoks, acesso no dia 8, nov., 2015, p. 4).

165

JANET ABBATE, Inventing the internet, Cambridge, MIT, 1999, Kindle Edition, pp. 138-146.

166 Nestes anos o crescimento do número de computadores com acesso à Internet foi meteórico. No ano de 1985 o número de computadores conectado era de 2000 computadores, no final de 1987 já havia quase 30.000 e em outubro de 1989 o número já era de 159.000 (JANET ABBATE, Inventing the internet, Cambridge, MIT, 1999, Kindle Edition, pp. 182-186).

167 É nesse período que são lançados o Altair 8800, o Apple II, o Commodore PET e o Tandy/Radio Shack TRS-80 (JANET ABBATE, Inventing the internet, Cambridge, MIT, 1999, Kindle Edition, p. 186). "Widespread development of LANS, PCs and workstations in the 1980's allowed the nascent Internet to flourish” (BARRY M. LEINER; ET. AL., Brief history of the Internet, Internet Society, 2012, disponível em: http://bit.ly/1S9Zoks, acesso no dia 8, nov., 2015, p. 6). 
portanto, como um mapa da Internet, no qual se associaria o endereço numérico utilizado pelo $T C P / I P$ a um endereço escrito de forma legível pelo homem. ${ }^{168}$

O crescimento da Internet fez com que a estrutura da ARPANET como backbone ${ }^{169}$ da rede começasse a se mostrar obsoleta no final dos anos de 1980. Assim, no final de 1987, decidiu-se pelo seu encerramento, sendo sua função realizada desde então pela NSFNET, que passou a ser o novo backbone da rede. ${ }^{170} \mathrm{O}$ fim da ARPANET marca também o fim das operações militares da Internet. ${ }^{171} \mathrm{O}$ passo final para sua abertura comercial ocorreria com a privatização no início dos anos de 1990, quando os serviços de Internet passaram a ser prestados por provedores de acesso (Internet Service Providers ISPS), e cada um ficou responsável por operar seu próprio backbone, permitindo que o backbone da NSFNET fosse desativado. ${ }^{172} \mathrm{~A}$ abertura comercial da Internet permitiu que um público muito maior tivesse acesso ao seu conteúdo, além de, finalmente, permitir que fossem desenvolvidas atividades comerciais, sociais e recreativas.

Nos primeiro anos, a Internet apresentava uma interface extremamente simples e pouco atrativa para o usuário, além de um complexo sistema de localização e atualização de arquivos, o que desencorajava fortemente seu uso. A solução para estes problemas

\footnotetext{
168 Originalmente havia uma tabela que fazia a correspondência entre o nome e os endereços de cada host conectado, porém, isso trazia grandes dificuldades. Como resultado, decidiu-se por criar um sistema que dividisse a Internet em "domínios" diferentes, de modo que os hosts seriam identificados sob a forma "host.domain" e os usuários fossem identificados pela forma "user@host.domain". Este sistema, que recebeu o nome de Domain Name System (DNS) foi criado por PAUL MOCKAPETRIS e adotado pela Internet no meio dos anos 1980. Decidiu-se por criar seis grandes domínios que dividiriam os sites por tipo: .edu (educational), .gov (government), .mil (military), .com (commercial), .org (organizations), e .net (network resources). Para cada um destes domínios criaram-se outros sub-domínios, que poderiam ser divididos em novos domínios. Isso descentralizou a atribuição de nomes para os hosts e facilitou esse procedimento (DAVID C. MOWERY; TIMOTHY SIMCOE, Is the Internet a U.S. invention? - An economic and technological history of computer networking, In Research Policy, n. 31, Elsevier, 2002, pp. 1376-1377).
}

169 O backbone é a espinha dorsal da rede, ou seja, consiste na rede principal por meio da qual todas as informações circulam antes de atingirem seu destino final.

170 A NFSNET apresenta uma série de melhorias técnicas em sua estrutura. A velocidade do backbone da rede, por exemplo, aumentou de 57.600 bits por segundo para 1,5 milhão de bits por segundo (DAVID C. MOWERY; TIMOTHY SIMCOE, Is the Internet a U.S. invention? - An economic and technological history of computer networking, In Research Policy, n. 31, Elsevier, 2002, p. 1376).

171 JANET ABBATE, Inventing the internet, Cambridge, MIT, 1999, Kindle Edition, pp. 193-195.

172 A desativação do backbone da NSFNET em 1995 marca o fim da propriedade do governo dos Estados Unidos sobre a infra-estrutura da Internet (JANET ABBATE, Inventing the internet, Cambridge, MIT, 1999, Kindle Edition, pp. 195-199). 
estaria na criação de uma aplicação que trouxe profundas mudanças sobre a rede: a World Wide Web. ${ }^{173}$

Tendo como inspiração o conceito de hypertext $^{174}$, TIM BERNERS-LEE desenvolve um sistema que permite linkar arquivos localizados em diferentes partes do mundo, além de permitir o uso de outros tipos de mídia como imagens e sons. Essa nova concepção modificou completamente o look and feel do usuário da Internet. ${ }^{175-176} \mathrm{~A}$ enorme facilidade de uso, por meio de interfaces gráficas e instruções do tipo "point and click", possibilitaram a qualquer usuário novo na Web aprender rapidamente a utilizar esta nova aplicação.

Em 1993, um grupo de desenvolvedores ligados ao NCSA cria o web browser Mosaic, o primeiro sistema a incluir imagens coloridas e a possibilitar seu uso como link para outros documentos. A adoção deste programa foi explosiva: em 1994 estima-se que mais de um milhão de cópias já estavam sendo utilizadas. ${ }^{177}$ No mesmo ano, os programadores responsáveis pelo Mosaic iniciam o desenvolvimento de uma versão comercial deste aplicativo chamada de Netscape. A maior facilidade de uso da interface, bem como a maior velocidade e segurança do Netscape fizeram com que este rapidamente se tornasse mais popular do que o Mosaic. ${ }^{178}$

173 JANET ABBATE, Inventing the internet, Cambridge, MIT, 1999, Kindle Edition, pp. 212-213.

174 Criado por uma das grandes personalidades da contracultura hacker dos anos de 1970 (TED NELSON), o hypertext permite que se interliguem pedaços de informação, desconstruindo o conceito linear que se tinha até então.

175 Para implementação deste sistema foi necessário o desenvolvimento do formato HTML (Hypertext markup language), linguagem desenvolvida por TIM BERNERS-LEE em conjunto com o físico ROBERT CAILLIAU que trabalhavam juntos na CERN da Suíça. Além disso criou-se um protocolo para transferência das informações entre os browsers e os servidores que foi chamado de HTTP (hypertext transfer protocol). "HTTP turned the Internet into a vast cross-referenced collection of multimedia documents" (DAVID C. MOWERY; TIMOTHY SIMCOE, Is the Internet a U.S. invention? - An economic and technological history of computer networking, In Research Policy, n. 31, Elsevier, 2002, p. 1378).

176 Por fim, com o objetivo de padronizar os endereços dos diferentes sites foi criado o URL (uniform resource locator), um formato de endereço padrão que especifica tanto o tipo de aplicação como o endereço do computador onde está localizado o arquivo (JANET ABBATE, Inventing the internet, Cambridge, MIT, 1999, Kindle Edition, pp. 214-216).

177 Durante o ano de 1993, primeiro ano em que o Mosaic esteve em atividade, o tráfego na Internet cresceu segundo o fator de 3416, em 1996, o HTTP já estava gerando mais tráfego do que qualquer outra aplicação na Internet (DAVID C. MOWERY; TIMOTHY SIMCOE, Is the Internet a U.S. invention? - An economic and technological history of computer networking, In Research Policy, n. 31, Elsevier, 2002, p. 1378). 
Segundo o modelo original da web, não havia uma forma de pesquisa por conteúdo, ou seja, o usuário só conseguia acessar outras páginas digitando sua URL ou clicando em links que davam acesso às outras páginas. Isto muda com a criação dos primeiros search engines (buscadores), que permitiam a busca de outras páginas na Internet por meio de palavras-chave. ${ }^{179}$

A criação da world wide web fez com que o número de usuários da Internet multiplicasse, o que levou a um enorme crescimento do interesse na exploração comercial de produtos e serviços pela rede virtual. O sucesso estrondoso da IPO (Initial Public Offering) do Netscape gerou um verdadeiro surto de novos negócios relacionados aos mercados pontocom, ${ }^{180} \mathrm{e}$, consequentemente, um aumento explosivo dos investimentos no setor. Os mercados financeiros dos Estados Unidos cumpriram um papel fundamental na captação investimentos para estes setores nos anos de $1990 .{ }^{181}$

Um importante fator da web é que todos os usuários são ao mesmo tempo produtores e consumidores de conteúdo. Isso se deve à arquitetura aberta e descentralizada da rede, que resulta na ausência de hierarquização dos links e na igualdade de tratamento entre eles. Além disso, a web opera sob o princípio da universalidade, segundo o qual a rede deve ser acessível a todos, por meio de qualquer hardware, software, linguagem ou mídia. Isso traz consequências tanto sobre questões comerciais quanto sobre problemas envolvendo liberdade de expressão, uma vez que nivela a influência dos agentes, independentemente de sua escala escala ou tamanho. Desse modo, pequenos empreendimentos podem atingir um público nunca antes imaginado. ${ }^{182}$ Conforme veremos

179 JANET ABBATE, Inventing the internet, Cambridge, MIT, 1999, Kindle Edition, pp. 217-218. O maior exemplo destes mecanismos é o site google.com.

180 Para se ter uma ideia da dimensão desse crescimento, em 1996, o número de domínios “.com” era 1,8 vezes maior que o número de domínios “.edu”, já em 2000 esse número já era seis vezes maior (DAVID C. MOWERY; TIMOTHY SIMCOE, Is the Internet a U.S. invention? - An economic and technological history of computer networking, In Research Policy, n. 31, Elsevier, 2002, p. 1379).

181 A partir do ano 2000, com o estouro da bolha da Internet, os investimentos nestes setores reduzem sensivelmente, voltando, porém, a se estabilizar nos anos seguintes (DAVID C. MOWERY; TIMOTHY SIMCOE, Is the Internet a U.S. invention? - An economic and technological history of computer networking, In Research Policy, n. 31, Elsevier, 2002, p. 1379).

182 TIM WU, Impérios da comunicação: Do telefone à internet, da AT\&T ao Google, Rio de Janeiro, Zahar, 2012, p. 338. 
no CAPÍTULO III, a quebra da neutralidade de rede modifica esta arquitetura, podendo trazer profundas consequências sobre o ecossistema no qual a Internet foi criada. ${ }^{183}$

\section{II.2 Desenvolvimentos recentes e tendências futuras da Internet}

O surgimento da Internet trouxe consigo um forte impacto sobre os oligopólios das tradicionais indústrias da comunicação, que viam nessa nova estrutura uma ameaça ao seu domínio. Até então, alguns poucos conglomerados detinham um confortável controle sobre a produção cinematográfica, as transmissões de televisão e os sistemas telefônicos. No entanto, os novos usos que passam a ser feitos da Internet começam a questionar tal hegemonia. ${ }^{184}$

Como afirmamos, a arquitetura aberta e o princípio da universalidade fizeram com que ocorresse um nivelamento entre pequenos e grandes players, permitindo o surgimento de grandes negócios a partir de pequenos empreendimentos, como ocorreu com todos os gigantes da web, como Google e Facebook. O poder que estes novos players passam a deter em relação aos antigos oligopólios de mídia coloca em dúvida toda a estrutura destes setores.

As grandes empresas de telecomunicações, como a Bell Labs, acreditavam que seu controle sobre a estrutura da web, decorrente do domínio sobre as redes de banda larga, proporcionaria o controle sobre toda a Internet. Nessa linha, seu plano de atuação consistia em oferecer serviços diferenciados para clientes selecionados que se dispusessem a pagar mais. Assim, poderia, por exemplo, exigir que o Netflix pagasse uma quantia para que seus usuários tivessem acesso a serviços mais rápidos. Isso criaria "pistas rápidas" às quais apenas alguns serviços teriam acesso. ${ }^{185}$

\footnotetext{
183 JANET ABBATE, Inventing the internet, Cambridge, MIT, 1999, Kindle Edition, pp. 217-218.

184 "Pois embora as origens sejam distintas, em 2010 a Internet havia se tornado uma rede universal para todos os tipos de dados: ligações telefônicas, vídeo, televisão, dados, um substituto potencial para todas as indústrias de informação do século XX. Em termos tecnológicos, isso era produto de seu próprio projeto: a internet fora concebida para ser indiferente ã natureza do conteúdo que transportava. Contudo, para as antigas indústrias da mídia do século XX, a natureza multifacetada da net, sua capacidade de ser telefone, TV ou algo novo, como o Facebook, consistia numa ameaça existencial. Daí o poderoso desejo de colocar a rede de joelhos, de um modo ou de outro." (TIM WU, Impérios da comunicação: Do telefone à internet, da AT\&T ao Google, Rio de Janeiro, Zahar, 2012, pp. 307-308)
}

185 TIM WU, Impérios da comunicação: Do telefone à internet, da AT\&T ao Google, Rio de Janeiro, Zahar, 2012, pp. 342-343. 
Essas manobras, porém, causaram o descontentamento de diversas personalidades influentes, como blogueiros e outros produtores de conteúdo da web, que viam no projeto uma forte ameaça contra os pequenos negócios que poderiam surgir nos próximos anos. Diante da reação pública que surge a partir de 2006, tais planos foram abandonados momentaneamente. ${ }^{186}$ Em 2010, o presidente Barack Obama decide criar um grupo de trabalho formado por representantes de diversos setores da indústria para elaborar um projeto de lei de regulamentação da Neutralidade de Rede. Dessa forma, a primeira lei que regulamentou este princípio foi aprovada pelo Congresso norte-americano em dezembro do mesmo ano, trazendo relevantes restrições à sua aplicação. ${ }^{187}$

A primeira década dos anos 2000 trouxe consigo um outro fenômeno relevante, caracterizado pela progressiva substituição do computador pessoal pelos dispositivos móveis. ${ }^{188}$ A tríade de dispositivos lançados neste período pela Apple (Ipod, Iphone e Ipad) antecipou a mudança e a tornou mais evidente. ${ }^{189} \mathrm{O}$ desenvolvimento das tecnologias móveis levou à completa inserção do universo on-line no cotidiano das pessoas, independentemente de sua localização física. A partir daí, surge um processo no qual "online and off-line worlds are merging". 190

\footnotetext{
186 Conforme relata TIM WU, as empresas do setor de telecom se mobilizaram através de seus lobistas no Congresso americano de forma a tolher poder da FCC de regulamentação do setor. Porém, o fato inesperado foi que um programa de TV a cabo passou a transmitir diversas discussões no congresso que diziam respeito ao tema da neutralidade de rede, o que trouxe enorme atenção para o tema.
}

187 TIM WU, Impérios da comunicação: Do telefone à internet, da AT\&T ao Google, Rio de Janeiro, Zahar, 2012, pp. 345-346.

188 Conforme apontam DAVID S. EVANS e ELISA V. MARISCAL: "The online industry has resulted from the evolution of two related technologies, the World Wide Web and the development of mobile telecommunications." (DAVID S. EVANS, ELISA V. MARISCAL, Market Definition Analysis in Latin America with Applications to Internet-Based Industries, disponível em: http://bit.ly/1Qkz0He, 2013, acesso no dia 12, nov., 2015, p. 18).

189 TIM WU, Impérios da comunicação: Do telefone à internet, da AT\&T ao Google, Rio de Janeiro, Zahar, 2012, pp. 348-350. Conforme apontou JONATHAN ZITTRAIN: "It is not easy to imagine the PC going extinct, and taking with it the possi- bility of allowing outside code to run - code that is the original source of so much of what we find useful about the Internet. But along with the rise of in- formation appliances that package those useful activities without readily allow- ing new ones, there is the increasing lockdown of the PC itself. PCs may not be competing with information appliances so much as they are becoming them." (JONATHAN ZITTRAIN, The Future of the Internet - And How to Stop It, New Haven, Yale University, 2008, p. 4).

190 DAVID S. EVANS, ELISA V. MARISCAL, Market Definition Analysis in Latin America with Applications to Internet-Based Industries, disponível em:disponível em: http://bit.ly/1Qkz0He, 2013, acesso no dia 12, nov., 2015, p. 19. 
Neste contexto, surge um importante embate pela hegemonia não só da plataforma dominante nos dispositivos móveis, mas também pela disputa entre concepções diferentes de sistemas: a abertura associada ao sistema Android da Google, contraposta ao fechamento do iOS da Apple. ${ }^{191}$

O sistema Android, lançado em 2007 pela Google, consistia em um sistema operacional para smartphones baseado em Linux (sistema operacional de código livre adotado em computadores pessoais), e que trazia consigo uma série de ferramentas para programadores desenvolverem livremente aplicações para a plataforma. O que intrigava os analistas do setor é que o projeto não tinha um modelo de negócios evidente, uma vez que a empresa distribuía o programa de forma gratuita, assim como ocorria com seus outros serviços. Porém, verificou-se que o objetivo da empresa não tinha um fim em si mesmo: o propósito era tornar o ecossistema dos smartphones mais amigável para a Google e outras empresas, instituindo um novo paradigma de abertura do sistema, ao mesmo tempo em que se garantia a continuidade da utilização de seus produtos também nas plataformas móveis. ${ }^{192}$

Nesse momento, mais uma vez se instituiu a disputa entre os sistemas abertos e fechados. Como havia ocorrido anteriormente no caso do PC nos anos 1990, quando a aposta da Apple em um modelo fechado quase levou a empresa à falência, os executivos da Google acreditavam que seu sistema venceria a concorrência da empresa de Cupertino ${ }^{193}$. O aumento de market share da Google foi estrondoso e se deu em grande medida pelo fato de o sistema poder ser utilizado em qualquer telefone, independentemente da marca. ${ }^{194}$

No entanto, a medida que a utilização do sistema Android crescia, a necessidade de concorrer com o sistema da Apple fazia com que a empresa se valesse de táticas antes

\footnotetext{
191 Seguindo a noção de Steve Jobs de que "os seres humanos na verdade não anseiam pela liberdade total, mas por algo mais próximo da ditadura iluminista conjecturada por Platão em A República.", a Apple abandonou os princípios de sua fundação, desenvolvidos por Steve Wozniak, de descentralização e empoderamento do usuário, substituindo por uma plataforma fechada em que o usuário se torna mero consumidor daquilo que a empresa decide oferecer (o ponto central dessa ideia está no fato da empresa decidir o que será e o que não será disponibilizado na loja de aplicativos para dispositivos iOS) (TIM WU, Impérios da comunicação: Do telefone à internet, da AT\&T ao Google, Rio de Janeiro, Zahar, 2012, pp. 350352).

192 TIM WU, Impérios da comunicação: Do telefone à internet, da AT\&T ao Google, Rio de Janeiro, Zahar, 2012, pp. 353-354.

193 Cidade do Estado da California onde se localiza a sede da Apple.

194 TIM WU, Impérios da comunicação: Do telefone à internet, da AT\&T ao Google, Rio de Janeiro, Zahar, 2012, pp. 353-354.
} 
criticadas por ela mesma. Ou seja, a empresa passa a utilizar estratégias como a de bloquear aplicativos que interferiam em seus modelos de receita, ou de consentir com a quebra da neutralidade de rede em determinadas situações. ${ }^{195}$ Vale ressaltar que a abertura defendida pela empresa acaba trazendo a grande questão da nova era: seria possível um monopólio operar sobre um sistema aberto? Devemos lembrar que todas as empresas dominantes das indústrias de informação sempre operaram sobre sistemas fechados. ${ }^{196}$

A evolução dos sistemas fixos de computação para os sistemas móveis (especialmente smartphones e tablets) ao longo dos anos 2000 trouxeram profundas alterações sobre a rentabilidade de determinados setores e sobre a concorrência em setores de Internet. A grande mudança ocorreu com o surgimento dos apps, aplicativos desenvolvidos para estes novos dispositivos móveis por programadores independentes. Tanto no caso do sistema Android, da Google, como no caso do iOS, da Apple, as empresas disponibilizaram as chamadas APIs (Application Program Interfaces), que permitiam a qualquer desenvolvedor escrever um programa para rodar sobre a sua plataforma, e criaram lojas para comercialização e distribuição desses Apps (em muitos casos de forma gratuita). Até o ano de 2013, havia mais de 1 milhão de apps disponíveis nessas lojas. ${ }^{197}$

Em um espaço de poucos anos, houve aumento significativo do tempo gasto pelos usuários nessas novas plataformas móveis. Estudos apontam que no ano de 2010 os usuários gastavam em média 24 minutos por dia nos dispositivos móveis, ao passo que em 2013 passaram a gastar em média 2,35 horas por dia, o que igualou o tempo médio gasto pelos usuários em desktops e laptops. Isso se deve em grande medida à maior facilidade de acesso que estes dispositivos móveis proporcionam. Atualmente, as pessoas costumam carregá-los consigo durante o dia inteiro, aproveitando todos os momentos livres, como na espera do elevador, no trânsito para o trabalho, ou na fila do restaurante, para checar seus e-mails ou as últimas publicações do Facebook. Estes dispositivos, da mesma maneira,

195 Conforme aponta TIM WU, em meados de 2010, a empresa acabou se aproximando da Verizon de modo a concordar que as regras de neutralidade de rede não seriam necessárias em transmissões sem fio. Fato este que contraria frontalmente o princípio tão defendido pela empresa (TIM WU, Impérios da comunicação: Do telefone à internet, da AT\&T ao Google, Rio de Janeiro, Zahar, 2012, pp. 355-356).

196 TIM WU, Impérios da comunicação: Do telefone à internet, da AT\&T ao Google, Rio de Janeiro, Zahar, 2012, pp. 355-358.

197 DAVID S. EVANS, Rivals for attention: How competition for scarce time drove the web revolution, what it means for the mobile revolution, and the future of advertising, 2014, disponível em: http://bit.ly/1WZhJHL, acesso no dia 18, nov., 2015, pp. 14-15. 
facilitam o multitasking, permitindo que as pessoas realizem várias atividades simultaneamente, como assistir televisão e acessar a programação do cinema ao mesmo tempo. $^{198}$

Por isso, uma das principais tendências futuras que se esboça está, justamente, na crescente substituição do computador pessoal pelos dispositivos móveis. As vendas dos computadores vem diminuindo ao longo dos últimos anos ao passo que a venda de smartphones só aumenta. A chamada "morte do PC" mostra-se cada vez mais real com o aumento de novas funcionalidades dos smartphones, sendo aquele relegado a nichos cada vez mais específicos (como em algumas atividades empresariais e profissionais que exigem o uso do PC). Esse fenômeno é corroborado pelos grandes players da era da Internet, como Google, Apple, Facebook, Amazon e Microsoft, que investem cada vez mais na melhoria de suas plataformas móveis. ${ }^{199}$

\section{II.3 Governanca e regulação da Internet}

Estruturas de governança surgem com o objetivo de lidar com as externalidades geradas pelos agentes econômicos. Estas estruturas podem ser criadas por organizações estatais, como, por exemplo, estruturas de controle criminal, ou podem ser desenvolvidas espontaneamente pelos próprios agentes envolvidos. Alguns desses exemplos foram apresentados por ELINOR OSTROM, dentre os quais podemos destacar os casos dos pastos nas áreas de montanha da Suíça e das florestas no Japão, onde as próprias comunidades locais instituíram as regras para uso dos CPRs (common-pool resources). ${ }^{200}$ Tratam-se de situações que não dependem do mercado, da delimitação de direitos de

198 DAVID S. EVANS, Rivals for attention: How competition for scarce time drove the web revolution, what it means for the mobile revolution, and the future of advertising, 2014, disponível em: http://bit.ly/1WZhJHL, acesso no dia 18, nov., 2015, pp. 15-16.

\footnotetext{
199 "These days, the big players-Google, Amazon, Apple, Microsoft, Facebook-are putting their resources toward optimizing their businesses for mobile. They haven't all cracked the code, but they're trying. In the meantime, PCs have yet to settle into a niche, given their diminished place in tech's new hierarchy. With mobile, the question is, what else can we do with it? With PCs, the question is, what are they still good for?" (DAVEY ALBA, The death of the PC has not been greatly exaggerated, disponível em: http://bit.ly/1eNXKr4, acesso no dia 19, nov., 2015).

200 "In these cases, the appropriators designed basic operational rules, created organizations to undertake the operational management of their CPRs, and modified their rules over time in light of past experience according to their own collective-choice and constitutional-choice rules. The cases in this chapter are particularly useful for gaining insight regarding how groups of self-organized principals solve [...] the problem of commitment and the problem of mutual monitoring." (ELINOR OSTROM, Governing the commons: The evolution of institutions for collective action, Cambridge, University Press, 1990).
} 
propriedade ou da regulação estatal. Esse cenário também pode ser observado, por exemplo na indústria de diamantes, mercado no qual seus participantes historicamente rejeitam o direito estatal para se valer de uma série de normas internas, com instituições e sanções próprias. ${ }^{201} \mathrm{O}$ caso da Internet se enquadra justamente nesse tipo de regulação em que os próprios participantes se organizam para regular aspectos técnicos da rede.

Uma característica fundamental da Internet introduzida já no ano de 1972 por ROBERT KAHN foi o conceito de arquitetura aberta de rede. Segundo este conceito, cada rede individual pode ser desenhada e desenvolvida separadamente, com uma interface própria, sem a criação de obstáculos para seu ingresso na Internet. As quatro regras fundamentais pensadas por KAHN para a arquitetura da rede são: (i) cada rede deve ser independente e não devem ser exigidas mudanças para sua conexão à Internet; (ii) as comunicações devem ocorrer na base dos "best effort"; (iii) Black Boxes, na forma de gateways e routers podem ser usados para conexão à Internet; e (iv) não deve haver um controle global no nível operacional da rede. ${ }^{202}$

Por esta razão, a administração de questões relacionadas à estrutura da rede e à padronização de protocolos foi realizada ao longo dos anos por uma série de órgãos informais. ${ }^{203}$ As primeiras organizações informais começaram a surgir a partir de 1980, com a criação de entidades como a ICCB, fundada por VINTON CERF e posteriormente renomeada para Internet Activities Board $(I A B) .{ }^{204}$ Este órgão tinha a participação de membros de diversas organizações como a ARPANET, o MIT, o Department of Defense, dentre outros. Ao longo dos anos, o $I A B$ tornou-se um importante fórum de discussões sobre políticas relacionadas à estrutura da Internet. Após a criação da NSFNET, outro

201 LISA BERNSTEIN, Opting out of the legal system: Extralegal contractual relations in the diamond industry, In The Journal of Legal Studies, vol. 21, n. 1, 1992, pp. 115-157.

202 BARRY M. LEINER; ET. AL., Brief history of the Internet, Internet Society, 2012, disponível em: http://bit.ly/1S9Zoks, acesso no dia 8, nov., 2015, p. 4.

203 Estas organizações informais remontam ao processo de troca de correspondências chamado de Request for Comments (RFC): "RFCs combined open dissemination and peer review, features characteristic of academic journals, with the speed and informality characteristic of an e-mail discussion list. The documents were used to propose specifications for important new applications such as Telnet (used to control networked computers from a remote terminal) and FTP (used to transfer files between machines), as well as to refine networking protocols such as TCP/IP." (DAVID C. MOWERY; TIMOTHY SIMCOE, Is the Internet a U.S. invention? - An economic and technological history of computer networking, In Research Policy, n. 31, Elsevier, 2002, p. 1374).

$204 \quad$ A IAB foi renomeada em 1992 para Internet Architecture Board e o conselho é atualmente gerido pela Internet Society (ISOC) (BARRY M. LEINER; ET. AL., Brief history of the Internet, Internet Society, 2012, disponível em: http://bit.ly/1S9Zoks, acesso no dia 8, nov., 2015, p.12). 
órgão chamado de Internet Engineering Task Force (IETF) foi criado com o intuito de discutir questões relacionadas a rede. A IETF consiste em uma organização nãogovernamental formada pela comunidade internacional de pessoas interessadas na arquitetura da Internet, e é aberta à participação de quaisquer interessados. ${ }^{205}$

Por fim, a privatização da Internet e o aumento da rede tornou necessária a criação de um novo órgão responsável pela coordenação destas entidades. ${ }^{206}$ Assim, em janeiro de 1992, foi fundada a Internet Society (ISOC), organização não-governamental responsável por este papel. Nos anos que se seguiram, as organizações permaneceram em atividade, contribuindo para a definição de uma série de decisões relacionadas aos standards e à arquitetura da rede. ${ }^{207}$ Isso contribuiu para que a administração dos aspectos técnicos e estruturais permanecesse extremamente descentralizado, não havendo até os dias de hoje uma autoridade central única e responsável por tais decisões. ${ }^{208}$ Apenas nos últimos anos, organizações como o Fórum Econômico Mundial passaram a se interessar por questões relacionadas à Governança da Internet, criando um grupo de trabalho para discutir matérias relacionadas às políticas envolvendo a rede mundial de computadores. ${ }^{209}$

\section{II.4 Principais características dos setores pontocom}

O advento da Internet causou uma verdadeira revolução na maneira como as pessoas se relacionam, trazendo profundas consequências sobre todas as formas de

\footnotetext{
205 "The Internet Engineering Task Force (IETF) is a large open international community of network designers, operators, vendors, and researchers concerned with the evolution of the Internet architecture and the smooth operation of the Internet. It is open to any interested individual." (Conforme definição disponível em: https://www.ietf.org/about/).
}

206 DAVID C. MOWERY; TIMOTHY SIMCOE, Is the Internet a U.S. invention? - An economic and technological history of computer networking, In Research Policy, n. 31, Elsevier, 2002, p. 1374. JAANET ABBATE aponta, ainda, que a privatização da rede aumentou a pressão para a criação de um órgão desvinculado do estado norte-americano (JANET ABBATE, Inventing the internet, Cambridge, MIT, 1999, Kindle Edition, pp. 205-208).

207 DAVID C. MOWERY; TIMOTHY SIMCOE, Is the Internet a U.S. invention? - An economic and technological history of computer networking, In Research Policy, n. 31, Elsevier, 2002, p. 1374.

208 JANET ABBATE, Inventing the internet, Cambridge, MIT, 1999, Kindle Edition, pp. 205-208.

209 Chamada de NETMundial, foi criada por meio da colaboração entre governos, indústria, acadêmicos e parceiros da sociedade civil, incluindo membros da ICANN, tendo como objetivo criar um espaço para discussão das diversas questões relacionadas as políticas da Internet, conforme se observa em: http://www.weforum.org/news/new-initiative-internet-governance-live-event. 
interações sociais, políticas e econômicas. ${ }^{210}$ Isso modifica por completo o mecanismo de funcionamento dos mercados, sua abrangência e suas regras. Por esta razão, a doutrina antitruste tradicional vem enfrentando inúmeros desafios regulatórios quando confrontada com a realidade destes mercados.

Esta nova realidade traz consigo mudanças como a substituição do mercado de massa para o mercado de nichos, a saída de uma economia de escassez para uma economia de abundância e o advento de formas colaborativas como essenciais para as novas empresas. Controle sobre estruturas tradicionais como canais de distribuição, pessoas, produtos e propriedade intelectual não pode mais ser considerado garantia de sucesso. ${ }^{211}$

JONATHAN LEVIN aponta que as diferenças fundamentais entre mercados de Internet e outros mercados seriam: (i) a escala, uma vez que a Internet possibilita a operação de mercados com milhões de participantes muitas vezes a um custo muito baixo; (ii) a customização da experiência do usuário, porque a Internet possibilita uma individualização sem precedentes da experiência do usuário por meio do uso de dados coletados pelo sistema; e (iii) o potencial para experimentação e inovação, já que o baixo custo para aplicar novas ideias cria um ambiente propício para a tentativa e erro e para a constante inovação. ${ }^{212}$

Além destas características, os mercados de Internet apresentam outras particularidades típicas de muitos setores da Nova Economia, como a problemática das externalidade de rede, a exploração de plataformas de múltiplos lados, estruturas de preço zero, dentre outras que passaremos a analisar.

\section{II.4.1 - As externalidades de rede}

Uma primeira característica dos setores pontocom que traz diversas consequências em relação a sua análise é a presença de redes. Diferentemente daquelas presentes em

\footnotetext{
$210 \quad$ "The world is upside-down, inside-out, counterintuitive, and confusing. Who could have imagined that a free classified service could have had a profound and permanent effect on the entire newspaper industry, that kids with cameras and internet connections could gather large audiences than cable networks could, that loners with keyboards could bring down politicians and companies, and that dropouts could bring companies worth millions? They didn't break the rules. They operate by new rules of a new age" (JEFF JARVIS, What would google do?, New York, Harper Collins, 2009, p. 3).

211 JEFF JARVIS, What would google do?, New York, Harper Collins, 2009, p. 4.

212 JONATHAN LEVIN, The economics of Internet markets, 2010, disponível em: http://bit.ly/1GRkYde, acesso no dia 8, nov., 2015, pp. 1-2.
} 
setores tradicionais como o das telecomunicações, tais redes não são físicas, mas sim virtuais. Podemos afirmar que estruturas em rede estão presentes em quaisquer conjuntos de bens compatíveis, que compartilhem uma plataforma técnica comum. ${ }^{213}$ Como exemplos de redes virtuais podemos citar o conjunto de Blu-ray players, o conjunto de computadores rodando Microsoft Windows, sistemas de serviços bancários, ou mesmo as já referidas redes sociais. A compreensão dos problemas concorrenciais relacionados a estes setores passa necessariamente pela consideração da estrutura de rede em que se inserem estes serviços, pois é neste contexto que surgem uma das principais barreiras da nova economia: os chamados efeitos ou externalidades de rede. ${ }^{214-215}$

A noção de rede abarca qualquer situação em que um conjunto de pontos complementares são ligados entre si por meio de links ou conexões. ${ }^{216} \mathrm{Um}$ requisito essencial das redes, portanto, é a complementaridade: um serviço prestado por uma rede requer, necessariamente, o uso de dois ou mais componentes da rede. ${ }^{217}$

Esta complementaridade gera efeitos positivos sobre a elasticidade-cruzada da demanda entre os dois bens. Ou seja, o aumento da demanda pelo bem "A" leva ao aumento da demanda e da disponibilidade do bem "B". Devemos lembrar que tal efeito também ocorre nas indústrias tradicionais, uma vez que o aumento da demanda por bens complementares leva ao aumento da demanda pelo bem principal. Porém, no caso das indústrias de rede, a relação da utilidade do bem é inversa: em indústrias tradicionais, bens complementares tem como característica a utilidade marginal decrescente com o aumento

213 NICHOLAS ECONOMIDES, Antitrust issues in network industries, 2008, disponível em: http://bit.ly/1SC1s5C, acesso no dia 8, nov., 2015, p.2.

214 Conforme STAN J. LIEBOWITZ e STEPHEN E. MARGOLIS, rigorosamente, externalidades de rede e efeitos de rede não se confundem. Os efeitos de rede seriam "the circumstance in which the net value of an action (consuming a good, subscribing to telephone service) is affected by the number of agents taking equivalent actions", enquanto as externalidades de rede seriam um tipo específico de efeito de rede "in which the equilibrium exhibits unexploited gains from trade regarding network participation". Segundo os autores, a vantagem desta diferenciação se deve à aproximação da expressão "externalidade" ao termo usualmente utilizado em literatura econômica (Network externality: An uncommon tragedy, In The journal of economic perspectives, vol. 8, no 2,1994, p. 135).

215 Para uma breve análise da implicação da intervenção antitruste sobre indústrias de rede vide LEANDRO SAITO, Desafios da intervenção antitruste em indústrias de rede, In Revista de defesa da concorrência, n. 1, 2013, pp. 197-220.

216 JOHN E. KWOKA JR.; LAWRENCE J. WHITE, The antitrust revolution: Economics, competition, and policy, $5^{\text {th }}$ ed., New York, Oxford University Press, 2009, p. 474-476.

217 NICHOLAS ECONOMIDES, Antitrust issues in network industries, 2008, disponível em: http://bit.ly/1SC1s5C, acesso no dia 8, nov., 2015, p.2. 
da quantidade demandada, ao passo que, nas indústrias de rede, a utilidade marginal dos bens aumenta com o maior número de unidades vendidas. ${ }^{218}$

É por esta razão que tais indústrias tem a complementaridade como característica essencial: a utilidade destes bens aumenta quando utilizados em conjunto, sendo que alguns deles só possuem alguma utilidade quando usados desta forma. Assim, nestes mercados, os consumidores adquirem antes sistemas do que produtos individuais. Um exemplo pode ser o dos computadores, que são úteis apenas após a instalação de um ou mais softwares.

Dessa primeira característica decorre um segundo requisito fundamental: a compatibilidade $^{219}$ entre os bens. Ou seja, o funcionamento do conjunto depende da operação sob um padrão técnico comum. Os $C D s$, por exemplo, devem ter especificações iguais às do $C D$ Player para que possam funcionar em conjunto. Por esta razão, o acesso ao padrão é requisito essencial para a compatibilidade. ${ }^{220} \mathrm{~A}$ operação em conjunto entre estes bens cria faz surgir um problema com profundas consequências sobre a atuação dos agentes econômicos inseridos nestes mercados: a criação das chamadas externalidades ou efeitos de rede.

Efeitos de rede podem ser definidos como o fenômeno segundo o qual o valor da participação individual de cada membro aumenta de acordo com número de participantes de uma rede. ${ }^{221}$ Por esta razão, é comum classificá-los como uma forma distinta de economia de escala. Diversamente das economias de escala na oferta, nas quais o aumento da quantidade ofertada leva a uma redução de custos, as externalidades de rede se relacionam à situação em que os bens se valorizam na medida em que o número de

218 NICHOLAS ECONOMIDES, Antitrust issues in network industries, 2008, disponível em: http://bit.ly/1SC1s5C, acesso no dia 8, nov., 2015, pp. 4-5.

219 A compatibilidade pressupões e existência de padrões físicos (como bitolas de redes ferroviárias, plugues elétricos, etc...) ou tecnológicos (como equipamentos que compartilhem de mesma voltagem, tevês que recebem o sinal sob a mesma codificação, etc...) similares. (JOHN E. KWOKA JR.; LAWRENCE J. WHITE, The antitrust revolution: Economics, competition, and policy, $5^{\text {th }}$ ed., New York, Oxford University Press, 2009, p. 476-477.

220 OZ SHY, Economics of network industries, New York, Cambridge University Press, 2001, p. 1-3.

$221 \quad$ 'The term 'network effect' describes the phenomenon according to which the value of participation in a network increases over some range as the number of members of the network increases." (GEORGE L. PRIEST, Rethinking antitrust Law in age of networks, Yale Law \& Economics Research Paper No. 352 , disponível em: http://bit.ly/1MiDyYy, acesso no dia 8, nov., 2015, p. 2). 
usuários aumenta. Trata-se, portanto, de fenômeno relacionado ao lado da demanda. ${ }^{222-223}$ Exemplo recorrente é o do telefone, no qual o aumento do número de usuários leva ao aumento do valor da rede para todos seus usuários, uma vez que todos terão um maior número de pessoas com quem se comunicar. ${ }^{224-225}$

Em outras palavras, quanto mais consumidores ingressarem em uma rede, mais atrativa ela será, gerando, assim, um feedback positivo que se auto alimenta. A rede será, portanto, mais valiosa quando todos os consumidores (ou quase todos) nela ingressarem, o que leva à tendência de restarem poucas redes substitutas. ${ }^{226}$

Como ocorre com qualquer externalidade ${ }^{227}$, o benefício privado que o consumidor recebe pela adesão à rede é inferior ao benefício social total gerado pelo seu aumento, ou

$222 \quad$ "Economies of scale in manufacture are familiar; up to a point, the longer the production run, the lower average cost is. Economies of scale in consumption refer to the situation in which the larger the firm's output is (up to some point), the more valuable that output is to its customers" (RICHARD A. POSNER, Antitrust in the new economy, $2^{\text {nd }}$ ed., Chicago, The University of Chicago Press, 2001, p. 928).

223

MICHAEL L. KATZ; CARL SHAPIRO, Network externalities, competition and compatibility, In The american economic review, vol. 75, n. ${ }^{\circ} 3,1985$, pp. 424-440. A literatura sobre o assunto é vasta nos Estados Unidos e na Europa, dentre as principais, podemos apontar STAN J. LIEBOWITZ; STEPHEN E. MARGOLIS, Network externality: An uncommon tragedy, In The Journal of Economic Perspectives, vol. 8, n. $^{\circ}$ 2, 1994, pp. 133-150; STAN J. LIEBOWITZ; STEPHEN E. MARGOLIS, Dismal science fictions: Network effects, Microsoft, and antitrust speculation, In Policy analysis, n. ${ }^{\circ}$ 324, 1998: MARK A. LEMLEY; DAVID MCGOWAN, Legal implications of network economic effects, In California law review, vol. 86, 1998; NICOLAS ECONOMIDES, Network externalities, complementarities, and invitations to enter, In The European journal of political economy, vol. 12, 1996, pp. 211-232; CARL SHAPIRO, Exclusivity in network industries, In George Mason law review, vol. 7, n. ${ }^{\circ}$ 3, 673-683.

$224 \quad$ "Would I subscribe to a telephone service knowing that nobody else subscribe to a telephone service? The answer should be: Of course not! What use Will anyone have from having a telephone for which there is no one to talk to?" (OZ SHY, Economics of network industries, Cambridge University Press, 2001, p. 3).

225 RICHARD A. POSNER, Antitrust in the new economy, $2^{\text {nd }}$ ed., Chicago, The University of Chicago Press, 2001, p. 928.

226 DAVID S. EVANS; RICHARD SCHMALENSEE, A guide to antitrust economics of networks, In Antitrust, vol. 10, n. 36, 1995-1996, p. 36.

227 Externalidades podem ser definidas como os "impactos de escolha individual, que transcendem os limites do indivíduo", sendo o exemplo clássico o da poluição (BERNARDO GUIMARÃES; CARLOS EDUARDO GONÇALVES, Introdução à economia, Rio de Janeiro, Elsevier, 2010, p. 11). Estas se dividem em externalidades de consumo e de produção. Haverá externalidade de consumo quando "um consumidor for afetado pelo consumo de outro ou pela produção de uma empresa. Exemplos de externalidades de consumo negativas são o vizinho tocando música alta às três horas da manhã, o consumidor na mesa ao lado de um restaurante fumando charuto ou a poluição produzida pelos carros. Um exemplo de externalidade de consumo positiva é ter prazer em observar as flores do vizinho.” Por outro lado, haverá externalidade de produção quando "as possibilidades de produção de uma empresa são afetadas pelas escolhas de outra empresa ou consumidor. Um exemplo de externalidade de produção negativa é a situação em que uma empresa de pesca é afetada por poluentes jogados na área de pesca. Um exemplo de externalidade de produção positiva é um pomar de maçãs localizado próximo de uma colméia" (HAL R. VARIAN, 
seja, o consumidor se apropria apenas do benefício privado decorrente de seu ingresso na rede. ${ }^{228}$ Cabe apontar que estas externalidades podem ser positivas ou negativas. Basta pensarmos em um sobrecarregamento da rede telefônica: a entrada de mais um usuário nesta rede terá um efeito negativo sobre o todo.

Conforme classificação proposta por MICHAEL L. KATZ e CARL SHAPIRO, externalidades de rede podem ser diretas ou indiretas. ${ }^{229}$ As externalidades diretas seriam decorrentes de efeitos físicos causados diretamente pelo maior número de usuários sobre a qualidade do produto. É o caso, por exemplo, das redes de telefonia: na medida em que aumenta o número de usuários aumentam também as interferências e os problemas associados ao sobre carregamento da rede. Externalidades diretas, por sua natureza, ocorrem apenas em redes de duas vias (two way), não sendo, por isso, encontradas em redes virtuais (que em regra são de uma via) ${ }^{230}$. As externalidades indiretas, por sua vez, ocorrem em circunstâncias nas quais não há o efeito físico direto sobre a rede, por exemplo, no caso dos computadores: quanto maior o número de usuários de computadores, mais abundantes e baratos serão os softwares disponíveis para estes equipamentos. ${ }^{231}$

Além desses dois efeitos, os autores indicam, ainda, uma terceira categoria de externalidades, que estaria relacionada à qualidade dos serviços de pós venda. A qualidade destes serviços dependerá justamente do número de usuários e do número de unidades de atendimento da marca. Podemos pensar no caso dos carros importados que, ao serem introduzidos em um país, possuem vendas baixas, principalmente pelo receio dos consumidores em adquirir um produto que possui uma rede de serviços questionável e

Intermediate Microeconomics, 8th Ed., 2009, traduzido por SERGIO DA SILVA, disponível em: http://works.bepress.com/sergiodasilva/101, acesso no dia 19, out., 2011).

228 GEORGE L. PRIEST, Rethinking antitrust Law in age of network industries, Yale Law \& Economics Research Paper No. 352, disponível em: http://bit.ly/1MiDyYy, acesso no dia 8, nov., 2015, p. 4.

229 Os autores elencam, ainda, uma terceira categoria que seria a dos serviços de suporte técnico pósvenda (MICHAEL L. KATZ; CARL SHAPIRO, Network externalities, competition and compatibility, In The american economic review, vol. 75, n. ${ }^{\circ} 3,1985$, p. 424).

230 NICHOLAS ECONOMIDES, Antitrust issues in network industries, 2008, disponível em: http://bit.ly/1SC1s5C, acesso no dia 8, nov., 2015, 2008, p. 5-6.

231 MICHAEL L. KATZ; CARL SHAPIRO, Network externalities, competition and compatibility, In The american economic review, vol. 75, n. ${ }^{\circ} 3,1985$, p. 424. MARK A. LEMLEY e DAVID MCGOWAN, com base na classificação proposta por KATZ e SHAPIRO, os autores dividem os efeitos em actual networks, virtual networks e simple positive-feedback fenomena (MARK A. LEMLEY; DAVID MCGOWAN; Legal implications of network economic effects, In California law review, vol. 86, 1998, pp. 479-612). Lembram os autores também que as classificações não são estanques, havendo casos em que uma rede pode ter características de actual e de virtual networks, como no caso da Internet. 
incipiente. Necessário apontar que este último fenômeno não constitui propriamente uma externalidade de rede. As externalidades de rede se relacionam a efeitos ligados à demanda, ou seja, o valor adicional da rede ocorre por conta da entrada de um novo consumidor na rede. Os serviços de pós-venda são, na realidade, efeitos ligados a oferta, ou seja, dizem respeito à redução do custo de produção, independentemente da demanda pelo produto. ${ }^{232}$

Os primeiros modelos baseados em estruturas de rede tinham clara ênfase nos efeitos diretos de rede, sendo sua principal preocupação o fenômeno de tipping em estruturas monopolizadas. No entanto, a aplicação de tal modelo se mostrou insuficiente para lidar com situações reais, nas quais setores com fortes efeitos indiretos de rede não tendiam à formação de um monopólio. EVANS e SCHMALENSEE afirmam que esta insuficiência decorre de dois pontos principais: (i) plataformas concorrentes oferecem produtos diferenciados; e (ii) em alguns casos consumidores podem adotar mais de uma plataforma distinta (fenômeno chamado de "multi-homing"). É por essa razão que surgem os modelos de plataformas de múltiplos lados, que evidenciam os efeitos indiretos de rede, inserindo novas complexidades aos modelos. ${ }^{233}$

\section{II.4.2 - Mercados de múltiplos lados ("multi-sided platforms")}

Indústrias de rede possuem estrutura diversa das tradicionais estruturas de um lado, ou one-sided. A ocorrência de externalidades de rede, em quase todos os casos, vem acompanhada de estruturas de múltiplos lados, ou multi-sided platforms. ${ }^{234}$ Nestas, a presença de duas ou mais partes interagindo através de uma plataforma permite que a empresa distribua seu faturamento em um ou dois lados da rede. ${ }^{235} \mathrm{O}$ exemplo clássico é o do jornal: ao mesmo tempo em que os exemplares são vendidos para os leitores, seus espaços de publicidade são comercializados para os anunciantes, de modo que o aumento

\footnotetext{
232 "Unlike actual or virtual networks, no technological compatibility, interoperability, or even contractual relationships are necessary to sustain this 'network'. Strictly speaking, it is not a network at all." (MARK A. LEMLEY; DAVID MCGOWAN, Legal implications of network economic effects, In California law review, vol. 86, 1998, pp. 494-495).

233 DAVID S. EVANS; RICHARD SCHMALENSEE, The antitrust analysis of multi-sided platform businesses, disponível em: http://bit.ly/1KhV5mT, acesso no dia 19, mai, 2015, pp. 13-14.

234 JEAN-CHARLES ROCHET; JEAN TIROLE, Platform competition in two-sided markets, In Journal of the European Economic Association, MIT Press, vol. 1, 2003, p. 990.

235 NICHOLAS ECONOMIDES, Antitrust issues in network industries, 2008, disponível em: http://bit.ly/1SC1s5C, acesso no dia 8, nov., 2015, p. 8.
} 
do número de leitores influi na valorização dos espaços publicitários do jornal. Isso traz profundas consequências sobre a estrutura de preços neste setor. $\mathrm{O}$ jornal pode, por exemplo, optar por vender os exemplares a preços módicos com o intuito de aumentar o número de leitores, e ao mesmo tempo aumentar o preço dos anúncios, obtendo daí seu faturamento. ${ }^{236}$ Esta mesma situação se aplicaria ao caso dos softwares, dos portais de informação da internet e dos sistemas de pagamento.

Os primeiros trabalhos sobre estruturas de múltiplos lados surgem com o objetivo de trazer explicações racionais para situações que a teoria econômica não conseguia justificar, como a cobrança de preços iguais a zero como estratégia maximizadora de lucro. Com o tempo, outros elementos passaram a integrar a teoria, como a diferenciação entre externalidades diretas e indiretas. ${ }^{237}$

Nestes setores, as externalidades de rede tem papel crucial para o sucesso da plataforma, sendo a diferenciação de preços entre os lados da cadeia uma característica marcante. Assim, uma empresa deve cobrar preços maiores de um dos lados, de modo a garantir os lucros, ao mesmo tempo em que cobra preços menores do outro, de modo a aumentar a rede de usuários. ${ }^{238-239}$ Assim, um dos lados seria caracterizado como "profit center" ao passo que o outro seria uma espécie de "loss leader" ou "financially neutral". 240

236 FEDERICO ETRO, Competition, innovation, and antitrust - A theory of market leaders and its policy implications, Berlin, Springer, 2007, pp. 212-213. O autor cita outros exemplos de indústrias de rede multi-sided, como os video-games, os mecanismos de busca na Internet (como o Google), as redes sociais (Facebook, MySpace) sites de compra (Amazon, eBay), entre outros. Nesse sentido, ainda, NICHOLAS ECONOMIDES: "The availability of prices on both sides of the network allows for complex pricing strategies, and, depending on the dynamics and market shares on the two sides of the market, can be used strategically to enhance and leverage a firm's strong strategic position on one side of the network" (NICHOLAS ECONOMIDES, Antitrust issues in network industries, 2008, disponível em: http://bit.ly/1SC1s5C, acesso no dia 8, nov., 2015, p. 8-9).

237 GIACOMO LUCHETTA, Is the Google platform a two-sided market?, disponível em: http://bit.ly/1TRQw8o, acesso no dia 18, ago., 2015, pp. 5-6.

238 Em setores pontocom os serviços, na maioria das vezes, são oferecidos sem qualquer cobrança direta do usuário, como demonstram alguns dos principais serviços utilizados atualmente como o Facebook, os serviços da Google, como Gmail ou o Google Maps, dentre inúmeros outros casos.

239 É por esta razão que JEAN-CHARLES ROCHET e JEAN TIROLE afirmam que nestas situações as empresas devem se preocupar nÃo apenas com o nível de preços, mas também com a estrutura de preços (JEAN-CHARLES ROCHET; JEAN TIROLE, Platform competition in two-sided markets, MIT Press, vol. 1, 2003, p. 990).

240 JEAN-CHARLES ROCHET; JEAN TIROLE, Platform competition in two-sided markets, MIT Press, vol. 1, 2003, p. 991. Os autores citam diversos exemplos desta divisão. No caso dos video-games os consumidores seriam o loss leader, ao passo que os desenvolvedores de jogos seriam os profit-making. No caso dos cartões de pagamento, da mesma forma, os portadores dos cartões seriam os loss leaders, enquanto os comerciantes seriam os profit making. 
A decisão com relação a estas variáveis decorre da elasticidade da demanda, bem como dos valores atribuídos pelos participantes a cada um dos lados. ${ }^{241}$ Tais estruturas se diferem dos monopólios ou oligopólios de multi-produtos pela incapacidade de internalização pelo usuário final das externalidades gerada pelas complementaridades. Essa característica não está restrita aos mercados de tecnologia, estando presente em quaisquer mercados em que haja forte complementaridade entre os bens. ${ }^{242}$ No caso dos negócios baseados em web, a estrutura de dois lados decorre justamente do fato de estas serem plataformas transacionais, que conectam agentes com interesses distintos, sejam eles compradores e vendedores (como no caso de sites como eBay e Amazon), amigos (como no caso das redes sociais) ou anunciantes e compradores (como nos portais de informação como a $C N N){ }^{243}$

Dessa forma, a maior parte dos mercados com externalidade de rede terão características de múltiplos lados. Há situações, porém, em que mercados com aparência de múltiplos lados devem ser tratados como mercados de um único lado para fins de análise econômica. Para que isso ocorra deve haver capacidade de coordenação entre os usuários finais dos dois lados da cadeia, e a possibilidade de pass-through, ou seja, capacidade de transferências monetárias paralelas entre os lados que impeçam o subsídio cruzado gerado pela plataforma. $^{244}$

Diversas razões fazem com que tais características dificilmente ocorram no mundo real, dentre as quais podemos apontar: (i) os custos de transação, que elevam os custos do pass-through; (ii) a ocorrência de custos não sensíveis ao volume, ou seja, que tenham influência da plataforma ou que não sejam proporcionais ao número de transações realizadas; e (iii) as limitações criadas pela própria plataforma para impedir as transferências. $^{245}$

241 FEDERICO ETRO, Competition, innovation, and antitrust - A theory of market leaders and its policy implications, Berlin, Springer, 2007, pp. 214-215.

242 NICHOLAS ECONOMIDES, Antitrust issues in network industries, 2008, disponível em: http://bit.ly/1SC1s5C, acesso no dia 8, nov., 2015, p. 9.

243 DAVID S. EVANS, Antitrust issues raised by the emerging global internet economy, In Northwestern University Law Review, vol. 102, n.4, 2008, p. 8.

244 JEAN-CHARLES ROCHET; JEAN TIROLE, Platform competition in two-sided markets, MIT Press, vol. 1, 2003, pp. 1017-1018.

245 JEAN-CHARLES ROCHET; JEAN TIROLE, Platform competition in two-sided markets, MIT Press, vol. 1, 2003, pp. 1017-1018. 
Mercados de dois lados reduzem custos de transação, na medida em que servem como plataforma para realização de negócios comerciais entre dois ou mais grupos distintos de consumidores que confiam nela para efetuar sua transação. ${ }^{246} \mathrm{~A}$ definição do que seria uma plataforma de múltiplos lados geralmente tem como foco a estrutura de preços desses mercados, que possibilita a distribuição assimétrica do preço entre os dois grupos (reduzindo o preço para um dos lados na mesma medida em que o outro lado se responsabiliza por esse custo $)^{247}$. Além disso, cumpre ressaltar que os custos de transação devem ser reduzidos para ambos os lados e deve existir interdependência decorrente das externalidades indiretas de rede. A estrutura de preços seria responsável, assim, por gerar incentivos para a associação de novos membros ao mesmo tempo em que a plataforma aumenta o número de usuários (gerando maximização do valor da plataforma). ${ }^{248}$

Dessa forma, algumas características destas plataformas que podemos destacar são: (i) existência de dois ou mais grupos de consumidores; (ii) interdependência entre eles; (iii) impossibilidade de capturar o valor dessa interação por conta própria; (iv) a plataforma como meio para facilitar a geração de valor dessas interações. ${ }^{249}$

Conforme afirmamos, as externalidades desempenham papel fundamental para o funcionamento destas plataformas. As externalidades indiretas, conforme classificação de ROCHET e TIROLE, podem ser usage externalities ou membership externalities. ${ }^{250}$ As usage externalities surgem quando dois agentes precisam utilizar a plataforma de modo conjunto para gerar valor. Estas externalidades podem ser positivas para os dois agentes envolvidos, ou até mesmo positiva para um dos agentes e negativa para o outro. É o caso dos serviços financiados por propaganda (advertising-supported media), nos quais o

246 DAVID S. EVANS, Antitrust issues raised by the emerging global internet economy, In Northwestern University Law Review, vol. 102, n.4, 2008, p. 9.

247 Conforme aponta GIACOMO LUCHETTA, citando o trabalho de ROCHET e TIROLE, o mercado apenas será caracterizado como de dois lados se bem estar total depender da estrutura de preços como um todo e não apenas do agregado dos preços das duas categorias de usuários (GIACOMO LUCHETTA, Is the Google platform a two-sided market?, disponível em: http://bit.ly/1TRQw8o, acesso no dia 18, ago., 2015 , p. 7).

248 DAVID S. EVANS; RICHARD SCHMALENSEE, The antitrust analysis of multi-sided platform businesses, disponível em: http://bit.ly/1KhV5mT, acesso no dia 19, mai, 2015, p. 6-7.

249 DAVID S. EVANS; RICHARD SCHMALENSEE, The antitrust analysis of multi-sided platform businesses, disponível em: http://bit.ly/1KhV5mT, acesso no dia 19, mai, 2015, p. 7.

250 JEAN-CHARLES ROCHET; JEAN TIROLE, Two-Sided Markets: A Progress Report, In The RAND Journal of Economics, Vol. 37, N. 3, 2006, pp. 646-647. 
anunciante se beneficia da publicidade de seu produto a possíveis compradores, ao passo que o consumidor valora negativamente as propagandas involuntariamente apresentadas pela plataforma. O subsídio cruzado implementado pela plataforma consiste justamente na possibilidade de oferecer um serviço gratuito ao consumidor que será financiado pelos anunciantes. $^{251}$

As membership externalities, por sua vez, surgem quando o aumento do número de usuários de um dos lados da cadeia beneficia pelo menos um dos agentes do outro lado. Um exemplo seria o dos desenvolvedores de aplicativos para determinado sistema operacional. Ao mesmo tempo em que os desenvolvedores valorizam mais as plataformas que possuem maior número de usuários, os usuários também valorizam as plataformas que possuem mais aplicativos desenvolvidos para ela. Isso leva ao fenômeno do feedback loop, que se auto-alimenta positivamente. ${ }^{252-253}$ Para que estas plataformas se consolidem é necessário atingir uma massa crítica ${ }^{254}$ que permita ao sistema entrar nesse loop. ${ }^{255}$

Um outro exemplo seria o serviço prestado pelo site OpenTable ${ }^{256}$, que atua como plataforma para os consumidores realizarem reservas em restaurantes. Antes do surgimento desse tipo de aplicação, os consumidores precisavam ligar para diversos restaurantes antes de conseguir uma reserva no horário desejado, ao mesmo tempo em que os restaurantes

251 DAVID S. EVANS; RICHARD SCHMALENSEE, The antitrust analysis of multi-sided platform businesses, disponível em: http://bit.ly/1KhV5mT, acesso no dia 19, mai, 2015, p. 8.

252 DAVID S. EVANS; RICHARD SCHMALENSEE, The antitrust analysis of multi-sided platform businesses, disponível em: http://bit.ly/1KhV5mT, acesso no dia 19, mai, 2015, p. 8.

253 Tal fato pode ser observado no mercado de apps (aplicativos) para smartphones, em que uma intensa batalha entre os sistemas Android, da Google, e o iOS, da Apple, tem como um dos pontos centrais o número de aplicativos desenvolvidos para estas duas plataformas. Outros sistemas operacionais como o Windows Phone, Symbian e Blackberry OS, enfrentaram diversos problemas por conta da baixa disponibilidade de aplicativos para suas plataformas. No caso Microsoft esse efeito foi chamado de Applications Barrier to Entry.

254 A massa crítica consiste no "número mínimo de usuários necessários para que uma tecnologia seja adotada pelos outros potenciais consumidores" para que, então, a rede possa se expandir de forma extremamente rápida (LEANDRO SAITO, Desafios da intervenção antitruste em indústrias de rede, In Revista de defesa da concorrência, n. 1, 2013, p. 205).

255 EVANS e SCHMALENSEE apontam o exemplo do cartão Diners, que surgiu na década de 1950, operando inicialmente com 14 restaurantes em Manhattan, e algumas centenas de consumidores. Em alguns meses esses números foram se multiplicando, de modo que após um ano mais de 42.000 consumidores utilizavam o cartão e mais de 330 comerciantes aceitavam o cartão como forma de pagamento. Em 1956, mais de 9.000 comerciantes aceitavam o cartão, com valores de transação anual superiores a 54 milhões de dólares (DAVID S. EVANS; RICHARD SCHMALENSEE, The antitrust analysis of multi-sided platform businesses, disponível em: http://bit.ly/1KhV5mT, acesso no dia 19, mai, 2015, pp. 8-9). 
eram forçados a manter recursos para receber estas ligações e manter os registros das reservas atualizados.

O serviço do OpenTable acaba, assim, por reduzir custos de transação tanto para os consumidores como para os restaurantes. ${ }^{257}$ No caso, os consumidores não desembolsam nenhum valor de forma $\operatorname{direta}^{258}$ (sendo, com frequência, o custo negativo, uma vez que o site oferece aos usuários alguns tipos de bônus pela utilização da plataforma que podem ser utilizados como desconto nos restaurantes), ao passo que os restaurantes licenciam o software de reservas do site e pagam uma taxa por cada reserva realizada pela plataforma. $^{259}$

Conforme EVANS e SCHMALENSEE, podemos apontar três características presentes nessa plataforma que são típicas das plataformas de múltiplos lados: (i) dois tipos de externalidades indiretas de rede (usage externality - consumidores e restaurantes se beneficiam do sistema; membership externality - o sistema é mais valioso para o consumidor quanto maior forem o número de restaurantes utilizando o sistema); (ii) a plataforma facilita interações consideradas valiosas pelos dois grupos de agentes; (iii) a estrutura de preços utilizada constitui importante ferramenta para coordenação entre os dois lados, de modo que o valor gerado pelas externalidades sejam distribuídos e capturados. $^{260}$

O desafio das plataformas seria o de criar os incentivos corretos para que os dois lados da cadeia tenham membros suficientes para atingir a massa crítica necessária. É por essa razão que a estratégia de um entrante será diferente da estratégia de um player consolidado, uma vez que a necessidade de aumentar a base faz com que o entrante aumente o subsídio sobre o lado mais sensitivo ao preço. Nesse ponto reside uma das principais diferenças em relação aos mercados de um lado. A teoria microeconômica aponta que a demanda depende do preço de um produto, de seus complementos e

257 DAVID S. EVANS; RICHARD SCHMALENSEE, The antitrust analysis of multi-sided platform businesses, disponível em: http://bit.ly/1KhV5mT, acesso no dia 19, mai, 2015, p. 5.

258 É evidente que o consumidor acaba indiretamente arcando com estes custos, uma vez que, conforme a teoria microeconômica da tributação afirma, a aplicação de um imposto sobre o fornecedor ou sobre o consumidor gera o mesmo resultado, uma vez que o consumidor acaba arcando com o custo.

259 DAVID S. EVANS; RICHARD SCHMALENSEE, The antitrust analysis of multi-sided platform businesses, disponível em: http://bit.ly/1KhV5mT, acesso no dia 19, mai, 2015, p. 5.

260 DAVID S. EVANS; RICHARD SCHMALENSEE, The antitrust analysis of multi-sided platform businesses, disponível em: http://bit.ly/1KhV5mT, acesso no dia 19, mai, 2015, p. 6. 
substitutos. No caso dos mercados de múltiplos lados, o preço depende também do número de participantes presentes em cada um dos lados. ${ }^{261}$

Os trabalhos de ROCHET e TIROLE ${ }^{262}$ e de ARMSTRONG ${ }^{263}$ foram os responsáveis pelos dois principais modelos de precificação destes mercados. O modelo de ROCHET e TIROLE considera um mercado que opera apenas com usage externalities, ou seja, sem membership externalities e apenas com a cobrança por transações. O exemplo poderia ser de um grupo de comerciantes e um grupo de consumidores mediados por uma plataforma de pagamento. Nessa situação, os preços de maximização satisfazem duas condições de otimalidade. A primeira determina que o markup em relação ao custo é menor quanto maior for a elasticidade da demanda, sendo muito similar à condição de Lerner para o equilíbrio monopolista. A segunda condição, por outro lado, deixa claro não se tratar de um simples fornecedor multi-produtos, uma vez que a maximização ocorre com a condição inversa, ou seja, os preços de otimalidade são diretamente proporcionais à elasticidade da demanda. Isso ocorre pela necessidade de balanço entre os dois grupos da plataforma. $^{264}$

O modelo de ARMSTRONG, por sua vez, considera apenas as membership externalities, ignorando as taxas de utilização e cobrando somente taxas de associação. $\mathrm{O}$ exemplo seria o de um jornal acadêmico, no qual os autores valorizam jornais com grande número de leitores, ao passo que os leitores valorizam os jornais em que os bons autores desejam publicar. A demanda de cada grupo para se associar à plataforma depende do valor da taxa de associação e do número de membros do outro grupo. Nesse caso, o modelo se relaciona ao de um monopólio comercializando bens complementares. Em se tratando de bens complementares, a redução do preço de um bem aumenta a demanda pelo bem complementar. O modelo, no entanto, não apresenta condições gerais de otimalidade, demonstrando apenas um caso especial em que as funções de demanda $\left(D_{i}\right)$ são lineares e

261 DAVID S. EVANS; RICHARD SCHMALENSEE, The antitrust analysis of multi-sided platform businesses, disponível em: http://bit.ly/1KhV5mT, acesso no dia 19, mai, 2015, p. 9.

262 JEAN-CHARLES ROCHET; JEAN TIROLE, Platform competition in two-sided markets, MIT Press, vol. 1, 2003.

263 MARK ARMSTRONG, Competition in two-sided markets, In RAND Journal of Economics, Vol. 37, n. 3, 2006, pp. 668-691.

264 DAVID S. EVANS; RICHARD SCHMALENSEE, The antitrust analysis of multi-sided platform businesses, disponível em: http://bit.ly/1KhV5mT, acesso no dia 19, mai, 2015, p. 9-10. 
nos quais, assim como ocorre com bens complementares, os preços serão menores do que poderiam ser no caso de não ocorrência de efeitos cruzados. ${ }^{265}$

Os problemas dessa estrutura para o direito da concorrência se relacionam à possível diminuição do bem estar social decorrente das decisões tomadas por agentes detentores dessas plataformas. ${ }^{266} \mathrm{~A}$ enorme dificuldade de análise se relaciona à necessidade de consideração das decisões de todos os grupos de consumidores servidos pela plataforma, bem como das memberships e usage externalities. Em geral, as preocupações antitruste se relacionam à diminuição do bem estar decorrentes de duas falhas de mercado: (i) poder de mercado; e (ii) escolha pela plataforma de uma estrutura que não leve à maximização do bem estar social. ${ }^{267}$

Devemos notar que, nos setores pontocom, a união de anunciantes e consumidores sob uma mesma plataforma cria uma relação de confiança entre os usuários e os intermediários. Isso se deve a natureza de "creedence goods" desse tipo de produto, que se caracteriza pela dificuldade de apuração de sua qualidade, mesmo após a compra e o consumo. Por essa razão, no caso desses bens "the ordinary consumer must trust the provider more than an ordinary vendor, because it's expensive (and sometimes impossible)

265 DAVID S. EVANS; RICHARD SCHMALENSEE, The antitrust analysis of multi-sided platform businesses, disponível em: http://bit.ly/1KhV5mT, acesso no dia 19, mai, 2015, p. 9-10.

266 Em alguns casos, o uso de direitos intelectuais permitem que detentor da plataforma tenha um controle ainda maior sobre os grupos. No caso das auto-peças de reposição de automóveis, a discussão gira em torno dos direitos de propriedade intelectual conferidos aos titulares dos desenhos industriais das peças visíveis dos automóveis. Argumentam alguns que estes direitos de exclusivo poderiam impedir outros fabricantes de produzirem peças de reposição não autorizadas no mercado secundário. KARIN GRAUKUNTZ, sustentando posição contrária, defende que esta proteção não estimularia o investimento, mas, do contrário, apenas inviabilizaria a concorrência de superação inovadora: "A proteção exclusiva das peças must-match no mercado secundário gera uma situação indesejada do ponto de vista da finalidade da propriedade intelectual: gerando um "monopólio de alternativas" faz inviável a concorrência de superação inovadora. $\mathrm{O}$ argumento que a proteção exclusiva no mercado secundário seria fundamental para possibilitar aos titulares dos direitos recuperarem seus investimentos para que, assim, tenham recursos para continuar investindo no setor automobilístico e inovando, só poderá ser aplicado à situação das peças must-match no mercado secundário às custas do fomento da concorrência de superação inovadora o que, por sua vez, não gera inovação e, por fim, em nada promove o bem-estar social.” (KARIN GRAU-KUNTZ, Ainda sobre a questão das peças de reposição, In Revista eletrônica do IBPI - Edição especial sobre a questão das peças de reposição must-match, 2010, disponível em: http://bit.ly/1MFwRz7, acesso no dia 8, nov., 2015, p. 80).

267 DAVID S. EVANS; RICHARD SCHMALENSEE, The antitrust analysis of multi-sided platform businesses, disponível em: http://bit.ly/1KhV5mT, acesso no dia 19, mai, 2015, p. 9-10. 
to know if the provider has actually given her best efforts". ${ }^{268}$ Nessa categoria se enquadram tanto mecanismos de buscas ${ }^{269}$ como, por exemplo, serviços de advocacia.

O poder de mercado nestas indústrias se relaciona à impossibilidade de existir concorrência perfeita nesta estrutura de mercado, permitindo que a plataforma estabeleça preços superiores ao socialmente desejável. No entanto, tal fato não difere substancialmente da concorrência em estruturas de um único lado, uma vez que a estrutura de quase todas as indústrias também se afasta da competição perfeita. ${ }^{270}$

A segunda falha relacionada a estes mercados, por sua vez, traz preocupações particulares. A estrutura de preços presente nestes setores permite que o detentor da plataforma considere apenas o impacto dos preços sobre os usuários marginais nos dois grupos de participantes, de modo a balancear sua participação, ao passo que o impacto sobre os usuários médios é que determinará os efeitos sobre o bem estar geral. De forma diversa à questão do sobrepreço decorrente do poder de mercado, nessa situação a estrutura da demanda será determinante para a precificação e para a qualidade dos bens nos lados da cadeia. ${ }^{271}$ Esta estrutura de custos faz com que um dos lados acabe por arcar com a maior parte dos investimentos. Essa estrutura acaba por trazer inúmeros questionamentos quanto aos tradicionais métodos de delimitação de mercados relevantes, por apresentar características muito mais complexas do que mercados one sided. A complexidade associada a essa distribuição tem feito com que as autoridades antitruste desconsiderem essa distorção.

Desde o início dos anos 2000, a doutrina econômica vem demonstrando que modelos matemáticos desenvolvidos para estruturas de um lado não encontram aplicação nos mercados de dois lados. Diversos métodos analíticos tradicionalmente utilizados em

268 FRANK PASQUALE, Paradoxes of digital antitrust: Why the FTC failed to explain its inaction on search bias, In Harvard journal of law and technology occasional paper series, July, 2013, disponível em: http://bit.ly/1FbNQVJ, Acesso em 11, jun. 2015, pp. 17-18.

269 "Rare is the person who takes time to compare results at one search engine with those at other." (FRANK PASQUALE, Paradoxes of digital antitrust: Why the FTC failed to explain its inaction on search bias, In Harvard journal of law and technology occasional paper series, July, 2013, disponível em: http://bit.ly/1FbNQVJ, Acesso em 11, jun. 2015, p. 18).

270 DAVID S. EVANS; RICHARD SCHMALENSEE, The antitrust analysis of multi-sided platform businesses, disponível em: http://bit.ly/1KhV5mT, acesso no dia 19, mai, 2015, p. 11-12.

271 DAVID S. EVANS; RICHARD SCHMALENSEE, The antitrust analysis of multi-sided platform businesses, disponível em: http://bit.ly/1KhV5mT, acesso no dia 19, mai, 2015, p. 11-12. 
antitruste, como o do SSNIP (teste do monopolista hipotético), não encontram aplicação nestes setores sem que sejam adaptados. ${ }^{272}$

Há poucos trabalhos empíricos suficientes para que se possam inferir regras gerais para esses setores, razão pela qual é impossível redigir qualquer espécie de guideline para direcionar estas análises. Devemos lembrar que estes setores guardam uma complexidade muito superior a setores de um único lado, e que qualquer análise que desconsidere este fato corre o risco de cometer equívocos. Assim, os estudos devem levar em conta as possíveis estratégias competitivas e eficiências que não seriam evidentes em outros setores. $^{273}$

\section{II.4.3 - Mercados baseados em plataformas de software}

O uso de plataformas de software tornou-se cada vez mais frequente, sendo hoje parte de nosso cotidiano. Seja ao pagarmos uma conta no supermercado com cartão de crédito, seja ao utilizar um aplicativo de mapas no celular, ou acessar as redes sociais no computador, estamos sempre utilizando algum serviço por meio de uma dessas plataformas. ${ }^{274}$ Não por outra razão, mercados baseados em web possuem como marca típica o uso intensivo de plataformas baseadas em software. ${ }^{275}$

272 Conforme apontam EVANS e SCHMALENSEE, um exemplo seria o modelo de concorrência imperfeita, segundo o qual os preços no longo prazo tendem a ser superiores ao custo marginal, o que não necessariamente ocorre no caso das plataformas de múltiplos lados (DAVID S. EVANS; RICHARD SCHMALENSEE, The antitrust analysis of multi-sided platform businesses, disponível em: http://bit.ly/1KhV5mT, acesso no dia 19, mai, 2015, p. 4). "The SSNIP test generally relates to a single market rather than to a business ecosystem with multiple types of non-competing products." (MICHAL S. GAL; DANIEL L. RUBINFELD, The hidden costs of free goods: Implications for Antitrust enforcement, New York University Law and Economics Working Papers, disponível em: http://bit.ly/1Qg96Ds, acesso no dia 05, nov., 2015, p. 32).

273 DAVID S. EVANS; RICHARD SCHMALENSEE, The antitrust analysis of multi-sided platform businesses, disponível em: http://bit.ly/1KhV5mT, acesso no dia 19, mai, 2015, pp. 37-38.

274 "Sometimes this computer takes the form of a smart cash register, part of a sophisticated point of sale system, or a website. In each of these cases, the computer creates a record of the transaction." (HAL R. VARIAN, Computer-mediated transactions, In BERIN SZOKA; ADAM MARCUS, The next digital age: Essays on the future of the Internet, Washington, Tech Freedom, 2010, p. 240).

275 "Most people use software platforms and the applications that run on them constantly over the course of the day for work and leisure. They run our mobile phones, computers, and videogame consoles and are behind our social networks. New ones are behind innovations in payments, transportation, health and fitness, connected homes, and connected shopping, all of which are transforming how we live. They are helping to break down the walls between the online and offline worlds as physical space becomes connected to the cloud. Some software platforms include operating systems that manage hardware, like Windows, but 
Tais plataformas, assim como qualquer software, consistem em linhas de código fonte compreensíveis pelo computador. Esses códigos realizam diversas tarefas que dão suporte às aplicações oferecidas pela plataforma. Os serviços operam por meio de programas de computador hospedados em servidores, podendo rodar programas de terceiros por meio de interfaces, chamadas de Application Programming Interfaces (API's). Algumas plataformas dependem profundamente do desenvolvimento de aplicações compatíveis e, por conta disso, são oferecidas diversas facilidades para que programadores desenvolvam aplicações para as plataformas, como os chamados Software Developer Kits $(S D K s)$. Isso ocorre por conta das externalidades de rede supra mencionadas (o maior número de usuários leva a um maior número de desenvolvedores propensos a escreverem programas para aquela plataforma, que por sua vez cria incentivos para aumentarem o número de usuários). ${ }^{276}$

Um problema que surge, no entanto, se encontra na fragmentação entre diferentes versões dos mesmos softwares, que afeta negativamente a formação das externalidades positivas. Esse problema ocorre quando são lançadas diferentes versões de uma mesma plataforma de software. Nesse caso, os aplicativos que desejam interagir com esta plataforma precisam realizar adaptações em seus programas de modo a efetuar a compatibilidade com as diferentes versões. Isso impõem custos ao desenvolvedor de software, criando uma barreira à entrada adicional. ${ }^{277}$

No caso dos serviços web based, as plataformas de software sobre a qual rodam as aplicações web se encontram instaladas em servidores conectados à Internet. Muitos aplicativos que operam em conjunto com estas plataformas, por sua vez, se situam em

many others do not, like Facebook." (DAVID S. EVANS, The antitrust analysis of rules and standards for software platforms, 2014, disponível em: http://bit.ly/1Sd0yMu, acesso no dia 22, nov., 2015).

276 Em muitos casos os fabricantes de Hardware (ou seja, a parte física do computador, como o processador, a memória, o monitor) atuam em conjunto com os fabricantes de software, de modo a garantir que estas aplicações irão funcionar sem problemas em sua plataforma. (DAVID S. EVANS, The antitrust analysis of rules and standards for software platforms, 2014, disponível em: http://bit.ly/1Sd0yMu, acesso no dia 22, nov., 2015, p. 4).

277 Um caso paradigmático dessa fragmentação ocorre com o sistema Android. Este sistema que possui uma licença Open Source, de código aberto, foi disponibilizado para que qualquer empresa que adequasse seu equipamento aos standards estabelecidos pudessem instalar uma versão adaptada em seu aparelho. No entanto, tal abertura fez com que mais de 18 mil aparelhos distintos rodassem o sistema. Nesses aparelhos com diferentes formas e tamanhos, rodam alguma das 8 versões adaptadas do Android. Essa enorme fragmentação cria um enorme desafio para qualquer desenvolvedor que desejar lançar um aplicativo pelo loja de aplicativos da Google, uma vez que deve lançar versões adaptadas para todos esses diferentes dispositivos (DAVID S. EVANS, The antitrust analysis of rules and standards for software platforms, 2014, disponível em: http://bit.ly/1Sd0yMu, acesso no dia 22, nov., 2015, pp. 12-13). 
outros servidores conectados à Internet. Esta relação entre diversos servidores distintos que são acessados por computadores conectados individualmente por usuários recebe o nome de computação em nuvem, ou cloud computing. ${ }^{278}$ Essa nova infraestrutura permite o oferecimento de serviços por meio de estruturas "software as service" e, mais recentemente, de "platform as service". O advento dessas formas contratuais permitiu que empresas pequenas tivessem acesso a serviços antes muito caros, como a aquisição de espaço para armazenamento de dados em servidores, ambiente para desenvolvimento de aplicações e conexão à Internet off the shelf, de fornecedores como Amazon, Google, IBM, Microsoft e Sun. A maior acessibilidade a estes serviços reduz dramaticamente o custo para novos negócios. ${ }^{279}$

O uso de plataformas de smartphones como iOS, Android e Windows Mobile, estão por trás do grande número de aplicativos operando nesses ambientes. Ao criarem maneiras de facilitar a comercialização e distribuição de aplicativos para suas plataformas através de lojas como a "App Store", da Apple, e a Google Play Store, da Google, as empresas permitiram que milhões de aplicativos fossem desenvolvidos para suas plataformas. ${ }^{280}$

Se considerarmos a estrutura física de instalação dessas plataformas, seu custo de entrada se mostra muito inferior às indústrias tradicionais. Além disso, a mudança e a inserção de novas funcionalidades é mais simples nessas indústrias, uma vez que estas tarefas são realizadas inteiramente por meio de código de computação. ${ }^{281}$ Isso permite uma enorme eficiência e um baixo custo operacional às empresas que operam nesses setores.

Essa estrutura, ao mesmo tempo em que aumenta de forma significante a eficiência do sistema, também permite às empresas terem acesso a uma gama de informações muito mais ampla sobre os consumidores. ${ }^{282}$ Por outro lado, há uma maior complexidade técnica

278 DAVID S. EVANS, Antitrust issues raised by the emerging global internet economy, In Northwestern University Law Review, vol. 102, n.4, 2008, p. 11.

279 HAL R. VARIAN, Computer-mediated transactions, In BERIN SZOKA; ADAM MARCUS, The next digital age: Essays on the future of the Internet, Washington, Tech Freedom, 2010, pp. 253-255.

280 DAVID S. EVANS, The antitrust analysis of rules and standards for software platforms, 2014, disponível em: http://bit.ly/1Sd0yMu, acesso no dia 22, nov., 2015, p. 6.

281 DAVID S. EVANS, ELISA V. MARISCAL, Market Definition Analysis in Latin America with Applications to Internet-Based Industries, disponível em: http://bit.ly/1Qkz0He, 2013, acesso no dia 12, nov., 2015, p. 21.

282 "Alongside this pro-competitive promise, digitalised algorithm based markets are characterised by the ability of sellers to "shadow' the activities of users and harvest data on human behaviour." (ARIEL 
para que analistas externos possam compreender os mecanismos de funcionamento destes negócios. A dificuldade de análise de casos antitruste relacionada a estes setores muitas vezes decorre desta complexidade técnica, como ocorreu no caso Google, que será analisado em Capítulo posterior.

O impacto da introdução dos computadores nestas transações pode ser dividido em quatro grandes categorias: (i) emergência de novas formas contratuais; (ii) maior capacidade de extrair e analisar dados; (iii) possibilidade de experimentação controlada; e (iv) capacidade de personalização e customização. ${ }^{283}$

Em primeiro lugar, a maior capacidade de monitoramento e captação de informações permite que as partes estabeleçam condições contratuais antes não possíveis de serem acompanhadas, fato que proporciona uma eficiência muito maior nos contratos. Um exemplo seria o das locadoras de filmes. Inicialmente, as distribuidoras de filmes cobravam altos preços pela venda de fitas de vídeo às locadoras (algo em torno de 65 dólares por fita), fazendo com que estas tivessem poucas cópias de cada filme. Isso deixava os consumidores insatisfeitos, pois os filmes mais concorridos nunca estavam disponíveis, da mesma forma que as locadoras também ficavam insatisfeitas porque perdiam diversas locações. No entanto, em 1998, algumas locadoras e distribuidores passaram a adotar modelos de negócios distintos, pelos quais as distribuidoras recebiam parte da receita das locações (algo entre $40 \%$ a $60 \%$ da receita), mas cobravam valores muito menores por cada fita adquirida pela locadora (algo entre 3 a 8 dólares). Tais acordos apenas se tornaram viáveis por conta do advento de tecnologias como os scanners de código de barras, as caixas registradoras computadorizadas e as redes de computadores, que permitiam o monitoramento do acordo por parte das distribuidoras. Os exemplos modernos desse tipo de acordo seriam os contratos de click, nos quais a receita é dividida entre site e anunciantes. $^{284}$

Em segundo lugar, o uso de plataformas de software permite uma capacidade de coleta e analise de dados não possível sem estas inovações. Sistemas de coleta de dados

EZRACHI; MAURICE E. STUCKE, Artificial Intelligence \& Collusion: When Computers Inhibit Competition, disponível em: http://bit.ly/1MXhdC3, acesso em 06, out., 2015, pp. 3-4.

283 HAL R. VARIAN, Computer-mediated transactions, In BERIN SZOKA; ADAM MARCUS, The next digital age: Essays on the future of the Internet, Washington, Tech Freedom, 2010, p. 241.

284 HAL R. VARIAN, Computer-mediated transactions, In BERIN SZOKA; ADAM MARCUS, The next digital age: Essays on the future of the Internet, Washington, Tech Freedom, 2010, pp. 241-244. 
foram desenvolvidos inicialmente para operacionalizar vendas de produtos e serviços, porém, com o tempo passaram a ser utilizados pelos fornecedores para análise de padrão de consumo. $\mathrm{O}$ advento das redes e da Internet permitiram acompanhamento em tempo real de diversos dados, como cartões de crédito, entrega de encomendas e dados financeiros. O uso destas informações obtidas em tempo real para estimar o estado da economia ficou conhecido como nowcasting. Isso possibilitou o desenvolvimento de diversas novas áreas de estudo da econometria. ${ }^{285}$

Em terceiro lugar, estas novas plataformas aumentaram a capacidade de experimentação controlada, especialmente tratando-se de setores web-based. Em 2008, por exemplo, o Google rodou mais de 6000 experimentos envolvendos seu mecanismos de buscas, que levaram a quase 500 modificações em seu sistema. Dentre estas modificações estão desde adaptações da interface do usuário até mudanças no algoritmo. Nota-se, assim, que a possibilidade de experimentação permite que inúmeras melhorias sejam realizadas em relação aos produtos e serviços oferecidos e o custo destas experimentações se reduz consideravelmente com a introdução de sistemas de computação. ${ }^{286}$

Por fim, o uso de software permitiu um nível de customização e personalização da experiência do usuário sem precedentes. $O$ uso de sistemas de recomendação personalizados, de diferenciação de preços com base em histórico de compras, bem como personalização de anúncios e da experiência do usuário, fez com que o mercado no modelo "one size fits all" fosse substituído por um modelo de "market of one". 287

A complexidade associada a estas plataformas de software, no entanto, traz uma ausência de transparência em relação aos termos de troca sob o ponto de vista do consumidor dos serviços. É por essa razão que muitas vezes o consumidor fica preso a uma alternativa pior sem que tenha consciência desse fato. Conforme veremos, os chamados Clever Algorithms acabam por tomar decisões que seriam do usuários, omitindo, por exemplo, determinados conteúdos de suas buscas, no caso da Google, por julgar que tal conteúdo não interessaria ao usuário. Da mesma forma a linha do tempo de publicações do

285 HAL R. VARIAN, Computer-mediated transactions, In BERIN SZOKA; ADAM MARCUS, The next digital age: Essays on the future of the Internet, Washington, Tech Freedom, 2010, pp. 241-244.

286 HAL R. VARIAN, Computer-mediated transactions, In BERIN SZOKA; ADAM MARCUS, The next digital age: Essays on the future of the Internet, Washington, Tech Freedom, 2010, pp. 244-250.

287 HAL R. VARIAN, Computer-mediated transactions, In BERIN SZOKA; ADAM MARCUS, The next digital age: Essays on the future of the Internet, Washington, Tech Freedom, 2010, p. 250. 
Facebook (chamada de timeline) seleciona os conteúdos que serão mostrados ao usuário, sem que este tome consciência dos critérios utilizados. É por essa razão que argumentos que defendam a liberdade dos agentes econômicos com base na noção de que eles mesmo irão procurar alternativas superiores diante do abuso por parte do agente dominante devem ser tomadas com cautela. ${ }^{288}$

Além disso, conforme afirmamos, plataformas de software tem como característica a presença de estruturas de múltiplos lados. Surgem, portanto, duas principais externalidades destas estruturas de rede, as membership externalities e as usage externalities. ${ }^{289}$ No caso dos sistemas operacionais para smartphones, por exemplo, os desenvolvedores criaram as lojas de aplicativos com o objetivo de reduzir custos de transação entre usuários e desenvolvedores de apps e incentivar os efeitos de rede da plataforma.

\section{II.4.3.1 - Algoritmos inteligentes ou Clever Algorithms}

A utilização ubíqua do computador e o crescente uso da Internet através de praticamente todos os dispositivos eletrônicos modernos nos levaram ao que SALIL K. MEHRA chama de a "Era dos algoritmos". Seu surgimento decorre da sinergia entre a matemática, os poderes do computador e a Internet. O poder conferido por esses três elementos tornou possível a análise de volumes massivos de informação, possibilitando decisões cada vez mais baseadas em dados empíricos tomadas por algoritmos préprogramados. $^{290}$

Inicialmente utilizados em sistemas de finanças do mercado acionário, por sua enorme capacidade de processamento de dados em tempo real, a presença dos algoritmos

\footnotetext{
288 "If a search engine is abusing its position, market-oriented scholars say, economic forces will usually solve the problem. Can't find something on Google? Hop over to the Bing search engine. Don't like the new version of iTunes? Buy a subscription to a music service." (FRANK PASQUALE, Paradoxes of digital antitrust: Why the FTC failed to explain its inaction on search bias, In Harvard journal of law and technology occasional paper series, July, 2013, disponível em: http://bit.ly/1FbNQVJ, Acesso em 11, jun. 2015, p. 4).

289 As membership externalities se relacionam ao aumento do valor da plataforma para um grupo na medida em que outro grupo também passe a utilizar a plataforma. As usage externalities, por sua vez, surgem quando a capacidade de dois agentes obterem valor depender da utilização por ambos da plataforma (DAVID S. EVANS, The antitrust analysis of rules and standards for software platforms, 2014, disponível em: http://bit.ly/1Sd0yMu, acesso no dia 22, nov., 2015, pp. 9-10).
}

290 SALIL K. MEHRA, Antitrust and the Robo-Seller: Competition in the time of algorithms, disponível em: http://bit.ly/1kZQtrk, acesso no dia 16, nov., 2015, p. 10. 
no nosso cotidiano e nos produtos eletrônicos que utilizamos se mostra cada vez mais frequente nessa nova era. Desde o buscador Google, com seu sofisticado algoritmo de buscas até o uso em carros auto-guiados, diversas decisões cotidianas vem sendo delegadas aos algoritmos. $^{291}$

Nos últimos anos uma área que vem ganhando enorme atenção e desenvolvimento é o da Inteligência Artificial e dos algoritmos inteligentes ("Clever Algorithms"). Tais algoritmos tem como principais objetivos antecipar hábitos de consumo, gostos e preferências dos consumidores. Diversamente dos algoritmos tradicionais, que seguem instruções estáticas pré-programadas, os novos algoritmos se utilizam dos dados informados para realizar previsões e tomar decisões. Por essa razão que se afirma que eles tem a capacidade de aprender com os dados. ${ }^{292}$

As chamadas técnicas de deep learning, que se valem das tentativas e do feedback do usuário para definir suas decisões futuras, vem sendo utilizadas na tecnologia presente em diversos produtos cotidianos, como smartphones e em protótipos de carros autoguiados $^{293}$ (como o desenvolvido pela empresa Google). No mercado acionário, eles vem sendo empregados em sistemas de compra e venda automáticos de ações ao passo que nos setores pontocom tais algoritmos vem sendo utilizados intensamente por sites de $e$ commerce para determinação dos preços de venda dos produtos e em aplicativos de smartphones como o da empresa Uber.

O uso de mecanismos de preços dinâmicos, em que os preços são determinados por fatores que tenham alguma influência sobre a demanda, como, por exemplo, horário do dia, clima ou estação do ano, já vem sendo há tempos utilizados por empresas que atuam em ramos como o de passagens aéreas e de turismo. No entanto, o desenvolvimento de

291 SALIL K. MEHRA aponta como exemplos dessas decisões aquelas tomadas por aplicativos de encontros, como o eHarmony, que decidem quais usuários ele ligará pelo aplicativo com base nas preferências demonstradas pelos usuários, bem como os sistemas de transplante de órgãos, que se valem de algoritmos para decidirem para quem o órgão sera doado (SALIL K. MEHRA, Antitrust and the Robo-Seller: Competition in the time of algorithms, disponível em: http://bit.ly/1kZQtrk, acesso no dia 16, nov., 2015, p. 12).

292 "Indeed, with the rise of data-driven business models, companies are increasingly turning to computer algorithms that can learn from the data they process. Such algorithms operate by 'building a model from example inputs and using this to make predictions or decisions, rather than following strictly static program instructions'" (ARIEL EZRACHI; MAURICE E. STUCKE - Artificial Intelligence \& Collusion: When Computers Inhibit Competition, disponível em: http://bit.ly/1MXhdC3, acesso em 06, out., 2015, p. 4).

293 ARIEL EZRACHI; MAURICE E. STUCKE, Artificial Intelligence \& Collusion: When Computers Inhibit Competition, disponível em: http://bit.ly/1MXhdC3, acesso em 06, out., 2015, p. 6. 
mecanismos de coleta e processamento de dados permitiu que preços fossem fixados por algoritmos de forma cada vez mais sofisticada. Dessa forma, a inteligência artificial vem contribuindo de forma cada vez mais presentes para que softwares e algoritmos inteligentes sejam utilizados na tomada de decisões sobre preços, se valendo para tanto de dados coletados dos usuários, bem como de previsões sobre mudanças na oferta e demanda dos bens. A velocidade que estes algoritmos tomam tais decisões se mostra muito superior à capacidade humana de monitorar e realizar estas mudanças. ${ }^{294}$

No entanto, o advento destas novas tecnologias, por conta da falta de transparência com relação ao seu funcionamento, a enorme influência que podem exercer sobre os usuários, bem como as possíveis distorções que podem causar sobre o mercado, acabam por suscitar inúmeras dúvidas de cunho ético e concorrencial.

JONATHAN ZITTRAIN aponta como exemplo o experimento implementado pelo Facebook em sua plataforma durante as eleições de 2010 para a Presidência da República dos EUA. Aponta o autor que, no dia 2 de novembro daquele ano, a empresa norte americana inseriu na página principal de milhões usuários selecionados do Facebook uma interface gráfica contendo: (i) um link que direcionava para a busca de locais de votação; (ii) um botão que anunciava para os seus amigos que você já havia votado; e (iii) a foto do perfil de seis amigos do Facebook que já haviam anunciado pela plataforma que tinham votado. Ao mesmo tempo, em uma outra amostra selecionada de usuários, a empresa colocou apenas um lembrete simples do dia da votação, ou não mostrou lembrete nenhum. ${ }^{295}$

Por meio da análise estatística destes dois grupos os analistas concluíram que o grupo que ficou exposto à interface gráfica da eleição teve um aumento de $0,39 \%$ de propensão a votar em comparação com o outro grupo que não foi exposto. ${ }^{296} \mathrm{O}$ interessante notar é que nenhum dos dois grupos tomou conhecimento da seletividade em

294 Por essa razão empresas que atuam nos ramos tradicionais de varejo de eletrônicos como as lojas Best Buy e Macy's se valem de algoritmos para poderem reagir rapidamente a mudanças de preço realizadas por competidores online (SALIL K. MEHRA, Antitrust and the Robo-Seller: Competition in the time of algorithms, disponível em: http://bit.ly/1kZQtrk, acesso no dia 16, nov., 2015, p. 17).

295 JONATHAN ZITTRAIN, Facebook could decide an election without anyone ever finding out, Disponível em: bit.ly/1m3tA3e, acesso no dia 05, out., 2015.

296 Importante ressaltar que o voto nos Estados Unidos é facultativo sendo o percentual de não votantes extremamente elevado dentre a parcela com idade para votar. Nas últimas eleições esse percentual chegou a mais de 50\% dos votantes (conforme informações disponíveis em http://bit.ly/1eiKhRq, Acesso no dia 05, out., 2015). 
relação à exposição à interface, nem mesmo com relação aos critérios para a escolha dos que estariam expostos à interface.

Conforme aponta ZITTRAIN, nada impediria que numa futura eleição o criador do Facebook, ou outro influente diretor da plataforma, decidisse implementar tal interface gráfica com o objetivo de influenciar diretamente no resultado das eleições. Ao selecionar os usuários que ele acredita serem os mais propensos a votar no candidato que ele busca eleger (por meio, por exemplo, da análise dos "likes" e de "compartilhamentos" realizados pelo usuário) para estarem expostos à interface do dia do voto a plataforma poderia claramente direcionar o resultado das eleições. Se os dados apresentados pela análise estatística estiverem corretos e considerando a estreita margem de votos que decidem a eleição em alguns estados americanos, a empresa certamente teria poderes de decidir a eleição. $^{297}$

Outro exemplo de manipulação de algoritmos inteligentes apresentada por ZITTRAIN é a do algoritmo do buscador da Google. A empresa implementou algumas modificações para impedir que sites com conteúdo antisemita figurassem entre os sites mais buscados do resultado de pesquisa quando se digitassem palavras-chave como “judeus". ${ }^{298}$ Para definir estas situações em que o site manipula a informação oferecida com o objetivo de adequar esta à sua "agenda" ideológica o autor cunhou o termo "Digital Gerrymandering". De modo geral, este enviesamento da informação é possível em qualquer serviço que personalize a informação apresentada ao usuário em sua plataforma, sendo, inclusive, muito comum que sites atuem em prol da defesa de alguma medida política, como ocorreu no caso da modificação do "doodle" 299 da empresa Google como

297 JONATHAN ZITTRAIN, Facebook could decide an election without anyone ever finding out, Disponível em: bit.ly/1m3tA3e, acesso no dia 05, out., 2015.

298 Outro exemplo apresentado por ZITTRAIN ocorre quando se busca o termo "vacinar meu filho", em que o algoritmo busca elencar os sites com opiniões favoráveis a vacinação intercalados com sites contrários à vacinação (JONATHAN ZITTRAIN, Love the Processor, Hate the Process: The Temptations of Clever Algorithms \& When to Resist Them, palestra na Harvard Law School em 02, abr., 2015, disponível em: http://bit.ly/1OJph7V, acesso no dia 22, dez., 2015)

299 O "doodle" é uma alteração temporária do logo da empresa Google no site de seu buscador, geralmente fazendo referência a algum evento ou a alguma personalidade que tenha ligação com o dia em que a empresa publicou o desenho. 
forma de protestar contra a aprovação do "Stop Online Piracy Act" (SOPA), lei de combate a pirataria que teria consequências diversas sobre a censura de conteúdo na web. ${ }^{300}$

De modo geral, nenhuma dessas empresas se comprometeu com uma obrigação de neutralidade em relação à tópicos de conteúdo político. Além disso, uma intervenção estatal sobre estas condutas poderia suscitar inúmeros problemas de censura e livre manifestação do pensamento. Se considerarmos que os usuários da rede são livres para decidirem quais sites ou serviços desejam utilizar, tais problemas não gerariam grande preocupação, na medida em que estes poderiam simplesmente boicotar os sites que tentassem impor aos seus usuários alguma visão de mundo ou opinião política. No entanto, em muitas situações, a operação não transparente destes algoritmos inteligentes dificulta a percepção do usuário com relação a esses bias ${ }^{301}$ da mesma forma que, como demonstraremos, dificulta a percepção do usuário com relação à qualidade destes creedence goods.

Uma das soluções apontadas para tentar solucionar este tipo de problema seria a criação de algum tipo de "information fiduciaries", ou seja, de agentes de confiança que teriam como função fiscalizar a atuação das empresas web based. Para tanto teriam acesso a informações relacionadas ao compartilhamento de informações pessoais dos usuários, bem como a visualização de resultados de pesquisa sem a personalização dos resultados. A adoção destes agentes seria voluntária, de forma semelhante a de consultores de investimentos. $^{302}$

Para o presente trabalho, devemos lembrar que além dos diversos uso de natureza política ideológica, tais algoritmos tem como principal objetivo a modificação da experiência de compra do usuário na Internet, otimizando a publicidade ofertada por meio de anúncios direcionados, além da capacidade de executar complexos mecanismos de discriminação de preços. ${ }^{303}$ Conforme veremos, tais problemas podem gerar uma série de

300 JONATHAN ZITTRAIN, Facebook could decide an election without anyone ever finding out, Disponível em: bit.ly/1m3tA3e, acesso no dia 05, out., 2015.

$301 \quad$ "But while a propagandistic Google doodle or similarly ideological alteration to a common home page lies in plain view, newsfeeds and search results have no baseline. They can be subtly tweaked without hazarding the same backlash." (JONATHAN ZITTRAIN, Facebook could decide an election without anyone ever finding out, Disponível em: bit.ly/1m3tA3e, acesso no dia 05, out., 2015).

302 JONATHAN ZITTRAIN, Facebook could decide an election without anyone ever finding out, Disponível em: bit.ly/1m3tA3e, acesso no dia 05, out., 2015.

303 "Computer algorithms may be used to optimise behavioural advertisements, individualised promotions and targeted, discriminatory pricing." (ARIEL EZRACHI; MAURICE E. STUCKE, Artificial 
problemas de natureza concorrencial, bem como podem levar o problema da colusão entre agentes a um nível sem precedentes.

II.4.3.2 - Estrutura de governança em plataformas de software

Conforme observamos, estruturas de governança surgem para lidar com problemas de externalidades gerados por usuários de uma plataforma. No caso das plataformas de software os gestores das plataformas se valem geralmente de três mecanismos para regular as condutas dos agentes que operam sobre estas estruturas: (i) criação de standards, como ocorre com a limitação das postagens do Twitter a 140 caracteres; (ii) criação de regras, como a proibição de cancelamento da reserva com menos de 30 minutos de antecedência do horário marcado pelo OpenTable; e (iii) enforcement, ao violar regras contidas nos termos de uso das plataformas os participantes estão sujeitos a penalidades como exclusão. $^{304}$

Plataformas de software geralmente se valem do uso desses três mecanismos de regulação. Da mesma forma, estas plataformas podem adotar modelos proprietário, abertos (open source) ou modelos híbridos. Os modelos proprietários envolvem o uso dos direitos intelectuais para impedirem que terceiros façam modificações no código fonte do software da plataforma ao passo que os modelos open source disponibilizam livremente o código fonte para adaptações.

\section{II.4.4 - Ecossistema interconectado}

O ecossistema dos negócios baseados em web adquire ainda maior complexidade quando tomamos em conta que este se forma pela junção de inúmeros negócios interconectados, todos baseados em plataformas multi-sided e em plataformas de software. Além disso, cada vez mais, negócios diferentes atuam em conjunto no fornecimento de determinados serviços, o que cria uma relação de dependência entre eles. O maior exemplo destas inter-relações pode ser visto no caso do Google, que estrutura seu sistema de buscas

Intelligence \& Collusion: When Computers Inhibit Competition, disponível em: http://bit.ly/1MXhdC3, acesso em 06, out., 2015, p. 4).

304 DAVID S. EVANS, The antitrust analysis of rules and standards for software platforms, 2014, disponível em: http://bit.ly/1Sd0yMu, acesso no dia 22, nov., 2015, pp. 18-20. 
na Internet por meio de um complexo sistema de precificação baseado numa intrínseca relação entre seu mecanismo de buscas e seu sistema de anúncios. ${ }^{305}$

\section{II.4.5 - Concentração de mercado}

Plataformas de Internet operam em escala muito superior a dos mercados tradicionais. A possibilidade de atingir um público de milhões de usuários a um custo baixo faz com que a escala eficiente de operação seja muito maior do que em setores tradicionais. ${ }^{306}$ Por esta razão, a combinação de fortes economias de escala na produção com efeitos indiretos de rede fez com que estes setores se caracterizassem por intensa concentração de mercado. Deve-se notar, ainda, que tais concentrações se consolidaram apenas nos últimos anos, uma vez que a maior parte das empresas que atuam neste setor não possuem mais do que uma década de existência. ${ }^{307}$

A natureza da concorrência nestes mercados faz com que a expansão de mercado e os ganhos de share ocorrem de modo muito mais rápido. A expansão depende da adoção da plataforma por um número mínimo de usuários (massa crítica), ponto a partir do qual a rede tende a se expandir de forma extremamente rápida. ${ }^{308}$ Tal dinamismo se relaciona com a teoria da destruição criativa proposta pelo economista austríaco JOSEPH A. SCHUMPETER. Conforme observamos, segundo sua teoria, a enorme instabilidade destes mercados permitiria que a entrada e saída de competidores ocorresse de forma

305 DAVID S. EVANS, Antitrust issues raised by the emerging global internet economy, In Northwestern University Law Review, vol. 102, n.4, 2008, pp. 11-13.

306 A relação entre o número de funcionários e o número de usuários já dá uma magnitude desta escala. Basta pensarmos que o Facebook, por exemplo, emprega menos de um engenheiro para cada milhão de usuários (JONATHAN LEVIN, The economics of Internet markets, 2010, disponível em: http://bit.ly/1GRkYde, acesso no dia 8, nov., 2015, p. 4).

307 Em países como Brasil e Argentina o Market share da empresa Google no mercado de buscas era superior a $90 \%$ em 2007, mantendo patamares superiores a $80 \%$ na maior parte dos países da Europa. No mercado de leilões pela web, o site Ebay possuía mais de $98 \%$ de market share em alguns países europeus e de $96 \%$ nos Estados Unidos (DAVID S. EVANS, Antitrust issues raised by the emerging global internet economy, In Northwestern University Law Review, vol. 102, n.4, 2008, pp. 11-16).

OZ SHY aponta que as expectativas dos consumidores quanto ao tamanho da rede e quanto à possibilidade de sua adoção generalizada tem enorme impacto sobre a decisão de ingressar nesta. A Internet , durante muitos anos, foi marcada pela utilização de poucos usuários, até que, na década de 1990, o tráfego de usuários praticamente passa a dobrar a cada ano. Ou seja, uma vez atingida a massa critica, sua adoção sofre um crescimento estrondoso, muito por conta destas expectativas (OZ SHY, Economics of network industries, New York, Cambridge University Press, 2001, p. 3). Conforme veremos, a abertura comercial da Internet e sua popularização decorreu de uma série de fatores tecnológicos, políticos e econômicos. 
extremamente rápida e dinâmica ${ }^{309}$. As firmas competiriam, então, não pela tentativa de comercializar mais produtos, mas em inovação, ao desenvolver novos produtos ou processos que pudessem tomar o lugar dos produtos existentes. ${ }^{310}$ Por esta razão, seguidores da Escola de Chicago defendem que a manutenção de longos períodos de monopólios e de cartéis se mostra inviável nestes setores. ${ }^{311}$ Nesse sentido, POSNER afirma que a enorme quantidade de capital disponível para investimento e a velocidade com que estas novas redes podem ser instaladas leva a uma competição sem fim pela hegemonia, não estando nenhuma rede protegida da destruição criativa descrita por SCHUMPETER. ${ }^{312}$

Outra decorrência disso é a distinta natureza da competição nestes setores. Em indústrias de rede, como a Internet, a competição em geral leva ao predomínio de um único player. Por esta razão, muitos defendem que nestes mercados a concorrência seria do tipo "winner takes most" ou mesmo de "winner takes all", ou seja, a competição ocorreria "pelo mercado", e não "no mercado", como nas indústrias tradicionais. Desse modo, a presença de uma extrema desigualdade entre market shares e lucratividade entre as empresas é característica marcante destes setores, mesmo na ausência de condutas anticompetitivas. ${ }^{313}$

Tal enfoque, porém, vem sendo colocado em dúvida nos últimos anos por economistas como DAVID S. EVANS, que, ao ampliarem o conceito de mercado relevante destes setores, afirmam que a concorrência mais relevante ocorreria "no

\footnotetext{
309 "O surgimento e o desaparecimento de empresas líderes de mercado em períodos muito curtos pode ser visto como uma marca registrada dessa nova realidade." (PAULO MARCOS RODRIGUES BRANCHER, Direito da concorrência e propriedade intelectual - Da inovação tecnológica ao abuso de poder, Tese de Doutorado, PUC-SP, pp. 90).
}

310 KRISTINE LAUDADIO DEVINE, Preserving competition in multi-sided innovative markets: How do you solve a problem like Google?, In North Carolina Journal of Law \& Technology, Vol. 10, n. 1, 2008, p. 92.

311 Conforme aponta ROBERT PITOFSKY: "It is often argued that the high-tech sector of the American economy is so dynamic that cartels and monopoly power will be short-lived, They will be defeated more quickly and efficiently by market forces, such as new entry, than by any band of bureaucrats. Moreover, government regulation is likely to make more, and longer-lasting, mistakes than market." (ROBERT PITOFSKY, Challenges of the new economy: Issues at the intersection of antitrust and intellectual property, In Antitrust law journal, vol. 68, 2000-2001, pp. 915-916).

312 RICHARD A. POSNER, Antitrust in the new economy, $2^{\text {nd }}$ ed., Chicago, The University of Chicago Press, 2001, p. 930.

313 NICHOLAS ECONOMIDES, Antitrust issues in network industries, 2008, disponível em: http://bit.ly/1SC1s5C, acesso no dia 8, nov., 2015, p. 13-16. 
mercado" e não "pelo mercado". Conforme será exposto, tais teorias se baseiam na ideia de que a dimensão relevante de análise está na competição por "atenção"314 e não na disputa pelo oferecimento dos serviços, como pressupõe a análise antitruste tradicional. Segundo tal enfoque, nestes setores, os competidores não enfrentam necessariamente a concorrência de produtos e serviços similares, mas antes disputam entre si a atenção dos consumidores, sofrendo maior concorrência de produtos e serviços que, segundo a análise tradicional, estariam inseridos em mercado relevante distinto.

Evidências empíricas demonstram que, quando considerado estes mercados sob a dimensão da competição por atenção, a competição raramente tende à formação de monopólios, conforme apontavam as teorias sobre efeitos de rede. A concorrência nesses setores, de forma contrária, apresenta enorme entrada e saída de players, e baixa concentração de mercado. DAVID S. EVANS aponta que o HHI dos 233 sites mais acessados, que obtém seu faturamento da venda de seus espaços publicitários, atinge $1088^{315}$. Tais evidências indicam, portanto, que o mercado de competição por atenção não constitui um negócio do tipo "winner takes all” conforme prediziam as teorias sobre externalidades de rede, mas sim de um mercado com intensa competição por atenção dos usuários. Dessa forma, as definições de mercado relevante e de poder de mercado mostram indícios de que deveriam ser reformuladas de modo a considerar tal enfoque, conforme detalharemos abaixo. ${ }^{316}$

\section{II.4.6 - Ausência de lucro por longos períodos}

Outra característica peculiar a muito destes novos negócios se encontra nos elevados investimentos, com ausência de lucro contábil por longos períodos de anos. Isso ocorre especialmente no chamado e-commerce (comércio eletrônico), nos quais o modelo de negócios se baseia em pesados investimentos de marketing durante longos períodos de

314 Para DAVID S. EVANS, atenção pode ser entendida como "the time that consumers spend focusing their minds on content" (DAVID S. EVANS, Attention rivalry among online platforms, In Journal of Competition Law \& Economics, 9 (2), 2013, pp. 313-357).

315 HHI, ou Herfindahl-Hirschman Index, é um conhecido método de mensuração da participação das firmas em relação à indústria. O resultado é obtido pela soma dos quadrados dos market-shares das empresas em uma determinada indústria. O índice varia de 0 a 10.000 pontos, sendo os maiores valores indicativos de maior concentração da indústria. Por essa razão, um índice próximo de 1.000 pontos seria baixo indicativo de concentração de mercado.

316 DAVID S. EVANS, Attention rivalry among online platforms, In Journal of Competition Law \& Economics, 9 (2), 2013, pp. 314-315. 
anos, com aportes significativos de investidores, o que permite a manutenção e a crescente expansão do negócio, e, como consequência, a ausência de lucro durante longos períodos. ${ }^{317} \mathrm{O}$ exemplo típico deste modelo foi $\mathrm{o}$ da empresa norte-americana Amazon.com, pioneira no desenvolvimento deste modelo de negócios. Durante anos a empresa vem reinvestindo todo lucro de seus negócios em novas linhas de produto, novos centros de distribuição e expandindo suas instalações para novos países, de modo a sempre se manter a frente de seus concorrentes e não perder sua participação de mercado. Tal estratégia fez com que a empresa crescesse continuamente ao longo dos anos, tornando-se a maior empresa de e-commerce do mundo, sem que seus balanços financeiros apresentassem lucro ao final dos anos.

\section{II.4.7 - Mercados com estrutura de preço "zero"}

Ao assistir um programa de televisão na TV aberta, ou ao ouvir uma música no rádio o consumidor está consumindo um bem de forma gratuita. A ocorrência deste tipo de mercado, em que o consumidor paga um preço igual a zero, ou seja, recebe seu produto ou serviço de forma gratuita ${ }^{318}$, não constitui propriamente uma novidade da era da Internet. Devemos ressaltar, porém, que seu advento fez com que o número de negócios adotando modelos de distribuição com base em cobrança de preços zero explodisse ${ }^{319-320}$, sendo

\footnotetext{
317 "Em três anos, a Dafiti chegou a uma receita estimada em 800 milhões de reais e assumiu a liderança do mercado de moda na internet brasileira. No caminho, recebeu muito dinheiro. Foram 660 milhões de reais em aportes de investidores internacionais, como o fundo alemão Rocket e o braço de investimentos do Banco Mundial. [...] Neste ano, tem tudo para chegar à emblemática marca de 1 bilhão de reais em vendas. Tudo muito bom, mas, por trás da história de sucesso, esconde-se uma realidade um pouco mais complexa. Quanto mais a Dafiti cresce, mais perde dinheiro. A empresa, que não concedeu entrevista, nunca deu lucro e atualmente perde até 20 milhões de reais por mês, segundo executivos que conhecem os números da companhia." (ANA LUIZA LEAL; LUCAS AMORIM, Bolha.com.br? Lojas online crescem, mas não lucram, In Revista Exame, ed. 1062, abr., 2014, disponível em: http://abr.ai/1PjiK9c, acesso no dia 8, nov., 2015).
}

318 Conforme ressalta DAVID S. EVANS, rigorosamente, pagar um preço zero não significa a mesma coisa que obter um bem de forma gratuita, uma vez que o dinheiro as vezes é apenas um dos valores que o comprador troca com o vendedor. Conforme veremos, o consumidor incorre em uma série de outros custos como os custos de atenção e de informação, quando realiza operações nestes mercados. (DAVID S. EVANS, The antitrust economics of free, 2011, disponível em: http://bit.ly/1GhLjB0, acesso no dia 21, out., 2015, p. 2). Para os propósitos do presente trabalho utilizaremos os termos preço zero e gratuito para todas as situações que o custo monetário seja igual a zero, sem que se desconsiderem os possíveis custos não monetários envolvidos na transação.

319 "Despite the observation that free has a long pedigree, zero-price offers seem to have exploded with the growth of the web-based economy" (DAVID S. EVANS, The antitrust economics of free, disponível em: http://bit.ly/1GhLjB0, acesso no dia 21, out., 2015, p. 3).

$320 \quad$ "Today a growing number of goods and services are provided in the marketplace free of charge. 1 Some examples include Linux's operating system, Google's search engine, Facebook's or Twitter's social 
praticamente o modelo padrão na maior parte destes negócios. Tal fenômeno se explica em grande medida por conta da baixa importância dada pelos consumidores a questões de privacidade, bem como aos altos graus de leniência com relação aos anúncios direcionados. Além disso, os custos marginais infinitamente menores para distribuição destes bens, a irracionalidade presente nas relações com preço zero (conforme explicitadas pela economia comportamental), e a ocorrência de externalidades de rede também auxiliam na compreensão desse fenômeno. ${ }^{321}$

É evidente que bens gratuitos trazem claros benefícios ao consumidor, sendo de modo geral pró-competitivos. No entanto, conforme veremos, a ausência de cobrança de preços faz com que diversos analistas desconsiderem a existência de outros custos implícitos. Esse enfoque acaba por desconsiderar a possibilidade de abuso por parte dos agentes econômicos decorrente desses custos. Além disso, a ausência de preços traz uma série de dificuldades para aplicação do instrumental de análise fortemente baseado em teoria dos preços.

As características destas transações trazem a necessidade de revisão das estruturas de governança destas relações para que não haja um acirramento da assimetria negocial. Nesse ponto um enfoque baseado na economia dos custos de transação pode apresentar importantes considerações sobre estes mercados. Os impactos psicológicos do preço zero, da mesma forma, implicam na necessidade de considerações de economia comportamental para melhor compreensão dessas relações. Ambos serão vistos adiante.

\section{II.4.7.1 - Estrutura de preços em mercados de preço zero}

A estrutura de preços nos mercados de preço zero de modo geral não se diferencia da estrutura dos outros setores, uma vez que qualquer empresa atuando neste setor realiza diversos investimentos, que envolvem custos, com o objetivo de obter retorno financeiro em um momento posterior. Uma diferença fundamental, no entanto, se encontra na

network, Wikipedia's online encyclopedia, YouTube's on-line video and music streaming services, Dropbox's online storage services, and Typepad's blogging platforms. While the phenomenon of free consumer goods is not new, there has been a rapid growth in the number of free goods and services" (MICHAL S. GAL; DANIEL L. RUBINFELD, The hidden costs of free goods: Implications for Antitrust enforcement, New York University Law and Economics Working Papers, disponível em: http://bit.ly/1Qg96Ds, acesso no dia 05, nov., 2015, p. 1).

321 MICHAL S. GAL; DANIEL L. RUBINFELD, The hidden costs of free goods: Implications for Antitrust enforcement, New York University Law and Economics Working Papers, Disponível em: http://bit.ly/1Qg96Ds, acesso no dia 05, nov., 2015, p. 2. 
ausência de cobrança de preços por parte dos usuários de seus serviços (do lado do consumidor). Tais estratégias são plenamente racionais na medida em que os agentes decidem cobrar preços iguais a zero por entenderem que dessa forma podem obter um retorno financeiro maior do que se cobrassem preços positivos. ${ }^{322-323}$ Por outro lado, para que este negócio seja sustentável no longo prazo, o agente deve se valer de estratégias sustentáveis que permitam garantir o faturamento e a lucratividade do negócio. Dentre os modelos sustentáveis podemos destacar as estratégias de venda casada, de plataformas de múltiplos lados ou de comercialização dos chamados "pacotes premium". 324

Um primeiro modelo de negócios que surge envolve a comercialização de bens complementares de forma conjunta. A estratégia, que geralmente envolve a prática de venda casada ("tying"), pode ser realizada por via contratual ou tecnológica. No caso da venda casada contratual a empresa condiciona a venda de um produto a compra de outro produto. Os mecanismos tecnológicos, por sua vez, envolvem alguma forma de integração dos dois produtos. Um exemplo deste tipo de integração ocorreu com a empresa Microsoft que passou a oferecer seu navegador de Internet (Internet Explorer) juntamente com a compra de seu sistema operacional (Windows). ${ }^{325-326}$

A lucratividade deste modelo de negócios dependerá das características da demanda dos dois bens. A complementaridade entre os bens faz com que o aumento do preço de um produto leve a redução das vendas e da lucratividade do produto complementar. As variações dependerão dos graus de complementaridade e da elasticidade da demanda dos dois bens. Da mesma forma, em muitas situações, a viabilidade deste modelo depende da presença de direitos intelectuais, como patentes ou desenho industrial,

322 DAVID S. EVANS, The antitrust economics of free, Disponível em: http://bit.ly/1GhLjB0, acesso no dia 21, out., 2015 , p. 4.

323 Ou seja, a motivação é a da maximização do lucro, conforme apontam MICHAL S. GAL e DANIEL L. RUBINFELD: "All of the strategies just discussed are driven by a monetary profit maximization motive.” (MICHAL S. GAL; DANIEL L. RUBINFELD, The hidden costs of free goods: Implications for Antitrust enforcement, New York University Law and Economics Working Papers, Disponível em: http://bit.ly/1Qg96Ds, acesso no dia 05, nov., 2015, p. 8).

324 JOHN M. NEWMAN, Antitrust in zero-price markets: Foundations, In University of Pennsylvania Law Review, Vol. 164, disponível em: http://bit.ly/1jEUMaX, acesso no dia 15, out., 2015, p 5.

325 JOHN M. NEWMAN, Antitrust in zero-price markets: Foundations, In University of Pennsylvania Law Review, Vol. 164, disponível em: http://bit.ly/1jEUMaX, acesso no dia 15, out., 2015, p. 5.

326 Esta venda casada foi um dos argumentos que deram início a uma série de investigações por parte das autoridades antitruste de diferentes países com relação à práticas anticompetitivas por parte da empresa norte-americana. 
que permitam o monopólio do produtor sobre os produtos complementares. ${ }^{327}$ De modo geral, o produtor deve possuir algum poder de mercado para que possa influenciar as decisões de consumo sobre o produto não gratuito. A dificuldade de implementação desse modelo faz com que, na prática, sejam poucos os bens e serviços oferecidos segundo este desenho. $^{328}$

Um segundo modelo de negócios envolve a utilização de plataformas de múltiplos lados. Conforme vimos acima, estas plataformas cumprem a função de conectar dois grupos de consumidores, de forma que ao menos um dos grupos valorize positivamente a presença do outro. Nestes casos, o faturamento do detentor da plataforma é dividido entre os dois grupos, sendo que, no caso de mercados com preço zero, todo o faturamento é obtido de um único lado da plataforma.

Em setores pontocom, o modelo mais comum é o das mídias financiadas por anúncios publicitários (advertising supported media). ${ }^{329}$ A empresa Google, por exemplo, oferece seu buscador de Internet de forma gratuita, obtendo sua renda dos anúncios direcionados mostrados junto com os resultados de pesquisa. O Facebook, por sua vez, fornece o serviço gratuito de rede social, obtendo sua renda dos anúncios e de produtos complementares, como os jogos oferecidos em sua plataforma. ${ }^{330-331}$

327 Trata-se do famoso e controvertido caso dos barbeadores. Segundo alguns, os direitos de patente e desenho industrial sobre as lâminas permitiria que o produtor oferecesse o barbeador de forma gratuita, cobrando apenas pela venda das lâminas de barbear. O grande debate em torno desse tipo de modelo está na impossibilidade do consumidor adquiri os insumos de outro produtor para tornar o modelo viável. (DAVID S. EVANS, The antitrust economics of free, Disponível em: http://bit.ly/1GhLjB0, acesso no dia 21 , out., 2015, pp. 5-6).

328 "Casual observation suggests that setting the price of a complementary good exactly at zero is relatively rare. As of today, even the famous free razor has an implied price of several dollars." (DAVID S. EVANS, The antitrust economics of free, Disponível em: http://bit.ly/1GhLjB0, acesso no dia 21, out., 2015, p. 7)

329 Uma das poucas exceções parece ser a indústria de cartões de pagamento, em que o faturamento decorre das taxas cobradas dos comerciantes (JOHN M. NEWMAN, Antitrust in zero-price markets: Foundations, In University of Pennsylvania Law Review, Vol. 164, disponível em: http://bit.ly/1jEUMaX, acesso no dia 15, out., 2015, p. 7).

330 DAVID S. EVANS, The antitrust economics of free, Disponível em: http://bit.ly/1GhLjB0, acesso no dia 21, out., 2015, p. 9.

331 "Many Internet sites are also financed solely by advertising revenues from click-throughs and popup ads, which are also frequently a nuisance to surfers (at least those who do not click through!)" (SIMON P. ANDERSON; JEAN J. GABSZEWICZ, The media and advertising: A tale of two-sided markets, 2005, disponível em: http://bit.ly/2161rN1, acesso no dia 19, nov., 2015). 
Deve-se observar que o modelo de plataforma de múltiplos lados não exige que um dos lados seja necessariamente caracterizado pelo oferecimento de serviços a preço zero, ou a preços abaixo do custo marginal. Tal estrutura permite que, em muitas situações, sejam cobrados preços positivos dos dois lados da plataforma. ${ }^{332}$ Fato é que, tais estruturas, sofreram intensa modificação nos últimos anos. Muitos serviços que antes eram oferecidos apenas de forma paga agora são oferecidos de forma gratuita, sendo esse o modelo predominante nos setores de Internet.

Uma diferença fundamental entre o modelo de bens complementares e o de mercados de múltiplos lados se encontra no beneficiário do subsídio, que, geralmente são distintos. Enquanto no caso dos bens complementares o consumidor arca com o custo de um dos bens, no caso das plataformas de múltiplos lados o custo para o consumidor geralmente é igual a zero. Tal diferença tem implicações sobre a análise do bem estar nestas estruturas. ${ }^{333}$

Um terceiro modelo de negócios consiste no oferecimento de duas versões do mesmo produto, sendo uma delas oferecida a preço zero e a outra versão, premium, com qualidades superiores, serviços distintos ou sem publicidade, oferecida mediante um preço positivo. ${ }^{334}$ Exemplos deste tipo de modelo podem ser vistos em aplicativos como o Spotify, aplicativo de música que disponibiliza músicas por streaming ${ }^{335}$ aos usuários, oferecendo um plano gratuito, com qualidade de áudio inferior e com anúncios publicitários entre as músicas, e um plano pago, com qualidade de áudio superior e sem os anúncios, além de outras funcionalidades, como a capacidade de salvar as músicas em seu aparelho.

Por fim, para que possamos compreender a evolução do ecossistema da Internet, devemos analisar a maneira como os anúncios publicitários e a competição por atenção,

\footnotetext{
332 DAVID S. EVANS, The antitrust economics of free, Disponível em: http://bit.ly/1GhLjB0, acesso no dia 21, out., 2015, pp. 9-10.

333 DAVID S. EVANS, The antitrust economics of free, Disponível em: http://bit.ly/1GhLjB0, acesso no dia 21, out., 2015, p. 10

334 JOHN M. NEWMAN, Antitrust in zero-price markets: Foundations, In University of Pennsylvania Law Review, Vol. 164, disponível em: http://bit.ly/1jEUMaX, acesso no dia 15, out., 2015, pp. 7-8.

335 Streaming consiste numa forma de distribuição de mídia em que o conteúdo não é armazenado de forma permanente pelo usuário, tendo este acesso a estes arquivos apenas enquanto estiver conectado ao serviço.
} 
aliada ao crescimento dos dispositivos móveis, remodelaram esse ambiente e trouxeram profundas mudanças sobre os modelos de negócios e sobre a concorrência.

\section{II.4.7.2 - A evolução da publicidade e os mercados de múltiplos lados}

$\mathrm{Na}$ era da web os anúncios estão mais do que nunca presentes em praticamente todas as atividades que desenvolvemos diariamente. Seja ao abrir nossa conta de e-mail (quando dedicamos um tempo a verificar as promoções e propagandas recebidas), ao olharmos notícias em sites da Internet (nos quais somos bombardeados por um número infinito de anúncios publicitários direcionados), ou ao utilizarmos o número cada vez maior de apps desenvolvidos para smartphones com as funcionalidades mais diversas, como chamar um taxi, ouvir música, tirar fotos ou compartilhar conteúdo em redes sociais, em que somos novamente expostos a uma infinidade de anúncios direcionados.

A emergência desses modelos baseados em plataformas de múltiplos lados teve papel fundamental para que o gratuito se tornasse a regra na era da Internet. Nesse contexto, nosso ativo mais valioso e escasso se torna o nosso tempo. Conforme veremos no CAPÍTULO III, a "gratuidade" desses novos serviços decorre justamente troca dos serviços pela nossa atenção e pelas informações pessoais coletadas pelas novas plataformas.

O oferecimento cada vez maior de novos conteúdos e funcionalidades por estas novas plataformas fizeram com que o número de horas médias gastas pelos usuários na Internet aumentasse de 9,4 horas por semana em 2001 para mais de 20,4 horas por semana em 2012. Da mesma forma, o percentual de casas com acesso a Internet aumentou de $46 \%$, em 2000 para mais de 78\% em 2012 nos Estados Unidos. ${ }^{336-337}$

Isso permitiu que o mercado de competição por atenção passasse por profundo desenvolvimento nesse período. Podemos apontar duas inovações que tornaram esse mercado distinto dos mercados tradicionais de mídia/propaganda. Em primeiro lugar, na

\footnotetext{
336 Conforme dados de pesquisa apresentada por DAVID S. EVANS, Rivals for attention: How competition for scarce time drove the web revolution, what it means for the mobile revolution, and the future of advertising, 2014, disponível em: http://bit.ly/1WZhJHL, acesso no dia 18, nov., 2015, p. 4.

337 No Brasil esse percentual passou de $18 \%$ dos domicílios em 2008 para mais de 50\% dos domicílios, no ano de 2014, conforme pesquisa TIC domicílios realizada pelo Comitê Gestor da Internet (Dados disponíveis em: http://cetic.br/pesquisa/domicilios/, acesso no dia 22, dez., 2015.
} 
era da Internet, os anúncios se tornam links, ou seja, ao clicar no anúncio, o usuário é direcionado para outro site, no qual poderá adquirir um produto ou ficar exposto a novo conteúdo publicitário. Em segundo lugar, a maior disponibilidade de informações sobre o consumidor faz com que o anúncio seja direcionado aos seus interesses, o que aumenta a probabilidade de que o anúncio tenha algum resultado útil, levando a um maior retorno por tempo gasto com a atenção do consumidor. ${ }^{338}$

\section{II.4.7.3 - Contribuições da Economia Comportamental para análise dos setores de preço} zero

Conforme observamos no Capítulo $\mathrm{I}$, muito se tem discutido com relação à aplicabilidade da economia comportamental ao direito concorrencial. A insuficiência do paradigma neoclássico para explicar alguns destes novos mercados, especialmente em setores com preço zero, faz com que os analistas busquem outros paradigmas de análise. Um dos paradigmas mais comentados nos últimos tempos é justamente o da escola de Economia Comportamental. Sua análise oferece importantes insights para melhor compreensão destes mercados.

A análise neoclássica baseada em agentes racionais, maximizadores de utilidade e que buscam a realização do auto interesse, partem da assunção que o agente irá adquirir uma unidade adicional do produto sempre que o benefício marginal for superior ao custo marginal do produto ou serviço. Segundo estes modelos lineares, o valor do benefício marginal se mantém constante em todas as faixas de preço, inclusive quando o preço for igual a zero. Por esta razão, segundo este modelo de análise, o preço igual a zero é apenas mais um preço, não trazendo diferenças substanciais com relação aos possíveis valores positivos que o preço possa assumir. ${ }^{339}$

No entanto, o que experimentos de economia comportamental vem demonstrando é que o produto gratuito (ou seja, com preço igual a zero) gera um efeito psicológico sobre o consumidor, de modo que o seu benefício se mostra superior ao dos produtos com preços

338 DAVID S. EVANS, Rivals for attention: How competition for scarce time drove the web revolution, what it means for the mobile revolution, and the future of advertising, 2014, disponivel em: http://bit.ly/1WZhJHL, acesso no dia 18, nov., 2015, pp. 5-6.

339 JOHN M. NEWMAN, Antitrust in zero-price markets: Foundations, In University of Pennsylvania Law Review, Vol. 164, disponível em: http://bit.ly/1jEUMaX, acesso no dia 15, out., 2015, pp. 33-34. 
positivos. ${ }^{340}$ DAN ARIELY apresenta como exemplo um experimento em que ofereciam chocolates da marca Lindt (de qualidade nitidamente superior) ao preço de 15 cents de dólar e chocolates da marca Hershey pelo preço de 1 cent de dólar. Nessa situação $73 \%$ das pessoas optaram pela escolha racional e compraram o chocolate da marca Lindt, que oferecia melhor relação custo benefício, tendo em vista a qualidade superior do produto. Porém, ao reduzir ambos os preços em 1 cent, ou seja, comercializando o chocolate Lindt por 14 cents e o chocolate Hersheys por 0 cents, ou seja, de forma gratuita, a demanda se inverte, fazendo com que $67 \%$ das pessoas optem pelo chocolate Hersheys gratuito. ${ }^{341}$ Este fenômeno recebeu o nome de "zero-price effect".

Outro estudo realizado por SPIEGEL, BENZION e SHAVIT com produtos em promoção aponta para sentido semelhante. Segundo tal estudo, quando confrontados com a opção de obter um segundo produto de forma gratuita ou de obter um desconto de $50 \%$ nos dois produtos (ou seja, em ambas situações o consumidor acaba pagando por um dos produtos apenas), os consumidores preferem obter um bem de forma gratuita, justamente por conta do Gift Effect, que faz com que o produto gratuito seja considerado maios valioso. $^{342}$

O que notamos com tais exemplos é que esse fenômeno, conhecido como "free effect", afeta o processo de decisão por conta de um viés cognitivo ou impacto emocional. Diferentemente do paradigma neoclássico, em que o aumento se mostra proporcional à diminuição do preço do bem, a economia comportamental nos mostra que, em muitos

\footnotetext{
$340 \quad$ "Zero often serves as a focal point, signaling to consumers that the product or service has a substantially higher benefit than if the same product or service was made available at a very low, but positive price" (MICHAL S. GAL; DANIEL L. RUBINFELD, The hidden costs of free goods: Implications for Antitrust enforcement, New York University Law and Economics Working Papers, Disponível em: http://bit.ly/1Qg96Ds, acesso no dia 05, nov., 2015, p. 9).
}

341 "A passing economist,twirling his cane and espousing conventional economic theory, in fact, would have said that since everything in the situation was the same, our customers should have chosen the truffles by the same margin of preference. And yet here we were, with people pressing up to the table to grab our Hershey`s Kisses, not because they had made a reasoned cost-benefit analysis before elbowing their way in, but simply because the Kisses were FREE! How strange (but predictable) we humans are!" (DAN ARIELY, Predictably irrational: The hidden forces that shape our decisions, New York, Harper Collins, 2009, p. 59).

\footnotetext{
342 "Consumers get such an emotional charge from an item being offered free that they perceive it as being much more valuable than it really is. [...]This can also explain why we find that participants were indifferent between the two promotions or preferred the option of one unit of the same product for free (BOGOF) over the option of a 50\% discount. This preference is inconsistent with economic theory since buying a product at a $50 \%$ discount without any restriction as to how many units must be purchased should dominate the restricted option of BOGOF." (URIEL SPIEGEL; URI BENZION; TAL SHAVIT, Free product as a complement or substitute for a purchased product-Does it matter?, In Modern Economy, disponível em: http://bit.ly/1O15UI0, Acesso no dia 22, dez., 2015, 2011, p. 129).
} 
casos, o efeito da diminuição do preço para zero causa um aumento sobre a demanda que não guarda qualquer proporção com a diminuição monetária do preço. ${ }^{343}$

Tal fenômeno guarda relações com o conceito de "nudge", desenvolvido por RICHARD H. THALER e CASS R. SUNSTEIN, que sustenta que estratégias de reforço positivo e de sugestões indiretas tem um efeito sobre o processo decisório dos indivíduos tão ou mais efetivo do que ordens diretas ou enforcement legal. ${ }^{344}$ A aplicação dessa teoria para o mercado leva a possibilidade das firmas se valerem destas estratégias para fazerem com que o consumidor adquira um bem diferente de suas preferências reveladas. ${ }^{345}$

Um segundo fenômeno que passa a ser questionado pela economia comportamental é o da tendência ao consumo excessivo ("overconsumption") quando o preço é igual a zero. A economia há anos aponta diversos casos em que a não cobrança de qualquer valor faz com que o bem seja consumido em uma escala não eficiente. Um exemplo é o das rodovias, que na ausência de cobrança de pedágios, tendem a gerar congestionamentos. $\mathrm{O}$ que a economia comportamental vem demonstrando é que, diante da presença de normas sociais, a tendência ao consumo excessivo é mitigada. ${ }^{346}$

O exemplo apresentado por DAN ARIELY é o de um experimento em que são vendidos doces para alunos de uma universidade ao preço de 1 cent. Nessa situação são vendidos, em média, 3,5 doces por aluno. Numa segunda situação em que o doce é vendido a preço zero, ou seja, distribuído gratuitamente, o número total de consumidores aumenta, porém, quase nenhum dos alunos pegou mais de um doce. O que se percebe é que, ao reduzir o preço para zero, nós passamos a nos guiar por uma norma social em detrimento

343 MICHAL S. GAL; DANIEL L. RUBINFELD, The hidden costs of free goods: Implications for Antitrust enforcement, New York University Law and Economics Working Papers, Disponível em: http://bit.ly/1Qg96Ds, acesso no dia 05, nov., 2015, pp. 9-11.

344 Conforme os autores, nudge seria "is any aspect of the choice architecture that alters people's behavior in a predictable way without forbidding any options or significantly changing their economic incentives. To count as a mere nudge, the intervention must be easy and cheap to avoid. Nudges are not mandates."(RICHARD H. THALER; CASS R. SUNSTEIN, Nudge - Improving decisions about health, wealth and happiness, London, Penguin Books, 2008, p. 6)

345 MICHAL S. GAL; DANIEL L. RUBINFELD, The hidden costs of free goods: Implications for Antitrust enforcement, New York University Law and Economics Working Papers, Disponível em: http://bit.ly/1Qg96Ds, acesso no dia 05, nov., 2015, pp. 11-12.

346 JOHN M. NEWMAN, Antitrust in zero-price markets: Foundations, In University of Pennsylvania Law Review, Vol. 164, disponível em: http://bit.ly/1jEUMaX, acesso no dia 15, out., 2015, pp. 35-36. 
das regras de mercado. Ou seja, deixamos de ser indivíduos egoístas, maximizadores de lucro, e passamos a nos preocupar mais com o bem estar geral da sociedade. ${ }^{347}$

Conforme já apontamos anteriormente, uma das grandes limitações da aplicação da economia comportamental para o direito concorrencial se encontra no fato dela apontar para tendência de condutas de indivíduos e não de firmas. Além disso, a maior parte dos estudos realizados tem como foco bens de baixo valor e se vale de estudantes como público alvo. Por essa razão, o impacto desse fenômeno sobre bens de maior valor, bem como sobre outros grupos da sociedade, tais como empresas, permanece inconclusivo. No entanto, enquanto críticos ao paradigma do agente racional, tais modelos trazem importantes observações para a compreensão do comportamento dos consumidores individualmente considerados.

\section{II.4.7.4 - Contribuições da Economia dos Custos de Transação (ECT) para análise dos setores de preço zero}

Conforme afirmamos, a assimetria informacional presente nestas relações faz com que a contratação de serviços de preço zero apresente uma série de riscos não previstos ao consumidor. Estes riscos podem levar ao surgimento de custos de transação. Dessa forma, as contribuições da ECT podem oferecer importantes reflexões sobre o aumento dos custos de transação ex-post, ou seja, custos que surgem após a assinatura do contrato.

As empresas web based coletam e armazenam diversas informações pessoais de seus usuários com a finalidade de atrair terceiros interessados na obtenção e uso desses dados. Tais procedimentos são autorizados pelos termos de uso assinados pelo consumidor ao contratarem os serviços. No entanto estes se apresentam muitas vezes em formato de contratos de adesão (nesse caso contratos de click), aos quais praticamente nenhum consumidor se atenta. Em alguns casos, porém, podem acabar surgindo usos não previstos por nenhuma das partes contratantes, como veremos no caso do aplicativo russo "Girls Around Me".

Este aplicativo de encontros, desenvolvido pela empresa russa SMS Services, com o objetivo de aproximar pessoas do sexo oposto ao do usuário que se encontrassem em uma

\footnotetext{
347 "What these results mean is that when price is not a part of the exchange, we become less selfish maximizers and start caring more about the welfare of others. [...] So while the product (candy, in our case) was more attractive to more people, it also made people think more about others, care about them, and sacrifice their own desires for the benefit of others." (DAN ARIELY, Predictably irrational: The hidden forces that shape our decisions, New York, Harper Collins, 2009, p. 109).
} 
localização próxima, colhia informações de perfis públicos do Facebook e de localizações obtidas do aplicativo Foursquare. O que devemos destacar é que os usuários do Facebook e do Foursquares autorizaram expressamente tanto o Facebook como o Foursquare a disponibilizarem publicamente suas informações, incluindo suas fotos e localizações. $\mathrm{O}$ que nenhuma das partes esperava, no entanto, é que estas fossem utilizadas por um terceiro (no caso o aplicativo Girls Around Me), que sem autorização de nenhuma delas, utilizaria tais informações com essas finalidades. Diante das preocupações de segurança e privacidade que o uso deste aplicativo poderia acarretar, a Apple decidiu retirá-lo da App Store (loja de aplicativos dos usuários do Iphone) e o Foursquare decidiu impedir o acesso do aplicativo russo às informações de seu aplicativo. ${ }^{348}$ Nota-se com esse exemplo, que o acesso e disponibilização destas informações traz consigo uma série de usos não previstos originalmente pelos usuários e pelas próprias empresas responsáveis pela coleta destas informações.

Este tipo de aplicativo apenas é viável por conta de empresas como o Facebook, que coletam armazenam e vendem informações pessoais dos usuários. $\mathrm{O}$ modelo de negócios destas empresas, como já afirmamos, se baseia no fornecimento de serviços gratuitos mediante a coleta de dados dos usuários e na posterior atração de terceiros interessados nessas informações (em geral anunciantes) para comercialização do uso desses dados. No caso do Facebook, a empresa comercializa anúncios de forma direta com os anunciantes (self-serve), desenvolve e lança aplicativos em sua plataforma com anúncios (apps que contém anúncios), lança aplicativos que coletam pagamentos na moeda proprietária da empresa (Facebook Credits), bem como se vale de combinações destas três modalidades. A plataforma recebe, ainda, valores crescentes dos anunciantes na medida em que os usuários visualizem seus anúncios, cliquem nos banners, se registrem nos sites dos anunciantes, bem como quando adquirem produtos nos sites dos anunciantes. ${ }^{349}$

O número de informações pessoais obtidas por estes sites aumenta na medida em que o usuário navega pela plataforma e interage com os anúncios. Todas essas informações

348 CHRIS JAY HOOFNAGLE; JAN WHITTINGTON, Free - Accounting for the costs of the Internet's most popular price, In UCLA Law Review, n. 61, vol. 3, 2014, pp. 629-630.

349 CHRIS JAY HOOFNAGLE; JAN WHITTINGTON, Free - Accounting for the costs of the Internet's most popular price, In UCLA Law Review, n. 61, vol. 3, 2014, pp. 630-631. Atualmente o maior anunciante em receitas obtidas pela plataforma é a empresa Zynga. Esta empresa que é proprietária dos seis jogos mais populares que rodam na plataforma do Facebook, foi responsável por $11 \%$ da receita do Facebook no primeiro quarto de 2012, tendo um valor de mercado de mais de 7 bilhões de dólares em sua IPO. 
são coletadas pelos já mencionados cookies de navegação, que registram todos esses dados no computador do usuário. Em muitos casos, ao acessar outros aplicativos, o usuário tem a opção de criar uma conta nova ou vincular este aplicativo a sua conta do Facebook. Ao acessar estes aplicativos, ou ao se registrar por meio da sua conta do Facebook, o usuário acaba anuindo aos termos deste novo aplicativo, autorizando este a utilizar suas informações salvas pelo Facebook. Tais exemplos demonstram a facilidade com que dados pessoais coletados através de redes sociais podem ser transferidos para terceiros sem que o usuário tenha consciência de tal fato. ${ }^{350}$

O valor econômico associado a estas informações nas relações entre as redes sociais e terceiros faz com que estas se tornem um ativo extremamente valorizado, tendo claros incentivos econômicos para ampliar seu acesso e compartilhamento de tais informações. Em muitas situações as empresas se valem de acordos de compartilhamento de faturamento em que ambas lucram com o uso das informações dos consumidores. Por fim, na impossibilidade de obter faturamento destas informações, as firmas podem, ainda, comercializá-las no mercado. ${ }^{351}$ Do mesmo modo, a empresa pode adquirir tais informações no mercado pela prática conhecida como "enhancement".

O que se nota é que tais práticas são muitas vezes realizadas sem que o usuário tenha consciência do uso que vem sendo feito de suas informações. De modo geral, nota-se que ao tomarem conhecimento destas práticas os consumidores tendem a uma posição fortemente contrária. ${ }^{352}$ Por conta disso, na maior parte dos casos as empresas se valem de cláusulas de confidencialidade nestes contratos com o objetivo de evitar que o consumidor tome consciência das transferências de suas informações. Assim, notamos que tais

\footnotetext{
350 "These processes of exchange illustrated by "Girls Around Me" and "Draw Something" demonstrate the ease with which personal information entered into social-networking services can be transferred to a third party and thereby become subject to the third party's privacy policies — whether or not the consumer intended for this result to occur." (CHRIS JAY HOOFNAGLE; JAN WHITTINGTON, Free Accounting for the costs of the Internet's most popular price, In UCLA Law Review, n. 61, vol. 3, 2014, p. 632).
}

351 "Firms can sell this personal information to brokers who aggregate the data into profiles of individual consumers and their households and then resell the data to other firms and interested parties." (CHRIS JAY HOOFNAGLE; JAN WHITTINGTON, Free - Accounting for the costs of the Internet's most popular price, In UCLA Law Review, n. 61, vol. 3, 2014, p. 633).

352 Estudo recente realizado com usuários norte-americanos revelou que $73 \%$ dos usuários eram contrários aos uso de seu histórico de navegação pela plataforma de buscas com o objetivo de melhorar os resultados de busca. Além disso, 68\% eram contrários ao uso de seus dados para auxiliar os anunciantes a oferecerem anúncios direcionados (NATHAN NEWMAN, The Costs of Lost Privacy: Consumer Harm and Rising Economic Inequality in the Age of Google, In William Mitchell Law Review, Vol. 40, n. 2, 2014, pp. 865-866). 
transações envolvem uma série de riscos contratuais ignorados pelos consumidores, sendo o primeiro passo para a sanção destes custos o reconhecimento de que transações em mercado de preço zero não são gratuitas, uma vez que envolvem tanto custos monetários como não monetários. ${ }^{353}$

Nestas transações online, portanto, a perda de privacidade dos consumidores leva ao surgimento dos principais custos de transação ex-post. Os custos pela distribuição não autorizada ou não esperada de suas informações pessoais representam um valor considerável para os usuários dessas plataformas, sendo que os diversos usos que podem ser feitos dessa informação podem gerar diversos outros custos de transação ex-post não previstos pelas partes. O fato das informações pessoais serem ativos únicos para cada consumidor faz com que este consumidor ingresse em relações bilaterais de dependência com cada uma das firmas que utilizarem estas informações. Dessa forma, os procedimentos já mencionados de compartilhamento de informações com outras plataformas cria ciclos de transferência que levam a um efeito cascata de transmissão dessas informações pelo mercado, criando relações bilaterais de dependência com empresas com as quais os usuários jamais tiveram a intenção de negociar. ${ }^{354}$

Os cinco principais custos de transação originados desse tipo de transação são: (i) o rastreamento do comportamento do consumidor; (ii) a necessidade do consumidor monitorar as atividades das firmas; (iii) o lock-in decorrente dos custos de mudança (switching costs); (iv) inseguranças geradas pela possibilidade de fraudes e vazamento destas informações pessoais; e (v) os custos de cancelamento. ${ }^{355}$

A racionalidade limitada faz com que o consumidor tenha pouco conhecimento em relação aos custos de produção e distribuição das firmas, bem como dos possíveis usos que serão realizados dos seus dados pessoais. Ex-ante, as expectativas de garantia de privacidade dos seus dados se encontra desalinhada em relação aos incentivos financeiros

353 CHRIS JAY HOOFNAGLE; JAN WHITTINGTON, Free - Accounting for the costs of the Internet's most popular price, In UCLA Law Review, n. 61, vol. 3, 2014, p. 634.

\footnotetext{
354 "Furthermore, scraping, sending personal information belonging to others, and other viral forms of exchange accelerate the cascading flow of personal information through the marketplace, rendering consumers subject to bilateral dependent relations that the consumer never initiated with firms with whom the consumer never intended to trade." (CHRIS JAY HOOFNAGLE; JAN WHITTINGTON, Free Accounting for the costs of the Internet's most popular price, In UCLA Law Review, n. 61, vol. 3, 2014, pp. 636-640).
}

355 CHRIS JAY HOOFNAGLE; JAN WHITTINGTON, Free - Accounting for the costs of the Internet's most popular price, In UCLA Law Review, n. 61, vol. 3, 2014, p. 640. 
detidos pelas empresas para realizar diversas operações comerciais com estas informações. Criam-se, assim, variados incentivos para que as empresas mascarem suas práticas relacionadas a posse e uso dessas informações pessoais, levando ao aumento dos custos de transação dos consumidores e tornando o real custo da transação cada vez mais obscuro. ${ }^{356}$

Nas transações ex-post surgem, ainda, custos de mudança decorrentes das dificuldades de interoperabilidade com outras aplicações e custos de monitoramento decorrente das crescentes práticas de rastreamento das atividades dos usuários. Um exemplo dessas práticas são os chamados HTTP referer ${ }^{357}$ De modo simplificado, trata-se de um campo de cabeçalho que identifica o endereço da web da última página visitada pelo usuário. Por meio desse recurso os sites podem ter informações relacionadas às intenções do usuário, sendo que no caso do usuário ter acessado o site por uma pesquisa através do Google este recurso indica os termos de busca utilizados pelo usuário para chegar ao site. O grande problema desse recurso se encontra na possibilidade de revelação de informações sensíveis do usuário, como dados de login, usernames, dentre outras informações pessoais. $^{358}$

Como afirmamos, os consumidores se encontram na impossibilidade de preverem os possíveis usos que serão feitos de suas informações pessoais bem como dos riscos associados a tais práticas. Além dos problemas de privacidade relacionados a possibilidade de rastreamento de suas atividades, surgem, ainda, problemas relacionados aos riscos de segurança destas informações. A implementação de mecanismos eficientes de proteção destas informações depende exclusivamente das empresas e se mostra fundamental, uma vez que o furto destes dados pode gerar substanciais custos aos usuários. ${ }^{359} \mathrm{Um}$ exemplo destas falhas de segurança ocorreu com a recente invasão da plataforma do videogame da

356 CHRIS JAY HOOFNAGLE; JAN WHITTINGTON, Free - Accounting for the costs of the Internet's most popular price, In UCLA Law Review, n. 61, vol. 3, 2014, pp. 640-642.

357 Referrer ou HTTP Referrer são definidos como: “A referrer is URL data from an HTTP header field identifying the Web link used to direct users to a Web page. Referrers are used in statistical Web analysis and often integrated with marketing strategies and security methodologies." (TECHOPEDIA, disponível em: http://bit.ly/1NCgZAV, acesso no dia 23, dez., 2015).

358 Diante das críticas a Google, inclusive, passou a utilizar criptografia para aumentar a privacidade em relação a estas informações. No entanto, com o tempo voltou a criar mecanismos pelos quais os anunciantes voltaram a ter acesso a estas informações (CHRIS JAY HOOFNAGLE; JAN WHITTINGTON, Free - Accounting for the costs of the Internet's most popular price, In UCLA Law Review, n. 61, vol. 3, 2014, pp. 643-644).

359 CHRIS JAY HOOFNAGLE; JAN WHITTINGTON, Free - Accounting for the costs of the Internet's most popular price, In UCLA Law Review, n. 61, vol. 3, 2014, pp. 643-646. 
empresa Sony, a Playstation Network, que levou ao vazamento de dados de 77 milhões de usuários. O problema principal ocorreu com informações não criptografadas pelo sistema como e-mails e senhas dos usuários. O fato destes utilizarem senhas semelhantes em diversos sites diferentes fez com que houvesse enorme exposição e risco de invasão em diversas outras contas de sites distintos. ${ }^{360}$

Sob o ponto de vista da eficiência, o que importaria nas transações seria a capacidade do consumidor estimar o valor do deu tempo, atenção, e suas informações pessoais. O problema é que os fatores supra mencionados fazem com que o consumidor não tenha a capacidade de avaliar todos os preços cobrados pelas suas informações no mercado, além dos custos, pecuniários e não pecuniários, associados a tais informações. Indo além, o consumidor se encontra sujeito a diversos riscos não previstos, como a possibilidade de invasão da base de dados da plataforma e vazamento de informações pessoais e financeiras, como seus dados de cartões de crédito. ${ }^{361}$

Sob o ponto de vista da economia dos custos de transação o fenômeno do deslumbramento em relação ao gratuito também tem uma explicação. Para explicar tal efeito os economistas criaram o termo "deceptive framing", sendo este entendido como a representação, pela firma, de um problema decisório de forma enviesada e incompleta, de forma que tende a levar o consumidor a uma decisão errônea quanto ao processo de decisão. Segundo esta concepção, portanto, ao descrever o produto como gratuito as empresas apresentam uma definição restrita que desloca o enfoque apenas sobre um dos aspectos quando, na verdade, a decisão envolve questões muito mais complexas. ${ }^{362}$

\footnotetext{
$360 \quad$ "Having user emails and passwords could lead malicious users to steal all sorts of other personal details, especially because many people use the same password on multiple sites - a security failing caused by the problem of remembering multiple different logins." (KEITH STUART; CHARLES ARTHUR, PlayStation Network hack: why it took Sony seven days to tell the world, In The Guardian, 27, abr., 2011, disponível em: http://bit.ly/1P7rgIo, acesso no dia 3, nov., 2015).

361 CHRIS JAY HOOFNAGLE; JAN WHITTINGTON, Free - Accounting for the costs of the Internet's most popular price, In UCLA Law Review, n. 61, vol. 3, 2014, pp. 646-648.

362 CHRIS JAY HOOFNAGLE; JAN WHITTINGTON, Free - Accounting for the costs of the Internet's most popular price, In UCLA Law Review, n. 61, vol. 3, 2014, pp. 649-651.
} 


\section{II.4.8 - Possibilidade de customização da experiência do usuário}

O esgotamento do modelo de sociedade de consumo massificado e padronização das opções comerciais fizeram com que surgisse nas últimas décadas um movimento de substituição de opções padronizadas e a emergência de formas de customização da experiência do cliente. O objetivo desta customização geralmente tem como principais objetivos o do aumento das vendas, com direcionamento de ofertas e anúncios personalizados, fidelização do consumidor, dentre outros.

Em muitos casos, com o objetivo de facilitar o armazenamento de informações relacionadas às preferências dos consumidores bem como aos seus padrões de consumo, algumas empresas, como a norte-americana Target, do ramo de varejo, passaram a identificar seus clientes por meio de números de identificação, que armazenariam suas informações de consumo na loja. Diversas empresas varejistas passaram a criar programas de recompensas, cartões de crédito com a marca das lojas, a oferer cupons de desconto, com o objetivo de obter tais informações dos consumidores e melhor compreender seus hábitos de consumo. ${ }^{363}$

Tais informações permitiram que as empresas pudessem de alguma forma ter conhecimento de informações como gênero, número de filhos e hábitos de consumo de seus clientes, e, de posse dessas informações, personalizar os anúncios enviados a suas residências. ${ }^{364}$

Além dos altos custos associados a estas modalidades de tratamento individualizado de gostos e preferências, como os custos de obtenção e armazenamento destas informação, outra limitação nos setores tradicionais se relaciona aos enormes custos necessários à adaptação das estruturas de venda e de propaganda para consumidores diferentes. Por esta razão, seria inviável criar uma estrutura de vendas em que os consumidores tivessem acesso à vitrines personalizadas ou que fosse veiculados anúncios personalizados em veículos de comunicação tradicionais, como jornais e televisão.

363 CHARLES DUHIGG, The power of habit - Why we do what we do in life and business, Ramdon House Trade Paperbacks, New York, 2012, p. 187-188.

$364 \quad$ "The computers looked for shoppers buying bikinis in April, and sent them coupons for sunscreen in July and weight-loss books in December. If it wanted, Target could send each customer a coupon book filled with discounts for products they were fairly certain the shoppers were going to buy, because they had already purchased those exact items before." (CHARLES DUHIGG, The power of habit - Why we do what we do in life and business, Ramdon House Trade Paperbacks, New York, 2012, p. 190). 
No caso da Internet, por outro lado, os custos são infinitamente inferiores, por conta da maior facilidade de obtenção de informações do consumidor, bem como dos baixos custos associados à adaptação do site aos diferentes usuários. Dessa forma, a capacidade de obtenção de informações das preferências de consumo dos clientes ganha outra dimensão. ${ }^{365}$ Em primeiro lugar, praticamente todas as compras realizadas por consumidores em plataformas on-line são registradas no nome do cliente, o que permite que as empresas tenham acesso a todo seu histórico de consumo nas lojas. Em segundo lugar, surgem os chamados cookies, pequenos pacotes de dados implantados nos navegadores de Internet, que estabelecem um número de identificação no disco rígido do computador e que permitem aos sites registrarem inúmeras informações de navegação do usuário. $^{366-367}$

Além disso, a possibilidade de customização dos preços ganha outro relevo. Um exemplo apresentado por SALIL K. MEHRA dessa nova capacidade de processamento de informações é o do número de mudanças de preços realizadas pela plataforma de compras da Amazon. Enquanto a empresa de e-commerce realizou, em novembro de 2012, uma média de 2,5 milhões de mudanças de preço, por dia, uma loja física do Walmart, tradicionalmente, não realiza mais do que 50.000 mudanças de preço por mês em seus produtos. $^{368}$

Por meio destes mecanismos os sites passaram a rastrear grande parte do histórico de navegação dos usuários, obtendo diversas informações tanto em sites de compras como em outros sites, como buscadores e sites de conteúdo informativo. De posse dessa enorme

\footnotetext{
365 "The new market environment provides sophisticated players with the capacity to monitor customers' activities, accumulate data and react to market changes with an ever-increasing speed." (ARIEL EZRACHI; MAURICE E. STUCKE, Artificial Intelligence \& Collusion: When Computers Inhibit Competition, disponível em: http://bit.ly/1MXhdC3, acesso em 06, out., 2015, p. 4).
}

366 "Os cookies transformam nossos hábitos em dados. Eles são minas de ouro para negociantes e anunciantes. Registram nossos sites preferidos, lembram as informações de nosso cartão de crédito, armazenam o que pomos nas nossas sacolas de compras eletrônicas e anotam em que anúncios de banners clicamos" (ANDREW KEEN, $O$ culto do amador: Como blogs MySpace, Youtube e a pirataria digital estão destruindo nossa economia, cultura e valores, tradução de Maria Luiza X. de A. Borges, Rio de Janeiro, Zahar, 2009, p. 163).

$367 \quad$ "A vast array of companies is now devoted to tracking people online, often on free sites, in order to target individuals for advertisements, measure the efficacy of advertising, or audit the delivery of advertising" (CHRIS JAY HOOFNAGLE; JAN WHITTINGTON, Free - Accounting for the costs of the Internet's most popular price, In UCLA Law Review, n. 61, vol. 3, 2014, p. 627).

368 SALIL K. MEHRA, Antitrust and the Robo-Seller: Competition in the time of algorithms, disponível em: http://bit.ly/1kZQtrk, acesso no dia 16, nov., 2015, p. 14. 
gama de informações, as empresas agora podem realizar suposições sobre seus desejos de consumo futuros de forma sem precedentes. ${ }^{369-370}$

Com o uso destas informações e tendo em vista os custos infinitamente menores de customização da experiência dos usuários, os sites da Internet ganham a capacidade de apresentar publicidade e resultados de pesquisas customizados de acordo com comportamentos passados do consumidor e suas preferências pessoais. Praticamente toda plataforma de Internet da atualidade armazena informações pessoais de usuários com o objetivo de detectar padrões de comportamento e preferências. Isso ocorre tanto nas recomendações de produtos feitas por sites de compra como Amazon, como nos algoritmos de buscas do Google e no sistema de buscas do Facebook. ${ }^{371}$

\section{II.4.9 - Elevado potencial para experimentação e inovação}

Por fim, uma última característica dos setores web based se encontra no elevado potencial de inovação e experimentação permitido pelo ambiente destes mercados. Os menores custos de adaptação e a velocidade de monitoramento de feedback possibilitados pela rede virtual criam enormes incentivos para que as empresas realizem experimentos com novas ideias, produtos e serviços, podendo rapidamente adaptá-los ou mesmo desistir de sua implementação. ${ }^{372-373}$

369 Tal área ganha o nome de Predictive Analytics, e suas aplicações vem aumentando com as novas plataformas de anúncios que vem surgindo. Conforme aponta DUHIGG, um analista da empresa Target estimava que no caso das lojas físicas seu sistema tinha capacidade de relacionar até $50 \%$ das compras realizadas a um cliente específico, ao passo que no caso da vendas online, o sistema permite relacionar praticamente todas as compras realizadas à clientes específicos e obter aproximadamente $25 \%$ dos dados de navegação de seus clientes (CHARLES DUHIGG, The power of habit - Why we do what we do in life and business, Ramdon House Trade Paperbacks, New York, 2012, p. 190-191).

$370 \quad$ Em sentido similar: "Because they are software-based media properties, however, attention rivals can engage in highly targeted advertising customized to the person viewing the advertisement." (DAVID S. EVANS, Attention rivalry among online platforms, In Journal of Competition Law \& Economics, 9 (2), 2013, p. 339).

371 "Virtually every internet platform collects extraordinarily detailed data on user behavior and activity, which can be mined to identify potentially successful matches." (JONATHAN LEVIN, The economics of Internet markets, 2010, disponível em: http://bit.ly/1GRkYde, acesso no dia 8, nov., 2015, pp. 4-5).

372 JONATHAN LEVIN, The economics of Internet markets, 2010, disponível em: http://bit.ly/1GRkYde, acesso no dia 8, nov., 2015, p. 5 .

373 A capacidade de experimentação depende em grande medida da ocorrência de baixas barreiras à entrada, de modo a não impedir que novos entrantes inovem e contestem o domínio de players consolidados. (GEOFFREY A. MANNE; WILLIAM RINEHART, The market realities that undermined the FTC's 
Este elevado potencial de experimentação faz com que estes setores tenham elevados índices de inovação e surgimento de novos players e modelos de negócio. Por essa razão, a intensa concorrência entre estes negócios leva a uma rápida alternância entre os sites com maior número de acessos. ${ }^{374}$ Este elevado índice de inovações remonta ao surgimento da Internet, quando o fluxo intenso de novas ideias e de adaptação difusa possibilitaram seu desenvolvimento e a superação de inúmeros obstáculos técnicos enfrentados ao longo do tempo.

Por essa razão, estes setores apresentam ciclo drástico de inovações, no qual produtos e serviços extremamente diferentes de tudo o que já se criou surgem a todo momento. DAVID S. EVANS aponta que, dos 25 sites com maior número de acessos em 2012, pelo menos 9 deles introduziram alguma inovação que possa ser considerada drástica. Dentre esses sites, o autor cita como exemplo de inovações drásticas os mecanismos de PageRank da Google, o Social Graph e as Business Pages do Facebook, o sistema de recomendações da Amazon, e o sistema de feedback do comprador introduzido pelo Ebay. ${ }^{375}$

Uma discussão recente que ainda enfrenta intenso debate se relaciona ao estabelecimento de regras de neutralidade de rede no âmbito da Internet. Segundo seus defensores, a manutenção destas regras, com ausência de cobrança de tarifas diferenciadas, permite a manutenção deste ambiente de inovação e intensa experimentação, com a elevada alternância de players e surgimento de novos serviços. Ou seja, ambiente que caracterizou a Internet desde sua criação. ${ }^{376}$ Por outro lado, seus críticos afirmam que o estabelecimento de regras de neutralidade ex-ante impedem que sejam realizados os investimentos necessários para os desenvolvimentos das estruturas de redes que permitirão

antitrust case against Google, In Harvard journal of law and technology occasional paper series, July, 2013, disponível em: http://bit.ly/1FCV4Ce, Acesso no dia 25, jun. 2015, p. 14.)

374 Conforme aponta DAVID S. EVANS, no período entre janeiro e julho de 2012, dentre os 15.000 sites com maior número de acessos $26 \%$ foram substituídos por novos sites nesse período de apenas 6 meses (DAVID S. EVANS, Attention rivalry among online platforms, In Journal of Competition Law \& Economics, 9 (2), 2013, pp. 325-328

375 DAVID S. EVANS, Attention rivalry among online platforms, In Journal of Competition Law \& Economics, 9 (2), 2013, pp. 334-336.

376 Dentre inúmeros outros podemos apontar autores como BARBARA VAN SCHEWICK e LAWRENCE LESSIG como defensores da neutralidade de rede. Para mais informações vide: BARBARA VAN SCHEWICK, Internet archtecture and innovation, Massachussets, MIT Press, 2010; MARK A. LEMLEY; LAWRENCE LESSIG, The end of end-to-end: Preserving the architecture of the Internet in the broadband era, In UCLA Law Review, n. 48, vol. 925, 2001. 
a continuidade dos ganhos de velocidade e eficiência do sistema, bem como podem impedir o surgimento de novos serviços que necessitem de bandas de conexão elevadas. Para alguns a solução estaria no tratamento de abusos por meio da autoridade antitruste ou por meio do incentivo à inovação por parte de políticas públicas estatais. ${ }^{377}$

Uma discussão relacionada a da neutralidade de rede é a da neutralidade de buscas, ou seja a obrigação de ausência de imposição de bias nos resultados de busca. Diversas críticas foram dirigidas à empresa Google pelo fato dela liderar a ofensiva a favor da neutralidade de rede, sendo, no entanto, contrária a qualquer estabelecimento de regra de neutralidade de buscas. O que devemos notar é que tratam-se de princípios aplicados sobre camadas distintas, uma vez que a neutralidade de rede busca garantir a ausência de bias sobre a camada física da Internet, ao passo que a neutralidade de buscas tem como intuito interferir sobre a camada do conteúdo. Deve-se notar que os impactos sobre o sistema das duas camadas são distintos, sendo que, conforme veremos, a aplicabilidade de princípio de neutralidade de buscas se mostra de difícil aplicação. A ausência de bias nos mecanismos de buscas se mostra impossível, uma vez que decisão sobre o design de qualquer sistema de buscas necessariamente envolve valores normativos. ${ }^{378}$

\footnotetext{
377 Dentre os críticos em relação ao estabelecimento de regras de neutralidade de rede ex-ante podemos citar autores como CHRISTOPHER S. YOO e JOSHUA WRIGHT. (CHRISTOPHER S. YOO, Beyond network neutrality, In Harvard Journal of Law \& Technology, Vol. 19, N. 1, 2005; JOSHUA WRIGHT, Broadband policy \& consumer welfare: The case for an antitrust approach to net neutrality issues, disponível em: http://1.usa.gov/1WHeOUb, acesso no dia 8, nov., 2015).

378 ERIC GOLDMAN, Revisiting search engine bias, In William Mitchell Law Review, Vol. 38, n. 1, 2011, pp. 106-107
} 


\section{CAPÍTULO III - CONDUTAS ANTICOMPETITIVAS EM SETORES "PONTOCOM"}

A intervenção antitruste, especialmente no sistema norte-americano, baseou-se originalmente na fragmentação do poder dos monopólios com o fim de evitar captura no processo legislativo. As influências da Escola de Chicago, especialmente da visão de ROBERT BORK, deslocaram o antitruste para a concepção de que o único monopólio que deveria ser sancionado é aquele obtido por meios ilegítimos. ${ }^{379}$ Dessa forma, desenvolveram-se diversas metodologias para avaliação desse postulado. $O$ grande problema ocorre quando lançamos a metodologia de controle post-hoc, baseada em modelos econométricos, em setores nos quais os negócios são implementados por complexos algoritmos, com inúmeras linhas de código não disponíveis ao conhecimento do público, como nos mercados de Internet. Nessa situação, por conta das características já analisadas, as conclusões podem apresentar resultados equivocados. ${ }^{380}$

Diante das particularidades dos setores pontocom, surgem algumas dúvidas no tocante à aplicação da doutrina antitruste tradicional na análise destes mercados. A combinação de efeitos indiretos de rede, mercados de múltiplos lados e de preço zero, com a distinta natureza da competição nestes setores, com níveis elevados de inovação e rápida mudança tecnológica, resulta em problemas para a análise concorrencial. ${ }^{381}$

Por se tratar de mercado de múltiplos lados, a aplicação da metodologia tradicional, desenhada para lidar com mercados com um único lado, nem sempre é adequada. Da mesma forma, os primeiros modelos baseados em indústrias de rede são insuficientes por conta dos problemas supra-mencionados de diferenciação de produtos e do fenômeno de multi-homing. Por essa razão, diversas condutas, quando analisadas segundo tal

$379 \quad$ Vide ROBERT BORK, The antitrust paradox: A policy at war with itself, New York, Free Press, 1993.

380 FRANK PASQUALE, Paradoxes of digital antitrust: Why the FTC failed to explain its inaction on search bias, In Harvard journal of law and technology occasional paper series, July, 2013, disponível em: http://bit.ly/1FbNQVJ, Acesso em 11, jun. 2015, p. 10.

381 GEOFFREY A. MANNE; JOSHUA D. WRIGHT, Google and the limits of antitrust: The case against the case against Google, In Harvard Journal of Law \& Public Policy, vol. 34, disponível em: http://bit.ly/1hHH4TR, acesso em 17, ago., 2015. 
metodologia, não suscitariam preocupação concorrencial, uma vez que seriam consideradas carecedoras de racionalidade econômica. Por outro lado, a análise das condutas sob o contexto em que estes mercados se inserem, e considerando os múltiplos lados envolvidos, poderia levar a uma conclusão completamente diferente. A aplicação de conceitos tradicionais como o mercado relevante, sem considerar as particularidades dos setores pontocom, como a noção de "competição por atenção", podem levar a aplicação desastrosa de medidas interventivas.

Por conta destas características, as autoridades concorrenciais vem enfrentando dificuldades na distinção entre o que seriam condutas pró-competitivas e anticompetitivas nestes novos mercados. As reais dimensões dessas questões serão apresentadas apenas nos próximos anos, com a evolução do ecossistema web, porém, DAVID S. EVANS levantou algumas tendências que suscitariam particular preocupação: (i) a emergência de monopólios indestrutíveis; (ii) alavancagem de poder de mercado sobre mercados adjacentes; (iii) questões envolvendo acesso à plataformas e direitos de propriedade intelectual relacionados à questão das compatibilidades; (iv) questões envolvendo vendas casadas; e (v) predação e exclusão de concorrentes. ${ }^{382}$

O fato é que o instrumental de análise antitruste se desenvolveu em uma economia baseada na produção de recursos naturais e de bens manufaturados, na qual os produtos são largamente homogêneos e sujeitos a produção em larga escala; as barreiras à entrada consistem basicamente em capital e tempo; e as firmas competem basicamente na definição de preços e quantidades. Assim, o desenvolvimento de ferramental econômico baseado na chamada "price-theory" se mostrava adequado para análise destes setores. No entanto, esta realidade se modifica completamente com as inovações baseadas em computação digital e sistemas em rede, que levam ao surgimento de estruturas econômicas muito mais complexas, com diferenciação de produtos e de estratégias competitivas distintas. $^{383}$

Um marco deste novo período, consequência direta da revolução digital, se encontra no crescimento de modelos baseados em oferecimento de bens e serviços a preços iguais a zero. Nesse contexto, o ferramental baseado em teoria dos preços desloca a

382 DAVID S. EVANS, Antitrust issues raised by the emerging global internet economy, In Northwestern University Law Review, vol. 102, n.4, 2008, pp. 16-20.

383 JOHN M. NEWMAN, Antitrust in zero-price markets: Foundations, In University of Pennsylvania Law Review, Vol. 164, disponível em: http://bit.ly/1jEUMaX, acesso no dia 15, out., 2015, pp. 44-45. 
atenção para um tipo de competição que não mais existe. Conforme veremos, esta nova perspectiva questiona, inclusive, a necessidade de intervenção antitruste sobre estes setores.

\section{$\underline{\text { III.1 - Intervencão antitruste sobre mercados de preco zero }}$}

A análise de cunho neoclássica com enfoque sobre preços colocou em dúvida a aplicabilidade do direito concorrencial sobre os mercados em que os serviços são oferecidos sem a cobrança de qualquer valor monetário do consumidor. Segundo o Sherman Act norte-americano, suas normas se aplicariam apenas sobre relações de "trade or commerce". A definição de quais atividades se enquadrariam nesses termos tornou-se objeto de intenso debate ao longo dos anos, e uma definição recente estabeleceu que commerce consiste em qualquer atividade na qual alguém possa antecipar ganho econômico. Dessa forma, as transações envolvem necessariamente trocas de bens que tenham valor para os agentes. ${ }^{384}$

Essa interpretação levou alguns analistas a entenderem que, na ausência de preços, não haveria possibilidade de prejuízo ao bem estar social: se os consumidores não pagam qualquer valor monetário, não existe cobrança de preços de monopólio, ${ }^{385}$ e, por isso, não há motivo para intervenção concorrencial em setores de preço zero. Alguns, inclusive, chegaram a afirmar que se o produto é obtido por preço igual a zero, não há venda e tampouco há mercado, razão pela qual não é possível instaurar uma investigação antitruste. Diversos precedentes das cortes norte-americanas sustentam este argumento, que foi central no caso KinderStart ${ }^{386}$, no qual uma empresa de pesquisa de preços acusava a Google de manipular os resultados para manter sua posição no mercado. Neste caso, a corte americana entendeu que o mercado de buscas não seria caracterizado pela venda de serviços, porque o usuário não paga nenhum preço. Assim, não havendo preços ou

384 JOHN M. NEWMAN, Antitrust in zero-price markets: Foundations, In University of Pennsylvania Law Review, Vol. 164, disponível em: http://bit.ly/1jEUMaX, acesso no dia 15, out., 2015, p. 10.

385 Conforme aponta DAVID S. EVANS, segundo este raciocínio: "If a product, by its nature, is free, then there is no concern that business practices will result in consumers paying a higher price for the product. Without the prospect of consumer harm, there is no reason to care about that product." (DAVID S. EVANS, The antitrust economics of free, Disponível em: http://bit.ly/1GhLjB0, acesso no dia 21, out., 2015, p. 12). 
mercado, o direito antitruste não poderia ser aplicado. ${ }^{387}$ Alguns teóricos, como ROBERT BORK e JOSHUA WRIGHT, sustentam posição semelhante ao defenderem que a ausência de preços implica a impossibilidade de monopolização ou de preços de monopólio. ${ }^{388}$

No entanto, estas conclusões devem ser analisadas com cautela, pois a ausência de custos monetários não corresponde à ausência de trocas nestas relações. Ainda que o preço seja igual a zero, os usuários incorrem em diferentes tipos de custos para terem acesso a estes serviços. ${ }^{389-390}$ Em alguns casos, estes custos são classificados como non-market signaling costs, e não seriam objeto do direito antitruste por não sinalizarem a existência de um mercado, ao passo que outros custos são classificados como market signaling costs (custos de sinalização de mercado), exercendo papel semelhante ao do dinheiro em outras transações. $^{391}$

Custos de oportunidade são exemplos de custos classificados como não sinalizáveis, uma vez que não podem ser transacionados. Nesse caso, a ausência de trocas no sentido relevante para o direito antitruste faz com que destas relações não surja um mercado. $^{392}$

Por outro lado, alguns custos podem ser classificados como custos de sinalização por apontarem a ocorrência de trocas e, consequentemente, a existência de mercado. Os

387 JOHN M. NEWMAN, Antitrust in zero-price markets: Foundations, In University of Pennsylvania Law Review, Vol. 164, disponível em: http://bit.ly/1jEUMaX, acesso no dia 15, out., 2015, pp. 11-12.

388 Conforme aponta BORK e SIDAK:“ A more general tying analysis is therefore irrelevant: with consumers paying a price of zero, there is no risk of Google using monopoly power in general search to charge a higher price to consumers in specialized search. Both are free to consumers." (ROBERT BORK; J. GREGORY SIDAK, What does the Chicago School Teach about Internet Search?, In Journal of Competition Law \& Economics, vol. 8, n. 4, 2012, p. 676).

389 Conforme aponta DAVID S. EVANS, "Price is only one dimension of competition" (DAVID S. EVANS, The antitrust economics of free, Disponível em: http://bit.ly/1GhLjB0, acesso no dia 21, out., 2015, p. 12).

$390 \quad$ "Free online products remain free only if the firm does not transfer the cost or risk of recouping cost to the consumer." e continuam os autores: "When a consumer can sample a product without the obligation to disclose personal information to the firm and without concern that the firm will track the consumer's behavior, then the interests of the firm are more closely aligned with ex ante interests of consumers" (CHRIS JAY HOOFNAGLE; JAN WHITTINGTON, Free - Accounting for the costs of the Internet's most popular price, In UCLA Law Review, n. 61, vol. 3, 2014, p. 625).

391 JOHN M. NEWMAN, Antitrust in zero-price markets: Foundations, In University of Pennsylvania Law Review, Vol. 164, disponível em: http://bit.ly/1jEUMaX, acesso no dia 15, out., 2015, pp. 12-13.

392 JOHN M. NEWMAN, Antitrust in zero-price markets: Foundations, In University of Pennsylvania Law Review, Vol. 164, disponível em: http://bit.ly/1jEUMaX, acesso no dia 15, out., 2015, pp. 13-14. 
dois custos não monetários de sinalização mais relevantes para os mercados de preço zero são a informação e os custos de atenção.

A informação, especialmente a informação do consumidor, ganha papel central em empresas dos setores pontocom. A elevada capacidade de obtenção e armazenamento de informação faz com que estes dados se transformem em um valioso bem de troca, e passem a ser utilizados pelas empresas e anunciantes de forma estratégica, como input de produção ou para oferecimento de anúncios direcionados aos consumidores. Além disso, na medida em que os consumidores podem fornecer suas informações pessoais em troca de serviços oferecidos pelas empresas, esses dados passam a cumprir a função de sinalização de mercado. ${ }^{393-394}$

Diversos serviços prestados por empresas pontocom se baseiam neste modelo de negócios em que os usuários compartilham determinadas informações e permitem o rastreamento de seu comportamento em troca da prestação de serviços de forma gratuita. ${ }^{395}$ A Google, por exemplo, oferece um serviço de busca de páginas na web em troca das informações oferecidas pelo usuário e que serão utilizadas para a exibição de anúncios direcionados. Em alguns casos, as informações dos usuários são o próprio produto oferecido pelo site. ${ }^{396}$ No caso das redes sociais, como o Facebook e o LinkedIn, as informações pessoais que os usuários inserem em suas plataformas são o principal produto oferecido pelas empresas. ${ }^{397}$

393 JOHN M. NEWMAN, Antitrust in zero-price markets: Foundations, In University of Pennsylvania Law Review, Vol. 164, disponível em: http://bit.ly/1jEUMaX, acesso no dia 15, out., 2015, pp. 15-16.

394 "One's personal information is, in the transaction cost economic sense, an asset unique to each consumer; consumers are therefore in bilateral dependent trading relations with the firms that obtain this information" (CHRIS JAY HOOFNAGLE; JAN WHITTINGTON, Free - Accounting for the costs of the Internet's most popular price, In UCLA Law Review, n. 61, vol. 3, 2014, p. 625).

395 "For some firms, the collection and monetization of data from and about consumers in exchange for purportedly free services is the core business proposition. These business models demonstrate the extent to which firms value, just as any other asset, the personal information they collect from or about each consumer, especially when the consumer is a free rider." (CHRIS JAY HOOFNAGLE; JAN WHITTINGTON, Free Accounting for the costs of the Internet's most popular price, In UCLA Law Review, n. 61, vol. 3, 2014, p. 626).

396 Essa modalidade de produção de conhecimento recebe o nome de formas colaborativas de produção do conhecimento, sendo característica marcante da Web 2.0. Segundo conceito popularizado por TIM O'REILLY e DALE DOUGHERTY, em 2004, tal termo se refere à tendência de ênfase na produção de conteúdo gerado pelo usuário, pela interoperabilidade e usabilidade da web.

397 CHRIS JAY HOOFNAGLE; JAN WHITTINGTON, Free - Accounting for the costs of the Internet's most popular price, In UCLA Law Review, n. 61, vol. 3, 2014, p. 628. 
Nestas transações, portanto, a informação desempenha papel semelhante ao da moeda, sendo ao mesmo tempo um custo para os consumidores e um meio de troca. ${ }^{398}$ Dessa forma, neste tipo de relação em que um consumidor troca suas informações por um serviço prestado a um preço zero, ambas as partes se beneficiam da transação, gerando os ganhos econômicos necessários para a caracterização de mercado, e enquadrando tais transações dentro da definição de trade ou commerce da lei antitruste norte-americana. ${ }^{399}$ Não faz sentido, portanto, falarmos que nessas relações não há compra e venda, uma vez que, mesmo com o preço igual a zero, os produtores ainda devem tomar decisões sobre fatores competitivos como nível de produção.

Nesse ponto surgem preocupações por conta da assimetria informacional e das estruturas de governança presentes nestas transações. Conforme observamos no Capítulo II, a racionalidade limitada e as profundas assimetrias informacionais presentes nessas relações fazem com que o consumidor se sujeite às decisões tomadas pela firma envolvendo suas informações pessoais, obtidas através da plataforma. O consumidor se sujeita, inclusive, a diversos riscos decorrentes dessas trocas, como a possibilidade de furto de seus dados pessoais, como senhas e números de cartão de crédito. Da mesma forma, o aumento dos custos de informação do consumidor levam também ao aumento dos seus custos de atenção, porque as empresas se valem dessas informações pessoais para oferecerem anúncios direcionados. ${ }^{400}$

Os custos de atenção, por sua vez, decorrem do tempo e da atenção despendida pelos usuários para ver ou ouvir um anúncio comercial. A publicidade ganha papel central em diversos modelos de negócios de setores pontocom como nos mercados de múltiplos lados sustentados por anúncios publicitários e no modelo de oferecimento de serviços premium pagos. ${ }^{401}$ Uma das principais plataformas baseadas nesse modelo são os sistemas

\footnotetext{
398 Conforme a concepção de CARL MENGER a moeda surge como fenômeno inerente à condição social, ou seja, não derivada de qualquer convenção social ou imposição legal, mas de necessidades e interesses privados. Tradicionalmente apontam-se como as principais funções da moeda a de funcionar como meio de troca, unidade de conta e reserve de valor (CARL MENGER, On the origins of money, Ludwig von Mises Institute, disponível em: http://bit.ly/1QLweLz, acesso no dia 23, dez., 2015).
}

399 JOHN M. NEWMAN, Antitrust in zero-price markets: Foundations, In University of Pennsylvania Law Review, Vol. 164, disponível em: http://bit.ly/1jEUMaX, acesso no dia 15, out., 2015, pp. 16-17.

400 CHRIS JAY HOOFNAGLE; JAN WHITTINGTON, Free - Accounting for the costs of the Internet's most popular price, In UCLA Law Review, n. 61, vol. 3, 2014, p. 625.

401 JOHN M. NEWMAN, Antitrust in zero-price markets: Foundations, In University of Pennsylvania Law Review, Vol. 164, disponível em: http://bit.ly/1jEUMaX, acesso no dia 15, out., 2015, pp. 19-20. 
de buscas, como o caso do Google. Nessas plataformas, as companhias comercializam espaços publicitários em suas páginas de resultados de busca para anunciantes, a um valor geralmente estabelecido por sistema de leilão, como, por exemplo, no sistema AdWorks da Google..$^{402}$

Anúncios publicitários trazem consigo custos e benefícios ao consumidor. Ao mesmo tempo em que podem oferecer informações sobre o funcionamento e as qualidades dos produtos, auxiliando na decisão de consumo, os anúncios acabam também por consumir o tempo do usuário, ao desviar sua atenção de outras atividades. ${ }^{403}$ Nesse ponto uma importante diferenciação se faz entre os anúncios solicitados e os não solicitados.

Os anúncios são classificados como não solicitados quando são oferecidos sem que a pessoa seja previamente convidada ou quando não tem a sua expressa permissão. Dentre estes exemplos se incluem os spams e as ligações de telemarketing. De modo geral, estes anúncios impõem custos mas não geram qualquer benefício ao seu alvo, razão pela qual não podem ser classificados como custos de sinalização, uma vez que estas trocas não agregam qualquer valor ao usuário. Por conseguinte, estas relações não podem ser objeto de análise antitruste pois não se enquadram na categoria de comércio. ${ }^{404}$

Por outro lado, os anúncios são classificados como solicitados quando são oferecidos com expressa ou implícita solicitação, convite ou permissão. Nesse caso, o consumidor troca sua atenção por um produto ou serviço, como, por exemplo, o conteúdo de um site ou o serviço de busca de sites na Internet. Dessa forma, estes custos de atenção podem ser considerados custos de sinalização de mercado, uma vez que servem como moeda de troca entre o usuário e o fornecedor do serviço, gerando valor para ambas as partes. Por esse motivo, estes custos são objeto de análise antitruste. ${ }^{405}$

Neste cenário, verifica-se que a ocorrência de custos de informação e de atenção faz com que estes mercados não sejam livres de custos. Por isso, mostra-se equivocado

402 DAVID S. EVANS, The antitrust economics of free, Disponível em: http://bit.ly/1GhLjB0, acesso no dia 21, out., 2015, p. 14.

403 JOHN M. NEWMAN, Antitrust in zero-price markets: Foundations, In University of Pennsylvania Law Review, Vol. 164, disponível em: http://bit.ly/1jEUMaX, acesso no dia 15, out., 2015, pp. 19-20.

404 JOHN M. NEWMAN, Antitrust in zero-price markets: Foundations, In University of Pennsylvania Law Review, Vol. 164, disponível em: http://bit.ly/1jEUMaX, acesso no dia 15, out., 2015, pp. 20-21.

405 JOHN M. NEWMAN, Antitrust in zero-price markets: Foundations, In University of Pennsylvania Law Review, Vol. 164, disponível em: http://bit.ly/1jEUMaX, acesso no dia 15, out., 2015, pp.21-22. 
concluir que a ausência de custos implica a desnecessidade de intervenção antitruste. Sendo a função destes custos de sinalização semelhante a do dinheiro nestas relações de troca, sua ocorrência indica a existência de mercado.

Conforme veremos, a ausência de trocas monetárias em mercados com preço zero não os torna imunes à possibilidade de abuso de poder econômico ou de monopolização de mercados. A existência de custos não monetários de sinalização, como os custos de informação e de atenção, criam particularidades mas não tornam estes setores isentos da aplicação do direito concorrencial. ${ }^{406}$

\section{III.2 - Poder de mercado e delimitacão de mercado relevante nos setores pontocom}

Tradicionalmente, a mensuração da capacidade de uma empresa incorrer em práticas anticompetitivas passa pela definição de seu mercado relevante e de seu poder de mercado. O mercado relevante tem como objetivo identificar as limitações da oferta e demanda que importam para o poder de mercado, ao passo que a análise do poder de mercado tem como intuito verificar se as limitações impostas pelo mercado previnem a imposição de preços supra competitivos pelo agente dominante. ${ }^{407}$

Como afirmamos, mercados baseados em web possuem como característica a presença de efeitos de rede e o oferecimento de produtos a preços iguais a zero. Estes efeitos podem criar diversas barreiras à entrada, protegendo redes dominantes contra a competição, e levando ao aumento de seu poder de mercado. Por isso, muitos consideram que a problemática dos efeitos de rede pode auxiliar na manutenção de monopólios, criando barreiras às vezes insuperáveis. Restrições impostas por uma empresa com maior base instalada, seja através de contratos ou mesmo de outros mecanismos ${ }^{408}$, pode levar a

$406 \quad$ Por essa razão defende JOHN M. NEWMAN que: "Zero-price markets present opportunities for the creation, enhancement, or abuse of market power-precisely the evils that antitrust laws are intended to remedy." e continua o autor: "Conduct that raises costs or restricts output of zero-price products can harm welfare just as seriously as conduct that raises price or reduces output in other markets." (JOHN M. NEWMAN, Antitrust in zero-price markets: Foundations, In University of Pennsylvania Law Review, Vol. 164, disponível em: http://bit.ly/1jEUMaX, acesso no dia 15, out., 2015, pp.23-24).

407 Conforme aponta HOVENKAMP, a definição clássica de poder de mercado consiste na: "ability of a firm to increase its profits by reducing output and charging more than a competitive price for its product" (HERBERT HOVENKAMP, Federal antitrust policy, $2^{\text {nd }}$ ed., St. Paul, West Group, 1999, p. 78).

408 Pode-se citar como exemplo a prática conhecida como "vaporware", que consiste na estratégia de anunciar o lançamento de um produto muito tempo antes e seu efetivo lançamento. Com isso busca-se postergar a decisão de compra do consumidor, uma vez que este ficará receoso de comprar produtos do 
uma redução brutal da participação de mercado de seus concorrentes, ou, então, à impossibilidade de contestabilidade de seu domínio. ${ }^{409}$ Por esta razão, em muitas situações, a rede dominante decide pela criação de incompatibilidades entre sua rede e a dos concorrentes como estratégia para criação de poder de mercado.

O oferecimento de diversos serviços a preço zero, por sua vez, cria uma estrutura de mercado particular. Nestes setores, empresas agindo de modo racional trocam produtos a preço zero pela atenção ou por informações do consumidor. Tal fato poderia erroneamente apontar para a não necessidade de qualquer intervenção estatal, uma vez que a ausência de preços impossibilitaria o abuso de poder econômico. Conforme veremos, a ausência de concorrência poderia permitir que o agente exigisse altos custos de atenção ou de informação, reduzindo output e gerando deadweight loss similar a um agente monopolista num setor tradicional. Da mesma forma, práticas relacionadas a produtos de preço-zero poderiam ter efeitos diretos sobre o mercado responsável pelo subsídio do produto oferecido gratuitamente. ${ }^{410}$

\section{III.2.1 - Delimitação do mercado relevante}

A delimitação do mercado relevante constitui importante medida para a identificação das restrições competitivas enfrentadas pela empresa. Conforme veremos, os novos setores de Internet apresentam diversos desafios à análise tradicional do poder de mercado e do mercado relevante, por conta da sua natureza altamente dinâmica e das

concorrente que podem se tornar obsoletos ou ultrapassados em pouco tempo. (CARL SHAPIRO, Antitrust in network industries, disponível em http://1.usa.gov/1kDLjkC, acesso no dia 8, nov., 2015, 1996, p. 15).

\footnotetext{
409 Tradicionalmente, cita-se o exemplo do caso Microsoft como paradigmático dessa situação. A empresa utilizou-se de uma série de artifícios para impedir que qualquer ameaça surgisse e pudesse questionar seu predomínio. Dentre suas estratégias, destacam-se os contratos de exclusividade firmados entre a empresa e os principais fabricantes de computador, pelos quais esta exigia que fosse instalado exclusivamente seu sistema operacional nos computadores vendidos. Para mais informações sobre o assunto, vide LEANDRO SAITO, A “propriedade" intelectual como barreira à entrada de novos players no mercado de softwares, IBPI, 2012, disponível em: http://bit.ly/1MQEGIp, acesso no dia 8, nov., 2015, Tais práticas foram também utilizadas no caso Nintendo. Neste caso, a empresa adquiriu posição dominante por conta da superioridade de seu produto e de suas estratégias de marketing. Porém, com o objetivo de manter esta posição e impedir a entrada da concorrência em seu mercado, a empresa passou se utilizar de contratos de exclusividade com os fabricantes de jogos, de modo que estes só poderiam desenvolver jogos para sua plataforma sob a condição de que não seria lançado o mesmo produto para as plataformas concorrentes. (CARL SHAPIRO, Antitrust in network industries, disponível em http://1.usa.gov/1kDLjkC, acesso no dia 8, nov., 2015, 1996, pp. 18-19).
}

410 DAVID S. EVANS, The antitrust economics of free, Disponível em: http://bit.ly/1GhLjB0, acesso no dia 21, out., 2015, p. 17. 
fronteiras muito mais fluidas entre mercados distintos. ${ }^{411}$ Estas características fazem com que a metodologia aplicada para estas definições deva ser adaptada, com o objetivo de deslocar a delimitação com enfoque no produto ou serviço oferecido, para um enfoque mais condizente com a nova realidade desses mercados. Do mesmo modo, o próprio conceito de mercado relevante acaba perdendo importância nos processos de análise antitruste, sendo, inclusive, sua aplicabilidade questionada por importantes analistas. ${ }^{412}$

O principal propósito da delimitação do mercado relevante consiste na identificação das restrições competitivas do fornecedor do produto, ou seja, de todas as forças de mercado que tem a capacidade de impedir uma firma de aumentar preços ou de diminuir a qualidade do produto. A força destas restrições é que determinará a possibilidade de haver prejuízos para a competição ou para os consumidores. Este processo guarda relação muito próxima com a mensuração do poder de mercado, uma vez que constitui o primeiro passo para determinação do grau de poder de mercado que um produtor possui. ${ }^{413}$

Conforme observamos no CAPÍTULO I, a metodologia tradicional passa por duas etapas: na primeira se estabelecem os mercados relevantes geográfico e do produto, para em seguida se verificarem as participações (market shares) detidas por cada uma das empresas pertencentes àquele mercado. ${ }^{414} \mathrm{O}$ mercado relevante geográfico identificará $\mathrm{o}$ espaço em que se travam as relações de concorrência, e sua abrangência dependerá da localização, da natureza do produto, bem como da conduta que está sendo analisada. A delimitação do mercado leva em consideração dois elementos: os substitutos do lado da oferta e da demanda. O mercado relevante material, ou do produto, por sua vez, considera o bem ou serviço oferecido pela empresa, bem como seus substitutos. ${ }^{415}$

411 DAVID S. EVANS, ELISA V. MARISCAL, Market Definition Analysis in Latin America with Applications to Internet-Based Industries, disponível em: http://bit.ly/1Qkz0He, 2013, acesso no dia 12, nov., 2015, p. 2.

412 Dentre eles podemos destacar LOUIS KAPLOW, Why (ever) define markets?, In Harvard Law Review, Vol. 124, n. 2, 2010.

413 Conforme aponta KAPLOW, a análise tradicional envolve o paradigma do market definition/market share, sendo o primeiro passo a delimitação do Mercado relevante (LOUIS KAPLOW, Why (ever) define markets?, In Harvard Law Review, Vol. 124, n. 2, 2010, p. 441).

414 Conforme aponta CALIXTO SALOMÃO FILHO, no caso da lei brasileira, a definição do Mercado relevante constitui medida do poder existente, para apuração de abuso de poder e para mensuração de poder futuro (CALIXTO SALOMÃO FILHO, Direito concorrencial, São Paulo, Malheiros, 2013, pp. 155-156).

415 PAUlA A. FORGIONI, Os fundamentos do antitruste, 6. Ed., São Paulo, Revista dos Tribunais, pp. 214-219. 
A definição do mercado relevante, portanto, passa pela análise dos eventuais substitutos do produto. O processo se inicia com os produtos considerados homogêneos, passando, em seguida, a considerar a possibilidade de ampliação de sua definição ao incluir os supostos substitutos deste produto (ou outras regiões no caso de mercado relevante geográfico). Nesse ponto, um dos principais testes consiste no SSNIP, ou Teste do Monopolista Hipotético, que procura definir o menor grupo de produtos no qual um suposto monopolista poderia manter seu preço acima do nível competitivo por um período significativo de tempo. ${ }^{416}$ Uma vez delimitada sua abrangência, podem, então, ser medidos os Market Shares dessas empresas (fatias de mercado), inferindo-se desses dados o nível do poder de mercado da empresa. ${ }^{417}$

Esta delimitação se mostra importante na análise de condutas unilaterais, na medida em que permite determinar a extensão do poder do suposto monopolista e a dinâmica do mercado em análise. Sem a definição de quem seriam os reais competidores de uma determinada empresa, não é possível apurar sua capacidade de reduzir o volume de produção ou de forçar a redução por parte dos concorrentes. Além disso, não é possível estabelecer os fornecedores e os canais de distribuição disponíveis para os concorrentes. ${ }^{418}$ A definição dessas fronteiras em geral contribui de forma determinante para o resultado da análise. $^{419}$

No entanto, inúmeras críticas surgem com relação à aplicabilidade desta metodologia, especialmente em relação aos novos setores da Internet. KAPLOW, por exemplo, sustenta que esta metodologia deveria ser completamente abandonada, uma vez

416 Conforme aponta LEONOR CORDOVIL, a definição trazida pela Lei 8.884/94 se encontrava envolta em polêmicas, sendo que sua interpretação ocorreu com a Resolução CADE 20/1999. Esta resolução acaba sugerindo o uso do SSNIP para delimitação dos mercados relevantes em análise (LEONOR CORDOVIL, Nova Lei de defesa da concorrência comentada, São Paulo, Revista dos Tribunais, 2011, p. 106.

417 LOUIS KAPLOW, Why (ever) define markets?, In Harvard Law Review, Vol. 124, n. 2, 2010, p. 439.

418 GEOFFREY A. MANNE; WILLIAM RINEHART, The market realities that undermined the FTC's antitrust case against Google, In Harvard journal of law and technology occasional paper series, July, 2013, disponível em: http://bit.ly/1FCV4Ce, Acesso em 25, jun. 2015, pp. 7-8.

419 Conforme aponta DAVID S. EVANS: "The placement of this fence often determines the final outcome of the matter. As a result, market definition sets up a battle between the - we-win because it is a narrow market plaintiffs and the - you-lose because it is a broad market defendants. Both sides naturally invest significant resources in trying to persuade the courts where to build the fence." (DAVID S. EVANS, Lightening Up on Market Definition, 2010, disponível em: http://bit.ly/1P15q44, acesso no dia 9, nov., 2015, p. 3). 
que não há método coerente para se delimitar um mercado relevante sem que antes se infira o poder de mercado da empresa. Sendo o principal objetivo da delimitação do mercado relevante o de inferir o poder de mercado, tal análise perderia seu sentido. ${ }^{420}$

Um primeiro equívoco dessa metodologia diz respeito à relação funcional estabelecida entre market share e poder de mercado. De um modo geral, entende-se que quando uma firma com grande market share decide agir de modo anticompetitivo, seus concorrentes, com baixa fatia de mercado, não poderão responder às condutas do monopolista, uma vez que estarão limitadas pelo seu tamanho. Tal relação se sustenta apenas sob determinadas condições, sendo a principal delas a assunção de bens homogêneos. Por isso, a relação raramente pode ser comprovada na prática. ${ }^{421}$

No caso dos novos setores de Internet, esse problema se mostra ainda maior, uma vez que o principal produto comercializado é a informação, que pode ter seu volume de produção rapidamente aumentado, inclusive por players com menor market share. No caso dos buscadores de Internet, por exemplo, condutas anticompetitivas por parte da Google poderiam levar os consumidores a rapidamente migrarem para concorrentes, sendo a única limitação para estes players menores a capacidade de seus servidores de Internet suportarem o aumento do número de usuários. É por essa razão que no caso dos setores de Internet o market share constitui um proxy ainda pior. ${ }^{422}$

Um segundo equívoco metodológico se encontra na impossibilidade de delimitação do mercado relevante sem uma estimativa prévia do poder de mercado. ${ }^{423} \mathrm{O}$ problema é que não existe um método específico e preciso para se obter esta estimativa, da mesma forma que não há parâmetro para se determinar se o resultado obtido foi o melhor possível. Estas estimativas podem ser obtidas por meio de técnicas econométricas aplicadas sobre dados de alta qualidade, por meio de experimentos, entrevistas sofisticadas com

${ }_{420}$ LOUIS KAPLOW, Why (ever) define markets?, In Harvard Law Review, Vol. 124, n. 2, 2010, p. 440.

421 LOUIS KAPLOW, Market Definition and the Merger Guidelines, 2011, disponível em: http://bit.ly/1OrAQ5S, acesso no dia 25, nov., 2015, p. 5.

$422 \quad$ "Although expanding server capacity imposes some costs and takes some time, those limitations are small compared with, say, expansion of capacity in the production of the archetypal widget." (MARK R. PATTERSON, Google and search-engine market power, In Harvard Journal of Law \& Technology Occasional Paper Series, jul. 2013, disponível em: http://bit.ly/1kQ1VZw, acesso no dia 23, nov., 2015, p. 6).

$423 \quad$ "In sum, any coherent method of choosing a relevant market must take, as a preexisting input, some best estimate of market power" (LOUIS KAPLOW, Market Definition and the Merger Guidelines, 2011, disponível em: http://bit.ly/1OrAQ5S, acesso no dia 25, nov., 2015, p. 8). 
compradores ou documentos internos das firmas. Em geral, a análise envolve a combinação de alguns desses métodos e a sua qualidade dependerá em grande medida de fatores como o estágio da investigação, a natureza e a qualidade da informação envolvida. Deve ser ressaltado que, independentemente de tais fatores, a autoridade deverá em qualquer situação realizar uma estimativa. ${ }^{424}$

O grande problema dessas estimativas é que a possível supervalorização ou subvalorização do poder de mercado pode levar a uma conclusão jurídica equivocada. Ao supervalorizar o poder de mercado, a autoridade pode instaurar procedimento ou condenar a conduta de forma injusta, da mesma forma que ao subvalorizá-lo a autoridade pode subestimar a capacidade de efeitos anticompetitivos e desconsiderar uma conduta prejudicial. O ponto central para KAPLOW é que, em qualquer situação, a melhor escolha seria a de simplesmente ignorar o procedimento de market definition por completo. ${ }^{425}$

As inúmeras críticas a essa metodologia fizeram com que o FTC e o DOJ revisassem suas Horizontal Merger Guidelines, especialmente no tocante a metodologia para delimitação do mercado relevante e do poder de mercado. Uma das principais mudanças das Guidelines se refere à inclusão da possibilidade das agências aceitarem métodos alternativos para análise do impacto de fusões, considerando o uso de métodos como o de simulação de fusões ou o de critical loss analysis. Além disso, o guia sugere, inclusive, a possibilidade de substituição da delimitação de mercado por algum desses métodos. ${ }^{426}$ Nota-se que as Guidelines acabaram por incorporar parcialmente tais críticas, ao reconhecerem a possibilidade de substituir a delimitação do mercado por outros métodos.

424 LOUIS KAPLOW, Market Definition and the Merger Guidelines, 2011, disponível em: http://bit.ly/1OrAQ5S, acesso no dia 25, nov., 2015, pp. 8-9.

425 LOUIS KAPLOW, Market Definition and the Merger Guidelines, 2011, disponível em: http://bit.ly/1OrAQ5S, acesso no dia 25, nov., 2015, pp. 9-10. Ainda que apresentando algumas divergências metodológicas, RICHARD S. MARKOVITS apresenta conclusão semelhante ao afirmar que "no marketoriented approach should be used to measure a firm's market (economic) power and for the more important (broader) conclusion that no market-oriented approach to the determination of the legality of any type of business conduct under U.S. antitrust law can be acceptably accurate or cost-effective and (2) by providing the foundation for developing acceptably accurate and cost-effective non- market-oriented protocols for addressing the relevant legal issues." (RICHARD S. MARKOVITS, Why one should never define markets or use market-oriented approaches to analyze the legality of business conduct under U.S. antitrust law, University of Texas Law, Law and Econ Research Paper n. 228, disponível em: http://bit.ly/1Ngveba, acesso no dia 29, nov., 2015).

426 LOUIS KAPLOW, Market Definition and the Merger Guidelines, 2011, disponível em: http://bit.ly/1OrAQ5S, acesso no dia 25, nov., 2015, p. 2. 
A radicalidade da visão de KAPLOW, no entanto, enfrentou inúmeras críticas no meio acadêmico. Se, por um lado, os economistas concordam com a necessidade de uma mudança conceitual em direção à análise dos efeitos competitivos em detrimento do apego ao paradigma da definição de mercado, por outro lado, muitos consideram seu abandono completo uma abordagem muito radical.

Analisando as críticas de KAPLOW, GREGORY J. WERDEN realiza algumas observações. Em primeiro lugar, afirma que a presunção apontada por KAPLOW de que o único propósito da definição de mercado seria para que se inferisse poder de mercado a partir dos market shares seria equivocada. Conforme sustenta o autor, o delimitação do mercado ainda se mostra essencial para análise do poder de mercado, mesmo quando não se vale da divisão do market share. Além disso, as próprias cortes há tempos já vem reconhecendo a impossibilidade de relacionar altas fatias de mercado com poder de mercado sem que se analise a durabilidade do controle sobre o preço (que pode se manter, por exemplo, por conta de poderosas barreiras à entrada). É por essa razão que as condições de entrada e de saída do mercado são analisadas de forma conjunta. ${ }^{427}$

Além disso, conforme aponta WERDEN, a delimitação do mercado permite que se compreendam quais produtos poderiam ser classificados como substitutos próximos e que poderiam gerar pressão competitiva sobre a empresa. Dessa forma, a delimitação do mercado se mostra essencial nas análises antitruste com o objetivo de definir a área em que ocorre a efetiva competição. Ainda que um mercado definido pelo direito antitruste não seja isolado do restante da economia, as forças atuantes do lado de fora da delimitação do mercado constituem apenas um background para o processo competitivo que ocorre dentro do mercado. ${ }^{428}$

A adequação desta análise envolve sua complementação com a consideração de outros fatores como as restrições competitivas associadas às empresas analisada. A inferência de poder de mercado deve, portanto, considerar se estes fatores podem contribuir para o aumento ou diminuição do bem estar em um mercado. Os principais fatores que devem ser considerados são: (i) a substitutibilidade da demanda: a possibilidade dos consumidores migrarem para outros produtos; (ii) os custos de mudança:

427 GREGORY J. WERDEN, Why (ever) define markets? An answer to Professor Kaplow, 2012, disponível em: http://bit.ly/1106TAF, acesso no dia 29, nov., 2015, pp. 4-5.

428 GREGORY J. WERDEN, Why (ever) define markets? An answer to Professor Kaplow, 2012, disponível em: http://bit.ly/1106TAF, acesso no dia 29, nov., 2015, p. 5. 
os custos associados a mudança do consumidor para outro produto; (iii) multihoming: ou a capacidade do consumidor ter acesso simultâneo a diversas versões alternativas; (iv) substitutibilidade da oferta: a capacidade dos produtores aumentarem sua produção de modo a suprirem uma eventual substituição realizada pelos consumidores; (v) entrada de novos players: a possibilidade de novas empresas ingressarem nesse mercado; (vi) inovação: a rapidez das inovações incrementais ou drásticas permite o questionamento do poder de mercado ou cria pressões competitivas para que os agentes melhorem seus produtos; (vii) buyer power: os compradores do produto possuem poder de mercado sobre os fornecedores; (viii) produtos complementares: o fornecedor fabrica produtos complementares que poderiam ter redução da demanda ou da lucratividade no caso de aumento de preços; (ix) regulação: os limites estabelecidos pela regulação reduzem a capacidade de impor mudanças prejudiciais ao mercado. ${ }^{429}$

Uma segunda crítica dirigida à delimitação dos mercados relevantes consiste na criação de fronteiras rígidas entre mercados relevantes distintos. $\mathrm{O}$ enfoque tradicional vem sendo colocado em dúvida, uma vez que os novos setores vem demonstrando serem raros os mercados caracterizados por fronteiras rígidas. Da mesma forma, tais economistas sustentam que o estabelecimento destas fronteiras não se mostra essencial para a análise destes casos. $^{430}$

Segundo a metodologia tradicional, a análise passa por julgamentos informados mas subjetivos em relação ao grau de substitutibilidade de um produto do lado da demanda, ou em que medida estes tenham alto grau de elasticidade cruzada de preços. Da mesma forma, são analizadas as dificuldades e os custos para as empresas substituírem sua produção por produtos substitutos. Dentre os equívocos de análise podemos apontar o foco excessivo sobre os consumidores médios, que faz com que se ignorem os consumidores marginais, ou seja, aqueles que estão mais propensos a migrarem para uma opção substituta. Via de regra, o consumidor médio não irá optar pelo produto substituto diante de um aumento de preços. Dessa forma, a lucratividade de um aumento de preços dependerá da existência de consumidores marginais, ou seja, que estão dispostos a

429 DAVID S. EVANS, ELISA V. MARISCAL, Market Definition Analysis in Latin America with Applications to Internet-Based Industries, disponível em: http://bit.ly/1Qkz0He, 2013, acesso no dia 12, nov., 2015, p. 5.

430 DAVID S. EVANS, Lightening Up on Market Definition, 2010, disponível em: http://bit.ly/1Pl5q44, acesso no dia 9, nov., 2015, p. 3. 
migrarem para uma alternativa similar e não do comportamento dos consumidores médios. ${ }^{431}$ As distintas categorias de consumidores decorre da diferenciação de produtos, uma vez que o valor do produto para cada pessoa dependerá de características particulares. Deve-se lembrar que a homogeneidade de produtos não constitui a regra na maior parte dos mercados, por essa razão, a análise deve considerar a multidimensionalidade dos produtos. Ou seja, a decisão de consumo realizada pelo consumidor considera não apenas o preço, mas as qualidades, os serviços anexos e os bens complementares disponíveis para aqueles produtos. Por conta disso, faz-se necessário compreender o funcionamento da segmentação de mercado.

A heterogeneidade dos produtos tem como efeito a inadequação da definição de mercados relavantes distintos de forma rígida. ${ }^{432}$ Diferentemente do que preveem os livrostexto de economia, no mundo real poucos produtos e serviços são homogêneos. Os consumidores, da mesma forma, possuem preferências pessoais distintas entre si, dependendo de uma série de fatores, inclusive das circunstâncias do caso. Isso leva ao surgimento de diferentes nichos de mercado, como é o caso do mercado de cervejas especiais e cafés especiais. Por essa razão, no mundo real, dificilmente se encontram substitutos perfeitos para um determinado produto. No entanto, muitos produtos são substitutos imperfeitos para outros produtos, e, por essa razão, podem impor restrições competitivas ao agente econômico. ${ }^{433}$

Constitui, portanto, consenso entre analistas e tribunais que a delimitação de um mercado relevante varia de forma casuística. Além disso, as fronteiras que separam mercados relevantes distintos se mostram menos rígidas e mais fluidas do que possam parecer. Por essa razão, a tentativa de localizar froteiras rígidas separando estes mercado e

431 DAVID S. EVANS, ELISA V. MARISCAL, Market Definition Analysis in Latin America with Applications to Internet-Based Industries, disponível em: http://bit.ly/1Qkz0He, 2013, acesso no dia 12, nov., 2015, pp. 6-7.

432 DAVID S. EVANS, Lightening Up on Market Definition, 2010, disponível em: http://bit.ly/1Pl5q44, acesso no dia 9, nov., 2015, p. 5.

\footnotetext{
433 "Therefore, hardly anything is a perfect substitute for anything else. But many products are imperfect substitutes and these, individually or collectively, could constrain the ability of a firm to impose adverse conditions on consumers." (DAVID S. EVANS, ELISA V. MARISCAL, Market Definition Analysis in Latin America with Applications to Internet-Based Industries, disponível em: http://bit.ly/1Qkz0He, 2013, acesso no dia 12, nov., 2015, p. 8).
} 
calcular market shares não constitui um método muito confiável para determinar a extensão do poder de mercado. ${ }^{434}$

Um terceiro desvio em relação aos livros-texto de economia se encontra na impossibilidade das firmas operarem com preços iguais ao custo marginal. Conforme vimos no CAPÍTULO I, segundo a teoria neoclássica, o preço de equilíbrio que maximizaria o bem estar seria o custo marginal. O que se percebe, porém, é que a necessidade das empresas recuperarem os custos fixos associados à produção desses bens e serviços faz com que estas tenham de cobrar preços superiores ao custo marginal. ${ }^{435}$

A aplicação desta metodologia para mercados de múltiplos lados enfrenta sérios problemas, uma vez que, ao desconsiderar o feedback positivo gerado na demanda, pode-se chegar a um resultado sub ou superestimado com relação ao tamanho do mercado. A aplicação, por exemplo, do teste do monopolista hipotético considera os efeitos do aumento de preços apenas de um dos lados, partindo do pressuposto de que o outro lado permanece imutável. No entanto, nestes setores o aumento de preços de um dos lados acaba por influenciar a demanda do outro lado, que, da mesma forma, também influencia a demanda do outro lado. Isso pode levar a uma definição ou muito restrita ou muito abrangente do mercado relevante do produto. ${ }^{436}$

Em algumas situações, como na que os bens são consumidos em proporções fixas por ambos os lados, alguns autores defendem ser possível estimar um preço composto, que possibilitaria a aplicação do SSNIP, do índice de Lerner ou de outros métodos de delimitação do mercado relevante. Porém, o que se percebe é que tal situação se aplica em poucos casos, uma vez que na maior parte deles os bens não são consumidos em proporções fixas. ${ }^{437}$

Em setores com preço zero o descompasso é ainda maior. $\mathrm{O}$ enfoque excessivo na teoria dos preços faz com que o principal teste seja o já referido teste do monopolista 434 DAVID S. EVANS, Lightening Up on Market Definition, 2010, disponível em: http://bit.ly/1P15q44, acesso no dia 9, nov., 2015, p. 7.

435 DAVID S. EVANS, ELISA V. MARISCAL, Market Definition Analysis in Latin America with Applications to Internet-Based Industries, disponível em: http://bit.ly/1Qkz0He, 2013, acesso no dia 12, nov., 2015, pp. 8-9.

436 DAVID S. EVANS; RICHARD SCHMALENSEE, The antitrust analysis of multi-sided platform businesses, disponível em: http://bit.ly/1KhV5mT, acesso no dia 19, mai, 2015, pp. 21-22.

437 DAVID S. EVANS; RICHARD SCHMALENSEE, The antitrust analysis of multi-sided platform businesses, disponível em: http://bit.ly/1KhV5mT, acesso no dia 19, mai, 2015, pp. 21-22. 
hipotético $(S S N I P)^{438}$, em que se o define o tamanho de um mercado pela capacidade de um monopolista realizar um pequeno mas significativo aumento de preços. ${ }^{439}$ Geralmente se aplica como critério a capacidade de um monopolista hipotético impor um aumento de 5 a 10\% do preço como limiar para definição desse limite. Em uma situação que os preços são iguais a zero tal análise se mostra completamente descabida, uma vez que 5\% de zero é igual a zero, levando a uma delimitação extremamente restrita do mercado relevante. ${ }^{440} \mathrm{Da}$ mesma forma que a avaliação do poder de mercado como a capacidade de controlar preços perde o sentido.

Por tais razões, no caso dos setores pontocom surgem diversas questões que colocam em xeque a utilização dos conceitos tradicionais para delimitação destes mercados. Os problemas surgem quando a análise chega a conclusões baseadas em delimitação de mercado relevante sem considerar o poder de mercado ou por meio de uma análise superficial do poder de mercado. ${ }^{441}$ Podemos apontar alguns enfoques possíveis para as situações de serviços premium e gratuito, serviços gratuitos e pagos complementares e para plataformas de múltiplos lados.

No caso acima referido em que a empresa oferece um serviço gratuito e um serviço premium, superior e substituto, o uso do market share para delimitação de mercado apresenta algumas complicações. Ao mesmo tempo que o uso do valor de venda desconsidera os produtos gratuitos, o uso do volume de vendas desconsidera a diferença de qualidade dos dois produtos. Por essa razão, nessas situações, o uso de qualquer variável matemática se mostra inadequada, sendo necessária uma análise qualitativa. ${ }^{442}$

\footnotetext{
$438 \quad$ Segundo as Guidelines do sistema antitruste norte-americano, a definição de mercado passa pelo uso de dois mecanismos o teste do monopolista hipotético e o HHI, utilizado nos casos de fusões e aquisições para análise do nível de concentração pós operação (U.S. Department of Justice and the Federal Trade Commission Horizontal Merger Guidelines, disponível em: http://1.usa.gov/21jA9Tt, acesso no dia 27, nov., 2015).

439 Conforme aponta DAVID S. EVANS, "Zero prices result in conundrums and confusion in antitrust analysis. The SSNIP test becomes inoperable when the basic price is zero." (DAVID S. EVANS, The antitrust economics of free, Disponível em: http://bit.ly/1GhLjB0, acesso no dia 21, out., 2015, p. 2).

440 MICHAL S. GAL; DANIEL L. RUBINFELD, The hidden costs of free goods: Implications for Antitrust enforcement, New York University Law and Economics Working Papers, Disponível em: http://bit.ly/1Qg96Ds, acesso no dia 05, nov., 2015, p. 32.
}

441 DAVID S. EVANS, The antitrust economics of free, Disponível em: http://bit.ly/1GhLjB0, acesso no dia 21, out., 2015, p. 20.

442 DAVID S. EVANS, The antitrust economics of free, Disponível em: http://bit.ly/1GhLjB0, acesso no dia 21, out., 2015, p. 21. 
No caso dos produtos pago e gratuito complementares duas abordagens analíticas são possíveis. Uma primeira abordagem seria a de considerar os produtos pago e gratuitos complementares de forma conjunta, como parte de um ecossistema para delimitação do mercado. Uma segunda abordagem seria a de considerar o papel dos produtos complementares gratuito e pago na análise do poder de mercado. ${ }^{443}$

Abordagem semelhante deveria ser utilizada para modelos de plataformas de múltiplos lados. Dessa forma, deve-se considerar que a competição ocorre entre as diferentes plataformas de múltiplos lados, sendo o mercado formado pelas empresas presentes nos dois lados da plataforma que tragam alguma restrição competitiva. ${ }^{44}$ Por essa razão, a consideração de serviços específicos em mercados de múltiplos lados de forma isolada desconsidera as relações entre os dois lados bem como os efeitos de feedback. A avaliação deveria, portanto, considerar os efeitos de rede cruzados para definição dos limites do mercado. ${ }^{445}$

Outra abordagem adotada pela Comissão Européia para lidar com mercados de múltiplos lados é a de deslocar o foco para o mercado da plataforma em que ocorre seu faturamento, que, via de regra, é o de anúncios publicitários. Tal abordagem, porém, se mostra insuficiente nas situações em que a empresa pretende oferecer serviços gratuitos sem obter faturamento num primeiro momento, de modo a criar uma base relevante de usuários, para apenas posteriormente passar a obter faturamento de um dos lados da plataforma. $^{446}$

443 DAVID S. EVANS, The antitrust economics of free, Disponível em: http://bit.ly/1GhLjB0, acesso no dia 21, out., 2015, p. 21. No mesmo sentido MICHAL S. GAL e DANIEL L. RUBINFELD: "we suggest that with regard to bundled goods, the SSNIP test should be adjusted to take into account the fact that profits accrue in a companion market and that firms consider both products simultaneously in maximizing profit" (MICHAL S. GAL; DANIEL L. RUBINFELD, The hidden costs of free goods: Implications for Antitrust enforcement, New York University Law and Economics Working Papers, Disponível em: http://bit.ly/1Qg96Ds, acesso no dia 05, nov., 2015, p. 33).

444 DAVID S. EVANS, The antitrust economics of free, Disponível em: http://bit.ly/1GhLjB0, acesso no dia 21 , out., 2015, pp. 21-22.

445 MICHAL S. GAL; DANIEL L. RUBINFELD, The hidden costs of free goods: Implications for Antitrust enforcement, New York University Law and Economics Working Papers, Disponível em: http://bit.ly/1Qg96Ds, acesso no dia 05, nov., 2015, p. 33 .

446 MICHAL S. GAL; DANIEL L. RUBINFELD, The hidden costs of free goods: Implications for Antitrust enforcement, New York University Law and Economics Working Papers, Disponível em: http://bit.ly/1Qg96Ds, acesso no dia 05, nov., 2015, p. 35. 
O que se conclui destas observações de um modo geral é que o ferramental analítico tradicional para delimitação de mercado relevante e avaliação de poder de mercado cai por terra por uma razão puramente matemática: a multiplicação de valores por zero será sempre igual a zero. Por essa razão, o cálculo de um aumento de, por exemplo, 5\% para realização do teste do monopolista hipotético, seria igual a zero. Da mesma forma o uso de métodos como da medida do price-cost margin envolveria uma divisão por zero. $^{447}$

O caso Google se mostra paradigmático em relação a esse tema. Em primeiro lugar, a estrutura de preços com preço zero do lado dos consumidores inviabiliza o uso de todo ferramental de análise baseada em preços. Em segundo lugar, conforme veremos, a divisão baseada no produto oferecido desconsidera particularidades, como o alto grau de substitutibilidade dos serviços destes novos setores. É comum que se associe o mercado de atuação da empresa norte americana como sendo o de buscas online ou de anúncios em buscas online. Porém, o que se percebe é que esta definição se mostra muito restrita, uma vez que a natureza destes mercados faz com que diversas empresas que não atuam diretamente nesse setor acabam por desafiar diariamente o poder desta companhia.

No caso do buscador da Google, alguns defendem que o mercado relevante deveria considerar todos os serviços prestados pela empresa que se utilizam dos resultados de busca orgânica do buscador. Da mesma forma, a análise deveria considerar o custo e a demanda dos dois lados da plataforma. Para tanto, a análise se valeria de métodos tradicionais como o SSNIP, porém, seriam considerados o somatório dos preços cobrados nos dois lados da cadeia. ${ }^{448}$

Além desse enfoque, a alta substitutibilidade presente neste serviços tem levado outros autores a deslocarem o enfoque para a dimensão da atenção, sustentando, assim,

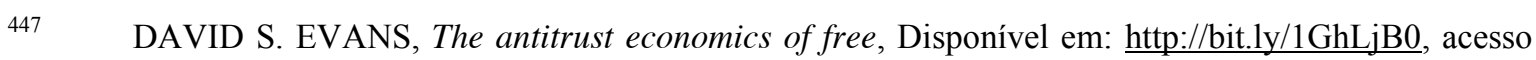
no dia 21, out., 2015, p. 22.

448 MICHAL S. GAL; DANIEL L. RUBINFELD, The hidden costs of free goods: Implications for Antitrust enforcement, New York University Law and Economics Working Papers, Disponível em: http://bit.ly/1Qg96Ds, acesso no dia 05, nov., 2015, pp. 26-27. 
uma abordagem de delimitação por "targeted eyeballs" 449 ou por "competição por atenção" ${ }^{450}$ para análise destes mercados.

\section{III.2.1.1 - Competição por atenção}

Uma característica marcante destes novos setores está no oferecimento de forma gratuita de diversos serviços por parte das empresas pontocom. ${ }^{451}$ Conforme já afirmamos, o financiamento destas atividades e sua lucratividade se encontram na possibilidade de venderem informações coletadas por suas plataformas, bem como os espaços em suas plataformas para anunciantes e outras empresas que desejam captar informação e veicular anúncios, de modo a atrair a atenção destes consumidores. É por esta razão que se afirma que estas empresas competem no fornecimento de atenção.

Os provedores de atenção da web se assemelham em grande medida às tradicionais plataformas de mídia, como os jornais e a televisão, em que as empresas fornecem entretenimento e informação em troca da comercialização dos espaços publicitários aos anunciantes. Porém, conforme já apontamos, a grande diferença destas novas empresas se encontra no fato destas estruturas se basearem em software, com enorme capacidade de customização e direcionamento dos anúncios veiculados. Dessa forma, enquanto revistas e jornais não podem oferecer anúncios direcionados a determinados clientes, redes sociais, como o Facebook, podem oferecer anúncios completamente personalizados aos usuários, com base em informações de navegação, dados pessoais informados e dos contatos do usuário. De forma semelhante, serviços de busca como o Google, tem a capacidade de oferecer anúncios direcionados com base nas pesquisas realizadas pelos usuários em sua plataforma de buscas. ${ }^{452}$

449 Conforme GEOFFREY A. MANNE; WILLIAM RINEHART, The market realities that undermined the FTC's antitrust case against Google, In Harvard journal of law and technology occasional paper series, July, 2013, disponível em: http://bit.ly/1FCV4Ce, Acesso em 25, jun. 2015, p. 8.

450 DAVID S. EVANS, Attention rivalry among online platforms, In Journal of Competition Law \& Economics, 9 (2), 2013, pp. 313-357.

451 Alguns autores como FEDERICO ETRO entendem que os serviços destas empresas não são fornecidos de forma gratuita, mas são antes o preço pago pela empresa para obter as informações dos usuários. FEDERICO ETRO, Leadership in Multisided Markets, University Ca' Foscari of Venice, Dept. of Economics Research Paper Series No. 19, disponível em: http://bit.ly/1PEcYMy, acesso em 21, ago., 2015.

452 DAVID S. EVANS, Attention rivalry among online platforms, In Journal of Competition Law \& Economics, 9 (2), 2013, pp. 338-339. 
Os tipos de anúncios veiculados por estas plataformas variam desde textos curtos até grandes imagens e vídeos, sendo a forma de remuneração também variável. Em alguns casos a remuneração ocorre pelo número de pessoas que visualizaram o anúncio, em outros casos ocorre pelo número de cliques nos anúncios. O conteúdo destes anúncios ocorre de forma direcionada, utilizando-se de complexos algoritmos inteligentes que buscam identificar e antecipar os desejos de consumo dos usuários. ${ }^{453}$ Em muitas situações, após o usuário clicar em algum produto ao navegar em um site, tal informação passa a ser utilizada pelos anunciantes de modo a oferecer anúncios desse produto ou de produtos relacionados em diversos outros sites que o usuário navegar por meio de sistemas como o AdWorks da Google.

Quando um anunciante decide investir em publicidade sua decisão se baseia prioritariamente entre uma relação de custo benefício entre os diferentes meios de mídia disponíveis. Para tanto estes vem se valendo de sofisticados softwares que analisam o retorno marginal do investimento entre os diferentes canais de publicidade. ${ }^{454}$ Nota-se, assim, que tais meios de divulgação são vistos pelos anunciantes como substitutos, possuindo altos graus de substitutibilidade. ${ }^{455}$

Dessa forma, a definição coloquial do mercado de empresas como o Google como mercado de buscas não encontra paralelo com a definição de mercado relevante para o direito concorrencial. Ao contrário do que se defende, a empresa não enfrenta concorrência apenas de outros buscadores web, mas de diversas fontes distintas. Segundo MANNE e RINEHART, o mercado em que o Google atua se relacionaria com todas as empresas que ofereçam alguma forma de serviço atrativo aos consumidores em troca do acesso a

453 DAVID S. EVANS, Attention rivalry among online platforms, In Journal of Competition Law \& Economics, 9 (2), 2013, pp. 339-340.

$454 \quad$ Chamados de cross-channel marketing technologies estes sistemas buscam coletar e analisar dados de audiência dos anúncios relacionando estas informações com dados sobre vendas dos produtos anunciados, inferindo por meio destas relações o impacto de cada meio de publicidade sobre as vendas dos produtos. Estas informações permitem a alocação entre os diferentes canais de publicidade. (DAVID S. EVANS, Attention rivalry among online platforms, In Journal of Competition Law \& Economics, 9 (2), 2013, pp. 339340).

\footnotetext{
$455 \quad$ "Another study suggests that there is indeed a trade-off between online and more traditional types of advertising: Avi Goldfarb and Catherine Tucker demonstrate that display advertising price is sensitive to the availability of offline alternatives.[...] At least one study concludes that online and offline advertising are economically-relevant substitutes, and no doubt that these interactions and cross elasticities are complicated, nuanced, and difficult to detect, isolate, and identify with certainty" (GEOFFREY A. MANNE; JOSHUA D. WRIGHT, Google and the limits of antitrust: The case against the case against Google, In Harvard Journal of Law \& Public Policy, vol. 34, disponível em: http://bit.ly/1hHH4TR, acesso em 17, ago., 2015, pp. 197198).
} 
informações que permitam direcionar anúncios específicos de acordo com o consumidor, favorecendo a customização da experiência anteriormente apontada. Nesse sentido, concorreriam com as empresas de busca aquelas que ofereçam buscas de produtos, redes sociais, email, comércio online dentre outras. ${ }^{456-457}$ É por essa razão que se afirma que, o real competidor do Google não seria o Bing (site de buscas da Microsoft) mas a Amazon (site de comércio eletrônico). Tanto assim que as evidências empíricas apontam uma diminuição das pesquisas por produtos no site Google com o aumento das pesquisas por produtos diretamente no site da Amazon. ${ }^{458}$

Outra evidência que corrobora esta tese se encontra no fato de que o uso de outras plataformas, como mídias sociais, pelos anunciantes vem ganhando espaço e ameaçando o faturamento da empresa no mercado de buscas. ${ }^{459}$ É por esta razão que, apesar do Facebook não concorrer diretamente no serviço de buscas por palavras-chave, esta concorre cada vez de forma mais direta pelo mindshare do usuário, ou seja, por seu tempo e atenção. ${ }^{460}$

Em sentido semelhante EVANS introduz o conceito de competição por atenção, sendo atenção entendida como "the time that consumers spend focusing their minds on

456 Conforme GEOFFREY A. MANNE; WILLIAM RINEHART, The market realities that undermined the FTC's antitrust case against Google, In Harvard journal of law and technology occasional paper series, July, 2013, disponível em: http://bit.ly/1FCV4Ce, Acesso em 25, jun. 2015, p. 8.

457 GIACOMO LUCHETTA, por sua vez, defende que a empresa atuaria no mercado de compra de informações pessoais com o objetivo de vender os perfis dos usuários aos anunciantes (GIACOMO LUCHETTA, Is the Google platform a two-sided market?, disponível em: http://bit.ly/1TRQw8o, acesso no dia 18, ago., 2015, p. 19).

\footnotetext{
458 Nesse ponto interessante ressaltar que estudos apontaram que em 2009 um quarto das buscas por produtos (25\%) se iniciou no Google, ao passo que $18 \%$ se iniciou no site da Amazon, enquanto no ano de 2011 quase 33\% das buscas se iniciou na Amazon enquanto apenas 13\% se iniciou no Google (GEOFFREY A. MANNE; WILLIAM RINEHART, The market realities that undermined the FTC's antitrust case against Google, In Harvard journal of law and technology occasional paper series, July, 2013, disponível em: http://bit.ly/1FCV4Ce, Acesso em 25, jun. 2015, p. 8).
}

459 GEOFFREY A. MANNE; WILLIAM RINEHART, The market realities that undermined the FTC's antitrust case against Google, In Harvard journal of law and technology occasional paper series, July, 2013, disponível em: http://bit.ly/1FCV4Ce, Acesso em 25, jun. 2015, pp. 9-10. Ainda no mesmo sentido: "In a world of scarce advertising dollars and effective marketing via social media sites, Google and all other advertisers, online and off, must compete with the growing threat to their revenue from these still-novel marketing outlets." (GEOFFREY A. MANNE; JOSHUA D. WRIGHT, Google and the limits of antitrust: The case against the case against Google, In Harvard Journal of Law \& Public Policy, vol. 34, disponível em: http://bit.ly/1hHH4TR, acesso em 17, ago., 2015, p 199).

460 ERIC GOLDMAN, Revisiting search engine bias, In William Mitchell Law Review, Vol. 38, n. 1, 2011, p. 100. 
content" ${ }^{461}$ Conforme aponta o autor, na era da Internet, as empresas pontocom competem entre si por quantidades limitadas de atenção, sendo seus produtos e serviços meras ferramentas para atrair esta atenção. ${ }^{462}$

As mudanças tecnológicas vivenciadas nos últimos anos, em especial o aumento explosivo do acesso à Internet banda larga e a migração para o uso dos smartphones e tablets como principais plataformas de acesso a web pelos usuários, fizeram com que houvesse um correspondente crescimento da quantidade de conteúdo disponível aos usuários. Por essa razão a quantidade de tempo gasta pelos usuários entre os diferentes sites sofreu profundas variações ao longo desse tempo, fruto do aumento da concorrência pela "atenção" destes usuários. Da mesma forma o tempo médio gasto pelos usuários vem crescendo nos últimos anos. ${ }^{463}$

Para tentar analisar a possibilidade de substituição entre serviços distintos, DAVID EVANS analisou dados relativos aos 500 sites com maior acesso na web entre os anos de 2002 e 2012, comparando as mudanças de tempo total gasto e a mudança de tempo gasto em relação ao total, dentre os sites caçadores de atenção (attention-seekers). O que se nota no longo prazo é a redução de tempo dos sites de busca e portais com o consequente aumento das redes sociais e dos sites de vídeo. Tais evidências, portanto, apontariam para a substitutibilidade entre produtos e serviços definidos de forma mais ampla. ${ }^{464}$

Por esta razão, as diferentes categorias são tratadas, inclusive pelos próprios competidores, como categorias fluidas. Nesse sentido, o site LinkedIn.com se vê concorrendo tanto com sites de empregos como Monster.com e CareerBuilder.com, como com redes sociais como o Facebook. Ainda que não se possa necessariamente relacionar os

461 DAVID S. EVANS, Attention rivalry among online platforms, In Journal of Competition Law \& Economics, 9 (2), 2013, pp. 313-314.

462 DAVID S. EVANS, Attention rivalry among online platforms, In Journal of Competition Law \& Economics, 9 (2), 2013, pp. 314.

463 Ao analisar a evolução dos 50 sites com maior número de acessos nos últimos 10 anos, DAVID S. EVANS aponta que nesse período houve uma enorme variação de posição nesse ranking. Dos 50 , quase 37 deixaram de figurar entre os top 50 sites, sendo que 5 nem mesmo passaram a figurar entre os 15.000 mais visitados. Relata, ainda, o autor que o tempo médio gasto por um americano na Internet aumentou de 9,4 horas em 2001 para 18,3 horas em 2010 (DAVID S. EVANS, Attention rivalry among online platforms, In Journal of Competition Law \& Economics, 9 (2), 2013, pp. 319-321).

464 Conforme aponta o autor o tempo gasto com redes sociais aumenta de $2,4 \%$ do tempo total para 29,4\% no período de 2002 até 2012. O tempo gasto com vídeos, por sua vez, aumenta de $0 \%$ para $13 \%$ no mesmo período. (DAVID S. EVANS, Attention rivalry among online platforms, In Journal of Competition Law \& Economics, 9 (2), 2013, pp. 323-325). 
mercados definidos pelos agentes de mercado à definição do mercado relevante concorrencial, uma grande disparidade entre as duas visões pode comprovar uma inadequação da definição realizada pelo antitruste. ${ }^{465}$

O aumento de funcionalidades de sites como o Facebook, Amazon e Twitter faz com que os serviços oferecidos pelo Google concorram cada vez de forma mais direta com estas outras empresas. ${ }^{466} \mathrm{O}$ Facebook, por exemplo, vem testando um sistema de buscas que desincentive o usuário a sair da plataforma para realizar a pesquisa no Google ${ }^{467} \mathrm{O}$ interessante é que o Facebook vem, inclusive, indexando as trilhões de postagens realizadas pelos seus usuários, de modo que a pesquisa abranja links já compartilhados pelos seus usuários, o que faria com que a empresa utilizasse informação que nem mesmo o Google tem acesso. ${ }^{468}$

Em primeiro lugar, o que se percebe é que a consideração de market shares em um momento específico desconsidera a dinâmica destrutiva destes setores e a possibilidade de entrada de novos players de forma muito mais rápida. E em segundo lugar, o ecossistema web com a presença de baixos switching costs, faz com que os usuários migrem para qualquer entrante que satisfaça suas necessidades de informação, mesmo que a solução apresentada seja completamente distinta. Por essa razão, provedores de informação estão sujeitos a elasticidades cruzadas da demanda decorrentes de fornecedores situados em nichos distintos. $^{469}$

465 DAVID S. EVANS, Attention rivalry among online platforms, In Journal of Competition Law \& Economics, 9 (2), 2013, pp. 325-328.

466 "While Google has dominated its direct competition in the search market, Google faces serious new competitive threats we did not anticipate in 2006. For example, both Facebook and Twitter have emerged as partial alternatives to Google keyword searching." (ERIC GOLDMAN, Revisiting search engine bias, In William Mitchell Law Review, Vol. 38, n. 1, 2011, pp. 99-100).

467 "Facebook is testing its own way 'in-app' search engine to help users find links within the mobile
app. This ensures that users don't have to Google Search for a link before they can post it to their status
update." (TECH DESK, Facebook testing 'in-app' search engine, wants users to skip Google: report,
disponível em: http://bit.ly/1BTSs84, acesso no dia 30, jun. 2015. Em sentido similar aponta DAVID S.
EVANS: "Facebook plans to add search features in order to reduce its customers' need to use Google,
gaining greater share of their attention" (DAVID S. EVANS, Attention rivalry among online platforms, In
Journal of Competition Law \& Economics, 9 (2), 2013, p. 333).

468 JOSH CONSTINE, KYLE RUSSELL, Skip Googling With Facebook's New "Add A Link” Mobile Status Search Engine, 9 de Maio de 2015, disponível em: http://crn.ch/1R1E7xl, acesso no dia 30, Jun. 2015.

469 ERIC GOLDMAN, Revisiting search engine bias, In William Mitchell Law Review, Vol. 38, n. 1, 2011, p. 101. 
A análise dos setores pontocom sob a dimensão da competição por atenção traz importantes observações com relação ao excessivo enfoque na divisão do mercado relevante pelo serviço ou pelo produto. Da mesma forma, se faz necessária a consideração de fronteiras menos rígidas do que em setores tradicionais. Para alguns, isso levaria à conclusão de que a intensa competição entre todos estes serviços distintos levaria à ausência de poder de mercado por parte desses agentes e a consequente impossibilidade de abuso de poder.

Devemos lembrar que esta visão suscita inúmeras dúvidas e não se mostra livre de críticas. JOHN M. NEWMAN, entende que, nestes mercados, a substitutibilidade possui características semelhantes ao de setores tradicionais, com a particularidade da consideração dos custos de atenção e de informação como variáveis relevantes para a decisão do consumidor. Segundo tal raciocínio, as decisões de consumo dos usuários, bem como da substitutibilidade destes produtos e serviços, não se baseia no preço cobrado pelo serviço, mas nos custos de atenção e de informação cobrados pelo fornecedor. ${ }^{470} \mathrm{Ou}$ seja, quando possível, consumidores tendem a substituir produtos e serviços que envolvam altos custos de atenção por produtos e serviços similares que cobrem menores custos.

Continua o autor afirmando que de forma semelhante a dos setores pontocom, vendedores de automóveis, restaurantes e lojas de roupas também se encontram em intensa competição entre si por um recurso escasso: o dinheiro do consumidor. Isso, porém, não leva à presunção de que todos seriam tomadores de preços sem poder de mercado. Além disso, a introdução de um produto por um novo entrante inovador sempre acaba por direcionar parte da atenção e do dinheiro de setores tradicionais, gerando um grau considerável de substituição. Tal fato, porém, não faz com que estes se enquadrem necessariamente dentro dos mesmos mercados relevantes. ${ }^{471}$

\footnotetext{
470 Um exemplo apresentado por JOHN M. NEWMAN vem do mercado de rádio difusão, em que se constatou que quanto maior o tamanho da empresa, e consequentemente maior o poder econômico e a concentração de mercado, o tempo de anúncios veiculados também aumenta. Da mesma forma, nos horários em que há menor número de substitutos os anúncios também se mostram mais longos (JOHN M. NEWMAN, Antitrust in zero-price markets: Foundations, In University of Pennsylvania Law Review, Vol. 164, disponível em: http://bit.ly/1jEUMaX, acesso no dia 15, out., 2015, p. 25).
}

471 JOHN M. NEWMAN, Antitrust in zero-price markets: Foundations, In University of Pennsylvania Law Review, Vol. 164, disponível em: http://bit.ly/1jEUMaX, acesso no dia 15, out., 2015, pp. 25-26. 
O que notamos nos novos setores surgidos com a Internet é, justamente, uma maior permeabilidade e um maior grau de substitutibilidade entre os diferentes serviços oferecidos. Isso, porém, não deve levar a conclusão de que o intenso grau de concorrência presente nestes setores faça com que nenhum desses agentes tenha poder de mercado. A abordagem da competição por atenção torna necessária a relativização da divisão do mercado relevante pela definição do serviço ou produto oferecido, por conta da alta permeabilidade e substitutibilidade desses novos serviços.

A ausência de material empírico confiável para delimitação destes mercados impede que haja uma definição precisa. Porém, o que notamos é que definições que tenham como enfoque a metodologia tradicional de delimitação dos mercados relevantes com base em testes como o SSNIP (Monopolista Hipotético) ou que tenham como enfoque o serviço oferecido podem levar a uma supervalorização do tamanho do mercado detido pelos agentes em setores pontocom.

Alguns apontam para uma possível adaptação do SSNIP, com a consideração do uso da qualidade como variável relevante do teste no lugar do preço. Nessa situação o teste analisaria a substituição no caso de redução da qualidade (ao invés do aumento do preço como no caso do SSNIP clássico). As variáveis de qualidade deveriam considerar tanto os aumentos de eficiência dinâmica como a redução de custos não monetários, como os custos de informação e atenção. ${ }^{472}$ Deve-se ressaltar que uma adaptação desse tipo enfrenta uma série de obstáculos de ordem prática, uma vez que o preço se mostra uma variável de análise muito mais simples de trabalhar e de fácil medição.

\section{III.2.2 - Poder de mercado}

Poder de mercado é definido como a capacidade de uma firma aumentar os preços acima do nível competitivo. Não há consenso com relação ao que seriam estes preços competitivos, sendo comumente definidos como os preços em situação de competição perfeita (que segundo modelo neoclássico seriam iguais ao custo marginal). Tal modelo, porém, enfrenta sérios problemas tanto em estruturas de um lado como em estruturas de múltiplos lados. Nesse último caso, em algumas indústrias como a de software e as indústrias baseadas em web, essa abordagem se mostra ainda mais problemática, uma vez

472 MICHAL S. GAL; DANIEL L. RUBINFELD, The hidden costs of free goods: Implications for Antitrust enforcement, New York University Law and Economics Working Papers, Disponível em: http://bit.ly/1Qg96Ds, acesso no dia 05, nov., 2015, pp. 35-36. 
que o custo marginal muitas vezes é igual a zero, sendo, inclusive, possível que em diversas situações o preço de equilíbrio seja igual a zero. ${ }^{473-474}$

Se o uso do market-share para inferir poder de mercado é questionável em empresas de um único lado, tal situação se mostra ainda mais problemática nas indústrias de múltiplos lados. Nestes casos, a mensuração da parcela de mercado de um dos lados da plataforma e sua comparação com outras plataformas desconsidera a possibilidade dos subsídios operarem de formas distintas entre elas, levando a market-shares igualmente distintos entre plataformas diferentes. Da mesma forma o cálculo de market-share com base no valor agregado dos produtos também se mostra problemático, uma vez que o subsídio de um dos lados implica que os custos serão próximos de zero, não refletindo seu real valor para o consumidor. ${ }^{475}$

O uso de lucratividade como critério também apresenta problemas, uma vez que as taxas de retorno variam com o tempo, a obtenção dos dados se mostra insuficiente para avaliações precisas, da mesma forma que desconsidera análises de risco e compensação. Não havendo, por estas razões, um método confiável para mensuração do poder de mercado nem mesmo em indústrias tradicionais, sendo este problema ainda pior em indústrias de múltiplos lados, por abarcarem problemas de análise adicionais. ${ }^{476}$

Tais setores apresentam diversos desvios em relação à estrutura de concorrência perfeita vista no CAPÍTULO I. Em primeiro lugar, os produtos geralmente são heterogêneos, uma vez que a quantidade e diversidade de diferentes produtos e serviços

473 DAVID S. EVANS; RICHARD SCHMALENSEE, The antitrust analysis of multi-sided platform businesses, disponível em: http://bit.ly/1KhV5mT, acesso no dia 19, mai, 2015, pp. 18-19. Ainda MICHAL S. GAL e DANIEL L. RUBINFELD: "Traditional market power analysis is not designed to apply to free goods." MICHAL S. GAL; DANIEL L. RUBINFELD, The hidden costs of free goods: Implications for Antitrust enforcement, New York University Law and Economics Working Papers, Disponível em: http://bit.ly/1Qg96Ds, acesso no dia 05, nov., 2015, p. 36).

\footnotetext{
$474 \quad$ "Several factors suggest that this price is dictated by competition and would not necessarily be chosen by a monopolist" (DAVID S. EVANS, Attention rivalry among online platforms, In Journal of Competition Law \& Economics, 9 (2), 2013, p. 331).

475 DAVID S. EVANS; RICHARD SCHMALENSEE, The antitrust analysis of multi-sided platform businesses, disponível em: http://bit.ly/1KhV5mT, acesso no dia 19, mai, 2015, pp. 19-20.

476 DAVID S. EVANS; RICHARD SCHMALENSEE, The antitrust analysis of multi-sided platform businesses, disponível em: http://bit.ly/1KhV5mT, acesso no dia 19, mai, 2015, p. 20.
} 
oferecidos nestes setores teve um crescimento exponencial nos últimos anos. Desse modo, o nível de diferenciação de produtos tende a ser elevado. ${ }^{477}$

Como afirmamos, a característica de mercado de múltiplos lados destes setores cria complicações adicionais. A desconsideração das múltiplas conexões entre os diferentes grupos de consumidores bem como entre os produtos e serviços oferecidos pode levar a uma inadequada delimitação de mercado relevante e, consequentemente, a uma aferição distorcida do poder de mercado detido pela empresa. Os efeitos indiretos de rede presentes nestes setores trazem particularidades para a análise. É perfeitamente possível que um agente com poder de mercado apresente preços inferiores ao custo marginal de um dos lados da plataforma, levando a uma conclusão de falso negativo para o poder de mercado. Da mesma forma que a análise do custo superior do outro lado pode levar a um resultado de falso positivo. ${ }^{478}$ Por essa razão, devem ser consideradas as múltiplas conexões entre os lados da plataforma e seus efeitos para análise de suas restrições competitivas.

Em primeiro lugar, o feedback positivo entre os diferentes grupos fruto dos efeitos indiretos de rede são relevantes para a análise de lucratividade do aumento de preço. Quando considerados estes efeitos a elasticidade da demanda é maior em todos os lados, em alguns casos podendo chegar ao dobro da elasticidade na hipótese de um único lado. ${ }^{479}$

Em segundo lugar, as restrições competitivas que limitam o aumento dos preços podem emergir de quaisquer dos lados da plataforma. A estratégia da empresa deve, portanto, considerar as consequências de um aumento sobre os dois lados da plataforma. Nestas situações o aumento do preço de um dos lados leva não apenas à redução do consumo dos outros lados da plataforma, mas pode ocasionar no aumento de usuários de uma plataforma concorrente, bem como no aumento de valor dessa plataforma como um todo, decorrência do feedback positivo. Por esta razão, o agente deve enxergar não apenas

477 JOHN M. NEWMAN, Antitrust in zero-price markets: Foundations, In University of Pennsylvania Law Review, Vol. 164, disponível em: http://bit.ly/1jEUMaX, acesso no dia 15, out., 2015, pp.28.

478 DAVID S. EVANS; RICHARD SCHMALENSEE, The antitrust analysis of multi-sided platform businesses, disponível em: http://bit.ly/1KhV5mT, acesso no dia 19, mai, 2015, p. 20.

479 Conforme exemplo das revistas apresentado por EVANS e SCHMALENSEE, citando M. SONG (DAVID S. EVANS; RICHARD SCHMALENSEE, The antitrust analysis of multi-sided platform businesses, disponível em: http://bit.ly/1KhV5mT, acesso no dia 19, mai, 2015, p. 18). 
a concorrência em relação a um dos lados, mas antes os efeitos da concorrência entre plataformas como um todo. ${ }^{480}$

Por fim, os efeitos indiretos de rede, ao criarem barreiras à entrada decorrentes da necessidade de escala e de massa crítica, podem trazer limitações à substitutibilidade pelo lado da oferta. ${ }^{481}$ Nesse ponto a diferenciação de produtos e a possibilidade de multihoming são determinantes para definir o grau destas barreiras à entrada.

Preços iguais a zero são comuns em diversos desses setores como redes sociais, $e$ mails, mecanismos de buscas, entre outros. O que se nota é que, nesses setores, mesmo entre as empresas que tragam profundas inovações, a cobrança de preços positivos poderia levar a uma quantidade de tráfego insuficiente para a viabilidade de seu negócio. Muitas empresas do ramo de comunicação tentaram implementar um sistema de paywall que obrigasse o usuário a pagar pelo conteúdo de seu site, porém, diversas dessas empresas vem abandonando esta abordagem pela drástica redução do número de acesso pelos usuários. $^{482}$

Conforme afirmamos, empresas que competem por atenção enfrentam sérias restrições competitivas, uma vez que não podem subir seus preços acima de zero, devem constantemente implementar melhorias em seus serviços, enfrentam intensa concorrência de outros caçadores de atenção (inclusive dos que oferecem serviços completamente distintos), bem como atuam em um setor com baixas barreiras à entrada (apesar de barreiras relevantes criadas pelas externalidades de rede). ${ }^{483}$ Por conta disso, deve-se analisar com extrema cautela a existência de poder de mercado para estes agentes.

Devemos lembrar que algumas particularidades como os efeitos de rede e a estrutura de múltiplos lados sobre a quais tais negócios operam podem trazer complicações

$480 \quad$ DAVID S. EVANS; RICHARD SCHMALENSEE, The antitrust analysis of multi-sided platform businesses, disponível em: http://bit.ly/1KhV5mT, acesso no dia 19, mai, 2015, pp. 18-19.

481 "Entrants have to obtain critical mass as well and that often takes time. Moreover, in a mature market the entrant has the challenge of persuading users who may benefit from these positive feedback effects to switch to a platform that has a smaller and therefore possibly less valuable group of customers on the other side" (DAVID S. EVANS; RICHARD SCHMALENSEE, The antitrust analysis of multi-sided platform businesses, disponível em: http://bit.ly/1KhV5mT, acesso no dia 19, mai, 2015, p. 19).

482 DAVID S. EVANS cita o caso do The Times of London que teve uma redução de $90 \%$ de sua audiência online após obrigar os usuários a se registrarem para ter acesso ao conteúdo do site (Attention rivalry among online platforms, In Journal of Competition Law \& Economics, 9 (2), 2013, p. 332).

483 DAVID S. EVANS, Attention rivalry among online platforms, In Journal of Competition Law \& Economics, 9 (2), 2013, p. 330. 
adicionais, além de fenômenos como a diferenciação de produtos podem criar significativo poder de mercado para um agentes específico. É evidente, porém, que todos estes efeitos devem ser visualizados sob o âmbito mais amplo da competição por atenção para que também não se superestime este poder. ${ }^{484}$

De uma forma geral, podemos apontar alguns aspectos que devem ser destacados nesses mercados. Em primeiro lugar, ao navegarem por diferentes sites, os usuários realizam multi-homing quando dividem seu tempo entre sites distintos. Por essa razão, estes não configuram um "competitive bottleneck" no sentido tradicionalmente utilizado em mercados de múltiplos lados. Em segundo lugar, a atenção dos usuários é limitada, e, por essa razão, a competição entre os caçadores de atenção se mostra intensa. Por fim, a diferenciação de produtos nesses mercados ocorre em relação aos nichos em que se inserem os anúncios a consumidores direcionados. ${ }^{485}$

Em seguida veremos de forma mais detalhada algumas dessas características.

\section{III.2.2.1 - Substituição no mercado de atenção}

Em setores caracterizados pela concorrência em preços, uma empresa que aumente os preços acima do nível competitivo terá uma redução considerável da demanda por conta da substituição por produtos distintos. A possibilidade dos consumidores compararem os custos relativos dos produtos e de seus similares permite que haja elevado grau de substitutibilidade entre opções similares.

Em setores caracterizados por preços iguais a zero, por outro lado, a comparação entre custos se mostra muito mais complicada, uma vez que não há uma base fungível e objetiva de comparação como o valor monetário (preço). Por essa razão, nestes setores a decisão de consumo dos usuários dependerá em grande medida de julgamentos qualitativos em relação ao produto que oferece o melhor serviço com o mínimo de custos de

$484 \quad$ "As a result of these differences, standard tools used in antitrust analysis for assessing market definition are not applicable, at least not without substantial modification, to multi-sided platforms. The analysis of multi-sided market definition and market power will depend on the particular factual circumstances of the attention rivals considered." DAVID S. EVANS, Attention rivalry among online platforms, In Journal of Competition Law \& Economics, 9 (2), 2013, p. 341.

485 DAVID S. EVANS aponta que muitas dessas plataformas se especializam em um tipo específico de consumidor, como, por exemplo, homens de meia idade que trabalham no mercado financeiro (que seriam clientes em potencial do mercado de carros de luxo) ou jovens mães (consumidoras em potencial de fraldas) (DAVID S. EVANS, Attention rivalry among online platforms, In Journal of Competition Law \& Economics, 9 (2), 2013, pp. 341-342). 
atenção/informação. Disso decorre uma dificuldade muito superior de comparação quando comparada com a simples comparação entre dois produtos com preços diferentes. ${ }^{486}$

Os serviços oferecidos pelos caçadores de atenção guardam profundas diferenças entre si. Um serviço de busca de sites é completamente distinto de um serviço de microblogs ou de redes sociais. Porém, o que devemos notar é que a dimensão relevante da competição entre estes players ocorre em relação à capacidade de manter a atenção do usuário em sua plataforma por mais tempo. Os anunciantes estão mais interessados na capacidade da plataforma gerar atenção para seus produtos ou serviços do que no fato desta ter sido gerada por uma rede social ou por um microblog. Por essa razão, a diferenciação sob o ponto de vista dos anunciantes ocorre mais em relação ao público alvo que o anunciante deseja atingir ${ }^{487}$ do que em relação ao serviço efetivamente prestado. Essa diferenciação acaba diminuindo a capacidade de substituição entre estes concorrentes. O que pode levar algumas dessas plataformas a possuírem significativo poder de mercado. $^{488}$

Uma primeira dimensão da substitutibilidade ocorre em relação às pessoas que fornecem atenção. As diferentes mídias produzem conteúdo com o objetivo de atrair um público específico, e, consequentemente, um determinado grupo de anunciantes interessado em atingir este segmento. Alguns desses nichos se mostram extremamente específicos o que poderia reduzir a capacidade de substitutibilidade ${ }^{489}$, ao passo que algumas dessas mídias se mostram extremamente genéricas em relação ao público alvo, o que poderia gerar competição em relação aos nichos específicos. Uma diferença crucial

\footnotetext{
$486 \quad$ "Without a perfectly fungible baseline of comparison like currency, customers are left to make qualitative judgments about which product will cost the least amount of information and attention. Price information is quantitative, simple, and almost costless to gather. Nonprice cost information is qualitative, complex, and relatively costly to gather." (JOHN M. NEWMAN, Antitrust in zero-price markets: Foundations, In University of Pennsylvania Law Review, Vol. 164, disponível em: http://bit.ly/1jEUMaX, acesso no dia 15, out., 2015, p. 29).

487 É por essa razão que algumas plataformas possuem maior capacidade de atingir o interesse de anunciantes em específico. Por exemplo, sites que tenham como usuários um público jovem (como algumas redes sociais) despertam maior interesse de empresas que atuam nesse segmento, ao passo que sites que atingem majoritariamente um público de alta renda (como por exemplo sites de negócios ou de finanças) acabam tendo como seus anunciantes empresas que buscam atingir esse público.
}

488 DAVID S. EVANS, Attention rivalry among online platforms, In Journal of Competition Law \& Economics, 9 (2), 2013, p. 343-344.

489 Como no exemplo usado por DAVID EVANS da revista Fly Fisherman especializada em pescaria. (DAVID S. EVANS, Attention rivalry among online platforms, In Journal of Competition Law \& Economics, 9 (2), 2013, p. 344). 
entre as mídias tradicionais e aquelas inseridas na Internet, como já ressaltamos, consiste na capacidade de customização completa da experiência do usuário em relação tanto ao conteúdo acessado como em relação ao usuário. Essa possibilidade de individualização faz com que vários tipos de mídia completamente distintas concorram entre si pelos anunciantes especializados. ${ }^{490}$

Em estudo recente, DAVID S. EVANS observou que houve uma alteração significativa nos 50 domínios mais acessados na web entre os anos de 2002 e 2012. Dos 50 sites mais acessados no ano de 2002, 46\% estavam entre os mais acessados em 2007 e apenas $26 \%$ estavam entre os mais acessados em 2012. O que se percebe, da mesma forma, é que a mudança entre tempo gasto ocorre entre sites que prestam serviços e oferecem conteúdo extremamente variável, não havendo, portanto, substituição por produtos considerados similares. Além disso, nota-se um relevante ingresso de novos players nesses setores de atenção. Conforme dados do site Compete.com, entre janeiro e julho de 2012, houve mudança em $26 \%$ dos sites presentes na lista dos 15.000 sites mais acessados. ${ }^{491}$

A segunda dimensão da substituição ocorre em relação à forma como os anúncios são veiculados. A primeira diferença ocorre no formato da mensagem, que pode consistir em um texto, uma imagem ou mesmo um vídeo. A segunda diferença ocorre em relação ao contexto. Sites de busca apresentam anúncios conforme as palavras-chave inseridas pelo usuário, ao passo que redes sociais mostram anúncios em páginas que normalmente apresentam informações pessoais de outros usuários (como no caso das timelines do Facebook). O contexto em que esses anúncios são inseridos afeta diretamente a disposição da pessoa a consumir um serviço ou produto do anunciante, bem como afeta a imagem da empresa. $^{492}$

\footnotetext{
490 É o caso de um site de notícias veiculando anúncios de nichos específicos, como, por exemplo, de empresas de pesca. Nas mídias tradicionais, a incapacidade de customização dos anúncios da revista em relação a cada usuário inviabilizava anúncios muito específicos em mídias com conteúdo geral e não específico. Porém, no caso da internet o direcionamento de anúncios em relação ao usuário permite que tal possibilidade de substituição aumente.
}

491 Conforme aponta DAVID S. EVANS: "These shifts occurred in large part because consumers were shifting their attention between different websites offering entirely different types of activities" (DAVID S. EVANS, Rivals for attention: How competition for scarce time drove the web revolution, what it means for the mobile revolution, and the future of advertising, 2014, disponível em: http://bit.ly/1WZhJHL, acesso no dia 18, nov., 2015, pp. 11-14).

492 DAVID S. EVANS, Attention rivalry among online platforms, In Journal of Competition Law \& Economics, 9 (2), 2013, pp. 345-346. 
A análise destes fatores nos leva a conclusão de que o aspecto chave que deve ser considerado para análise das restrições competitivas é a atenção. Por essa razão, diferentes produtos e serviços que recebem a atenção do usuário e, com isso, comercializam esta atenção se encontram em competição entre si. Isso não deve levar à conclusão de que, diante da intensa competição, nenhum deles teria poder de mercado. Antes disso, tal enfoque deve levar à percepção de que nesses setores as fronteiras entre mercados relevantes se mostram mais fluidas, de modo que a metodologia tradicional de delimitação que considera as características e utilidades dos produtos e serviços para análise de sua substitutibilidade não se adequa a estes setores. ${ }^{493}$

Aspecto central para a possibilidade de substituição se encontra na ausência de custos significativos de mudança (switching costs), uma vez que sua ocorrência pode dificultar ou inviabilizar a mudança para alternativas, causando os chamados efeitos de path dependence ou lock-in. Os switching costs são todos os custos que incorrem os consumidores ao migrarem para outro fornecedor de um bem ou serviço, dentre estes se incluem tanto os custos monetários como o valor do tempo dos consumidores. ${ }^{494}$

Os custos de mudança podem assumir diferentes roupagens em diferentes setores, sendo algumas vezes tangível e de fácil quantificação ao passo que em outras situações este se mostra intangível e de difícil observação. Em geral, podemos apontar sete tipos de switching costs: (i) custos de compatibilidade: custos necessários para que dois bens complementares possam funcionar conjuntamente; (ii) custos contratuais: custos decorrentes de cláusulas de penalidade ou de incentivo à fidelização; (iii) custos de transação: custos associados à contratação de fornecedor alternativo; (iv) custos de procura: custos necessários para se encontrar e avaliar possíveis alternativas ao fornecedor; (v) custos de aprendizado: custos necessários para que o consumidor aprenda a utilizar o novo produto ou serviço; (vi) custos de incenteza: surgem especialmente no caso dos bens que necessitam da experiência de uso para serem avaliados pelo usuário; e (vii) custos de

493 DAVID S. EVANS, Attention rivalry among online platforms, In Journal of Competition Law \& Economics, 9 (2), 2013, p. 346.

494 AARON S. EDLIN e ROBERT G. HARRIS, The role of switching costs in antitrust analysis: A comparison of Microsoft and Google, In Yale Journal of Law and Technology, n. 169, v. 15, 2013, p. 176. 
aquisição: o processo de compra de um novo produto ou serviço também gera custos ao consumidor. $^{495}$

Um dos primeiros casos a se valer do termo e analisar a problemática dos switching costs foi o caso Microsoft, julgado pela justiça norte-americana. Nesse caso, eram três os principais custos associados: os custos de compatibilidade, os custos de transação e os custos de aprendizado. Os custos de compatibilidade tinham papel central uma vez que os aplicativos desenvolvidos para o Windows não funcionavam em outros sistemas operacionais, fazendo com que os usuários incorressem em enormes custos ao migrar para um concorrente da plataforma. Tal fenônomeno, que ficou conhecido como "applications barrier to entry", decorria das externalidades de rede criadas pela compatibilidade dos aplicativos com o sistema operacional da empresa. ${ }^{496}$ A estratégia da empresa consistia, basicamente, em aumentar os switching costs necessários para que o usuário migrasse para um sistema operacional concorrente, de modo a enfraquecer as possíveis ameaças competitivas. $^{497}$

A consideração dos custos de mudança em muitos casos leva a uma definição de mercado mais restritiva. Além disso, switching costs constituem importante barreira à entrada, uma vez que limitam a entrada e a expansão de concorrentes, permitindo que empresas com elevado market share aumentem seus preços sem que sofram a perda de consumidores. $^{498}$

$495 \quad$ AARON S. EDLIN e ROBERT G. HARRIS, The role of switching costs in antitrust analysis: A comparison of Microsoft and Google, In Yale Journal of Law and Technology, n. 169, v. 15, 2013, pp. 178184.

496 Tratando do caso Microsoft, LEANDRO SAITO afirma: "Na área de softwares os custos de mudança se consubstanciam nos custos de treinamento para utilização da nova plataforma, bem como nos custos pecuniários de obtenção dos programas e atualizações compatíveis com o novo sistema operacional. Estes fatores geram uma "fidelização" do usuário, que acaba optando pela utilização de apenas uma plataforma (no caso em questão o Microsoft Windows). Aqui estamos diante do já mencionado "lock-in effect". Por esta razão, somente um produto com qualidade muito superior teria condições de angariar usuários da antiga plataforma." (LEANDRO SAITO, A “propriedade" intelectual como barreira à entrada de novos players no mercado de softwares, IBPI. 2012. Disponível em: http://bit.ly/1MQEGIp, acesso no dia 8 , nov., 2015, p. 167).

497 AARON S. EDLIN e ROBERT G. HARRIS, The role of switching costs in antitrust analysis: A comparison of Microsoft and Google, In Yale Journal of Law and Technology, n. 169, v. 15, 2013, pp. 186188 .

498 AARON S. EDLIN e ROBERT G. HARRIS, The role of switching costs in antitrust analysis: A comparison of Microsoft and Google, In Yale Journal of Law and Technology, n. 169, v. 15, 2013, pp. 189190. 


\section{III.2.2.2 - Barreiras à entrada}

Setores pontocom de um modo geral apresentam barreiras à entrada significativamente inferiores aos setores tradicionais. Os custos fixos para criar uma empresa web-based são muito inferiores aos de um negócio físico. Da mesma forma, a expansão destes negócios envolvem valores muito inferiores, uma vez que adicionar páginas ou novas seções a um site ou aplicativo custa consideravelmente menos do que alugar novos espaços e contratar novos funcionários. ${ }^{499}$

O custo para se distribuir conteúdo digital vem decrescendo com o avanço da computação, dos sistemas de armazenamento e a melhoria das transmissões de rede. Alguns modelos de negócios tão em voga nos dias atuais, como o do Netflix e do Youtube seriam impensáveis há alguns anos atrás. Porém, deve-se ressaltar que todas estas tecnologias apresentam custos como qualquer negócio da era anterior a da Internet. Todos eles necessitam de estruturas físicas como data-centers, servidores e cabos conectando todas estas estruturas com as residências dos usuários. ${ }^{500}$ Toda esta estrutura envolve um custo considerável. Ao contrário do popular mito de que na era da Internet qualquer empresa concorrente poderia surgir de um grupo de amigos instalados em uma garagem, a realidade demonstra que as barreiras à entrada apresentam enorme variabilidade a depender do tipo de produto oferecido. ${ }^{501}$ Enquanto para o desenvolvimento de um simples aplicativo de smartphone o custo pode ser de alguns dólares e uma pequena quantidade de tempo, em outras situações o custo de operação é elevadíssimo. Como ressalta FRANK PASQUALE, estima-se que a Google, em 2007, utilizava-se de um milhão de computadores para mapear e indexar a web, sendo necessária a energia equivalente a capacidade energética de uma cidade como Salt Lake City para o funcionamento de seu data center. ${ }^{502}$

499 DAVID S. EVANS, Attention rivalry among online platforms, In Journal of Competition Law \& Economics, 9 (2), 2013, p. 346.

500 CHRIS JAY HOOFNAGLE; JAN WHITTINGTON, Free - Accounting for the costs of the Internet's most popular price, In UCLA Law Review, n. 61, vol. 3, 2014, p. 621.

501 JOHN M. NEWMAN, Antitrust in zero-price markets: Foundations, In University of Pennsylvania Law Review, Vol. 164, disponível em: http://bit.ly/1jEUMaX, acesso no dia 15, out., 2015, pp.28.

502 FRANK PASQUALE, Paradoxes of digital antitrust: Why the FTC failed to explain its inaction on search bias, In Harvard journal of law and technology occasional paper series, July, 2013, disponível em: http://bit.ly/1FbNQVJ, Acesso em 11, jun. 2015, p. 5. Em sentido similar aponta JOHN M. NEWMAN que "At the other end of the spectrum are more complex products that require years of time, considerable expertise, and millions of dollars to launch. The barriers to launching a rival product are quite high, even if 
Como afirmamos, em alguns casos, os switching costs da mesma forma acabam criando barreiras à entrada significativas. Sendo os custos dos serviços na era da Internet na maior parte das vezes iguais a zero, o custos mais significativos de mudança se relacionariam aos custos de aprendizado, custos de procura e de incerteza. A mudança para uma opção similar muitas vezes envolve tempo e disposição do usuário para encontrar outras opções concorrentes, bem como para se ambientar ao novo site, além da incerteza gerada pelos resultados que a plataforma desse novo fornecedor irá oferecer. Em algumas situações, como no caso do webmail, ou de serviços de redes sociais, os custos tendem a ser maiores, uma vez que envolvem o cadastro de uma série de informações pessoais, a necessidade de informar seus contatos da mudança, dentre outros contratempos.

Deve-se ressaltar que, além dessa problemática particular a estes setores, os possíveis entrantes nesse setor enfrentam ainda barreias à entrada tradicionais, tais como a necessidade de escala e a existência de sunk costs consideráveis. Além disso, a mão de obra utilizada por estas empresas envolve os profissionais com um dos salários médios mais altos dos Estados Unidos. ${ }^{503}$ Por conta destes fatores, muitos jogos online, por exemplo, tem um custo de produção de milhões de dólares.

\section{III.2.2.3 - Poder de mercado nos novos setores de Internet}

O enfoque sobre a competição por atenção não deve levar da mesma forma à conclusão de que a intensa competição desses setores levaria a uma menor necessidade de atuação do direito antitruste sobre controle de condutas e estruturas. ${ }^{504}$ Uma visão muito restritiva do mercado relevante poderia levar a autoridade concorrencial a concluir pela capacidade do agente dominante aumentar seus preços. Uma visão muito ampla, por sua vez, poderia concluir pela incapacidade do agente dominante exercer seu poder de

the market price for such products is set at zero." (JOHN M. NEWMAN, Antitrust in zero-price markets: Foundations, In University of Pennsylvania Law Review, Vol. 164, disponível em: http://bit.ly/1jEUMaX, acesso no dia 15 , out., 2015, pp. 28).

503 Apontam os autores que em 2011, o salário médio dos EUA era de U\$ 45.230,00, enquanto os salários médios de programadores da indústria de games era de U\$ 92.962,00. (CHRIS JAY HOOFNAGLE; JAN WHITTINGTON, Free - Accounting for the costs of the Internet's most popular price, In UCLA Law Review, n. 61, vol. 3, 2014, p. 622).

504 "The competition among attention rivals described above does not imply that antitrust should reduce the vigor which it examines mergers and exclusionary practices among these platforms. It just needs to look for problems in the right places." (DAVID S. EVANS, Attention rivalry among online platforms, In Journal of Competition Law \& Economics, 9 (2), 2013, p. 347-348). 
mercado, desconsiderando a possibilidade de condutas exclusionárias por parte de um agente com poder de mercado.

A estrutura de múltiplos lados e de preço zero cria complicações adicionais sobre os setores de Internet. Deve-se, portanto, adaptar o ferramental de análise de modo que se possa compreender as particularidades decorrentes dessas novas estruturas de preços. No caso dos bens complementares, por exemplo, a análise do poder de mercado deve considerar o bem vendido a um preço positivo, uma vez que ao prover o bem de forma gratuita em um mercado, o vendedor pode aumentar os custos e as barreiras à entrada no mercado correlato, cobrindo os custos de ambos. Da mesma forma as restrições competitivas impostas pelos bens gratuitos devem ser consideradas na análise dos bens pagos. A mesma abordagem deveria ser aplicada no caso de bens não complementares que sejam oferecidos em mercados distintos mas que operem em sistema de mercado de múltiplos lados. ${ }^{505}$

Outro ponto de vital importância consiste na ampliação das dimensões de análise para compreensão adequada do poder de mercado nesses setores. Dessa forma, o ponto central que se busca defender é que diversas plataformas atuam no mercado de competição por atenção e por informação dos consumidores, buscando atrair atenção e obter informação dos usuários, com o objetivo de comercializar estes produtos com os anunciantes. Assim, a análise deve levar em conta aspectos como qualidade, possibilidades de escolha do consumidor, e custos de informação e atenção. ${ }^{506}$

O enfoque, portanto, para a análise do poder de mercado ocorreria não em relação aos produtos e serviços e a consequente análise de substituição entre estes e seus possíveis concorrentes. Nesse caso, os produtos e serviços que são oferecidos são apenas os meios que se valem os caçadores de atenção e informação para atrair usuários. Evidente que em algumas situações o produto oferecido é importante para a análise, conforme apontamos no caso em que a diferenciação de produtos exerce importante papel, porém, de um modo

505 MICHAL S. GAL; DANIEL L. RUBINFELD, The hidden costs of free goods: Implications for Antitrust enforcement, New York University Law and Economics Working Papers, Disponível em: http://bit.ly/1Qg96Ds, acesso no dia 05, nov., 2015, pp. 36-37.

506 MICHAL S. GAL; DANIEL L. RUBINFELD, The hidden costs of free goods: Implications for Antitrust enforcement, New York University Law and Economics Working Papers, Disponível em: http://bit.ly/1Qg96Ds, acesso no dia 05, nov., 2015, pp. 36-37. 
geral, o que devemos concluir é que as dimensões relevantes de análise para fins antitruste são a atenção ${ }^{507}$ e a informação. ${ }^{508}$

Além da dificuldade associada à diferenciação dos produtos, nesses setores nota-se, ainda, enorme diferenciação com relação aos custos de informação e atenção. Os anúncios apresentados por estas plataformas possuem conteúdo e formato diferentes, o que faz com que os custos de atenção sejam também diferentes. A qualidade do anúncio, formato, visibilidade, dentre outros inúmeros fatores, terão influência sobre o seu custo. Da mesma forma, a percepção e sensibilidade do usuário em relação ao anúncio ou em relação à informação capturada se mostram extremamente variáveis, fazendo com que o anúncio possa ter custo zero ou mesmo negativo, uma vez que o usuário pode extrair deste um valor positivo. ${ }^{509-510}$

Por fim, devemos apontar que serviços oferecidos em setores pontocom envolvem ainda uma problemática associada à capacidade de avaliação da qualidade do serviço pelo consumidor. Conforme veremos no caso Google analisado posteriormente, esta dificuldade de percepção da qualidade faz com que a empresa possa manipular seus resultados de busca, degradando a qualidade de seu buscador, sem que o usuário tenha real consciência e possa optar por utilizar opção concorrente.

Os bens podem ser classificados de acordo com a capacidade do consumidor avaliar a qualidade do produto. Segundo tal classificação os bens podem ser search goods, em que a qualidade pode ser avaliada antes do seu consumo, experience goods, quando a qualidade dificilmente pode ser avaliada antes do consumo, mas pode ser avaliada durante seu uso, e os creedence goods, que são difíceis de serem avaliada mesmo com seu consumo. Segundo os exemplos apresentados por PATTERSON, uma pintura seria um

507 DAVID S. EVANS, Attention rivalry among online platforms, In Journal of Competition Law \& Economics, 9 (2), 2013, p. 348.

508 CHRIS JAY HOOFNAGLE; JAN WHITTINGTON, Free - Accounting for the costs of the Internet's most popular price, In UCLA Law Review, n. 61, vol. 3, 2014, p. 608.

509 Isso pode ocorrer, por exemplo, em casos de anúncios publicitários com músicas ou artistas famosos, ou em que a qualidade do trabalho faz com que este seja assistido por diversas pessoas.

510 JOHN M. NEWMAN, Antitrust in zero-price markets: Foundations, In University of Pennsylvania Law Review, Vol. 164, disponível em: http://bit.ly/1jEUMaX, acesso no dia 15, out., 2015, p. 31. 
search good, um restaurante seria um experience good e um suplemento de vitaminas seria um creedence good. ${ }^{511}$

No caso dos bens e serviços oferecidos nestes novos setores de Internet, a maior parte deles se classifica na categoria de creedence goods, nos quais há dificuldade de avaliação da qualidade mesmo com seu consumo. Dessa forma, além da dificuldade de se mensurar os custos de informação e atenção associados a estes bens, surge uma dificuldade muito maior do consumidor avaliar as opções de substitutos disponíveis, podendo levar os usuários a um problema de path dependance. Por essa razão, em muitos casos, o consumidor se mantém completamente alheio a estes custos, especialmente com relação às políticas de privacidade e de uso de dados pessoais, o que constitui relevante fonte de falha de mercado. ${ }^{512-513}$

\section{III.3 - Bem estar social nos setores pontocom}

Sendo o papel do direito antitruste moderno o de sancionar desvios do processo competitivo que prejudiquem o bem estar social, cabe analisar se as falhas de mercado presentes nestes setores tendem a levá-los para resultados subótimos. O que percebemos é que, a estrutura das condutas que possam trazer prejuízo ao bem estar social não se mostram diferentes dos setores tradicionais. Porém, a desconsideração da distinta natureza das trocas realizadas pelos consumidores pode levar a análises equivocadas que entendem pela impossibilidade de abuso por parte de um agente econômico por conta da ausência de preços em um dos lados da cadeia. ${ }^{514}$

511 MARK R. PATTERSON, Google and search-engine market power, In Harvard Journal of Law \& Technology Occasional Paper Series, jul. 2013, disponível em: http://bit.ly/1kQlVZw, acesso no dia 23, nov., 2015, p. 11.

512 JOHN M. NEWMAN, Antitrust in zero-price markets: Foundations, In University of Pennsylvania Law Review, Vol. 164, disponível em: http://bit.ly/1jEUMaX, acesso no dia 15, out., 2015, pp. 29-30.

$513 \quad$ SHELANSKI aponta em sentido similar "Even in the absence of any conventional price or output effects, anticompetitive conduct or transactions could enable platforms to exercise market power to give customers less of the good things-improved service, innovative products, and good privacy and data security policies-for which consumers might implicitly barter their information. While increased competition, at least on its own, will not always cause firms to better use or protect customer information, any competitive effects analysis that misses these two nonprice dimensions of platform market performance will be incomplete and could be biased toward underenforcement." (HOWARD SHELANSKI, Competition Policy for the Internet, In University of Pennsylvania Law Review, n. 161, v. 1663, 2012-2013, p. 1687).

514 Conforme aponta JOHN M. NEWMAN, o DOJ norte-americano, por conta do excessivo enfoque na economia de preços, acabou por desconsiderar os efeitos que concentrações econômicas nos setores de rádio- 
Deve-se, portanto, lançar a atenção sobre uma dimensão negligenciada por parte dos analistas nestes setores, ou seja, os custos de atenção e de informação dos consumidores, e que pode ser fonte de abuso e de redução do bem estar social. Nos setores de rádio, o aumento da concentração levou ao aumento do tempo disponibilizado para os anúncios publicitários, gerando, portanto, aumento dos custos de atenção por parte dos consumidores. Um caso recente que desconsiderou esta dimensão de análise ocorreu com a aquisição do aplicativo Instagram pela gigante das redes sociais Facebook. O enfoque sobre possíveis danos apenas em mercados com preço positivo fez com que analistas do FTC desconsiderassem a possibilidade de eliminação de concorrentes em um mercado de preço zero. $^{515}$

De modo geral, podemos afirmar que o oferecimento de bens de forma gratuita traz uma série de benefícios ao consumidor. $\mathrm{O}$ excedente do consumidor surge quando não há qualquer cobrança pelo bem ou quando a compensação do produtor não é reconhecida pelo consumidor como um preço a ser pago. ${ }^{516} \mathrm{Da}$ mesma forma a concorrência entre estas empresas cria estímulos para que as empresas concorram em qualidade assim como em preço. O oferecimento destes bens pode, inclusive, gerar efeitos de rede positivos aos usuários na medida em que estimulam o aumento da base instalada. Da mesma forma, ao atingir um público maior, a empresa pode aprender mais rapidamente sobre as limitações e potencial do seu produto, corrigir falhas, e atingir economias de escala e massa crítica necessária para a introdução de um novo produto. Por fim, os benefícios gerados por tais bens podem, em alguns casos, causar externalidades sociais positivas, como acontece com os softwares open source. ${ }^{517-518}$

difusão (setores com preços iguais a zero por parte dos consumidores) poderiam gerar no aumento de custos de atenção por parte dos consumidores. O enfoque nitidamente se deslocou para a questão da possibilidade de aumento de preços para os anunciantes (JOHN M. NEWMAN, Antitrust in zero-price markets: Foundations, In University of Pennsylvania Law Review, Vol. 164, disponível em: http://bit.ly/1jEUMaX, acesso no dia 15, out., 2015, pp. 35-36).

515 JOHN M. NEWMAN, Antitrust in zero-price markets: Foundations, In University of Pennsylvania Law Review, Vol. 164, disponível em: http://bit.ly/1jEUMaX, acesso no dia 15, out., 2015, pp. 42-43.

516 Tanto assim que MICHAL S. GAL e DANIEL L. RUBINFELD apontam que bens oferecidos de forma gratuita e sem contrapartida gozam de presunção de legalidade, sendo o ônus da prova de quem alega a ocorrência de prejuízo ao bem estar comprovar tais prejuízos (MICHAL S. GAL; DANIEL L. RUBINFELD, The hidden costs of free goods: Implications for Antitrust enforcement, New York University Law and Economics Working Papers, Disponível em: http://bit.ly/1Qg96Ds, acesso no dia 05, nov., 2015, p. 39).

517 MICHAL S. GAL; DANIEL L. RUBINFELD, The hidden costs of free goods: Implications for Antitrust enforcement, New York University Law and Economics Working Papers, Disponível em: http://bit.ly/1Qg96Ds, acesso no dia 05, nov., 2015, pp. 13-14. 
Por outro lado, em algumas situações, a ausência de preços pode causar prejuízos ao bem estar social, como na situação em que a firma cobra preços iguais a zero até que toda a concorrência seja eliminada e esta passe a se valer de seu poder de monopólio para auferir lucros no mercado. Além disso, o oferecimento de bens gratuitos pode afetar negativamente a qualidade dos produtos oferecidos. Se, por um lado, a ausência de preços pode incentivar a concorrência em outras dimensões, como a qualidade do produto. Por outro lado, o fornecimento gratuito por uma empresa pode criar barreiras à operação lucrativa no mercado, afetando negativamente a qualidade dos bens e serviços oferecidos. Isso causa uma redução dos incentivos para que as firmas invistam em novas tecnologias e inovação. Nesses casos, a ocorrência de lock-in e path dependance podem desestimular o investimento em tecnologias produtivas mais eficientes. ${ }^{519}$

Algumas razões levam o consumidor a preferir uma opção pelo bem ou serviço gratuito, mesmo nas situações em que o produto da concorrência com preços positivos seja superior. Em primeiro lugar, conforme vimos anteriormente, o "free effect" torna a alternativa gratuita superior aos olhos do consumidor, ainda que apresente características inferiores. Da mesma forma, o também já mencionado "deceptive framing" pode levar o consumidor a ser influenciado em seu processo decisório. Por essa razão, a combinação de racionalidade limitada, informação imperfeita e comportamento estratégico pode apontar para preferências de curto prazo para bens gratuitos, sem que haja evidência de maximização do bem estar no longo prazo. ${ }^{520}$

Além disso, conforme já afirmamos, a ausência de preços afeta outras dimensões da competição, como os custos de informação e de atenção. Desconsiderar tais custos pode levar à subavaliação do poder de mercado de uma empresa, bem como à desconsideração

518 A gratuidade associada a estes softwares faz com que diversos desenvolvedores se sintam estimulados a trabalhar gratuitamente no desenvolvimento e no aperfeiçoamento destes produtos. Nestas situações o estímulo não guarda qualquer relação com incentivos monetários, levando a possibilidades inimagináveis em tempos pré internet. Para mais informações sobre o advento de formas colaborativas de produção do conhecimento e de como estas redefinem em boa medida o conceito de firma desenvolvido por RONALD COASE, consultar YOCHAI BENKLER, Coase's Penguin, or, Linux and The Nature of the Firm, In The Yale Law Journal, Vol. 112, 2002.

519 MICHAL S. GAL; DANIEL L. RUBINFELD, The hidden costs of free goods: Implications for Antitrust enforcement, New York University Law and Economics Working Papers, Disponível em: http://bit.ly/1Qg96Ds, acesso no dia 05, nov., 2015, pp. 20-21.

520 MICHAL S. GAL; DANIEL L. RUBINFELD, The hidden costs of free goods: Implications for Antitrust enforcement, New York University Law and Economics Working Papers, Disponível em: http://bit.ly/1Qg96Ds, acesso no dia 05, nov., 2015, pp. 21-23. 
de possíveis prejuízos ao bem estar social que podem ocorrer. Sendo a realidade dos novos setores de Internet a cobrança de preços zero do consumidor a concorrência em muitas situações ocorre em relação à quantidade de informação coletada, de atenção despendida, bem como em relação à qualidade do serviço oferecido.

Dessa forma, em situações de poder de mercado dos agentes com posição dominante a diminuição do bem estar pode se associar a excessiva quantidade de informações que o consumidor deve oferecer a plataforma para obtenção dos serviços de forma gratuita. Do mesmo modo, a excessiva quantidade de propagandas a que o consumidor fica exposto para ter acesso a um serviço muitas vezes indica um resultado subótimo, decorrente de exercício de poder de mercado da plataforma.

O que devemos ter em mente é que o principal papel do direito antitruste é o de garantir que através do processo competitivo as firmas tenham incentivos para aumentar qualidade, reduzir custos, e inovar de modo que haja aumento do bem estar dos consumidores. No mercados de preço zero os principais custos consistem em custos de atenção e de informação, e, por essa razão, o papel do direito antitruste é o de garantir que os compradores (usuários) recebam os melhores produtos e serviços possíveis ao menor custo de informação e de atenção. ${ }^{521}$

\section{III.4 - Condutas exclusionárias}

Condutas anticompetitivas podem ter como objetivo excluir concorrentes do mercado, prejudicando o bem estar geral e os consumidores. Diversos modelos foram desenvolvidos para análise destas práticas, uma vez que o resultado deve variar de acordo com as variáveis envolvidas. Em muitos casos, determinadas condutas podem ser tidas como prócompetitivas, ao passo que as mesmas condutas quando analisadas em outras situações podem levar a um resultado contrário. Um exemplo disso é o caso das restrições verticais, que dependem em muitas situações desta análise de seus efeitos para que se aponte para alguma conclusão. ${ }^{52}$

521 JOHN M. NEWMAN, Antitrust in zero-price markets: Foundations, In University of Pennsylvania Law Review, Vol. 164, disponível em: http://bit.ly/1jEUMaX, acesso no dia 15, out., 2015, p. 47.

522 Na maior parte dos casos as conclusões também variam com o tempo. Um destes casos é o do RPM (Resale Price Maintenance), que durante anos foi tratado como pró-competitivo pelas autoridades antitruste, porém, vem sendo questionado e relativizado, como demonstra o recente caso da SKF, julgado recentemente 
Os diversos modelos para análise destas situações, porém, foram desenvolvidos para lidar com estruturas de um único lado e com preços positivos, não abarcando a realidade destas novas estruturas de múltiplos $\operatorname{lados}^{523}$ e com preços iguais a zero. Conforme veremos, as novas realidades desse setores tornam necessárias adaptações para análise dessas questões.

\section{III.4.1 - Questões de acesso à rede}

A compreensão da possibilidade de exclusão de concorrentes em indústrias de rede se relaciona com o conceito de "massa crítica", e sua importância para o estabelecimento de qualquer plataforma. Uma plataforma recém-criada que possua baixa adoção não terá grandes atrativos para que novos membros ingressem nela. Em muitos casos, a baixa adesão por um longo período pode levar ao seu fracasso. No entanto, a partir de um determinado ponto, a adesão de novos integrantes à plataforma ocorre de forma estrondosa, levando em muitos casos ao uso generalizado daquela rede. Este ponto consiste na chamada massa crítica, os seja, o nível mínimo de demanda necessário para que uma plataforma possa gerar o feedback positivo de usuários da rede. No início, qualquer plataforma carece dessas externalidades que autoalimentam o número de membros da rede, uma vez que ausente o número mínimo de usuários que permitam o funcionamento e que estimulem o ingresso de novos membros à rede. OZ SHY aponta que a decisão de ingressar em uma rede depende, justamente, das expectativas dos consumidores quanto ao tamanho da rede e quanto à possibilidade de sua adoção generalizada. ${ }^{524}$ Esse nível de demanda, porém, dependerá em grande medida da natureza do setor analisado, podendo ser pequeno ou extremamente elevado. ${ }^{525}$

No caso das plataformas de múltiplos lados, a estratégia pode envolver o estímulo à adesão de um dos lados com o objetivo de atrair usuários para o outro lado da plataforma.

pelo Conselho Administrativo de Defesa Econômica, em que se condenou a empresa sob o fundamento de não terem sido demonstrados os efeitos benéficos de tal conduta (CADE, Processo Administrativo $\mathrm{n}^{\circ}$ 08012.001271/2001-44).

\footnotetext{
523 "Unfortunately, the work economists have done on single-sided firms does not provide much guidance for evaluating the conduct of multi-sided firms." (DAVID S. EVANS; RICHARD SCHMALENSEE, The antitrust analysis of multi-sided platform businesses, disponível em: http://bit.ly/1KhV5mT, acesso no dia 19, mai, 2015, p. 28).

$524 \quad$ OZ SHY, The economics of network industries, Cambridge University Press, 2001, p. 3.

525 DAVID S. EVANS; RICHARD SCHMALENSEE, The antitrust analysis of multi-sided platform businesses, disponível em: http://bit.ly/1KhV5mT, acesso no dia 19, mai, 2015, p. 29.
} 
Tal estratégia recebeu o nome de "divide and conquer". Em outros casos, a plataforma só terá valor quando possuir um número significativo de usuários em ambos os lados. Nesse caso o entrante deve estimular a adesão pelos dois lados de usuários para atingir a massa crítica. $^{526}$

As estratégias de exclusão, por sua vez, podem envolver condutas como acordos de exclusividade, venda casada e preço predatório, tendo por objetivo evitar que uma plataforma concorrente atinja massa crítica suficiente para concorrer nesse mercado. Porém, a interdependência da demanda entre os lados da plataforma pode fazer com que estas condutas levem ao aumento do bem estar social, como, por exemplo, na situação em que contratos de exclusividade de um dos lados levam ao aumento do número de usuários do outro lado. ${ }^{527}$

Em muitos casos, a concorrência depende do acesso a uma plataforma já existemte, e é por essa razão que boa parte das disputas envolvendo indústrias de rede, como no caso dos mercados pontocom, se relaciona a questões de acesso a redes existentes. Agentes dominantes tendem a impedir que seus rivais ingressem em suas redes, ao passo que os concorrentes apenas conseguem concorrer com estas redes quando apresentam uma melhoria técnica significativa. ${ }^{528}$ Estas restrições muitas vezes impossibilitam a concorrência nestes setores.

Um primeiro grupo de restrições, mais clássico, se relacionaria às chamadas restrições horizontais de acesso. O caso mais exemplificativo foi o da AT\&T, no qual a empresa foi acusada de impedir que outras empresas acessassem suas redes locais, o que inviabilizaria a concorrência no setor de ligações de longa distância. $\mathrm{O}$ julgamento do caso concluiu pela ilicitude de tais condutas e pela obrigação de compartilhamento de suas redes. $^{529}$

526 DAVID S. EVANS; RICHARD SCHMALENSEE, The antitrust analysis of multi-sided platform businesses, disponível em: http://bit.ly/1 KhV5mT, acesso no dia 19, mai, 2015, p. 29.

527 DAVID S. EVANS; RICHARD SCHMALENSEE, The antitrust analysis of multi-sided platform businesses, disponível em: http://bit.ly/1KhV5mT, acesso no dia 19, mai, 2015, p. 29.

528 CARL SHAPIRO, Antitrust in network industries, disponível em http://1.usa.gov/1kDLjkC, acesso no dia 8, nov., 2015, 1996, p. 10.

529 A. DOUGLAS MELAMED, Network industries and antitrust, disponível em http://1.usa.gov/1NCT7yx, acesso no dia 8, nov., 2015, p. 152-154. 
Outro grupo de condutas se relaciona às restrições de acesso por meio do controle dos padrões de interoperabilidade. Empresas com posição dominante, ou mesmo detentoras dos direitos intelectuais sobre os padrões utilizados em determinada rede, podem se utilizar de uma série de mecanismos para impedir o acesso de concorrentes ao seu mercado, como induzir organizações de padronização a utilizarem standards de seu interesse, fazer uso abusivo de direitos de propriedade intelectual relativos aos padrões ${ }^{530}$, ou criar incompatibilidades entre seu produto e o produto dos concorrentes (tornando-o menos atrativo). ${ }^{531}$

Devemos lembrar que nestes setores a cooperação entre concorrentes se mostra fundamental, uma vez que a compatibilidade entre os produtos depende justamente do acordo com relação aos padrões de conexão. É por esta razão que, em muitos casos, acordos de cooperação levam à consolidação de uma rede maior, capturando, portanto, benefícios de rede para o sistema. Isso ocorre, por exemplo, nos casos em que o acordo entre concorrentes visa padronizar produtos de modo a garantir a interoperabilidade dentro da rede. ${ }^{532} \mathrm{Um}$ exemplo que pode ser citado é a iniciativa da ITU (International Telecommunication Union), órgão da ONU que cuida de assuntos relacionados à tecnologia da informação, para padronização dos conectores dos carregadores de celular. Pelo acordo, os fabricantes voluntariamente se comprometeriam a utilizar o conector do tipo micro-USB em todos os seus aparelhos, de modo que quaisquer cabos e carregadores pudessem funcionar com qualquer aparelho celular. ${ }^{533}$

Acordos de cooperação deste gênero podem evitar uma guerra totalmente improdutiva pelo padrão predominante. ${ }^{534}$ Algumas vezes, inclusive, o funcionamento do 530 A. DOUGLAS MELAMED, Network industries and antitrust, disponível em http://1.usa.gov/1NCT7yx, acesso no dia 8, nov., 2015, p. 156.

531 CARL SHAPIRO, Antitrust in network industries, disponível em http://1.usa.gov/1kDLjkC, acesso no dia 8, nov., 2015, 1996, p. 15.

$532 \quad$ "There is a general consensus that standards provide a wide variety of substantial procompetitive benefits." (JAMES ANTON; DENNIS YAO, Standard-setting consortia, antitrust, and high technology industries, In Antitrust law journal, vol. 64, n. 1, 1995, p. 248).

533 BBC, Universal phone charger approved, disponível em: http://bbc.in/1mThMEG, acesso no dia 12, jan., 2016.

534 CARL SHAPIRO, Antitrust in network industries, disponível em http://1.usa.gov/1kDLjkC, acesso no dia 8, nov., 2015, 1996, p. 12. No mesmo sentido EVANS e SCHMALENSEE afirmam "having the major companies agree on the standard may be better than hoping a good standard will somehow emerge from a chaotic market without explicit communication between competitors." (DAVID S. EVANS; RICHARD SCHMALENSEE, A guide to antitrust economics of networks, In Antitrust, vol. 10, n. 36, 1995-1996, p. 38). 
sistema pode ser inviável sem que haja cooperação entre concorrentes, como é o caso do sistema de cartões de pagamento. ${ }^{535}$

Nos setores pontocom um exemplo de questão envolvendo acesso a plataformas ou interoperabilidade entre sistemas é o caso da loja de músicas da Apple. A empresa norteamericana não permite que lojas de música online concorrentes ofereçam músicas para seu aparelho Ipod, ao mesmo tempo em que restringe a compatibilidade das músicas adquiridas por meio de seu software iTunes com outros reprodutores de música concorrentes, bloqueando estes arquivos para que apenas possam ser tocadas nos aparelhos da própria empresa (Ipod). Tal estratégia se baseia em um modelo de negócios de integração fechada de software e hardware que vem sendo objeto de questionamentos por parte da Comunidade Européia. ${ }^{536}$

\section{III.4.2 - Acordos de exclusividade}

Em algumas situações acordos de exclusividade podem gerar aumento do bem estar social, quando permitem o surgimento de determinados mercados ou quando estimulam a diferenciação de produtos. Conforme apontam EVANS e SCHMALENSEE, alguns modelos relacionados ao mercado de jornais demonstram que em situações em que os consumidores não tenham preferências fortes sobre o conteúdo de um dos concorrentes e os custos fixos sejam substanciais, o bem estar pode ser maior na situação pós-contratual de equilíbrio monopolista. ${ }^{537}$

No mesmo sentido, alguns estudos na área de jogos eletrônicos tem demonstrado que as exclusividades podem muitas vezes permitir a entrada ao invés de impedi-la. Nesses casos, a ausência de exclusividades faz com que os desenvolvedores de jogo tenham estímulos para redigirem jogos apenas para a plataforma dominante, tendo em vista sua maior base instalada. Nessas situações, contratos de exclusividade assinados por uma possível nova plataforma de games com alguns desenvolvedores podem levar à criação de jogos exclusivos para essa plataforma, tornando-a mais atrativa e em condições de

535 DAVID S. EVANS; RICHARD SCHMALENSEE, A guide to antitrust economics of networks, In Antitrust, vol. 10, n. 36, 1995-1996, p. 38.

536 DAVID S. EVANS, Antitrust issues raised by the emerging global internet economy, In Northwestern University Law Review, vol. 102, n.4, 2008, p. 19.

537 DAVID S. EVANS; RICHARD SCHMALENSEE, The antitrust analysis of multi-sided platform businesses, disponível em: http://bit.ly/1KhV5mT, acesso no dia 19, mai, 2015, p. 30. 
concorrer. Isso traz benefícios ao bem estar social na medida em que permite a entrada de um novo player, bem como sua diferenciação em relação às outras plataformas. ${ }^{538}$

Por outro lado, o uso de exclusividades por players com posição dominante podem gerar efeitos de exclusão, especialmente em plataformas de múltiplos lados. Em alguns casos, um agente pode oferecer atrativos contratos de exclusividade de um dos lados da plataforma ao mesmo tempo em que obtém seu faturamento da cobrança de preços mais altos do outro lado da rede. Nessa situação, de forma semelhante às situações que exijam economias de escala, o ingresso de um novo player é impedido pela incapacidade de atingir um número suficiente de consumidores que supere a massa crítica necessária. ${ }^{539}$

Desse modo, o que devemos ter em conta é que, assim como nos outros setores, não há uma regra absoluta em relação a estes contratos. Sendo necessário, portanto, que ao analisar tais acordos, sejam considerados o contexto em que foram firmados, bem como seus eventuais efeitos pró-competitivos decorrentes da manutenção de sua massa crítica. ${ }^{540}$

\section{III.4.3 - Venda casada e integração de serviços}

A venda casada (tying) se refere à situação em que o vendedor condiciona a venda de um produto ou serviço à aquisição de outro produto ou serviço. Sua implementação pode ocorrer por via contratual ou por via tecnológica, quando ocorre uma integração por meio físico ou do design do produto. ${ }^{541}$

A estrutura do ecossistema web faz com que as empresas dominantes tenham claros incentivos para estenderem seu poder de mercado para produtos ou serviços adjacentes. Um exemplo desta prática, citado por DAVID S. EVANS, é o caso do Google Checkout, sistema de pagamentos da Google concorrente do sistema PayPal. Ao lançar tal serviço, a Google fez a integração deste com o código do Google Product Search (outro serviço da empresa) ao mesmo tempo em que oferecia este em conjunto com o AdWorks para os

538 DAVID S. EVANS; RICHARD SCHMALENSEE, The antitrust analysis of multi-sided platform businesses, disponível em: http://bit.ly/1KhV5mT, acesso no dia 19, mai, 2015, p. 30.

539 DAVID S. EVANS; RICHARD SCHMALENSEE, The antitrust analysis of multi-sided platform businesses, disponível em: http://bit.ly/1KhV5mT, acesso no dia 19, mai, 2015, p. 30.

540 DAVID S. EVANS; RICHARD SCHMALENSEE, The antitrust analysis of multi-sided platform businesses, disponível em: http://bit.ly/1KhV5mT, acesso no dia 19, mai, 2015, pp. 31-32.

541 BENJAMIN EDELMAN, Does google leverage market power through tying and bundling?, In Journal of Competition Law and Economics, vol. 11, n. 2, 2015, pp. 365-366. 
anunciantes. ${ }^{542-543}$ Isso permitia que a empresa se valesse do domínio no setor de buscas e de anúncios direcionados com o objetivo de entrar no mercado de sistemas de pagamentos.

Em diversas situações, a venda casada promove eficiências ao juntar dois bens complementares, fornecendo bens mais baratos e melhores. O exemplo clássico é o do sapato, que é comercializado com o cadarço ou o dos carros, comercializados juntamente com os pneus. Por outro lado, em algumas situações, tais práticas também podem acabar gerando efeitos exclusionários. A empresa pode se valer do poder de monopólio em um mercado para vender um bem de um segundo mercado de forma casada na tentativa de estender seu poder para o mercado desse bem complementar. ${ }^{544}$

A estratégia da empresa pode, ainda, visar proteger o mercado principal da entrada de um novo bem complementar que pudesse atuar como substituto do bem principal. Nessa situação a empresa vende de forma conjunta um bem complementar com o objetivo de fechar o mercado para esse bem, prevenindo a perda no mercado do bem principal. $\mathrm{O}$ objetivo, portanto, não seria a extensão de seu poder para mercados adjacentes, mas sim o de impedir que os consumidores migrem para novos serviços que venham a surgir. Foi o que ocorreu no caso Microsoft com a integração do browser Internet Explorer ao Windows. Prevendo que a competição se deslocaria para o mercado de browsers e prevendo que estes poderiam se tornar substitutos aos sistemas operacionais, a empresa integrou os serviços de modo a proteger seu sistema operacional. ${ }^{545}$ É por esta razão que, nestes mercados, as empresa dominantes possuem poderosos incentivos para estabelecer monopólios sobre serviços adjacentes. Em muitos casos, são as barreiras criadas pelos efeitos indiretos de rede que acabam viabilizando estratégias para eliminar ou excluir rivais. $^{546}$

542 DAVID S. EVANS, Antitrust issues raised by the emerging global internet economy, In Northwestern University Law Review, vol. 102, n.4, 2008, p. 18.

543 Outro exemplo que vem sendo investigado pelo Sistema Brasileiro de Defesa da Concorrência é o da Representação feita pelo site Buscapé, na qual a empresa alega que a Google manipulou seu algoritmo de modo a favorecer seus produtos em detrimento do site da empresa brasileira, líder no seguimento de busca de preços de produtos (PA n $\left.{ }^{\circ} 080012.010483 / 2011-94\right)$.

544 BENJAMIN EDELMAN, Does google leverage market power through tying and bundling?, In Journal of Competition Law and Economics, vol. 11, n. 2, 2015, pp. 365-366.

545 BENJAMIN EDELMAN, Does google leverage market power through tying and bundling?, In Journal of Competition Law and Economics, vol. 11, n. 2, 2015, p. 367.

546 A. DOUGLAS MELAMED, Network industries and antitrust, disponível em http://1.usa.gov/1NCT7yx, acesso no dia 8, nov., 2015, p. 151. 
Devemos apontar, ainda, que, no caso de bens complementares, cria-se a impressão de que um bem esteja sendo fornecido de forma gratuita, quando, na verdade seu preço está embutido no preço do bem principal. No caso Microsoft, por exemplo, o navegador oferecido de forma gratuita não era verdadeiramente gratuito, uma vez que seu preço estava embutido no preço cobrado pelo sistema operacional, ou seja, a combinação dos dois produtos tinha um custo positivo. É por essa razão que alguns autores defendem que a consideração do mercado destes produtos considere o conjunto dos produtos, conforme vimos acima. ${ }^{547}$

Desde o caso Microsoft, a discussão com relação à licitude da integração de novas funcionalidades a um programa de computador trazem enormes discussões de ordem concorrencial. Com o advento das plataformas web tais discussões tendem a se acirrar, uma vez que a prática de tying vem surgindo sob diversas roupagens distintas. Em 2013, por exemplo, a empresa Google passou a exigir que os usuários realizassem o login em sua conta da rede social Google+ para que pudessem realizar comentários nos vídeos do site YouTube. Apesar da empresa alegar a necessidade de login para evitar a ocorrência de Spams, neste caso não se nota qualquer justificativa para a necessidade do usuário assinar um novo serviço oferecido pela empresa (a rede social Google+) para que pudesse usufruir de um serviço que este já utilizava (no caso o YouTube). O que se percebe neste e em inúmeros outros casos é a utilização de uma plataforma estabelecida (o site de vídeos YouTube) com o único objetivo de tentar alavancar uma plataforma ainda incipiente (no caso a rede social Google+). ${ }^{548}$

Os baixos custos marginais destes produtos e a maior eficiência associada aos produtos com maior gama de funcionalidades constituem poderosos incentivos para que as empresas apostem nestas práticas. ${ }^{549}$ Em muitos casos, esta integração traz benefícios diretos aos consumidores, que recebem maiores funcionalidades em um mesmo pacote sem

547 MICHAL S. GAL; DANIEL L. RUBINFELD, The hidden costs of free goods: Implications for Antitrust enforcement, New York University Law and Economics Working Papers, Disponível em: http://bit.ly/1Qg96Ds, acesso no dia 05, nov., 2015, p. 24.

548 BENJAMIN EDELMAN, Does google leverage market power through tying and bundling?, In Journal of Competition Law and Economics, vol. 11, n. 2, 2015, p. 367. Para mais informações sobre o caso Microsoft consultar LEANDRO SAITO, A “propriedade” intelectual como barreira à entrada de novos players no mercado de softwares, IBPI. 2012. Disponível em: http://bit.ly/1MQEGIp, acesso no dia 8, nov., 2015.

549 DAVID S. EVANS, Antitrust issues raised by the emerging global internet economy, In Northwestern University Law Review, vol. 102, n.4, 2008, p. 20. 
a necessidade de adquirirem outros produtos. É por esta razão que as autoridades antitruste (inclusive o DOJ norte americano) tendem a aplicar a rule of reason para análise destas condutas.

A análise deve considerar seis questões principais: (i) o representado possui poder de mercado no setor do bem principal?; (ii) o bem principal e o complementar são distintos?; (iii) os produtos são vendidos de forma conjunta?; (iv) a venda casada impede a entrada de concorrentes?; (v) a venda casada gera prejuízos ao consumidor?; (vi) surgem eficiências dessa integração? ${ }^{550}$

Em qualquer economia baseada em redes o uso intensivo de discriminação de preços e de sistemas complexos de precificação traz enorme dificuldade para compreensão de mecanismos de tying e venda casada. As dificuldades aumentam quando lembramos que a análise tradicional se baseia em grande parte num cálculo de custos e preços e os bens da nova economia são em grande medida oferecidos gratuitamente. ${ }^{551}$ Deve-se ressaltar que a racionalidade econômica por trás dos mecanismos de precificação destes bens se liga diretamente à teoria dos mercados de múltiplos lados, nos quais a estratégia de distribuição de bens a preço zero muitas vezes se justifica pela necessidade de aumentar a base instalada da rede, com o objetivo de usufruir dos benefícios gerados pelas externalidades de rede. ${ }^{552}$ Da mesma forma, a cobrança de preços baixos pode ter como objetivo aumentar a demanda de outro bem complementar fabricado pela mesma empresa. Este tipo de estratégia é comum em mercados de dois lados, nos quais a empresa distribui estrategicamente a lucratividade pelos dois lados da cadeia. ${ }^{553}$

$550 \quad$ BENJAMIN EDELMAN, Does google leverage market power through tying and bundling?, In Journal of Competition Law and Economics, vol. 11, n. 2, 2015, pp. 368-369.

551 DAVID S. EVANS; RICHARD SCHMALENSEE, A guide to antitrust economics of networks, In Antitrust, vol. 10, n. 36, 1995-1996, p. 38.

$552 \quad$ "In such a context, the positive externality must be extended to the individual consumer to induce the consumer to join. Thus, apparent below cost pricing -- that is, setting price below the cost of joining to the individual consumer -- is essential in order to create optimal network size" (GEORGE L. PRIEST, Rethinking antitrust Law in age of network industries, Yale Law \& Economics Research Paper No. 352, disponível em: http://bit.ly/1MiDyYy, acesso no dia 8, nov., 2015, p. 9). No mesmo sentido EVANS e SCHMALENSEE: "Sellers may therefore price new products very low to generate a bandwagon effect" (DAVID S. EVANS; RICHARD SCHMALENSEE, A guide to antitrust economics of networks, In Antitrust, vol. 10, n. 36, 1995-1996, p. 38)

553 DAVID S. EVANS; RICHARD SCHMALENSEE, A guide to antitrust economics of networks, In Antitrust, vol. 10, n. 36, 1995-1996, p. 38. 
A análise de vendas casadas no contexto das indústrias de múltiplos lados traz uma série de complicações pela necessidade de consideração dos inúmeros lados envolvidos. Alguns modelos econômicos, porém, apontam que a existência de externalidades de rede pode permitir a lucratividade destas estratégias, mesmo na ausência de condutas exclusionárias. Em outros casos, como no dos cartões de pagamento analisado por ROCHET e TIROLE, a estratégia de integrar dois serviços podem levar ao aumento do bem estar social. Nessa situação, ao permitir que uma bandeira venda seus serviços de débito e crédito de forma integrada ao comerciante, esta consegue rebalancear suas taxas de modo que possa reduzir as tarifas dos cartões de crédito ao aumentar as tarifas do cartão de débito acima do nível competitivo. ${ }^{554}$

Nos casos de bundle, ou seja, do oferecimento de um bem gratuito em conjunto com outro produto pago (bundle) podem surgir relevantes barreiras à entrada. Estas decorrem da necessidade de um entrante oferecer os dois produtos de forma conjunta para ingressar nesse mercado. Para que possa concorrer, o novo competidor deve oferecer o produto complementar de forma gratuita, oferecer outro produto ou aumentar o valor do bem primário de modo que este seja maior do que o valor do bem oferecido gratuitamente pelos concorrentes. Nessa situação, algumas empresas simplesmente não devem conseguir ingressar nesse mercado, ainda que ofereçam um produto mais eficiente. As externalidades geradas pelo oferecimento de bens gratuitos também trazem consequências sobre o comportamento do consumidor, uma vez o oferecimento de bens gratuitos aos consumidores geram uma maior expectativa de que outros produtos também sejam oferecidos a preço zero. ${ }^{555}$ Isso ocorre, por exemplo, em regiões onde o café da manhã é tradicionalmente oferecido de forma gratuita com a estadia no hotel, como em hotéis localizados no Brasil. Nessas condições é comum que o consumidor espere pelo oferecimento desse bem de forma gratuita. Em regiões onde tradicionalmente não se goza desse benefício, como em hotéis norte-americanos, a inclusão do café da manhã como cortesia constitui um importante diferencial.

\footnotetext{
554 DAVID S. EVANS; RICHARD SCHMALENSEE, The antitrust analysis of multi-sided platform businesses, disponível em: http://bit.ly/1KhV5mT, acesso no dia 19, mai, 2015, pp. 31-32.

555 MICHAL S. GAL; DANIEL L. RUBINFELD, The hidden costs of free goods: Implications for Antitrust enforcement, New York University Law and Economics Working Papers, Disponível em: http://bit.ly/1Qg96Ds, acesso no dia 05, nov., 2015, pp. 15-16.
} 
Da mesma forma, o "free effect" explicitado pela Economia Comportamental causa potenciais efeitos sobre o consumidor que não podem ser previstos pela análise simples de preços. Alguns estudos do mercado de turismo apontam que a diferença do valor que o consumidor atribui para um pacote de hotel com café da manhã em comparação com um pacote sem café da manhã seja superior ao valor atribuído por este ao café da manhã isoladamente. ${ }^{556}$

É por estas razões que o oferecimento de bens de forma gratuita traz especial potencial de exclusão. A empresa Google, por exemplo, passou a exigir dos fabricantes de smartphones e tablets que desejassem instalar em seus dispositivos qualquer serviço da empresa como o Maps, YouTube, ou a loja Google Play, uma série de obrigações, dentre as quais se incluía a obrigação não apenas de instalar todos os aplicativos da Google especificados pela empresa, como também a de colocar os ícones desses aplicativos em posição de destaque na tela do aparelho. Além disso, os dispositivos teriam de se utilizar do serviços de localização da Google Location Services, ainda que tivessem a sua disposição o uso de concorrentes mais rápidos e precisos. Todas essas obrigações, por sua vez, não vinham acompanhadas de qualquer obrigação pecuniária por parte da Google.

$\mathrm{O}$ "free effect" descrito anteriormente aumenta o potencial de exclusão. O maior valor dado pelo consumidor aos produtos gratuitos cria estímulos para que a empresa realize menores investimentos na qualidade do produto gratuito, uma vez que este gera uma vantagem embutida no produto pago e reduz a importância do preço como variável competitiva. Essa situação não leva, necessariamente, à redução do bem estar social, uma vez que os potenciais prejuízos podem ser mitigados pelos benefícios decorrentes de efeitos positivos de rede e de efeitos cruzados de rede. ${ }^{557}$

A ausência de bundle torna a análise ainda mais complexa. Conforme observamos, em setores de múltiplos lados a demanda de um dos grupos acaba por afetar a demanda do outro grupo. Dessa forma, os agentes se valem do "free effect" para aumentarem a demanda de um dos lados da plataforma com a finalidade de aumentar os lucros do outro lado da plataforma. Tal modelo se aplica, por exemplo, ao Facebook, que oferece os

556 MICHAL S. GAL; DANIEL L. RUBINFELD, The hidden costs of free goods: Implications for Antitrust enforcement, New York University Law and Economics Working Papers, Disponível em: http://bit.ly/1Qg96Ds, acesso no dia 05, nov., 2015, pp. 15-16.

557 MICHAL S. GAL; DANIEL L. RUBINFELD, The hidden costs of free goods: Implications for Antitrust enforcement, New York University Law and Economics Working Papers, Disponível em: http://bit.ly/1Qg96Ds, acesso no dia 05, nov., 2015, p. 16. 
serviços de forma gratuita aos usuários, ao passo que tem seu faturamento garantido com a comercialização de espaços publicitários com anúncios direcionados. Esse modelo aumenta as barreiras à entrada, uma vez que a necessidade de economias de escala, de efeitos de rede e a necessidade de oferecimento de múltiplos produtos torna a entrada mais difícil. ${ }^{558}$

Outra estratégia adotada por tais empresas que se assemelham às práticas de venda casada consistem numa estratégia de duas fases. Numa primeira fase o produto é oferecido de forma gratuita, de modo que o consumidor possa conhecer o produto, levando ao aumento da base de usuários e construindo sua reputação. Em uma segunda fase, porém após a consolidação do produto, a empresa passa a cobrar por seu uso, por meio de upgrades ou versões premium. ${ }^{559-560}$

Nessas situações, a possibilidade de exclusão de concorrentes vai depender dos resultados gerados no curto e no longo prazo. O oferecimento de bens gratuitos em dois estágios pode gerar efeitos semelhantes ao da venda casada, ao criar a necessidade do possível entrante ingressar em dois mercados. Além disso, podem ser criadas barreiras temporárias durante o período de oferecimento do serviço de forma gratuita. A redução do bem estar social e os prejuízos aos consumidores dependerá em grande medida da natureza do bens oferecidos. Para que estas estratégias sejam viáveis devem ser criadas barreiras no segmento lucrativo do mercado, caso contrário uma empresa pode entrar apenas no segmento lucrativo, reduzindo seus custos ao evitar as perdas no segmento oferecido gratuitamente.

558 MICHAL S. GAL; DANIEL L. RUBINFELD, The hidden costs of free goods: Implications for Antitrust enforcement, New York University Law and Economics Working Papers, Disponível em: http://bit.ly/1Qg96Ds, acesso no dia 05, nov., 2015, pp. 16-17.

559 Um exemplo dessa estratégia ocorreu com o aplicativo de mensagens Whatsapp. Inicialmente oferecido de forma gratuita aos usuários do sistema Android, após o oferecimento por meio de cobrança única aos usuários do iOS a empresa passou a oferecer o app com um ano de uso gratuito com cobrança de tarifa anual nos anos seguintes. A gratuidade oferecida nos primeiros anos tinha justamente o objetivo de aumentar e fidelizar o número de usuários, consolidando sua reputação e seu uso no mercado.

560 A lucratividade do produto pode, ainda, decorrer da venda de seus direitos no segundo estágio. Esta foi a estratégia adotada pelo aplicativo de navegação Waze. Seus serviços sempre foram oferecidos de forma gratuita e, em um primeiro momento, sem o oferecimento de propagandas. Com a consolidação a empresa passou a oferecer anúncios e cupons para serviços de anunciantes. No entanto, o verdadeiro faturamento ocorreu com a venda dos direitos da empresa para a empresa Google (MICHAL S. GAL; DANIEL L. RUBINFELD, The hidden costs of free goods: Implications for Antitrust enforcement, New York University Law and Economics Working Papers, disponível em: http://bit.ly/1Qg96Ds, acesso no dia 05, nov., 2015, pp. 17-18). 
No caso do buscador da Google inúmeros outros serviços são oferecidos de forma conjunta. Ao realizar uma busca nessa plataforma, o usuário tem acesso não apenas aos resultados de busca, mas também aos resultados de inúmeros serviços de busca vertical, de busca em mapas, dentre outros serviços, como o Google Book Search, Google Flight Search, e Google Images. Os resultados de pesquisa dos sistemas de busca vertical da empresa sempre aparecem de alguma forma em destaque na página de seu buscador. Para tanto, estes se apresentam na página dos resultados de busca com formatação diferenciada dos outros resultados, com o uso de fotos e cores que tragam algum tipo de realce. $\mathrm{O}$ uso destas "rich user interfaces" levam o consumidor a dar preferência a estes links em detrimento dos outros resultados apresentados. ${ }^{561}$

Ainda que se possa argumentar não se tratar de um caso clássico de venda casada, uma vez que ambos serviços são oferecidos de forma gratuita ao usuário e sem a obrigação do usuário utilizar do segundo serviço complementar, a estrutura de decisão dos usuários faz com que ocorra um forte direcionamento para que estes decidam pelo uso dos serviços complementares da empresa. A escolha por um outro serviço implica numa atitude proativa por parte do usuário no sentido de ignorar os resultados da Google e procurar outros links não mostrados de forma ostensiva pelo buscador. A psicologia demonstra as dificuldades de mudança quando relacionada a hábitos automatizados pelo usuário. ${ }^{562}$ Muitas dúvidas surgem com relação aos prejuízos ao consumidor bem como à licitude de condutas como a do Google. As particularidades do caso Google serão estudadas em capítulo posterior.

O que devemos notar é que a análise de venda casada em setores pontocom envolve enorme complexidade, uma vez que a integração de novas funcionalidades, na maior parte das vezes, traz benefícios diretos aos consumidores sem que haja qualquer aumento direto de preços de venda dos produtos. Tais benefícios se mostram controvertidos, ao mesmo tempo em que a ausência de custos monetários não implica na ausência de quaiquer custos.

561 BENJAMIN EDELMAN, Does google leverage market power through tying and bundling?, In Journal of Competition Law and Economics, vol. 11, n. 2, 2015, pp. 369-370.

562 BENJAMIN EDELMAN, Does google leverage market power through tying and bundling?, In Journal of Competition Law and Economics, vol. 11, n. 2, 2015, p. 372. 


\section{III.4.4 - Preço predatório}

A análise tradicional de práticas de preço predatório envolve a consideração de dois momentos distintos: da possibilidade do agente cobrar preços baixos em um primeiro momento com o objetivo de eliminar a concorrência, para, em um momento posterior, aumentar seus preços e recuperar seu investimento. O sucesso dessa estratégia depende em grande medida de barreiras suficientes que impeçam a entrada de novos competidores no segundo momento. Para sua caracterização o monopolista deve cobrar um custo inferior a uma determinada medida de custo que aponte para a inviabilidade do negócio a longo prazo. Alguns ordenamentos, como o da União Européia, apontam presunção de ilegalidade para as situações de preços abaixo de um patamar de preços estabelecido, definido como o preço de custo do bem. Nestas situações um preço igual a zero se apresenta como nitidamente anticompetitivo uma vez que zero sempre será abaixo do preço de custo de um bem. ${ }^{563}$

Nessa linha, se valendo de uma abordagem baseada em uma análise estritamente formal um tribunal francês condenou a empresa Google pelo oferecimento de aplicações de mapas de forma gratuita. Segundo o entendimento da corte francesa, ao concorrer com outra empresa, chamada Bottin Cartographes, que cobrava pelo oferecimento de serviço similar, a Google incorreu em abuso de posição dominante ao cobrar preço predatório no mercado de serviços de cartografia on-line. O parâmetro utilizado para condenar a empresa foi o do custo variável médio: sendo o preço de zero inferior a este custo, entendeu o tribunal que houve prática de preço predatório por parte da Google. ${ }^{564}$

O que percebemos com a análise desses casos é que a aplicação de critérios baseados exclusivamente em preços, e que desconsidere a estrutura de múltiplos lados dessas novas plataformas pode levar a resultados desastrosos. A análise simples da variável preço em estruturas de preços iguais a zero não pode concluir pela cobrança de preços abaixo do custo marginal, desconsiderando por completo a possibilidade de financiamento e de sustentabilidade do negócio pela cobrança de outros lados da plataforma. Ao ignorar

563 MICHAL S. GAL; DANIEL L. RUBINFELD, The hidden costs of free goods: Implications for Antitrust enforcement, New York University Law and Economics Working Papers, Disponível em: http://bit.ly/1Qg96Ds, acesso no dia 05, nov., 2015, p. 41.

564 MICHAL S. GAL; DANIEL L. RUBINFELD, The hidden costs of free goods: Implications for Antitrust enforcement, New York University Law and Economics Working Papers, Disponível em: http://bit.ly/1Qg96Ds, acesso no dia 05, nov., 2015, pp. 41-42. 
estas características a autoridade corre sérios riscos de incorrer em falsos positivos ou de falsos negativos em sua análise.

\section{III.5 - Bases de dados e uso de informacões de navegacão}

Outro grupo de casos controvertidos envolvendo empresas pontocom se relaciona à obtenção e ao uso de dados com informações pessoais de consumidores, coletados durante a utilização de plataformas web pelos usuários. Dentre estas informações temos, por exemplo, dados relativos à confiabilidade de vendedores do site Ebay, dados de buscas armazenados pela Google, históricos de compras, entre outros. Tendo em vista que a posse destas informações muitas vezes é essencial para que um agente possa competir em determinados setores, DAVID S. EVANS relata que alguns casos relacionados à posse de dados vêm sendo levados à análise da autoridade européia com fundamento na teoria da essential facilities doctrine. ${ }^{565}$ Estas empresas alegam que o acesso a estas informações constitui uma "facilidade essencial" para que se possa competir nestes mercados e, portanto, deveriam ser compartilhadas com os concorrentes.

Tais discussões apresentam uma série de problemas relacionados à privacidade dos usuários, ao estímulo à inovação e mesmo à própria dinâmica competitiva destes mercados, portanto, ainda devem passar por intensas discussões para que se estabeleçam parâmetros adequados para sua resolução.

MANNE e WRIGHT, por exemplo, defendem que a posse de uma imensa base de dados de navegação por parte do Google não seria uma barreira que impedisse a contestabilidade desse monopólio, uma vez que, na medida em que estas informações passaram a ser comercializadas entre os agentes, se tornaram verdadeiras commodities. ${ }^{566}$ Assim, ainda que a posse de tais dados faça com que nenhum outro mecanismo de buscas

565 DAVID S. EVANS, Antitrust issues raised by the emerging global internet economy, In Northwestern University Law Review, vol. 102, n.4, 2008, p. 19.

\footnotetext{
566 Um caso recente que envolve a comercialização de dados pessoais como um verdadeiro ativo das companhias foi o caso da empresa Viber, maior aplicativo do mundo de voz sobre IP (aplicativo de comunicação através da Internet), adquirida por uma empresa chinesa interessada em acessar a base de dados de seus usuários (em torno de 40 milhões à época da venda. Tal aquisição não parece gerar preocupações em um primeiro momento, uma vez que os serviços continuam a ser prestados de forma gratuita, no entanto, podem ocorrer práticas exclusionárias em um segundo momento (MICHAL S. GAL; DANIEL L. RUBINFELD, The hidden costs of free goods: Implications for Antitrust enforcement, New York University Law and Economics Working Papers, Disponível em: http://bit.ly/1Qg96Ds, acesso no dia 05, nov., 2015, pp. 18-19).
} 
consiga competir com o Google, tal fato não torna esse monopólio perpétuo, uma vez que outra tecnologia poderá superá-lo se valendo de outras fontes de dados. Um exemplo dessa possibilidade estaria no fato do Facebook ter iniciado suas investidas no setor de buscas utilizando-se de dados de navegação de seus usuários em sua plataforma. ${ }^{567}$

Por essa razão, empresas como Facebook e Bing tem mostrado a possibilidade de sucesso no setor de buscas ao se utilizar de fontes de dados próprias e de tecnologias inovadoras capazes de satisfazerem aos usuários e anunciantes de forma até mesmo melhor que o Google em algumas situações. ${ }^{568}$

\section{III.6 - Condutas colusivas}

A interpretação do que seria um acordo entre concorrentes presente na lei antitruste (Sherman Act) envolve inúmeras discussões nos Estados Unidos. De modo geral, se considera que o simples comportamento paralelo, sem um acordo expresso não incorreria na proibição da lei. Alguns autores como POSNER, no entanto, entendem que a colusão tácita não constitui um estado de inconsciência do agente, uma vez que ao restringir o volume de vendas ou ao aumentar o preço o agente está aceitando um acordo tácito proposto pelo concorrente. Nessa linha de raciocínio, o autor entende que ocorreria colusão mesmo em situações em que os preços sejam definidos de forma independente e sem comunicação ou sinalização entre os concorrentes. Outros autores como TURNER acreditam que a interpretação dada por POSNER seria excessiva, uma vez que seria racional o concorrente adotar estratégia similar (paralelismo estratégico). ${ }^{569}$

No entanto, práticas colusivas, em geral, envolvem uma enorme complexidade associada a produção de provas com relação ao acordo. Isso se mostra ainda mais complexo nos novos setores de Internet. Conforme observamos no CAPÍTULO II, uma das marcas características dos setores de Internet consiste no uso cada vez mais frequente e disseminado dos chamados algoritmos inteligentes. Por essa razão, nestes setores, a análise

567 GEOFFREY A. MANNE; WILLIAM RINEHART, The market realities that undermined the FTC's antitrust case against Google, In Harvard journal of law and technology occasional paper series, July, 2013, disponível em: http://bit.ly/1FCV4Ce, Acesso em 25, jun. 2015, p. 15.

568 GEOFFREY A. MANNE; WILLIAM RINEHART, The market realities that undermined the FTC's antitrust case against Google, In Harvard journal of law and technology occasional paper series, July, 2013, disponível em: http://bit.ly/1FCV4Ce, Acesso em 25, jun. 2015, pp. 15-16.

569 SALIL K. MEHRA, Antitrust and the Robo-Seller: Competition in the time of algorithms, disponível em: http://bit.ly/1kZQtrk, acesso no dia 16, nov., 2015, p.20-22. 
da práticas de colusão tornam-se ainda mais complexas, uma vez práticas similares aos cartéis são realizadas com o uso destes algoritmos, ou por computadores programados, e que não incorrem em práticas concertadas tradicionais, sendo muitas vezes extremamente tênue a linha que separa a colusão do mero paralelismo de preços. Além disso, como a prática envolve o uso de computadores elas se encontram sujeitas a menores bias comportamental e se mostram menos eficazes à imposição de sanções pela autoridade antitruste. $^{570}$

A ocorrência deste tipo de conduta vem se tornando extremamente frequente na era da Internet, sendo exemplos dessas práticas o modelo de fixação de preços da plataforma de smartphones Uber bem como a fixação de preços na plataforma da Amazon Marketplace. O caso da Amazon é paradigmático dessa situação. No ano de 2011, um livro de biologia sobre insetos chamado "The making of a fly: The Genetics of animal design" teve seu preço fixado em 23,7 milhões de dólares pela plataforma da empresa norteamericana. Nesse caso, dois vendedores independentes, que utilizam a plataforma da Amazon Marketplace para comercializarem seus produtos, fixaram o preço do seu livro com base no preço de seu concorrente por meio de um algoritmo: enquanto o primeiro deles fixou o preço em 1,27 vezes o preço do segundo vendedor, o segundo vendedor fixou o preço em 0,99 vezes o preço atribuído pelo primeiro vendedor. Isso levou a uma espiral de aumento mútuo dos preços que levou o preço final ao valor inacreditável de 23,7 milhões de dólares, sem que nenhum dos dois agentes tivessem tomado consciência da situação absurda. ${ }^{571}$ Tal exemplo demonstra situações em que os agentes acabam incorrendo em um paralelismo de preços no qual a intenção dos agentes não seria a de subir preços de forma conjunta.

Conforme veremos, o uso de algoritmos inteligentes ou de robôs cria incentivos para que as firmas individualmente aumentem preços, mesmo na ausência de coordenação.

\footnotetext{
$570 \quad$ "Computers may limit competition not only through agreement or concerted practice, but also through more subtle means. For example, this may be the case when similar computer algorithms promote a stable market environment in which they predict each other's reaction and dominant strategy. Such a digitalised environment may be more predictable and controllable. Furthermore, it does not suffer from behavioural biases and is less susceptive to possible deterrent effects generated through antitrust enforcement." (ARIEL EZRACHI; MAURICE E. STUCKE, Artificial Intelligence \& Collusion: When Computers Inhibit Competition, disponível em: http://bit.ly/1MXhdC3, acesso em 06, out., 2015, p. 7).

571 Conforme relata SALIL K. MEHRA, Antitrust and the Robo-Seller: Competition in the time of algorithms, disponível em: http://bit.ly/1kZQtrk, acesso no dia 16, nov., 2015, p. 2. A história completa se encontra disponível em: http://cnn.it/1N76IiU.
} 
Tais acordos se mostram, inclusive, mais estáveis do que cartéis tradicionais, pela ausência de bias humano.

Num modelo de equilíbrio de NASH as firmas maximizam seu lucro não ao igualar o preço ao custo marginal do produto, como determina o modelo de competição perfeita, mas ao dividirem entre si o nível de produção de monopólio. Para que tal fim seja atingido, porém, as empresas devem agir de forma coordenada, de modo que todas reduzam o nível de produção. Conforme os modelos de teoria dos jogos (em especial o modelo de equilíbrio de NASH), se as firmas interagirem diariamente, de forma infinita, a tendência é que elas adotem uma estratégia de manter o nível de produção de monopólio, salvo se uma das empresas quebrar o equilíbrio e aumentar seu nível de produção. Segundo aponta a teoria econômica, o método mais eficiente de impedir que um dos jogadores traia o cartel consiste na ameaça dos outros competidores abaixarem seus preços aos patamares competitivos ao primeiro sinal de que um dos membros traiu o conluio. ${ }^{572}$

Uma traição por parte de uma empresa gera ganhos em um primeiro momento que serão logo descontados em um segundo momento por conta da perda do preço de cartel nos períodos subsequentes. Dessa forma, o participante do cartel apenas irá traí-lo se a taxa de desconto futura não superar os ganhos do primeiro período. Ou seja, a viabilidade do cartel depende da taxa de desconto não ser muito elevada. ${ }^{573}$

O uso de algoritmos e computadores nas decisões de precificação faz com que a detecção de uma eventual quebra do acordo seja muito mais barata e rápida. Três aspectos fazem com que o uso destes mecanismos aumente os riscos do dilema do oligopólio. Em primeiro lugar, as traições, com redução de preços se mostram mais rapidamente detectáveis, o que diminue os ganhos do primeiro período. Em segundo lugar, o maior volume de informações e o seu consequente processamento por meio desses algoritmos faz com que os erros de interpretação e de decisão sejam minimizados. Por fim, o uso de algoritmos diminui a possibilidade de bias humano, que podem levar os empregados das firmas a agirem contrariamente ao interesse da empresa. ${ }^{574}$

572 Conforme relata SALIL K. MEHRA, Antitrust and the Robo-Seller: Competition in the time of algorithms, disponível em: http://bit.ly/1kZQtrk, acesso no dia 16, nov., 2015, pp. 26-28.

573 Conforme relata SALIL K. MEHRA, Antitrust and the Robo-Seller: Competition in the time of algorithms, disponível em: http://bit.ly/1kZQtrk, acesso no dia 16, nov., 2015, pp. 27-28.

574 Conforme relata SALIL K. MEHRA, Antitrust and the Robo-Seller: Competition in the time of algorithms, disponível em: http://bit.ly/1kZQtrk, acesso no dia 16, nov., 2015, p. 30. Conforme aponta o 
As autoridades antitruste, da mesma forma, enfrentam enormes desafios para condenação de práticas que se valem do uso de computadores. Dentre esses podemos destacar três grandes dificuldades. A primeira se relaciona a excessiva ênfase na intenção dos agentes, a segunda se relaciona à incapacidade das agências se valerem de táticas de criação de quebra de confiança e medo para gerar instabilidade aos acordos com institutos como o da leniência, e, por fim, a ênfase em noções contratuais de acordo para prova do conluio. $^{575}$

A questão da intenção é objeto de intenso debate nos Estados Unidos. O parâmetro largamente adotado pela Suprema Corte norte-americana coloca a intenção como elemento essencial para condenação por práticas anticompetitivas, especialmente em matéria de condutas exclusionárias e de monopolização. O uso disseminado dos algoritmos faz com que a prova da intenção seja ainda mais complexa, uma vez que as decisões de excluir concorrentes não serão acompanhadas de e-mails ou qualquer registro escrito ou falado. Do mesmo modo, mudanças de política comercial e de preços são cada vez mais realizadas pela interação de complexos sistemas de algoritmos. As anotações realizadas pelos programadores também não fornecem material adequado uma vez que se mostram muito mais complexas do que conversas entre setores de vendas e de marketing das empresas. ${ }^{576}$

O modelo de comportamento desenvolvido para análise dos cartéis tradicionalmente aceito consiste numa sequência de jogos de dilema do prisioneiro. $\mathrm{O}$ problema para sua manutenção, portanto, consiste na impossibilidade de enforcement legal do acordo, uma vez que ilegal, e na possibilidade de traição por parte dos agentes. O que se nota é que as comunicações realizadas pessoalmente entre os agentes auxiliam na construção de confiança, elemento fundamental para a continuidade do cartel. É por essa razão que os programas de combate a cartéis se utilizam do instituto da leniência como

autor, o advento dos computadores e robôs permitiram que o experiemento imaginado no famoso trabalho de ROBERT AXELROD esteja cada vez mais próximo de se tornar realidade. No experimento de AXELROD diversos especialistas apresentaram softwares de computador para participarem de jogos contínuos do Dilema do Prisioneiro. Segundo seu experimento, o melhor candidato foi aquele que apresentou o programa com menor tempo de resposta, sendo sua conclusão a de que o menor tempo de resposta por parte de um jogador leva a maior estabilidade da cooperação (ROBERT AXELROD, The evolution of cooperation, 1984, versão adaptada disponível em: http://stanford.io/20aWHoH, acesso no dia 17, nov., 2015).

575 Conforme relata SALIL K. MEHRA, Antitrust and the Robo-Seller: Competition in the time of algorithms, disponível em: http://bit.ly/1kZQtrk, acesso no dia 16, nov., 2015, p. 33.

576 Conforme relata SALIL K. MEHRA, Antitrust and the Robo-Seller: Competition in the time of algorithms, disponível em: http://bit.ly/1kZQtrk, acesso no dia 16, nov., 2015, p. 35. 
principal instrumento. Ao premiar o primeiro membro do conluio a confessar a conduta ${ }^{577}$ as autoridades criam um elemento adicional de instabilidade, uma vez que os membros agora devem se preocupar com a possibilidade de traição tanto com a violação do acordo como com a denúncia do conluio à autoridade concorrencial. No caso dos preços fixados por algoritmos, no entanto, nenhum mecanismo de intimidação se mostra efetivo, uma vez que os computadores não sentem qualquer intimidação da mesma forma que não aumentam sua relação de confiança. Além disso, a estabilidade do cartel só aumenta com o uso de computadores, uma vez que a detecção de eventuais desvios se mostra muito mais rápida, assim como as retaliações por parte dos membros em relação ao traidor. Da mesma maneira, a possibilidade de condenação criminal é ainda menos efetiva. Dificilmente alguém será condenado criminalmente por conta de condutas realizadas por algoritmos e computadores. $^{578}$

A questão do acordo formal se mostra igualmente problemática na era dos robôs. A doutrina antitruste tradicional, fortemente presa à teoria contratual, entende pela necessidade de uma oferta e uma aceitação para a existência de um acordo. Dessa forma, muitos entendem que uma comunicação explícita, direta, se faz necessária para a prova da colusão. A jurisprudência norte-americana vem aceitando a condenação em situações em que não há acordo explícito, desde que presente o chamado "plus factor", ou seja, evidências de prática anticompetitiva como, por exemplo, reuniões clandestinas, trocas secretas de informação, condutas praticadas pelas empresas que facilitem a colusão, dentre outras. ${ }^{579}$ Tais adaptações, do mesmo modo, não se mostram suficientes para análise de colusão praticada por computadores, uma vez que estes não necessitam realizar encontros ou trocar informações para agirem de modo coordenado. ${ }^{580}$

\footnotetext{
577 Com redução de pena ou mesmo extinção da punibilidade.

578 Conforme relata SALIL K. MEHRA, Antitrust and the Robo-Seller: Competition in the time of algorithms, disponível em: http://bit.ly/1kZQtrk, acesso no dia 16, nov., 2015, pp. 37-39.
}

Conforme aponta AMANDA ATHAYDE LINHARES MARTINS, a doutrina do Plus Factor, ou do
Paralelismo Mais: "propõe não ser necessária a prova da existência de um acordo ou de um mecanismo
explícito de coordenação de preços para a configuração de um ilícito. Bastaria o comportamento paralelo,
mesmo se interdependente, desde que houvesse um fator a "mais" para qualificar a conduta como
anticompetitiva" (AMANDA ATHAYDE LINHARES MARTINS, Prova indireta de cartel no âmbito das
associações: comportamento paralelo e plus factors, In Economic Analysis of Law Review, Vol. 2, n. 1,
2011, p. 43).

580 Conforme relata SALIL K. MEHRA, Antitrust and the Robo-Seller: Competition in the time of algorithms, disponível em: http://bit.ly/1kZQtrk, acesso no dia 16, nov., 2015, pp. 40-41. 
A doutrina antitruste tradicional relacionada às práticas colusivas, ainda fortemente baseada na prova do acordo, deverá se adaptar para que possa analisar de forma adequada as diversas novas situações criadas pelo uso destes algoritmos. Para facilitar a análise destas diferentes situações, seguindo classificação proposta por EZRACHI e STUCKE, podemos apontar quatro categorias de práticas colusivas nestes setores: (i) Messenger; (ii) Hub and Spoke ; (iii) Predictable Agent; (iv) Autonomous Machine. ${ }^{581}$

Dentro da primeira categoria (Messenger) se enquadram as condutas em que os computadores são utilizados apenas para executar a vontade dos humanos de realizar a prática de cartel. Nesse caso, os executivos realizam o acordo de cartel e se valem do computador para implementar e monitorar a prática. Na segunda categoria (Hub and Spoke) se enquadrariam as condutas em que o algoritmo do computador é utilizado para determinar o preço de mercado praticado por vários usuários. Nessa situação, a ocorrência de inúmeros acordos verticais similares praticados por diferentes competidores pode levar à organização de uma estrutura de hub-and-spoke em que um desenvolvedor atuaria como $h u b$ e possibilitaria uma ampla colusão pela indústria. Na terceira categoria (Predictable Agent) os programadores desenvolvem a máquina para que ela atue de forma a realizar funções pré-definidas e reagir à mudança das condições de mercado. Nesse caso, o mercado tende a colusão tácita, mesmo na situação em que não haja prova da intenção de cartelização por parte dos agentes. Por fim, na quarta categoria (Autonomous Machine) os agentes se valem dos algoritmos de computador para atingir a maximização do lucro, sendo que as próprias máquinas através de mecanismos de self-learning determinam de forma independente do operador os meios para atingir tal objetivo. Nesse caso, o computador executa a estratégia ótima com base nas informações obtidas do mercado, não havendo participação direta de qualquer elemento humano nestas decisões. ${ }^{582}$

No primeiro caso apresentado, a introdução de um algoritmo de preços vem apenas agregar eficiência na implementação de um cartel tradicional previamente acordado. Nesse caso, vislumbra-se forte presença do elemento humano na combinação de preços, quantidades ou divisão territorial. Dessa forma, os executivos combinam previamente entre si um acordo sobre as variáveis competitivas e se valem do computador apenas para o

581 ARIEL EZRACHI; MAURICE E. STUCKE, Artificial Intelligence \& Collusion: When Computers Inhibit Competition, disponível em: http://bit.ly/1MXhdC3, acesso em 06, out., 2015, pp. 7-8.

582 ARIEL EZRACHI; MAURICE E. STUCKE, Artificial Intelligence \& Collusion: When Computers Inhibit Competition, disponível em: http://bit.ly/1MXhdC3, acesso em 06, out., 2015, pp. 8-10. 
monitoramento do acordo. Esse tipo de cartel não difere dos tradicionais cartéis analisados pela doutrina, uma vez que o computador vem apenas auxiliar na colusão. ${ }^{583}$

O segundo caso já apresenta complicações adicionais ao tornar nebulosa a relação entre acordos verticais lícitos e colusões horizontais ilícitas. Nessa situação, um mesmo algoritmo de preços é utilizado por diferentes agentes independentes, podendo, dessa maneira levar a uma colusão horizontal ilícita de forma tácita. O exemplo é o da empresa Uber, que, por meio de seu aplicativo para smartphones, fornece uma plataforma que conecta usuários a motoristas privados para oferecimento de serviços de transporte. No caso do aplicativo da empresa californiana, os motoristas atuam como agentes independentes, que, em tese, seriam concorrentes entre si, mas que optam por ter os preços das suas corridas fixados e cobrados pelo aplicativo, em troca de uma fatia de $20 \%$ do valor. ${ }^{584}$ Um dos mecanismo deste aplicativo é o chamado "surge pricing", que consiste num sobrepreço da tarifa cobrada pelo serviço nos casos em que a demanda não possa ser atendida pelo número de motoristas disponíveis naquele momento. ${ }^{585}$ Tal mecanismo, chamado de "algorithmic monopoly" atua para ajustar o preço da tarifa ao preço de concorrência naquele momento de surto de demanda. ${ }^{586}$

O problema desse tipo de mecanismo é que ele pode ser manipulado de modo que haja coordenação para aumento de preços e cobrança de preços supracompetitivos, como se relatou em alguns casos midiáticos. ${ }^{587} \mathrm{O}$ problema, portanto, não estaria no acordo vertical celebrado entre o motorista e o aplicativo, mas sim no paralelismo do aumento de

583 ARIEL EZRACHI; MAURICE E. STUCKE, Artificial Intelligence \& Collusion: When Computers Inhibit Competition, disponível em: http://bit.ly/1MXhdC3, acesso em 06, out., 2015, pp. 10-14.

584 SALIL K. MEHRA, Antitrust and the Robo-Seller: Competition in the time of algorithms, disponível em: http://bit.ly/1kZQtrk, acesso no dia 16, nov., 2015, p. 2.

585 Conforme definição presente no site da empresa: “At times of high demand, the number of drivers we can connect you with becomes limited. As a result, prices increase to encourage more drivers to become available." (http://ubr.to/1dQX309, acesso em 07, out., 2015).

586 “That algorithm has been referred to as 'algorithmic monopoly' as it is controlled by Uber and may mimic a perceived competitive price rather than the true market price. That algorithm has been referred to as 'algorithmic monopoly' as it is controlled by Uber and may mimic a perceived competitive price rather than the true market price" (ARIEL EZRACHI; MAURICE E. STUCKE, Artificial Intelligence \& Collusion: When Computers Inhibit Competition, disponível em: http://bit.ly/1MXhdC3, acesso em 06, out., 2015, p. 14).

587 Conforme noticiou o jornal Business Insider, Jessica Seinfeld, esposa do apresentador Jerry Seinfeld, pagou o valor de U\$ 415,00 dólares por uma corrida simples através do aplicativo durante uma tempestade de neve, valor 8,25 vezes superior ao valor normal cobrado pelo aplicativo (ALY WEISMAN, Jerry Seinfeld's Wife Spent \$415 During Uber's Surge Pricing To Make Sure Her Kid Got To A Sleepover, disponível em: http://read.bi/1WNDu9Y, acesso em 07, out., 2015). 
preços gerado pelo uso do algoritmo do aplicativo pelos diferentes motoristas. Nesse caso, a análise do abuso por parte do aplicativo se mostra extremamente complexa, sendo necessária uma análise mais apurada do código por trás do seu algoritmo para que se conclua pela ilicitude da colusão. ${ }^{588}$

A terceira situação apresenta novas complicações. Nesse caso, as empresas se valem do computador com o objetivo de obter uma melhor visualização das condições de mercado e antecipação do comportamento da concorrência. A ampla utilização destes mecanismos pelos diferentes agentes do mercado leva ao paralelismo consciente e ao aumento dos preços. O que devemos notar é que nessa situação as empresas não realizam qualquer acordo entre si com relação a preços ou quantidades, mas apenas seguem seu auto interesse confiando nos algoritmos para estabelecimento dos seus preços, configurando assim uma forma de colusão tácita. ${ }^{589}$ Conforme veremos, ainda que não haja um acordo expresso entre concorrentes, esta forma de colusão pode suscitar sérios problemas concorrenciais.

Em primeiro lugar, o aumento da transparência faz com que os movimentos competitivos dos concorrentes sejam prontamente identificados, o que tende a facilitar a colusão. Dessa forma, um computador pode ser programado para acompanhar a movimentação de preços da concorrência, podendo prontamente reagir a possíveis reduções ou aumentos de preços. Em segundo lugar, a possibilidade de redução de preços de forma imediata faz com reduções que busquem atrair consumidores da concorrência sejam menos efetivas, uma vez que uma promoção por parte de um dos agentes pode ser prontamente confrontada. Sendo menores os benefícios do first mover, uma vez que a resposta da concorrência será imediata, tal estrutura desestimula reduções de preço competitivas. Em terceiro lugar, a velocidade com que as decisões sobre preços são tomadas faz com que as respostas diante de aumento de preços sejam realizadas em segundos, o que também contribui para a colusão tácita. Por fim, a ausência de bias

588 ARIEL EZRACHI; MAURICE E. STUCKE, Artificial Intelligence \& Collusion: When Computers Inhibit Competition, disponível em: http://bit.ly/1MXhdC3, acesso em 06, out., 2015, pp. 14-15. Ainda SALIL K. MEHRA: "Whether this is a paradigm-shifting disruptive technology or a harmful $21^{\text {st }}$ century techno-cartel depends in part on the workings of that algorithm." (SALIL K. MEHRA, Antitrust and the Robo-Seller: Competition in the time of algorithms, disponível em: http://bit.ly/1kZQtrk, acesso no dia 16, nov., 2015, p. 2).

589 ARIEL EZRACHI; MAURICE E. STUCKE, Artificial Intelligence \& Collusion: When Computers Inhibit Competition, disponível em: http://bit.ly/1MXhdC3, acesso em 06, out., 2015, p. 16. 
humano nas decisões faz com que os algoritmos decidam de forma racional $^{590}$ e sem a influência de sentimentos humanos. Isso contribuiu para a maior previsibilidade e estabilidade do mercado, condição fundamental para a colusão tácita entre os agentes. ${ }^{591}$

A grande dificuldade para condenação desse tipo de conluio está no fato de que o paralelismo consciente, por meio de reação à movimentação da concorrência, não pode ser considerado um ilícito concorrencial. A dúvida, estaria na licitude da criação de condições para a colusão tácita por meio do uso destes algoritmos. No entanto, a evolução tecnológica faz com que o uso destes programas seja obrigatório para qualquer empresa que busque competitividade. Por essa razão, na ausência de uma prova expressa de acordo para modificação da dinâmica do mercado dificilmente uma autoridade antitruste teria capacidade de condenar uma empresa com base nesses argumentos, como demonstraram casos recentes do FTC. ${ }^{592}$

Por fim, a quarta situação se mostra ainda mais complexa, uma vez que, nesse caso, a programação dos algoritmos não prevê a colusão tácita como único resultado possível, mas apenas como um dos resultados possíveis para que se atinja o objetivo de maximização de lucros. Dessa forma, a programação do algoritmo encontra como únicas limitações a prática de atividades ilícitas, como fixação de preços e divisão de mercado, utilizando-se de mecanismos de experimentação e self learning para tomar decisões. Nessa situação, o sistema, por meio de auto aprendizagem e sem interferência humana, pode entender que a estratégia racional maximizadora seria justamente o paralelismo consciente. $^{593}$

Dessa forma, o grande diferencial dessa situação em relação a situação chamada de Predictable Agent é que nesse caso não há nenhuma intenção por parte do operador de

\footnotetext{
590 Na classificação proposta por DANIEL KAHNEMAN, conforme vimos no CAPÍTULO II, os algoritmos utilizariam predominantemente o Sistema 2 em detrimento do Sistema 1.

591 ARIEL EZRACHI; MAURICE E. STUCKE, Artificial Intelligence \& Collusion: When Computers Inhibit Competition, disponível em: http://bit.ly/1MXhdC3, acesso em 06, out., 2015, pp. 18-20.

592 Conforme caso Boise Cascade and Ethyl (ARIEL EZRACHI; MAURICE E. STUCKE, Artificial Intelligence \& Collusion: When Computers Inhibit Competition, disponível em: http://bit.ly/1MXhdC3, acesso em 06, out., 2015, pp. 21-22).

593 "Importantly, tacit coordination--when executed--is not the fruit of explicit human design but rather
the outcome of evolution, self-learning and independent machine execution." (ARIEL EZRACHI;
MAURICE E. STUCKE, Artificial Intelligence \& Collusion: When Computers Inhibit Competition,
disponível em: http://bit.ly/1MXhdC3, acesso em 06, out., 2015, pp. 22-23)
} 
facilitação do paralelismo consciente, sendo esta decisão inteiramente do computador por meio de mecanismos de inteligência artificial.

Os problemas ocorrem quando o uso destes algoritmos se dissemina no mercado de tal forma que programadores passam se valer de algoritmos semelhantes para desenvolvimento desses programas, o que faz com que estes passem a se "entender" mutuamente, agindo de forma semelhante e criando o ambiente perfeito para a colusão. ${ }^{594}$

O que percebemos da análise destas situações é que a intenção continua sendo uma importante evidência para caracterização da colusão ${ }^{595}$, porém, esta se mostra cada vez mais controvertida por conta do uso destes mecanismos de self learning e inteligência artificial. Por essa razão, a caracterização de ilícito deve necessariamente passar pela análise dos possíveis benefícios e prejuízos associados ao uso destes mecanismos. A transparência, ao mesmo tempo em que traz diversos benefícios ao mercado e aos consumidores, como aumento da concorrência e maior acesso à informação, em muitos casos pode ser utilizada com o objetivo de manipular preços e auferir maiores ganhos. É por essa razão que uma condenação de cartelização pelo uso de algoritmos inteligentes dependerá da análise das reais intenções da empresa ao utilizar tal sistema. Em muitos casos o uso de provas obtidas internamente, como e-mails ou a forma como funcionários da empresa se referiam ao programa ou algoritmo pode indicar o intuito ilícito da conduta, como se decidiu no caso da Athena Capital Research perante a Securities and Exchange Commission (SEC) norte-americana. ${ }^{596}$

594 ARIEL EZRACHI; MAURICE E. STUCKE, Artificial Intelligence \& Collusion: When Computers Inhibit Competition, disponível em: http://bit.ly/1MXhdC3, acesso em 06, out., 2015, pp. 24-25.

595 Apesar de autores como RICHARD POSNER defenderem que a intenção não deveria ser considerada nos casos de fixação de preços, conforme aponta SALIL K. MEHRA, excluir a intenção da análise continua sendo um sonho não realizado dos estudiosos. Dessa forma, a análise da intenção continua a exercer profunda influência sobre as investigações antitruste (SALIL K. MEHRA, Antitrust and the RoboSeller: Competition in the time of algorithms, disponível em: http://bit.ly/1kZQtrk, acesso no dia 16, nov., 2015, p. 35-36).

596 No caso apresentado por ARIEL EZRACHI e MAURICE E. STUCKE, a empresa de trading Athena Capital Research foi condenada pela Securities and Exchange Commission ao se valer de um algoritmo chamado de Gravy (em tradução livre seria algo como um dinheiro inesperado, fácil) para manipular o preço de fechamento de diversas ações e obter proveito com isso. Por meio de $e$-mails internos da empresa se constatou que o objetivo era claramente o de manipular preços e auferir ganhos com isso. No caso a empresa encerrou a investigação sem admitir culpa porém se comprometendo a pagar uma multa de U\$ 1 milhão de dólares (ARIEL EZRACHI; MAURICE E. STUCKE, Artificial Intelligence \& Collusion: When Computers Inhibit Competition, disponível em: http://bit.ly/1MXhdC3, acesso em 06, out., 2015, pp. 27-29). 
Conforme apontamos, na situação em que as máquinas passam a tomar decisões independentes, sem que seus operadores possam antecipar ou predeterminar seus resultados, surgem inúmeras dúvidas quanto à responsabilização por uma possível colusão. A complexidade associada a estes mecanismos dificulta a compreensão da autoridade antitruste e torna uma possível intervenção passível de trazer mais prejuízos que benefícios ao mercado. Da mesma forma, a determinação de proibições ou salvaguardas em relação a atuação dos computadores pode ser contornada pelo algoritmo na tentativa de maximização e tomada racional de decisões. Nesse ponto surgem inúmeras questões de ordem ética em relação ao relacionamento entre homem e máquina, especialmente no tocante a decisões que caminham no limite da licitude. ${ }^{597}$

Uma das soluções apontadas estaria na responsabilização da empresa apenas nos casos em que esta não tomar as medidas necessárias após tomar conhecimento da ilicitude. Tal solução é utilizada em outras áreas como no caso de hospedagem de conteúdo ilícito em servidores. ${ }^{598}$ No entanto, tal princípio se mostra de difícil aplicação, uma vez que a definição entre o que seria aumento de faturamento decorrente de decisões independentes da empresa e de coordenação ilícita entre concorrentes é de difícil mensuração pela empresa. Da mesma forma, a integração destes algoritmos a todo funcionamento dos sistemas destas empresas faz com que a mudança ou paralização de seu funcionamento muitas vezes seja impossível sem que suas atividades sejam completamente paralizadas. ${ }^{599}$

O que notamos é que o uso destes mecanismos informatizados tende a ser cada vez mais comum e a desafiar cada vez mais os limites da análise antitruste. O nível adequado de intervenção pela autoridade se mostra um complexo desafio, em que o remédio adotado pode levar a uma distorção ineficaz e ineficiente sobre o mercado, ao mesmo tempo que a não intervenção pode abrir margem para sofisticados mecanismos de condutas anticompetitivas implementadas por estas empresas.

597 ARIEL EZRACHI; MAURICE E. STUCKE, Artificial Intelligence \& Collusion: When Computers Inhibit Competition, disponível em: http://bit.ly/1MXhdC3, acesso em 06, out., 2015, pp. 31-33.

598 Conforme aponta MARCEL LEONARDI, a responsabilidade dos provedores seria subjetiva, ou seja, decorrente apenas de omissão, negligência ou imprudência por parte do provedor. Assim, este será responsabilizado quando "deixar de bloquear o acesso à informação ilegal disponibilizada por um usuário, ou quando não o fizer em tempo hábil, desde que tenha sido previamente informado a esse respeito e desde que não haja dúvidas sobre a ilicitude da conduta perpetrada pelo usuário." (MARCEL LEONARDI, Responsabilidade civil dos provedores de serviços de Internet, São Paulo, Juarez de Oliveira, 2005, p. 174) 


\section{III.7 - Regulacão de setores pontocom, eficiência dinâmica e inovacão}

Já afirmamos anteriormente que a natureza aberta e descentralizada da Internet fez com que surgissem inúmeros mecanismos de governança próprios para sua regulação, muitas vezes independentes do modelo estatal ou da regulação por participantes externos. O aumento de valor econômico das operações realizada em sua rede, no entanto, levaram a necessidade de regulação estatal de diversos aspectos relacionados ao sua operação. $O$ desconhecimento em relação a aspectos técnicos de seu funcionamento, bem como a desconsideração da amplitude e dos efeitos desse mercado podem levar a intervenções desastrosas sobre esse setor. ${ }^{600}$

Assim como analistas erraram ao afirmar que a posição de mercado da Microsoft era inquebrável, da mesma forma a suposta dominância do Google pode levar a uma falsa análise da situação. Por essa razão alguns autores afirmam que a noção de monopólio durável em setores dinâmicos se mostra complexa e o prejuízo ao consumidor de difícil sustentação. ${ }^{601}$

Muito se discute com relação ao aumento do bem estar com o uso de determinadas plataformas. Ao servir diversos grupos de usuários com demandas interdependentes, as externalidades de rede associadas a setores de múltiplos lados geram aumento do valor da plataforma não apenas para seus proprietários, mas também para seus usuários e para a sociedade como um todo. ${ }^{602}$ Com o objetivo de manter estes ganhos positivos e excluir ou

600 Exemplo desse tipo de intervenção pode ser vista no caso do bloqueio do aplicativo WhatsApp no Brasil em 2015, determinado por uma juíza de primeira instância de São Bernardo do Campo, por conta de suposto não cumprimento de ordem judicial por parte de sua representante no país. Conforme apontou RONALDO LEMOS, "O mais impressionante é como o bloqueio do WhatsApp expôs a fragilidade da rede brasileira. A ordem partiu de uma juíza estadual de primeira instância de São Bernardo do Campo. Em menos de 24 horas ela tirou do ar por completo um serviço com 100 milhões de usuários no país." e continua: "A internet é uma infraestrutura crítica do mundo contemporâneo, como é a eletricidade. É preciso garantir que ela permaneça neutra. Como diz o professor Tim Wu, mexer na 'chave mestra' da internet é mexer também na chave mestra da democracia." (RONALDO LEMOS, WhatsApp e a fragilidade da rede, In Folha de São Paulo, 21, dez., 2015, disponível em: http://bit.ly/1QYTfsZ, acesso no dia 24, dez., 2015).

601 "The notion of a durable monopoly in this evolving and uncertain environment is fanciful, and the claim of consumer harm difficult to support." (GEOFFREY A. MANNE; WILLIAM RINEHART, The market realities that undermined the FTC's antitrust case against Google, In Harvard journal of law and technology occasional paper series, July, 2013, disponível em http://bit.ly/1FCV4Ce, Acesso no dia 25, jun. 2015, p. 16).

602 O critério para determinar se houve aumento do bem estar social consiste na constatação de que o valor entregue pela plataforma seria superior aos preços cobrados por ela. Por essa razão, defendem EVANS e SCHMALENSEE que ao considerar as perdas por um dos grupos de consumidores, deve-se sempre 
penalizar usuários com comportamentos negativos, as plataformas acabam por desenvolver mecanismos de governança próprios. Estes podem se revestir de padrões de uso dos usuários como a limitação de caracteres da plataforma Twitter, ou da proibição de postagem de conteúdo inadequado no Facebook, sob pena de exclusão destes usuários do sistema.

Conforme afirmamos, a dinâmica destes setores traz questionamentos com relação ao papel do direito antitruste nos setores da nova economia. Três grandes linhas vem sendo defendidas por acadêmicos ligados às mais distintas escolas ${ }^{603}$ : enquanto alguns defendem que a velocidade destes setores impede que qualquer medida tenha alguma eficácia ${ }^{604}$, outros defendem que as regras de direito concorrencial simplesmente não deveriam se aplicar para setores com elevados níveis de inovação e de competição dinâmica ${ }^{605}$, e, por fim, outros defendem que características destes setores tornam a possibilidade de abusos serem ainda mais prejudiciais à inovação do que em outros setores, sendo necessária profunda intervenção governamental. ${ }^{606}$

A aplicação da moldura de "error-cost" descrita em capítulo anterior leva à conclusão de que os falsos positivos são mais prejudiciais ao mercado do que os falsos

considerar também os ganhos associados ao outro grupo. É por essa razão que qualquer análise antitruste desses setores que desconsidere um dos lados levará a resultados incorretos (DAVID S. EVANS; RICHARD SCHMALENSEE, The antitrust analysis of multi-sided platform businesses, disponível em: http://bit.ly/1KhV5mT, acesso no dia 19, mai, 2015, p. 35).

603 GEOFFREY A. MANNE; JOSHUA D. WRIGHT, Google and the limits of antitrust: The case against the case against Google, In Harvard Journal of Law \& Public Policy, vol. 34, disponível em: http://bit.ly/1hHH4TR, acesso em 17, ago., 2015.

604 Conforme apontam GEOFFREY A. MANNE e JOSHUA D. WRIGHT: "A proper application of error-cost principles would deter intervention in cases meeting the two criteria until empirical evidence could be amassed and assessed." (GEOFFREY A. MANNE; JOSHUA D. WRIGHT, Google and the limits of antitrust: The case against the case against Google, In Harvard Journal of Law \& Public Policy, vol. 34, disponível em: http://bit.ly/1hHH4TR, acesso em 17, ago., 2015, p. 187).

605 "Even if it could be demonstrated that the economy was on the wrong path of technology adoption, is public policy the solution? Market adoption of innovations is a complex process in which individual consumers choose what products to buy, firms choose what products to supply, and inventors choose directions for R\&D. As Schumpeter observed, entrepreneurs choose to innovate by making "new combinations', offering new products, production processes and transaction methods." e conclui: "By limiting the ability of successful firms to add product features and to bundle products, antitrust reduces incentives to improve technologies. Avoiding such misguided antitrust policies allows competitive markets to continue unlocking technology." (DANIEL F. SPULBER, Unlocking Technology: Antitrust and Innovation, In Journal of Competition Law and Economics, disponível em: http://bit.ly/1m7M8Ua, acesso no dia 24, dez., 2015, pp. 71-72).

606 CARL SHAPIRO, Exclusivity in network industries, In George Mason Law Review, vol. 7 , n.3, pp. 673-683, disponível em: http://bit.ly/1OkaZtS, acesso no dia 24, dez., 2015. 
negativos, uma vez que estes últimos podem ser auto corrigidos por efeitos do próprio mercado. No entanto, deve-se tomar com cautela estas visões que defendem a não intervenção como medida mais eficaz para estes setores, uma vez que a capacidade de auto correção do mercado depende, justamente, da eficiência do processo competitivo para atingir resultados pró-consumidor. O que percebemos nestes setores é que com frequência algumas características destes mercados, como a dificuldade de percepção da qualidade e avaliação dos custos acabam por reduzir a eficácia da concorrência. ${ }^{607}$

Além disso, deve-se analisar com cautela a conclusão de que, ao oferecerem os produtos de forma gratuita, tais agentes sempre tendem a gerar excedente do consumidor, produzindo, portanto, apenas efeitos pró-competitivos. Tal ponto de vista desconsidera os custos associados à aquisição destes bens e serviços, sejam deles de atenção, de informação ou mesmo monetários em casos de venda casada de produtos gratuitos. Por esta razão, não se pode concluir que nestes mercados os ganhos de bem estar sejam superiores aos dos setores com preços positivos. ${ }^{608}$

No caso do Google, por exemplo, ao contrário do que afirma a empresa, poucos competidores oferecem reais pressões competitivas sobre ela. Seus dois principais concorrentes, Yahoo e Microsoft, não se mostraram capazes de ameaçar a empresa em termos de inovação, agindo na maior parte das vezes de forma a imitar as inovações apresentadas pela empresa. A existência de poucos concorrentes efetivos, portanto, faz com que a empresa tenha menores preocupações com inovação, uma vez que as inovações apresentadas pelos seus concorrentes possam ser facilmente antecipadas e neutralizadas. ${ }^{609}$ Tal visão se coaduna com a teoria de KENNETH ARROW, segundo a qual monopolistas e grandes empresas tem menos incentivos para inovar uma vez que seus ganhos tendem a ser menores. ${ }^{610}$

607 JOHN M. NEWMAN, Antitrust in zero-price markets: Foundations, In University of Pennsylvania Law Review, Vol. 164, disponível em: http://bit.ly/1jEUMaX, acesso no dia 15, out., 2015, p. 47.

608 JOHN M. NEWMAN, Antitrust in zero-price markets: Foundations, In University of Pennsylvania Law Review, Vol. 164, disponível em: http://bit.ly/1jEUMaX, acesso no dia 15, out., 2015, p. 51.

609 KRISTINE LAUDADIO DEVINE, Preserving competition in multi-sided innovative markets: How do you solve a problem like Google?, In North Carolina Journal of Law \& Technology, Vol. 10, n. 1, 2008, pp. 100-104.

610 "the monopolist's incentive is always less than the cost reduction on the postinvention monopoly output, which in this case is, in turn, less than the competitive output (both before and after invention). Since the inventor's incentive under competition is the cost reduction on the competitive output, it will again always exceed the monopolist's incentive." (KENNETH ARROW, Economic Welfare and the Allocation of 
Conforme já apontamos, surgem, ainda, diversas questões de ordem ética que se relacionam diretamente com a qualidade do serviço prestado. A análise destes custos não monetários, porém, enfrenta uma série de dificuldades institucionais para a autoridade antitruste. Em primeiro lugar, estas agências não possuem expertise para lidar com muitas dessas variáveis. Isso se agrava quando consideramos questões como influência política ou redução da qualidade investigativa de um jornal. A ausência de modelo econômico adequado e de variáveis objetivas para lidar com estas questões, torna a análise extremamente subjetiva. Em segundo lugar, tais agências não possuem legitimidade democrática para lidar com tais questões. ${ }^{611}$

Dessa forma, questões de ordem ética e política devem ser deixadas de lado para que a autoridade analise apenas questões de ordem objetiva, como o volume de informações pessoais e os custos de atenção supra referidos.

A complexidade relacionada a estes setores torna necessária a possibilidade das agências terem acesso aos detalhes destas novas tecnologias, como, por exemplo, os algoritmos do Google, de modo que especialistas possam analisar as mudanças implementadas sobre esses algoritmos ao longo do tempo e avaliar o impacto das diretivas da empresa sobre estes aspectos técnicos. ${ }^{612}$

Por outro lado, alguns argumentam que essa abertura de informações poderia se tornar um grande fardo para estas empresas, uma vez que o algoritmo do Google, por exemplo, é alterado mais de 500 vezes ao ano. Empresas teriam, portanto, de deixar diversos funcionários à disposição para atendimento destas demandas, além da impossibilidade da autoridade regulatória avaliar todas essas mudanças. Deve-se notar, no entanto, que estas mudanças são documentadas de forma detalhada pela empresa e que em momento algum seria necessária a completa abertura de detalhes técnicos sigilosos da empresa, mas apenas o acesso à diretivas e determinadas informações que possam caracterizar condutas anticompetitivas. Por outro lado, deve-se ressaltar que essa abertura

Resources for Invention, In The Rate and Direction of Inventive Activity: Economic and Social Factors, disponível em: http://bit.ly/1NNRvyg, acesso no dia 24, dez., 2015).

611 MICHAL S. GAL; DANIEL L. RUBINFELD, The hidden costs of free goods: Implications for Antitrust enforcement, New York University Law and Economics Working Papers, Disponível em: http://bit.ly/1Qg96Ds, acesso no dia 05, nov., 2015, pp. 45-47.

612 FRANK PASQUALE, Paradoxes of digital antitrust: Why the FTC failed to explain its inaction on search bias, In Harvard journal of law and technology occasional paper series, July, 2013, disponível em: http://bit.ly/1FbNQVJ, Acesso em 11, jun. 2015, pp. 12-13 
parcial se encontra em um tênue equilíbrio entre a proteção dos direitos intelectuais da empresa e as prerrogativas do ente regulatório de analisar suas condutas. ${ }^{613}$

Muitos defendem que os falsos negativos ou falsos positivos gerados pela intervenção governamental podem trazer graves prejuízos à eficiência dinâmica e a inovação nestes setores. É evidente que a inovação tende a aumentar o número de opções do usuário e tornar os mercados mais eficientes. Portanto não restam dúvidas de que esta deve ser protegida e incentivada. No entanto, devemos antes de mais nada questionar qual tipo de inovação é desejável e de que forma os desejos e preferências não coordenadas dos milhões de usuários da Internet serão atendidos tendo em vista as inúmeras preocupações levantadas pelas condutas desses novos intermediários. ${ }^{614}$

Por fim, devemos lembrar que qualquer política regulatória que incida sobre estes setores acaba por impactar o ambiente competitivo trazendo profundos efeitos sobre os incentivos à inovação e a eficiência dinâmica. Um exemplo destas questões se relaciona à determinação de regras de neutralidade de rede aos servidores de Internet, assunto que vem sendo intensamente debatido nos Estados Unidos e que no Brasil levou à inclusão deste princípio no Marco Civil da Internet. Segundo seus defensores, tal princípio se mostra essencial para que haja estímulos à inovação por parte dos possíveis entrantes nestes novos setores. A cobrança de taxas diferenciadas de acesso pelos provedores de Internet faz com que novas empresas de Internet (startups) dificilmente possam ingressar em mercados que exijam elevada largura de banda, como serviços de streamming de vídeo e de comunicação por IP. Deve-se lembrar que foi justamente o tratamento isonômico dos dados que permitiu que empresas como Facebook, YouTube e Google ${ }^{615}$, cada uma ao seu modo, revolucionassem o ambiente web com inovações que modificariam completamente a forma

613 FRANK PASQUALE, Paradoxes of digital antitrust: Why the FTC failed to explain its inaction on search bias, In Harvard journal of law and technology occasional paper series, July, 2013, disponível em: http://bit.ly/1FbNQVJ, Acesso em 11, jun. 2015, pp. 12-13

614 "Scholars have tended to assume that the more innovation happens on the Internet, the more choices users will have and the more efficient the market will become. Yet these scholars have not paid enough attention to the kind of innovation that is best for society, and whether the uncoordinated preferences of millions of web users for low-cost convenience are likely to address the many concerns raised by dominant intermediaries." (FRANK PASQUALE, Paradoxes of digital antitrust: Why the FTC failed to explain its inaction on search bias, In Harvard journal of law and technology occasional paper series, July, 2013, disponível em http://bit.ly/1FbNQVJ, acesso em 11, jun. 2015, p. 4).

615 Não por outra razão três das maiores empresas pontocom (Google, Facebook e Amazon) encabeçaram petição ao FCC em defesa da neutralidade de rede (THE GUARDIAN, Google, Facebook and Amazon write to FCC demanding true net neutrality, disponível em: http://bit.ly/1jhlgMA, acesso no dia 12, jan., 2016). 
como lidamos com os serviços pontocom e criassem mercados extremamente rentáveis e inovadores.

\section{III.8 - Análise do caso Google}

Considerado por muitos como o grande caso antitruste da era digital após o caso Microsoft, a análise do caso Google traz diversas características relevantes para o presente trabalho. A empresa norte-americana, responsável por $90 \%$ das buscas realizadas no mundo, e com uma capitalização de mais de 350 bilhões de dólares, ${ }^{616}$ vem enfrentando uma série de investigações antitruste nos últimos anos. ${ }^{617}$ Conforme KRISTINE DEVINE, o Google seria o peixe grande de um pequeno lago, sendo o grande alvo das ações antitruste na atualidade. ${ }^{618}$

A empresa Google foi fundada por dois, então, alunos de $\mathrm{PhD}$ da Universidade de Stanford, LARRY PAGE e SERGEY BRIN em 1998. Considerada hoje uma das maiores empresas de tecnologia do mundo, a Google atua em diversas áreas de produtos e serviços e relacionados à Internet. Desde serviços de busca, com seu buscador Google, passando por serviços de comunicação e de mídia, como o Picasa e o Google Hangouts, softwares de programação, serviços de mapeamento, aplicativos e sistemas operacionais (Chrome OS, para desktops e Android para sistemas móveis), até plataformas de propaganda como o

616 MICHAEL LUCA; TIMOTHY WU; ET. AL., Does Google degrade Google search? Experimental evidence, 2015, disponível em: http://bit.ly/1NpGX9J, acesso no dia 17, dez., 2015, p. 2.

617 Em 2008 a Google sofreu ameaças de investigação por parte do DOJ norte americano por conta de seu acordo na área de anúncios publicitários com a empresa Yahoo. Além dessa investigação, em 2009, o DOJ passou a investigar se o acordo entre a Google, o Yahoo e a Apple de não contratarem os talentos das outras empresas trazia preocupações concorrenciais. No final de 2009 houve também o acordo entre a Google e a Authors Guild (AG) e a Association of American Publishers (AAP) segundo o qual a empresa de buscas pagou 125 milhões para encerrar as investigações relacionadas ao projeto do Google Book Search. No mesmo ano de 2009 o FTC passou a investigar se a prática das empresas Google e Apple de manterem os mesmos diretores nos quadros de seus conselhos violava o Clayton Act. Em 2010 um membro do conselho da Amazon já antecipando possível investigação por parte do FTC anunciou sua saída por ocupar também posição no conselho da Google. A investigação norte-americana com relação ao viés em seu mecanismo de buscas foi encerrada em janeiro de 2013 após o FTC concluir pela ausência de infração concorrencial. Na Comissão Européia foi instaurado procedimento investigatório em novembro de 2010 por conta da manipulação do algoritmo de buscas, sendo que, após tentativa de acordo frustrada em 2014, a Comissão emitiu um Statement of Objections contendo suas objeções com relação ao mecanismo de buscas. (ANDRESSA LIN FIDELIS, Entre o "laissez-faire” americano e o "intervencionismo” europeu: para qual direção aponta a atual investigação do CADE sobre o mecanismo de busca do Google, In Revista de defesa da Concorrência, vol. 3, n. 2, 2015, pp. 74-77).

618 Em 2008, a empresa detinha 64\% do market share de buscas nos Estados Unidos, e recebia $73 \%$ do orçamento das companhias que anunciam online (KRISTINE LAUDADIO DEVINE, Preserving competition in multi-sided innovative markets: How do you solve a problem like Google?, In North Carolina Journal of Law \& Technology, Vol. 10, n. 1, 2008, pp. 60-61). 
AdWorks e o Double Click. A empresa atua praticamente em todas às áreas relacionadas aos novos setores de Internet. ${ }^{619}$

Dentre as inúmeras atividades da empresa, sem dúvidas o de maior relevância é seu buscador. A evolução da web fez com que os mecanismos de buscas se tornassem centrais, influenciando a forma como acessamos, classificamos e utilizamos o enorme conteúdo oferecido na Internet. De forma simplificada, todo sistema de buscas funciona com base em três elementos: um programa que mapeia a web, um index de sites já mapeados, e uma interface que se vale de um algoritmo para elaborar listas de resultados desses sites mapeados. Os primeiros buscadores funcionavam como grandes listas de sites conhecidos. ${ }^{620}$ A evolução dos primeiros indexadores levou gradativamente ao uso de robôs para mapeamento da web e à indexação de uma gama de informações cada vez maiores. Com isso foi possível o desenvolvimento da busca por palavras-chave. O primeiro grande buscador foi o Alta-Vista, lançado em 1995, que se valia de milhares de mapeadores para indexar os primeiros milhões de sites até então criados. Depois vieram sites como o Lycos, e o Yahoo!. ${ }^{621}$

Mecanismos de busca se diferem de outros sites da Internet por exercerem um papel de gateway. Ao mesmo tempo em que fornecem informação sobre o que pode ser encontrado na web (de modo semelhante as páginas amarelas), se mostra como o ponto de partida de qualquer pessoa se aventurando na Internet. É por essa razão que são qualificados como verdadeiros "information gatekeepers", ou, conforme TIM WU, o

619 Tendo em vista que hoje praticamente tudo vem sendo conectado de alguma forma com a Internet, pode-se afirmar que a empresa atua em praticamente todas as áreas da vida social. Atuamente a empresa trabalha, por exemplo, em projetos relacionados à carros auto-guiados e sistemas de automatização de residencias.

620 O primeiro buscador de Internet foi o software Archie. Este foi desenvolvido com foco nos usuários do meio acadêmico, sendo seu funcionamento bem simples, atuando como um index com todos os sites conhecidos (KRISTINE LAUDADIO DEVINE, Preserving competition in multi-sided innovative markets: How do you solve a problem like Google?, In North Carolina Journal of Law \& Technology, Vol. 10, n. 1, 2008, pp. 66-67). Ainda MICHAEL LUCA e TIM WU: "In the early days of the World Wide Web, simple lists of links and directory services (like the early Yahoo!) were used, in competition with early, primitive search engines. Eventually, in the early 2000s, the "general" search engine (which searches the entire web) became the tool of choice; Google is the preeminent example." (MICHAEL LUCA; TIMOTHY WU; ET. AL., Does Google degrade Google search? Experimental evidence, 2015, disponível em: http://bit.ly/1NpGX9J, acesso no dia 17, dez., 2015, pp. 8-9).

621 KRISTINE LAUDADIO DEVINE, Preserving competition in multi-sided innovative markets: How do you solve a problem like Google?, In North Carolina Journal of Law \& Technology, Vol. 10, n. 1, 2008, pp. 67-69. 
guardião da "chave geral da Internet" ${ }^{622}$. Isso faz com que os usuários desses mecanismos sejam mais valiosos para os anunciantes do que os usuários de sites comuns, uma vez que os buscadores obtém de seus usuários tanto informações pessoais como informações relacionadas as suas intenções por meio das palavras-chave digitadas no buscador. ${ }^{623}$

Tais empresas operam em setor intensivo em Pesquisa e Desenvolvimento (P\&D), com altas taxas de inovação. A concorrência se mostra intensa não apenas pela participação de mercado, mas também pela completa exclusão de outros players do mercado. É comum empresas dominantes adquirem tecnologias concorrentes, bem como possíveis ameaças com o objetivo de manterem a vantagem competitiva. Além disso a estrutura de preços se assemelha em grande medida a dos monopólios naturais, por conta dos relevantes custos fixos, com quase nenhum custo marginal tanto do lado do anunciante como do lado do usuário. Isso leva a tendência à concentração e a prática de estratégias de exclusão ou recusa de contratar com concorrentes localizados no mercado downstream, bem como de práticas anticompetitivas ou aquisição de concorrentes no mercado upstream com o objetivo de manter sua posição de domínio. ${ }^{624}$

A grande inovação introduzida pela Google ocorreu com a criação do algoritmo chamado PageRank, que media a reputação dos sites com base no número de citações no formato de links. O grande mérito do sistema da empresa foi o de desenvolver um sistema de indexação da web que se baseava na reputação da página perante outras páginas ao invés da auto promoção da página. ${ }^{625}$ A melhoria sensível da qualidade das buscas fez com que os usuários migrassem em grande parte para esta nova plataforma. ${ }^{626}$

\footnotetext{
622 "Assim como sua precursora, a telefonista, o Google oferece uma maneira rápida, precisa e elegante de chegar ao interlocutor. Em outras palavras, ele é a chave da internet. Na verdade, é a chave mais popular do mundo; sendo assim, poderia até ser definido como o atual guardião da chave geral." (TIM WU, Impérios da comunicação: Do telefone à internet, da AT\&T ao Google, Rio de Janeiro, Zahar, 2012, p. 336)
}

623 IOANNIS LIANOS; EVGENIA MOTCHENKOVA, Market dominance and search quality in the search engine market, In Journal of Competition Law \& Economics, vol. 9, n. 2, 2013, p. 422.

624 IOANNIS LIANOS; EVGENIA MOTCHENKOVA, Market dominance and search quality in the search engine market, In Journal of Competition Law \& Economics, vol. 9, n. 2, 2013, p. 423.

625 "Larry Page and Sergey Brin, Google's cofounders, changed all this. They developed an algorithm that ranks web results based on 'relevance', which represents some combination of the web page's presence in links from other sites and its popularity with users searching similar queries." (JOSHUA G. HAZAN, Stop being evil: A proposal for unbiased Google Search, In Michigan Law Review, vol. 111, n. 5, 2013, p. 792).

626 KRISTINE LAUDADIO DEVINE, Preserving competition in multi-sided innovative markets: How do you solve a problem like Google?, In North Carolina Journal of Law \& Technology, Vol. 10, n. 1, 2008, pp. 71-72. 
A questão da lucratividade da plataforma, por sua vez, gerou inúmeras dúvidas em seus criadores, sendo que desde o início estes se mostravam contrários aos anúncios pagos se misturando com os resultados de busca orgânica de seu buscador. Alguns acreditavam que o seu faturamento poderia ser obtido do licenciamento de seu mecanismo para outros sites. Em 2000 foi desenvolvido o sistema do AdWorks, que permitia que anunciantes publicassem pequenos anúncios de seus produtos, selecionando as palavras-chave que deveriam ser associadas a eles. Anos depois foi desenvolvido um sistema similar ao do GoTo porém com a introdução do Quality Score, que tinha como objetivo determinar qual anunciante deveria ganhar o leilão. Para tanto o sistema se utiliza de mecanismo semelhante ao do algoritmo de busca orgânica para determinar a relevância do anúncio. Isso permitiu que o sistema de anúncios fosse sensitivo aos interesses dos usuários da mesma forma que seu sistema de buscas. A qualidade do algoritmo de buscas permitiu que a empresa oferecesse não só os melhores resultados de busca como também os melhores anúncios direcionados. Tais fatores certamente contribuíram para seu predomínio neste setor. $^{627}$

O domínio da empresa vem sendo garantido por intensa inovação nos setores em que atua, mas também por inúmeras aquisições realizadas nos últimos anos. Dentre elas se destacam a do Google Docs (adquirido da empresa Writely), do Google Maps (adquirido da empresa Keyhole), bem como especialmente da empresa DoubleClick, que gerou inúmeros questionamentos quanto à concentração no mercado de anúncios publicitários via $w e b .^{628-629}$

\footnotetext{
627 "Google dominates the search engine market because its search algorithm provides the most relevant organic results to user queries. Likewise, Google dominates search advertising because its Quality Score measures-which are very similar to its organic search algorithm - provide users with the most relevant sponsored results." (KRISTINE LAUDADIO DEVINE, Preserving competition in multi-sided innovative markets: How do you solve a problem like Google?, In North Carolina Journal of Law \& Technology, Vol. 10, n. 1, 2008, pp. 73-75).
}

628 KRISTINE LAUDADIO DEVINE, Preserving competition in multi-sided innovative markets: How do you solve a problem like Google?, In North Carolina Journal of Law \& Technology, Vol. 10, n. 1, 2008, pp. 76-77.

629 "Google não está envolvido em aquisições estranhas de empresas vistosas, coisa qualificada por Jonathan Knee como a 'maldição dos magnatas'. Em vez disso, a maioria dos investimentos serve para defender sua primazia no 'paradigma de busca (...) Produtos como Gmail, Android, Google Local e Google+ não dão lucros em sim mesmos, contudo, mantêm a pesquisa na rede como o centro da experiência do usuário.” (TIM WU, Impérios da comunicação: Do telefone à internet, da AT\&T ao Google, Rio de Janeiro, Zahar, 2012, p. 337). 
Os mecanismos de buscas funcionam como lentes que colocam o mundo online em foco. No entanto, como qualquer lente, esta redireciona, revela, magnifica e distorce. ${ }^{630}$ Por essa razão, algumas práticas realizadas pela empresa vêm sofrendo inúmeros questionamentos por parte das autoridades concorrenciais. Dentre estes um dos principais casos se relaciona à manipulação do algoritmo de seu buscador para favorecimento de serviços da própria empresa em detrimento de serviços concorrentes, de modo a prejudicar eventuais concorrentes. O argumento é o de que ao manipular os resultados de sua busca “orgânica" a empresa não estaria oferecendo os resultados que melhor servem aos consumidores, mas aqueles que servem aos seus próprios interesses competitivos. Os prejudicados por tais condutas seriam dois grupos de concorrentes: os provedores de informação, como o site Yelp, e sites de busca vertical, como Foundem e Trade Comet. ${ }^{631}$

$\mathrm{O}$ argumento antitruste para a condenação dessa conduta se baseia na possibilidade de exclusão de competidores do mercado. Ao listar sites concorrentes de serviços oferecidos pela empresa em posições abaixo do que o resultado de busca orgânica retornaria, a empresa estaria impedindo que estes concorrentes tivessem acesso aos seus usuários. Dessa forma, os favoráveis a condenação da empresa sustentam que a ausência de regras objetivas e sem bias no funcionamento do algoritmo pode constituir prática exclusionária. Por outro lado, diversos argumentos contrários são apresentados, sendo que na maior parte das vezes se sustenta a impossibilidade de delimitar o que seriam condutas procompetitivas ou anticompetitivas nessa área.

O que devemos notar é que o sistema de buscas da empresa evoluiu ao longo dos últimos anos de modo que se apresenta muito mais complexo nos dias atuais. O layout simplificado com dez resultados de busca orgânica evolui para um layout com inúmeras “zonas" de busca, dentre as quais se aprentam resultados de notícias, de sites de compras, resultados de vídeo, mapas, dentre outros. Em cada uma dessas zonas os anunciantes concorrem para chamar a atenção do usuário, estando cada uma dessas zonas sujeitas ao bias do resultado de modo a favorecer os anunciantes. A mudança de paradigma vai de uma plataforma pensada e desenvolvida para que o usuário gaste o menor tempo possível

$630 \quad$ JAMES GRIMMELMANN, Some skepticism about search neutrality, In BERIN SZOKA; ADAM MARCUS, The next digital age: Essays on the future of the Internet, Washington, Tech Freedom, 2010, p. 435 .

631 MARK R. PATTERSON, Google and search-engine market power, In Harvard Journal of Law \& Technology Occasional Paper Series, jul. 2013, disponível em: http://bit.ly/1kQ1VZw, acesso no dia 23, nov., 2015, pp. 2-3. 
para encontrar o link buscado para o paradigma da "portalização", ou seja, da concentração de inúmeras informações em um único lugar. Assim, o site passa a tentar responder a inúmeras perguntas realizadas pelo usuário, como as condições do tempo, estado de vôos, cotação de moedas entre outras. Dessa forma, com o objetivo de expandir sua oferta de produtos, a Google passa a desenvolver seu próprio conteúdo, fazendo com que o usuário se mantivesse cada vez mais tempo na página da empresa. ${ }^{632}$

A oferta de conteúdo próprio pela empresa faz com que esta concorra cada vez mais diretamente com outros sites como Amazon e Tripadvisor. Tal movimento ocorre com o surgimento dos mecanismos de busca especializada (ou busca vertical), ou seja, de mecanismos responsáveis por realizar buscas em categorias específicas de informação (dentre os exemplos podemos citar o Kayak no mercado de passagens aéreas, o TripAdvisor no mercado de avaliações de hotéis, e o Yelp no mercado de médicos locais). Apesar deste tipo de busca não concorrer diretamente com mecanismos de busca geral, estes representam uma verdadeira ameaça para o paradigma de busca geral. ${ }^{633}$

A empresa passa a usar do seu domínio sobre os mecanismos de busca geral com o objetivo de alavancar a popularidade de seus mecanismos de busca especializada. Para tanto, a empresa unifica o mecanismo de busca geral (baseado no paradigma do "ten blue links") com o de busca especializada (“OneBox"), colocando os dois sob a mesma interface no mecanismo de busca. Dessa forma, uma pesquisa com os termos "restaurantes em São Paulo" deveria apontar sites como o Yelp ou o TripAdvisor como primeiros resultados, porém, acaba mostrando como primeiro resultado a pesquisa do "OneBox" que apresenta resultados oferecidos pelo mecanismo de busca especializada da Google (conforme Figura 1 abaixo).

632 ERIC GOLDMAN, Revisiting search engine bias, In William Mitchell Law Review, Vol. 38, n. 1, 2011, pp. 102-105.

633 MICHAEL LUCA; TIMOTHY WU; ET. AL., Does Google degrade Google search? Experimental evidence, 2015, disponível em: http://bit.ly/1NpGX9J, acesso no dia 17, dez., 2015, p. 8-10. 
Figura 1 (Busca realizada em 18, dez., 2015):

$\begin{aligned} & \text { Google restaurantes em são paulo } \mathbf{Q} \\ & \text { All Images Maps News Shopping More * Search tools }\end{aligned}$

All Images Maps News Shopping More - Search tools

About $16,300,000$ results $(0.66$ seconds)

Anúncios Patrocinados

\begin{tabular}{|c|c|}
\hline & 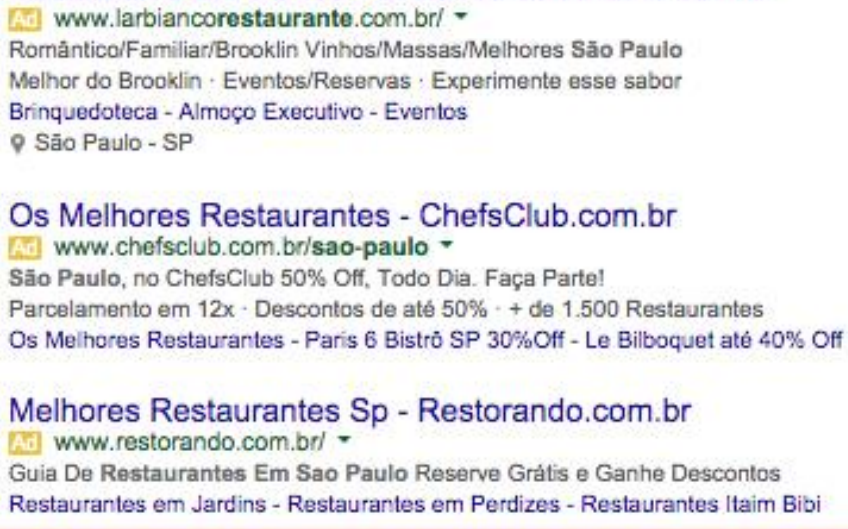 \\
\hline $\begin{array}{l}\text { Local } \\
\text { OneBox }\end{array}$ & $\begin{array}{l}\text { Osasco. } \\
\text { Rating }\end{array}$ \\
\hline & $\begin{array}{l}\text { Restaurante Sushi Hiroshi } \\
4.5 * \star \star \star * \star \\
\text { Rua Capitão Manuel Novaes, } 189 \\
\text { Opens at 11:30 AM }\end{array}$ \\
\hline & $\begin{array}{l}\text { Degas Pompéia } \\
4.3 * \hbar \star \star \star(65) \cdot \text { Pizza } \\
\text { Av. Pompéia, } 796\end{array}$ \\
\hline & $\begin{array}{l}\text { Mori Sushi Ohta } \\
4.2 \star \star \star \star \star(140) \text { - Japonesa } \\
\text { R. da Consolaçäa, } 3610 \\
\text { Opens at 12:00 PM }\end{array}$ \\
\hline
\end{tabular}

Restaurante Tre Bicchieri uww.trebicchieri.com.br/ Auténtica Cozinha Toscana. Massa Artesanal, Vinho e Sobremesa.

Restaurantes Sao Paulo, Brazil uww.tripadvisor.com/ .

Browse 100+ Million Travel Reviews \& Opinions. Plan Your Perfect Trip!

\section{Conheça o Café Voyage}

uww.cafevoyage.com.bri .

Viaje em uma experiẻncia

gastronômica incrivel. Visite-nos!

\section{Restaurante Sabor e Fé}

uww.saborefe.com.br/ -

Self-service de qualidade.

Traslado para romeiros!

Feijoada in Sao Paulo uww. pontochic.com.brl .

The best Feijoada on Wed \& Sat

Ponto Chic a Sao Paulo's tradition

Q Praça Oswaldo Cruz, Săo Paulo

(11) $3289-1480$

Restaurante Salsa ZN SP uww.restaurantesalsa.com.br/ Restaurante - Lanchonete - Pizzaria Av. Nossa Senhora do Loreto, 1050

\section{Best Restaurantes:}

uww.bestrestaurantes.com.brl Os Melhores Restaurantes do Brasil. Reservas em tempo real. Qualidade.

\section{Mr. Veggy}

uww.mrveggy.com/ Alimentos Congelados Vegetarianos e Salgados Integrais

See your ad here "
Busca Orgânica
Os 10 melhores restaurantes em São Paulo - TripAdvisor https://www.tripadvisor.com.br/Restaurants-g303631-... Translate this page Refeiçōes em São Pauio, Estado de São Paulo: Veja 341.229 dicas e avaliaçōes do TripAdvisor dos 35.707 restaurantes em São Paulo e faça a busca por .. 


\section{III.8.1 - Google como plataforma de múltiplos lados}

O Google opera na parte superior da cadeia de valor, adquirindo informações pessoais dos usuários em troca dos serviços de busca oferecidos a preço zero. No mercado downstream, os anunciantes adquirem tais informações pessoais, que serão utilizadas para oferecimento de anúncios direcionados. O mecanismo de buscas atua, portanto, como uma plataforma, intermediando provedores de conteúdo (que procuram usuários) e usuários (que procuram conteúdo), ao mesmo tempo em que comercializa seus espaços com os anunciantes. Tal estrutura permite que o preço seja distribuído de forma que os usuários não arquem com nenhum custo monetário, ao passo que os anunciantes pagam preços positivos e financiam seu funcionamento. ${ }^{634}$

No caso dos buscadores, portanto, são três os grupos de agentes envolvidos: (i) os websites indexados pela plataforma de buscas; (ii) as pessoas utilizando o mecanismo de busca; e (iii) os anunciantes do site de busca. Os três grupos geram entre si tanto memberships como usage externalities, sendo o papel da plataforma o de balancear os interesses desses três grupos de modo a maximizar seu lucro. ${ }^{635}$

Mercados de múltiplos lados geralmente apresentam três características principais: (i) dois grupos distintos de consumidores; (ii) o valor obtido por um dos grupos aumenta com o crescimento do outro grupo; (iii) a existência de um intermediário conectando as duas partes. No caso do Google, a empresa criou uma plataforma em que oferece conteúdo e serviços aos usuários, ao mesmo tempo em que comercializa os espaços publicitários da plataforma para os anunciantes. O aumento do número de usuários traz um efeito direto sobre a valorização dos anúncios da plataforma. Por outro lado, o aumento do número e do volume de anúncios pode trazer efeitos positivos, nulos ou negativos ao usuários. ${ }^{636}$ Constata-se, assim, que o aumento do número de participantes de um dos lados gera efeitos sobre a utilidade dos participantes do outro lado. Da mesma forma, o aumento da

\footnotetext{
634 IOANNIS LIANOS; EVGENIA MOTCHENKOVA, Market dominance and search quality in the search engine market, In Journal of Competition Law \& Economics, vol. 9, n. 2, 2013, p. 421.

635 DAVID S. EVANS; RICHARD SCHMALENSEE, The antitrust analysis of multi-sided platform businesses, disponível em: http://bit.ly/1KhV5mT, acesso no dia 19, mai, 2015, p. 11.

636 IOANNIS LIANOS; EVGENIA MOTCHENKOVA, Market dominance and search quality in the search engine market, In Journal of Competition Law \& Economics, vol. 9, n. 2, 2013, p. 445.
} 
qualidade da plataforma aumenta a utilidade de ambos os lados. Por fim, a plataforma acaba atuando como o intermediário que conecta os usuários do sistema de buscas aos anunciantes. Constata-se assim, que o Google preenche os requisitos para que possa se enquadrar sobre a estrutura de um mercado de dois lados. ${ }^{637}$ Como em outros mercados desse tipo, o preço, a qualidade e o nível de produção dos dois lados se encontra interrelacionado. A estrutura de preços da mesma forma é viabilizada pela estrutura da plataforma, que permite que a empresa cobre preços iguais a zero do lado dos usuários ao mesmo tempo em que obtém seu faturamente do lado dos anunciantes. ${ }^{638}$

No entanto, alguns autores sustentam que plataformas de mídia, bem como algumas plataformas web, como o Google, não seriam uma plataforma de múltiplos lados. Segundo seus defensores, para que uma indústria fosse considerada de múltiplos lados dois requisitos fundamentais deveriam estar presentes: a ocorrência de uma única transação entre os diferentes grupos e a necessidade de troca de externalidades recíprocas positivas entre os lados. De acordo com esta visão, se estruturas com trocas unilaterais de externalidades pudessem ser classificadas como de múltiplos lados, praticamente todo revendedor de produtos, como supermercados e lojas em geral, seriam incluídas nesta classificação. ${ }^{639}$

Para que possamos enfrentar estes argumentos faz-se necessário uma melhor descrição do funcionamento do mecanismos de buscas da empresa. Como afirmamos, a plataforma do Google opera com duas classes de usuários: os usuários que realizam buscas e os anunciantes. Os usuários digitam palavras-chave com o objetivo de obterem os

637 KRISTINE LAUDADIO DEVINE, Preserving competition in multi-sided innovative markets: How do you solve a problem like Google?, In North Carolina Journal of Law \& Technology, Vol. 10, n. 1, 2008, pp. 78-79. Dentre inúmeros outros, podemos citar MICHAL S. GAL e DANIEL L. RUBINFELD, falando do caso Google, apontam que: "This assertion ignores the two-sided nature of the searchadvertising platform and the feedback effects that link the provision of organic search results to consumers, on the one hand, and the sale to businesses of advertising accompanying those search results on the other." (MICHAL S. GAL; DANIEL L. RUBINFELD, The hidden costs of free goods: Implications for Antitrust enforcement, New York University Law and Economics Working Papers, Disponível em: http://bit.ly/1Qg96Ds, acesso no dia 05, nov., 2015, p. 26); Ainda, AARON S. EDLIN e ROBERT G. HARRIS: "We acknowledge that Google and other generalized search engines typically operate in a "two-sided market," with users on one side and advertisers on the other." (AARON S. EDLIN e ROBERT G. HARRIS, The role of switching costs in antitrust analysis: A comparison of Microsoft and Google, In Yale Journal of Law and Technology, n. 169, v. 15, 2013, p. 175).

638 MARK R. PATTERSON, Google and search-engine market power, In Harvard Journal of Law \& Technology Occasional Paper Series, jul. 2013, disponível em: http://bit.ly/1kQlVZw, acesso no dia 23, nov., 2015, pp. 16-17.

639 GIACOMO LUCHETTA, Is the Google platform a two-sided market?, disponível em: http://bit.ly/1TRQw8o, acesso no dia 18, ago., 2015, pp. 9-10. 
resultados mais relevantes relacionados àquelas palavras-chave. Esse mecanismo é chamado de "busca orgânica", pois funciona conforme os princípios de relevância do algoritmo de buscas do sistema. Além do resultado da busca orgânica, a plataforma pode também apresentar juntamente com os resultados outros serviços fornecidos pelo próprio Google, como o serviço de mapas, bem como os anúncios patrocinados direcionados (os anúncios podem ser adquiridos tanto através da plataforma do empresa chamada de AdWorks como por agências de publicidade). Dessa forma, duas transações são realizadas: (i) o fornecimento da informação presente no resultado da busca ao usuário, e (ii) a comercialização do espaço publicitário com o anunciante. ${ }^{640}$

Além disso, um segundo requisito para caracterização de uma plataforma de múltiplos lados estaria na necessidade da presença de ambos os lados para a própria existência do mercado. O mercado de cartões de pagamento, por exemplo, não existiria se compradores ou vendedores não aderissem à plataforma. Isso ocorre pois as duas partes são fundamentais para a existência e funcionamento do sistema. Esta característica ficou conhecida como o dilema do ovo e da galinha, ou "chicken-and-egg", e é tida como característica essencial para que um mercados seja considerado de dois lados. GIACOMO LUCHETTA aponta que em setores de mídia, como alguns canais de televisão, a decisão pela estrutura de dois lados constitui mera estratégia de negócios, como ocorre com canais de pay-per-view em que o faturamento decorre das subscrições dos usuários. Tais setores, no entanto, não apresentariam o dilema do ovo e da galinha, uma vez que a plataforma precisa do usuário para que possa oferecer anúncios, sem que a recíproca seja verdadeira. $^{641}$

Por fim, um terceiro argumento se relaciona à troca de externalidades recíprocas entre as partes. No caso do Google, os efeitos indiretos de rede surgem quando a base instalada de usuários de um dos lados da plataforma aumenta o valor da plataforma para os anunciantes situados no outro lado. No entanto, se as externalidades positivas recebidas pelos anunciantes com o aumento do número de usuários são incontroversas, o eventual

640 GIACOMO LUCHETTA, Is the Google platform a two-sided market?, disponível em: http://bit.ly/1TRQw8o, acesso no dia 18, ago., 2015, p. 14.

641 GIACOMO LUCHETTA, Is the Google platform a two-sided market?, disponível em: http://bit.ly/1TRQw8o, acesso no dia 18, ago., 2015, pp. 11-12. 
benefício recebido pelos usuários da pesquisa com o aumento do número de anunciantes seria ausente ou mesmo desprezível. ${ }^{642}$

Dessa forma, seguindo esta abordagem, o Google não seria uma plataforma de múltiplos lados, sendo sua plataforma caracterizada, na realidade, por dois mercados de um lado com Externalidades de Rede Unidirecionais Constantes (Constant Unidirectional Network Externalities), por conta de três características principais: (i) a plataforma da empresa apresenta duas transações e não apenas uma; (ii) a operação com duas classes de usuários constitui antes uma estratégia de negócios do que uma necessidade estrutural do setor; e (iii) não haveria troca de externalidades recíprocas entre as duas classes de usuários. $^{643}$

A visão de que a plataforma da Google conteria apenas efeitos uni-direcionais e não externalidades indiretas de rede, porém, dificilmente se constata na prática. Ainda que se argumente que o aumento do valor da plataforma para os anunciantes não traga qualquer benefício para os usuários do sistema de busca, na realidade o que se observa é uma relação de interdependência entre os dois lados. O desenvolvimento e uso do mecanismo de buscas pelos usuários leva ao aumento do valor da plataforma de anúncios, por conta da maior visibilidade e abrangência, permitindo que a empresa cobre valores mais altos e assim receba um maior volume de recursos dos anunciantes. Esse incremento do lado dos anunciantes, por sua vez, permite que a empresa forneça mais recursos e de melhor qualidade ao seus usuários, por meio do investimento em desenvolvimento do sistema de buscas além de novos produtos complementares como serviços de e-mail e mapas. ${ }^{644}$

A combinação do mecanismos de buscas com a plataforma de anúncios faz com que surjam relevantes externalidades recíprocas de rede. ${ }^{645}$ Por essa razão, o Google atua

642 GIACOMO LUCHETTA, Is the Google platform a two-sided market?, disponível em: http://bit.ly/1TRQw8o, acesso no dia 18, ago., 2015, p. 15.

643 GIACOMO LUCHETTA, Is the Google platform a two-sided market?, disponível em: http://bit.ly/1TRQw8o, acesso no dia 18, ago., 2015, pp. 13.

644 KRISTINE LAUDADIO DEVINE, Preserving competition in multi-sided innovative markets: How do you solve a problem like Google?, In North Carolina Journal of Law \& Technology, Vol. 10, n. 1, 2008, pp. $78-80$.

645 Nesse sentido, dentre inúmeros outros, JAMES D. RATLIFF e DANIEL L. RUBINFELD: "In the context of search advertising, however, there can be no doubt that the indirect network effects between organic search on the one side and search advertising on the other are highly significant, because it is obvious that those network effects are crucial for the viability of the platform. As we pointed out above, organic search is unprofitable as a standalone business." (JAMES D. RATLIFF; DANIEL L. RUBINFELD, Is there 
como uma verdadeira plataforma ligando usuários e anunciantes, sendo que a estruturas de preços zero é viabilizada justamente pela possibilidade de cobrança dos anunciantes. Criase, portanto, uma relação em que os usuários valorizam a plataforma na medida em que tenham acesso a mais serviços gratuitos e melhores, ao passo que os anunciantes valorizam na medida em que tem acesso a um número maior de consumidores. ${ }^{646}$ A lucratividade de todo negócio depende, portanto, da atração de anunciantes para sua plataforma. Para tanto a empresa necessita torná-la cada vez mais atrativa aos usuários, ou seja, fornecendo novos e melhores serviços. Essa estrutura cria a relação de interdependência típica das plataformas de múltiplos lados.

Além disso, sendo a cobrança de preço zero a realidade destes novos setores de serviço web-based, a presença dos anunciantes se mostra fundamental e não mera estratégia de negócios.

A conclusão dessa abordagem traz diversas consequências sobre a análise destes setores. Conforme já observamos, enquanto em mercados de um único lado as empresas definem o nível de produção até o ponto em que o custo marginal seja igual ao preço marginal, no caso dos mercados de múltiplos lados, estas se encontram sujeitas à outras restrições competitivas no processo de definição dos preços. O aumento dos preços de um dos lados pode levar à perda de usuários de ambos os lados da plataforma, uma vez que os efeitos de rede criam uma interrelação entre as demandas. O oposto também se mostra verdadeiro, ou seja, um aumento da demanda de um dos lados pode levar ao aumento da demanda pelo outro lado. Dessa forma, na medida em que o Google atrai mais usuários para a plataforma, esta se torna mais valiosa para os anunciantes. $\mathrm{O}$ valor pago pelos anunciantes, por sua vez, permite ao Google oferecer mais e melhores serviços aos usuários, seja por meio de inovação ou de aquisições. ${ }^{647}$

a Market for organic search engine results and can their manipulation give rise to antitruste liability?, In Journal of Competition Law \& Economics, vol. 10, n. 3, 2014, p. 22)

\footnotetext{
646 "Increased advertising pays not only for the continuing development and refinement of the organic search algorithm, but also for additional free products that enable Google users to send and receive email, store and share pictures online, and find relevant information via organic search (KRISTINE LAUDADIO DEVINE, Preserving competition in multi-sided innovative markets: How do you solve a problem like Google?, In North Carolina Journal of Law \& Technology, Vol. 10, n. 1, 2008, pp. 81-83).

647 KRISTINE LAUDADIO DEVINE, Preserving competition in multi-sided innovative markets: How do you solve a problem like Google?, In North Carolina Journal of Law \& Technology, Vol. 10, n. 1, 2008, pp. 78-80.
} 
A desconsideração dos efeitos sobre os múltiplos lados envolvidos pode levar a análises equivocadas e que subestimam a complexidade do sistema de precificação e da dinâmica competitiva nesse setor.

\section{III.8.2 - Análise do poder de mercado do Google}

O setor em que a empresa opera, por conta das características supra mencionadas apresenta elevada concentração de mercado. Nos EUA, por exemplo, o Google detém um market share de 66,2\%, enquanto o Yahoo detém 16,4\% e o Bing 11,8\%. Nos mercados europeus essa concentração é ainda maior, sendo a participação do Google de 90,83\% no Reino Unido e na maior parte da Europa. ${ }^{648}$

Conforme observamos, os novos setores de Internet apresentam enorme desafio no tocante à delimitação do mercado relevante em que atuam bem como no tocante à análise das restrições competitivas enfrentadas pela empresa. O caso Google se mostra paradigmática destas dificuldades. Apesar da definição tradicionalmente apontar para o mercado de "online search advertising", devemos lembrar que a própria extensão da concorrência é variável dependendo das dimensões de análise, o que faz com que essa definição possa ser mais restritiva ou mais ampla. Além disso, as interações entre busca patrocinada e busca orgânica se mostra, da mesma forma, complexa, o que torna a metodologia tradicional, baseada na definição com base em market shares inadequada. ${ }^{649}$

A aplicação de testes tradicionais, como o do do monopolista hipotético (SSNIP), para este mercado poderia levar a resultados absurdos como o de considerar cada termo de busca e sua página de resultados como um mercado relevante distinto. ${ }^{650}$ Por essa razão,

\footnotetext{
648 IOANNIS LIANOS; EVGENIA MOTCHENKOVA, Market dominance and search quality in the search engine market, In Journal of Competition Law \& Economics, vol. 9, n. 2, 2013, p. 423.

\begin{abstract}
649 "Although the extent of competition along these dimensions varies considerably by search term and by advertiser and industry characteristics, the existence of such competition suggests that relevant markets may be narrower or broader than presumed and market power difficult to determine. In either case, the complex interactions between organic and paid search results, which are at once both complements and substitutes, dramatically complicates the U.S. Department of Justice Merger Guidelines' traditional, narrowest possible market test." (GEOFFREY A. MANNE; JOSHUA D. WRIGHT, Google and the limits of antitrust: The case against the case against Google, In Harvard Journal of Law \& Public Policy, Vol. 34, disponível em: http://bit.ly/1hHH4TR, acesso no dia 17, ago., 2015, p. 201).
\end{abstract}

650 "many distinct search terms and their search results pages-each the product of a particular auction and a particular set of web pages crunched through Google's PageRank algorithm — would constitute separate relevant markets under a Small but Significant and Non-Transitory Increase in Price (SSNIP) test." (GEOFFREY A. MANNE; JOSHUA D. WRIGHT, Google and the limits of antitrust: The case against the 
conclusões baseadas em medidas de market share não apresentam resultados conclusivos para este setor. A intensa concorrência enfrentada pela empresa não deve levar à conclusão de que ela não possui poder de mercado, assim como medidas de market share também não devem ser tomadas como base para auferição do poder de mercado. ${ }^{651}$ Deve-se, portanto, deslocar o enfoque para a análise das restrições competitivas para uma adequada análise do poder de mercado detido pela empresa.

Um primeira restrição competitiva a ser considerada se relaciona à possibilidade de substitutibilidade do lado da demanda, ou seja, na capacidade dos consumidores migrarem para concorrentes que ofereçam serviços similares. Nesse ponto um aspecto central se encontra nas dificuldades decorrentes da chamada path dependence e do efeito lock-in. No caso do Google tais efeitos surgiriam por conta do efeitos de rede, uma vez que o consumidor incorre em custos, bem como na perda de benefícios de rede ao migrar para alternativas similares. Tais efeitos operam tanto sobre o lado dos anunciantes como sobre o lado dos usuários. Ao adquirir os serviços da plataforma AdWorks os anunciantes tendem a permanecer utilizando este serviço, uma vez que diante de uma ruptura contratual, a Google poderia alterar seu algoritmo da busca orgânica de modo que o site do anunciante seja alocado ao final do resultado de pesquisas. Tal efeito recebe o nome de third-order path dependence. ${ }^{652}$

Em relação aos usuários, ainda que o serviço de busca seja de fácil múdança, os serviços complementares ao serviço de buscas, como serviços de e-mail, de hospedagem de blogs ou de fotos possuem custos significativos de mudança. Além disso, o próprio look and fell dos serviços da empresa são muito semelhantes, o que faz com que um usuário acostumado a utilizar os serviços da empresa optem por utilizar outros serviços da mesma empresa. No caso do Google, a conveniência da barra de navegação da empresa favorece a

case against Google, In Harvard Journal of Law \& Public Policy, Vol. 34, disponível em: http://bit.ly/1hHH4TR, acesso no dia 17, ago., 2015, p. 201).

651 "it is unlikely that monopoly power can be inferred from a search engine's high share of the general search traffic." (MARINA LAO, Neutral search as a basis for antitrust action, In Harvard Journal of Law \& Technology Occasional Paper Series, July, 2013, disponível em: http://bit.ly/1QT9bgq, acesso no dia 20, dez., 2015, p. 7).

652 KRISTINE LAUDADIO DEVINE, Preserving competition in multi-sided innovative markets: How do you solve a problem like Google?, In North Carolina Journal of Law \& Technology, Vol. 10, n. 1, 2008, p. 86. 
utilização de serviços da própria empresa. Por fim, o próprio custo de busca de uma alternativa faz com que o usuário decida permanecer nesta opção. ${ }^{653}$

Em sentido oposto alguns autores sustentam que no caso do Google os custos de mudança seriam baixos ou praticamente nulos. ${ }^{654}$ Os custos de compatibilidade seriam praticamente nulos, uma vez que o buscador da Google opera sobre as plataformas abertas da Internet e da World Wide Web. Como afirmamos, tais sistemas foram desenvolvidos com o objetivo de promover a interoperabilidade e a interconectividade, por meio do funcionamento com base em standards como o http e o html. ${ }^{655}$

Os custos de transação também se mostram extremamente baixos no caso do Google. Os usuários facilmente alternam entre buscadores entre sessões de buscas e, muitas vezes, durante uma mesma sessão de busca. Da mesma forma os custos de procura de alternativas e de aprendizado se mostram praticamente nulos. No caso dos custos de procura, o próprio Google pode apresentar através de um resultado de buscas um concorrente tanto em relação a buscas verticais como gerais. Apesar da interface guardar significativas diferenças entre os diferentes mecanismos, o mecanismo de funcionamento é semelhante e envolve custos de aprendizado praticamente nulos. ${ }^{656}$

Estudos realizados em 2013 pela Microsoft Research apontam que 72,6\% da amostra analisada de usuários utilizou mais de um tipo de mecanismo de busca em um

653 KRISTINE LAUDADIO DEVINE, Preserving competition in multi-sided innovative markets: How do you solve a problem like Google?, In North Carolina Journal of Law \& Technology, Vol. 10, n. 1, 2008, pp. 85-87.

654 "One significant difference between Google search and Microsoft Windows is that the latter requires a substancial commitment. By contrast, someone who has Google search stored on a computer or other device can download additional search engines or substitute away in a few moments at no cost. This makes lock-in problems virtually non-existent, although there might still be opportunities for Google to discriminate in favor of its own subsidiaries, such as YouTube." (HERBERT HOVENKAMP, Federal antitrust Policy: The Law of Competition and its Practice, $5^{\text {th }}$ ed., 2015, 401-402). Ainda MARINA LAO: "Unhappy Google users can instantly switch to another search engine, such as Bing or Yahoo!, without incurring any penalties or costs" (MARINA LAO, Neutral search as a basis for antitrust action, In Harvard Journal of Law \& Technology Occasional Paper Series, July, 2013, disponível em: http://bit.ly/1QT9bgq, acesso no dia 20, dez., 2015, p. 7).

655 Fazendo uma comparação com o caso Microsoft, EDLIN e HARRIS apontam que o Windows operava sobre bases proprietárias e em um ambiente em que a compatibilidade se mostrava como uma questão mais crítica que no caso do Google (AARON S. EDLIN e ROBERT G. HARRIS, The role of switching costs in antitrust analysis: A comparison of Microsoft and Google, In Yale Journal of Law and Technology, n. 169, v. 15, 2013, pp. 193-194).

656 AARON S. EDLIN e ROBERT G. HARRIS, The role of switching costs in antitrust analysis: A comparison of Microsoft and Google, In Yale Journal of Law and Technology, n. 169, v. 15, 2013, pp. 194198. 
período de análise de 6 meses. Além disso, 50\% da amostra trocou de mecanismo de busca durante a mesma sessão de buscas, enquanto $67,7 \%$ dos usuários trocou de mecanismo entre sessões diferentes de busca. Deve-se apontar, ainda, que a substituição ocorre não apenas entre mecanismos de buscas gerais, mas também entre mecanismos de busca geral e busca vertical. Tais dados apontam, portanto, para o alto grau de mudança entre mecanismos diferentes por parte dos usuários, o que sustenta a tese da insignificância dos switching costs neste setor. ${ }^{657}$

Com relação ao motivo do usuário se valer de mais de um buscador diferente, EDLIN e HARRIS apontam que a principal razão seria a insatisfação com os resultados de busca apresentados pelo mecanismo de busca. Sustentam os autores que na medida que os resultados de busca fossem manipulados, de modo a favorecer os próprios produtos, os usuários tenderiam a procurar alternativas. Segundo os autores, portanto, o argumento de que o Google manipularia o algoritmo para favorecer seus produtos carece de sentido econômico, uma vez que tais manipulações levam a perda de receita por parte da empresa. $^{658}$

No entanto, tais argumentos devem ser vistos com ressalva, uma vez que a própria natureza destes serviços envolve uma dificuldade de mensuração de sua qualidade por parte dos usuários. Nesse ponto surge uma segunda fonte do poder de mercado: a ocorrência de custos de informação, ou seja, a capacidade dos usuários determinarem claramente os benefícios associados a mudança para um concorrente da empresa.

A ausência de preços ao consumidor faz com que a concorrência se desloque para a qualidade do serviço. ${ }^{659}$ Conforme veremos, a dificuldade de consideração em relação à

657 AARON S. EDLIN e ROBERT G. HARRIS, The role of switching costs in antitrust analysis: A comparison of Microsoft and Google, In Yale Journal of Law and Technology, n. 169, v. 15, 2013, pp. 198203.

658 "Therefore, the argument that Google would bias its search results in a manner that would degrade users' experience makes no economic sense, because users could and would switch some of their searching usage to other search engines, causing a loss of click-through advertising revenue to Google." (AARON S. EDLIN e ROBERT G. HARRIS, The role of switching costs in antitrust analysis: A comparison of Microsoft and Google, In Yale Journal of Law and Technology, n. 169, v. 15, 2013, p. 203).

659 "If users had to pay to use Google services, competitors could offer a cheaper price, indu- cing users to try a new service that might be unattractive if it merely matched Google's price. In contrast, by foregoing a direct charge to users, Google leaves no room for competitors to offer lower prices." (BENJAMIN EDELMAN, Does google leverage market power through tying and bundling?, In Journal of Competition Law and Economics, vol. 11, n. 2, 2015, p. 371). 
qualidade do bem ofertado faz com que o consumidor tenha dificuldades de considerar os custos e benefícios associados à mudança para um concorrente da empresa.

Já observamos que economistas classificam os bens com relação a capacidade dos usuários avaliarem a qualidade de um bem em três categorias: (i) search goods; (ii) experience goods; e (iii) creedence goods. O enquadramento das buscas em uma destas categoria irá depender do tipo de busca realizada pelo usuário. Raramente uma busca será enquadrada como search good, sendo esta possível apenas nas raras situações em que o usuário tem confiança de que encontrará o resultado esperado no buscador, como, por exemplo, quando procura a definição de uma palavra, ou o resultado de um jogo esportivo realizado recentemente. Em outros casos, a busca poderá se enquadrar como experience good, quando, por exemplo o usuário busca uma explicação mais complexa para um fenômeno natural. Nesse caso, ao receber o resultado da busca, o usuário provavelmente poderá avaliar a qualidade do resultado apresentado. Por fim, em diversas situações o consumidor não toma conhecimento da qualidade do serviço mesmo após receber os resultados de busca. Isso ocorre, por exemplo, quando se pesquisam hotéis bons e baratos em Nova York. Ao receber os resultados de pesquisa, o usuário não saberá se os hotéis mostrados pelo buscador realmente preenchem os requisitos desejados. Da mesma forma, ao buscar em um site distinto o consumidor também não saberá se o resultado apresentado é superior. ${ }^{660}$

Por meio de análise experimental em ambiente controlado, estudo recente realizado por MICHAEL LUCA e TIM WU concluiu que, ao procurar opções de busca vertical especializada, os consumidores preferem o conteúdo apresentado pelo resultado de busca orgânica da Google, ou seja, os links que direcionam para outros sites de busca especializada. O que indica que a empresa estaria produzindo resultados inferiores ao decidir apresentar seu próprio conteúdo em destaque em detrimento dos resultados de busca orgânica. ${ }^{661}$

A dificuldade de avaliação do serviço prestado pela empresa Google faz com que esta esteja menos propensa a sofrer pressões competitivas de concorrentes. Ainda que a

660 MARK R. PATTERSON, Google and search-engine market power, In Harvard Journal of Law \& Technology Occasional Paper Series, jul. 2013, disponível em: http://bit.ly/1kQlVZw, acesso no dia 23, nov., 2015, pp. 11-12.

661 MICHAEL LUCA; TIMOTHY WU; ET. AL., Does Google degrade Google search? Experimental evidence, 2015, disponível em: http://bit.ly/1NpGX9J, acesso no dia 17, dez., 2015, pp. 5-6. 
empresa não possa produzir serviços ruins, sob o risco de perder usuários, seus incentivos estão direcionados à produção de resultados sub-ótimos. Deve-se ressaltar, no entanto, que isso não torna tais empresas imunes à competição, como se pode ver com as constantes mudanças realizadas pela empresa para melhorar as qualidades das buscas realizadas por seu algoritmo. ${ }^{662}$

Outra evidência que aponta para a possibilidade de resultados sub-ótimos por parte do buscador é a existência dos chamados "Search Engine Optimization" (SEO) ${ }^{663}$ utilizados por sites que tenham interesse de que seu link figure sempre entre os primeiros resultados de pesquisa do Google. A possibilidade de manipulação dos resultados de busca por estes mecanismos corrobora a hipótese de manutenção do poder de mercado da empresa mesmo diante de resultados degradador por SEOs. Devemos lembrar, ainda, que sendo o Google o site de buscas com maior número de acessos, naturalmente, os SEOs serão usados principalmente no site da empresa, o que aponta para maior ocorrência de manipulação em seus resultados por SEOs dentre todos os concorrentes. Três conclusões podem ser extraídas da análise dessas evidências: (i) os SEOs produzem pouco efeito sobre os resultados, o que não parece ser o caso, tendo em vista o enorme dinheiro gasto pelos sites com tais mecanismos; (ii) a qualidade das buscas do Google antes da existência desses mecanismos era tão elevada que mesmo com a redução pelo uso dos SEOs esta continua alta; (iii) os usuários consideram a qualidade das buscas elevada, mesmo diante da manipulação pelos SEOs. Tanto a segunda como a terceira hipótese apontam para a existência de poder de mercado por parte da empresa. ${ }^{664}$

662 MARK R. PATTERSON, Google and search-engine market power, In Harvard Journal of Law \& Technology Occasional Paper Series, jul. 2013, disponível em: http://bit.ly/1kQlVZw, acesso no dia 23, nov., 2015, pp. 12-13.

663 Os SEOs são definidos pela empresa Google como: "Search engine optimization is often about making small modifications to parts of your website. When viewed individually, these changes might seem like incremental improvements, but when combined with other optimizations, they could have a noticeable impact on your site's user experience and performance in organic search results." (Google Search Engine Optimization Starter Guide, disponível em: http://bit.ly/1cpVpgW, acesso no dia 29, nov., 2015). Deve-se ressaltar, no entanto, que existem dois tipos de SEOs, os black hats, que distorcem os resultados de busca, e os white hats, que melhores aspectos da apresentação do site para o algoritmo dos buscadores, melhorando os resultados de busca (MARK R. PATTERSON, Google and search-engine market power, In Harvard Journal of Law \& Technology Occasional Paper Series, jul. 2013, disponível em: http://bit.ly/1kQlVZw, acesso no dia 23, nov., 2015, p. 14). O guia apresentado pela empresa Google parece descrever o segundo tipo de SEO.

664 MARK R. PATTERSON, Google and search-engine market power, In Harvard Journal of Law \& Technology Occasional Paper Series, jul. 2013, disponível em: http://bit.ly/1kQlVZw, acesso no dia 23, nov., 2015, pp. 14-15. 
No caso dos buscadores de Internet, a capacidade de mover um site para cima ou para baixo nos resultados de busca pode ser vista como uma redução do nível de qualidade dos resultados de busca e que, ausente o poder de mercado, poderia levar o site a perder usuários. Sendo os preços iguais a zero, a capacidade de redução da qualidade seria vista, então, como evidência de exercício de poder de mercado. ${ }^{665}$ Para que isso seja possível, no entanto, se faz necessário quantificar a redução da qualidade. Conforme PATTERSON, uma dessas maneiras poderia ser por meio do uso dos preços pagos pelos anunciantes para utilização da plataforma Google AdWorks. O valor das posições da busca orgânica não podem ser quantificados, porém, as posições do AdWorks poderiam funcionar como um proxy para os resultados de busca orgânica. Nesse caso espera-se que a diferença de valor entre as posições nos resultados de busca orgânica sejam superiores aos dos resultados do AdWorks. ${ }^{666}$

A intensa competição e dinâmica competitiva do setor fazem com que a empresa tenha que modificar frequentemente seu modelo de negócios. É por essa razão que autores como MANNE e RINEHART defendem que as estratégias implementadas pela empresa não configurariam estratégia anticompetitiva, mas antes decisões de design de produtos de extrema necessidade. ${ }^{667}$ É por essa razão que os indícios tradicionais de poder de mercado não configurariam necessariamente infração antitruste nesses setores, uma vez que seriam fruto direto e necessário da inovação de produtos. ${ }^{668}$

JOSHUA WRIGHT apresenta estudo que aponta que a frequência de manipulação do algoritmo do buscador Bing, da Microsoft, é comparável ou mesmo superior ao do

\footnotetext{
665 "The ability of Google to profitably degrade its search in some areas, as suggested by the results here, has natural empirical relevance to the firm's possession of market power. Indeed, it might be taken as direct evidence of market power" (MICHAEL LUCA; TIMOTHY WU; ET. AL., Does Google degrade Google search? Experimental evidence, 2015, disponível em: http://bit.ly/1NpGX9J, acesso no dia 17, dez., 2015, p. 16).
}

666 MARK R. PATTERSON, Google and search-engine market power, In Harvard Journal of Law \& Technology Occasional Paper Series, jul. 2013, disponível em: http://bit.ly/1kQlVZw, acesso no dia 23, nov., 2015, pp. 16-18.

667 "But viewed from the point of view of the competitive dynamics of the broader market in which Google operates, these allegedly exclusionary acts look like sensible, even necessary, product design decisions. Although competitors might prefer that Google's products operate differently, those wishes are not a sound basis for antitrust liability, as the FTC realized." (GEOFFREY A. MANNE; WILLIAM RINEHART, The market realities that undermined the FTC's antitrust case against Google, In Harvard journal of law and technology occasional paper series, July, 2013, disponível em: http://bit.ly/1FCV4Ce, Acesso em 25, jun. 2015, p. 12).

668 GEOFFREY A. MANNE; JOSHUA D. WRIGHT, Innovation and the limits of antitrust, In Journal of Competition Law \& Economics, vol. 6, 153, 2010, pp. 170-178. 
Google. Dessa forma, sustenta o autor que o bias não seria função de poder de mercado, mas antes uma estratégia competitiva decorrente da intensa competição e da inovação no mercado de buscas. ${ }^{669}$ Tal premissa, porém, apenas se mantém se considerarmos que o pequeno market share do buscador da Microsoft aponta para a ausência de poder de mercado por parte do Bing. Nesse caso devemos lembrar que a fonte de poder de mercado não consiste no market share detido pela empresa, mas sim na dificuldade dos consumidores avaliarem a qualidade do serviço prestado. Por essa razão, mesmo agentes com pequeno market share podem exercer poder de mercado nestes setores.

A disciplina de mercado se baseia em dois elementos centrais: a existência de intensa competição e a capacidade de resposta dos usuários diante do abuso. ${ }^{670}$ No entanto, ambos elementos se mostram questionáveis no caso Google. Nenhum player apresenta real ameaça à empresa, salvo em nichos específicos. Da mesma forma, a capacidade de "votar com os pés", ou seja, do consumidor migrar para concorrentes diante da insatisfação em relação aos serviços, da mesma forma se mostra limitada. Assim, a existência de assimetria informacional e significativas barreiras à entrada faz com que o mercado se mostre incapaz de corrigir suas falhas sem intervenção governamental. ${ }^{671}$

Nota-se, portanto, que características presentes nesse caso, como a questão das assimetrias informacionais, da dificuldade de mensuração da qualidade, a baixa substitutibilidade pelo lado dos anunciantes, dentre outras, nos leva a concluir pela posse de poder de mercado por parte da Google.

669 JOSHUA D. WRIGHT, Defining and measuring search bias: Some preliminary evidence, George Mason University Law and Economics Research Paper Series, 2011, disponível em: http://bit.ly/1Lxa90i, acesso no dia 25, nov., 2015.

670 "The market discipline argument is based on two key premises: robust competition in the search market and users' responsiveness to abuse. Unfortunately, both of these premises are highly problematic." (OREN BRACHA; FRANK PASQUALE, Federal Search Commission?: Access, Fairness, and Accountability in the Law of Search, In Cornell Law Review, vol. 93, 2008, p. 1180).

671 "Moreover, Google gains in every arena it enters, whether by technologically superior products (its email product) or by acquisition (YouTube). The market does not appear to be capable of balancing the strong network effects present in the search advertising industry." (KRISTINE LAUDADIO DEVINE, Preserving competition in multi-sided innovative markets: How do you solve a problem like Google?, In North Carolina Journal of Law \& Technology, Vol. 10, n. 1, 2008, p. 108). 


\section{III.8.3 - Barreiras à entrada no mercado de buscadores}

A análise das barreiras à entrada presentes neste mercado nos permite compreender a dinâmica de entrada de novos concorrentes no setor. Já afirmamos que as barreiras à entrada em novos setores de Internet sejam significativamente inferiores às barreiras presentes nas indústrias tradicionais. No entanto, a estrutura de múltiplos lados da plataforma da Google cria alguns custos adicionais aos eventuais entrantes no mercado.

Em setores com tal estrutura a rede desempenha papel fundamental para sucesso da plataforma. Os efeitos de rede fazem com que a plataforma seja mais valiosa na medida em que cada lado do mercado aumente, o que incentiva o path dependence e o efeito lock-in supramencionados. Isso cria dificuldades para que um novo competidor ganhe mercado e permite a manutenção do domínio do mercado por uma empresa. Além disso, os próprios efeitos de rede acabam gerando o problema do ovo e da galinha, uma vez que a plataforma necessita de uma larga base instalada para que seja atrativa aos anunciantes, ao mesmo tempo em que necessita de um número considerável de anunciantes para que possa atrair usuários, uma vez que estes financiam os serviços oferecidos gratuitamente aos usuários.

Os custos para desenvolvimento de um mecanismo de busca também se mostram significativos. Tanto assim que a empresa Yahoo decidiu terceirizar o desenvolvimento de seu mecanismo de busca geral para a empresa Microsoft, estimando que com este acordo tenha economizado em torno de 200 milhões de dólares por ano. ${ }^{672}$ Os custos para manutenção de um sistema de buscas desse porte é considerável. Como afirmamos anteriormente, Google se vale de mais de um milhão de computadores para mapear e indexar a web, utilizando energia elétrica equivalente a de uma cidade como Salt Lake City. $^{673}$

Da mesma forma, o desenvolvimento de um mecanismo de buscas envolve economias de escala, uma vez que os resultados de busca gerados auxiliam na melhoria do algoritmo e dos resultados. Sendo os resultados de buscas realizada no Google sigilosos, nenhum competidor pode ter acesso a tais dados com o objetivo de aperfeiçoar seu sistema

\footnotetext{
672 "Running an industry-competitive search engine is really expensive. Yahoo expected to save $\$ 200$ million a year by outsourcing its search operations to Microsoft" (ERIC GOLDMAN, Revisiting search engine bias, In William Mitchell Law Review, Vol. 38, n. 1, 2011, p. 98).

673 FRANK PASQUALE, Paradoxes of digital antitrust: Why the FTC failed to explain its inaction on search bias, In Harvard journal of law and technology occasional paper series, July, 2013, disponível em: http://bit.ly/1FbNQVJ, Acesso em 11, jun. 2015, p. 5.
} 
de buscas. ${ }^{674}$ Segundo os defensores da empresa, inclusive, não haveria qualquer obrigação do agente compartilhar ou permitir o acesso de qualquer de seus competidores a recursos controlados por esta empresa. ${ }^{675}$

\section{III.8.4 - Análise da conduta}

Inúmeros debates tem se travado no tocante à licitude da manipulação do algoritmo para favorecimento de serviços da própria empresa. A Google vem sendo investigada por diversas autoridades antitruste do mundo, sendo a principal acusação a de praticar conduta exclusionária ao direcionar o tráfega dos mecanismos de busca especializada para suas próprias versões desses mecanismos.

A estratégia da empresa se assemelha em grande medida o padrão de conduta de outras empresas de tecnologia de outros períodos. Nos anos de 1970, a AT\&T também foi acusada de excluir competidores nos mercados de telefonia e de comunicação de longa distância apesar das obrigações impostas pelos reguladores. Da mesma forma, a Microsoft sofreu intensa investigação na década de 1990 acusada de usar de seu poder no mercado de sistemas operacionais com objetivo de excluir competidores do mercado de navegadores de Internet (browsers). ${ }^{676}$

O bias sobre o algoritmo tem um efeito determinante sobre as decisões de navegação do usuário, uma vez que a maior parte dos usuários acredita que os primeiros resultados listados no resultado de buscas sejam efetivamente os mais relevantes. É por

\footnotetext{
$674 \quad$ “Google's Chief Scientist Peter Norvig has made this very point. 'We don't have better algorithms than everyone else', he has stated; 'we just have more data'. Thus Google itself controls the chief input into better search services: the data that engineers need in order to better personalize results." (FRANK PASQUALE, Paradoxes of digital antitrust: Why the FTC failed to explain its inaction on Search Bias, In Harvard Journal of Lwa \& Technology Occasional Paper Series, July, 2013, disponível em: http://bit.ly/1FbNQVJ, acesso no dia 21, dez., 2015, p. 7).
}

675 GEOFFREY A. MANNE; WILLIAM RINEHART, The market realities that undermined the FTC's antitrust case against Google, In Harvard journal of law and technology occasional paper series, July, 2013, disponível em: http://bit.ly/1FCV4Ce, Acesso em 25, jun. 2015, pp. 2-3.

676 MICHAEL LUCA; TIMOTHY WU; ET. AL., Does Google degrade Google search? Experimental evidence, 2015, disponível em: http://bit.ly/1NpGX9J, acesso no dia 17, dez., 2015, pp. 11-12. 
essa razão que se afirma que o Google tem a capacidade de direcionar o tráfego da Internet. $^{677-678}$

Apesar da aparência de objetividade em relação aos critérios utilizados pelo mecanismo de busca orgânica, suas decisões se baseiam em uma combinacão de decisões algorítimicas e editoriais, sendo estas últimas carregadas de carga subjetiva. É por essa razão que os resultados podem ser manipulados por razões punitivas, quando o mecanismo pune sites que buscam distorcer os resultados por meio dos SEOs, por razões políticas, como observamos nos casos de sites anti-semitas, ou por interesses comerciais da empresa. $^{679}$

A própria opinião da empresa com relação à objetividade de seu algoritmo muda ao longo dos anos. Em 2007, a empresa afirmava que os resultados de buscas eram gerados de forma completamente objetiva e independente das preferências dos membros da empresa. Anos depois, o $C E O$ da empresa passa a defender que os resultados seriam fruto de opinião científica em relação ao que os usuários consideram mais útil. Por fim, recentemente a empresa não faz mais qualquer referência à preferência dos consumidores, ressaltando que, apesar de usar algoritmos em seus rankings, os resultados de busca expressam unicamente a opinião da empresa. ${ }^{680}$

$\mathrm{O}$ argumento econômico da empresa se encontra na inovação e nos benefícios recebidos pelo consumidor decorrentes da mudanças introduzidas no Google Universal

677 JOSHUA G. HAZAN, Stop being evil: A proposal for unbiased Google Search, In Michigan Law Review, vol. 111, n. 5, 2013, p. 794.

\footnotetext{
678 Alguns autores, como JOSHUA D. WRIGHT, defendem que os rankings seriam próxis grosseiros, uma vez que o fato de um site aparecer entre os primeiros na pesquisa não significa que os consumidores estarão mais propensos a consumir aquele conteúdo (JOSHUA D. WRIGHT, Moving beyond naive foreclosure analysis, disponível em: http://bit.ly/1LEVs8p, acesso no dia 25, jun., 2015, p. 1188). Tal visão, no entanto, não parecem condizentes com os dados empíricos, uma vez que estes demonstram uma propensão do consumidor selecionar os primeiro resultados apresentados.
}

679 JOSHUA G. HAZAN, Stop being evil: A proposal for unbiased Google Search, In Michigan Law Review, vol. 111, n. 5, 2013, p. 795-796. nov., 2015, p. 22. 
Search. Conforme sustentam MANNE e RINEHART, a integração vertical praticada pelo Google tende a ser procompetitiva, por gerar benefícios aos consumidores. ${ }^{681}$

Com base no teorema do monopólio único, autores como ROBERT BORK e SIDAK, defendem que a empresa não possui qualquer estímulo para estender seu poder de mercado para o setor de busca vertical, e que as mudanças implementadas consistem em inovações que trazem claros benefícios ao consumidor. ${ }^{682-683}$

Ao decidir dar maior visibilidade aos seus próprios serviços de busca vertical, a empresa acaba enfrentando um tradeoff: ao optar por dar destaque aos resultados de busca especializada de serviços da própria empresa os usuários acabam tendo acesso a resultados menos relevantes e a empresa usufrui de publicidade gratuita desses serviços, ao passo que se a empresa decide por apresentar resultados mais relevantes da concorrência seu mecanismos de busca orgânica ganha em qualidade, ao passo que seus serviços de busca vertical perdem visibilidade. Grande parte dos autores, no entanto, entende que uma perda de qualidade no resultado de busca orgânica seria facilmente percebido pelos usuários, criando pressão competitiva para que a empresa não incorra nessa prática. Dessa forma, a empresa teria incentivos para sempre optar por dar maior destaque a sites de terceiros quando estes forem melhores para o usuário. ${ }^{684}$

681 GEOFFREY A. MANNE; WILLIAM RINEHART, The market realities that undermined the FTC's antitrust case against Google, In Harvard journal of law and technology occasional paper series, July, 2013, disponível em: http://bit.ly/1FCV4Ce, Acesso em 25, jun. 2015, pp. 2-3.

682 "Google has no incentive to foreclose competitors from search because doing so is unlikely to offer additional profit at the potential cost of driving away consumers" (ROBERT BORK; J. GREGORY SIDAK, What does the Chicago School Teach about Internet Search?, In Journal of Competition Law \& Economics, vol. 8, n. 4, 2012, p. 666).

683 Tal visão decorre das críticas a teoria da alavancagem ("leverage theory") realizadas pela Escola de Chicago, segundo a qual "o agente será capaz de impor preços típicos de monopólio somente em um dos mercados e não em ambos.” (PAULA A. FORGIONI, Direito concorrencial e restrições verticais, São Paulo, Revista dos Tribunais, 2007, p. 249)

684 Esse é o argumento de JAMES D. RATLIFF e DANIEL L. RUBINFELD: "In any case, Google would be more likely to more prominently display the assumed less-relevant Google-affiliated link (1) the less the relevance differen- tial between the two websites (and hence the less harm to the user from more prominent display of the lower-quality website) and (2) the greater the benefi- cial effect of the enhanced free publicity on Google's affiliated business. Conversely, Google would be more likely to more prominently display the more-relevant website (not affiliated with Google) the greater the relevance ad- vantage of the non-Google website and the lower the beneficial effect of the enhanced free publicity on Google's affiliated business." (JAMES D. RATLIFF; DANIEL L. RUBINFELD, Is there a Market for organic search engine results and can their manipulation give rise to antitruste liability?, In Journal of Competition Law \& Economics, vol. 10, n. 3, 2014, p. 16). 
Esta conclusão assume a informação perfeita do consumidor com relação à qualidade das buscas, bem como a ausência de custos de mudança significativos. A dificuldade de mensuração e avaliação da qualidade dos resultados de pesquisa, porém, pode fazer com que a pressão competitiva não ocorra de forma a pressionar a empresa a evitar o bias do algoritmo. ${ }^{685}$ Deve-se ressaltar que a pressão competitiva poderia vir do lado dos anunciantes, ou seja, os resultados de baixa qualidade poderiam levar os anunciantes a procurarem canais alternativos de divulgação.

MANNE e RINEHART defendem, inclusive, que outras plataformas de anúncio direcionado, como as criadas pelas mídias sociais, podem ser até mesmo mais eficientes do que os sistemas de buscas. Não por outra razão, uma das grandes ameaças para a empresa se encontra no aumento do uso de smartphones e redes sociais como plataforma de anúncios nos últimos anos. É por essa razão que se afirma que o mercado deve ser considerado de forma ampliada, de modo que o Google se mostra detentor de apenas uma pequena parcela desse setor. Tanto assim que uma tendência que se apresenta para os próximos anos está justamente no aumento da participação dos displays ads em detrimento dos search ads. Isso decorre em grande medida dessa substituição pelos smartphones e outras plataformas móveis. ${ }^{686}$ No entanto, as evidências indicam que, sob o ponto de vista da substituição pelo lado dos anunciantes, o mercado de buscas online seria distinto de outros mercados de anúncios, uma vez que o grau de substituição entre anúncios online e tradicionais se mostra limitado, da mesma forma que a substituição entre search based e display ads. ${ }^{687}$

\footnotetext{
${ }_{685}$ "Like many information providers in both the old and new media, Google provides its search results to consumers for free in order to sell advertising. In one important respect, though, Google differs from other information providers: there is no clear benchmark against which to evaluate the quality of the search results it provides. Consequently, the price-quality-cost relationship that determines market power is difficult to evaluate." (MARK R. PATTERSON, Google and search-engine market power, In Harvard Journal of Law \& Technology Occasional Paper Series, jul. 2013, disponível em: http://bit.ly/1kQlVZw, acesso no dia 23, nov., 2015, p. 19-24).
}

686 GEOFFREY A. MANNE; WILLIAM RINEHART, The market realities that undermined the FTC's antitrust case against Google, In Harvard journal of law and technology occasional paper series, July, 2013, disponível em: http://bit.ly/1FCV4Ce, Acesso em 25, jun. 2015, pp. 9-10.

687 "Earlier findings imply that there is no substitutability between online and traditional advertising and only limited substitutability between displayed and search-based advertising. Hence, search-based advertising can be considered as a separate market." (IOANNIS LIANOS; EVGENIA MOTCHENKOVA, Market dominance and search quality in the search engine market, In Journal of Competition Law \& Economics, vol. 9, n. 2, 2013, p. 427). 
Para que se pudesse verificar a existência de reais alternativas, seria necessário verificar os preços efetivamente pagos para a plataforma AdWorks em comparação com as plataformas concorrentes. Uma diferença significativa de preços poderia indicar, justamente, a ausência de reais alternativas. ${ }^{688}$

Os defensores das práticas do Google defendem que a concorrência estaria "one click away" por conta dos baixos custos de mudança associados aos serviços de Internet. ${ }^{689}$ No entanto, devemos tomar com cautela estas visões.

Em primeiro lugar, conforme já observamos a natureza de creedence goods ${ }^{690}$ da maior parte dos resultados de buscas oferecidos pela plataforma faz com que a percepção quanto sua qualidade seja de difícil mensuração. É por essa razão que o consumidor dificilmente possui uma concepção predefinida de relevância dos resultados. Da mesma forma, o usuário raramente irá comparar os resultados obtidos por plataformas distintas para avaliar qual delas oferece os melhores resultados. Na maior parte das vezes ele acaba acreditando que o primeiro resultado listado é realmente o mais relevante, simplesmente porque o algoritmo do mecanismo colocou ele em primeiro lugar. ${ }^{691-692}$

688 "Thus, not only do the pric- es paid for AdWords seem likely to reflect value of advertisements to consumers, differences in value seem likely to be evidence of alterna- tives. As such, an investigation of these values seems to be a reasona- ble approach to assessing Google's power." (MARK R. PATTERSON, Google and search-engine market power, In Harvard Journal of Law \& Technology Occasional Paper Series, jul. 2013, disponível em: http://bit.ly/1kQlVZw, acesso no dia 23, nov., 2015, p. 20).

689 “As antitrust authorities investigated it in 2012, Google's spokespersons never tired of repeating that 'competition is just a click away'; users had only to type in 'Bing' to find another search engine." (FRANK PASQUALE, Paradoxes of digital antitrust: Why the FTC failed to explain its inaction on Search Bias, In Harvard Journal of Lwa \& Technology Occasional Paper Series, July, 2013, disponível em: http://bit.ly/1FbNQVJ, acesso no dia 21, dez., 2015). Conforme MARINA LAO: "Unhappy Google users can instantly switch to another search engine, such as Bing or Yahoo!, without incurring any penalties or costs" (MARINA LAO, Neutral search as a basis for antitrust action, In Harvard Journal of Law \& Technology Occasional Paper Series, July, 2013, disponível em: http://bit.ly/1QT9bgq, acesso no dia 20, dez., 2015, p. 7).

690 'Thus the 'credence' nomenclature: the ordinary consumer must trust the provider more than an ordinary vendor, because it's expensive (and sometimes impossible) to know if the provider has actually given her best efforts (let alone provided appropriate advice or care). Search is also often a credence service: you would probably not be using a search engine if you already knew what you wanted. And rare is the person who takes the time to compare results at one search engine with those at another." (FRANK PASQUALE, Paradoxes of digital antitrust: Why the FTC failed to explain its inaction on Search Bias, In Harvard Journal of Lwa \& Technology Occasional Paper Series, July, 2013, disponível em: http://bit.ly/1FbNQVJ, acesso no dia 21, dez., 2015, p. 18).

691 DANIEL A. CRANE aponta que estudos empíricos demonstram a confiança que os usuários depositam sobre a neutralidade do buscador com relação a relevância dos resultados apresentados, diferentemente do que ocorre com serviços concorrentes como o Bing, que não buscam afirmar sua neutralidade (DANIEL A. CRANE, Search neutrality and referral dominance, In Journal of Competition Law \& Economics, vol. 8, n. 3, 2012, pp. 467-468). 
Em segundo lugar, o argumento acima ignora a relação da Google com seus anunciantes. Para estes a concorrência não se encontra a um clique, uma vez que dependem da visibilidade oferecida pela plataforma da empresa, especialmente diante da exclusão de possíveis rivais de busca vertical. ${ }^{693}$

Conforme observamos no item III.8.2, a empresa possui poder de mercado, tendo a capacidade de gerar prejuízos ao incorrer em prática de venda casada. Ao colocar seu conteúdo de busca vertical entre os primeiros resultados da busca, a empresa acaba por direcionar o tráfego para seus sites, impedindo que este seja dirigido aos seus concorrentes de busca vertical. Isso faz com que a concorrência não ocorra pela superioridade dos serviços oferecidos, mas sim na maior exposição que seu produto goza por conta de seu poder de mercado no setor de busca orgânica. ${ }^{694}$

Com o objetivo de avaliar os prejuízos ao consumidor da prática de bias decorrente do Google Universal Search, MICHAEL LUCA e TIM WU realizaram um experimento por meio do qual comprovam que a manipulação realizada pela empresa acaba por degradar o mecanismo de buscas, causando diminuição do bem estar social. Para analisar as preferências do consumidor foi utilizado o software FOTUL (Focus On The User Local), desenvolvido por engenheiros da empresa Yelp em parceria com engenheiros da empresa TripAdvisor dentre outros membros da sociedade civil, e que tinha por objetivo apresentar resultados de busca alternativos àqueles apresentados pela plataforma OneBox da Google. Para tanto o algoritomo do FOTUL seleciona diversos sites de avaliações (reviews) como, por exemplo, o TripAdvisor, Yelp, ZocDoc, além de sites da Google, e realiza um ranking desses sites. Para elencar a ordem de prioridades desses resultados, o mecanismos se vale dos princípios de busca orgânica da Google, além da avaliação média

692 "Consumers lack both the incentive and the ability to detect manipulation as long as they are getting "good enough" results. Given the opacity of search algorithms, neither users nor trusted proxies can reverse engineer the hundreds of factors that go into a ranking." (FRANK PASQUALE, Paradoxes of digital antitrust: Why the FTC failed to explain its inaction on Search Bias, In Harvard Journal of Lwa \& Technology Occasional Paper Series, July, 2013, disponível em: http://bit.ly/1FbNQVJ, acesso no dia 21, dez., 2015, p. 9).

693 JOSHUA G. HAZAN, Stop being evil: A proposal for unbiased Google Search, In Michigan Law Review, vol. 111, n. 5, 2013, pp. 814-815.

694 "By elevating its own content to the top of its results without necessarily 'earning' that position based on the algorithm, Google generates traffic for its own services (and enjoys the resulting advertising revenue on those pages) while simultaneously depriving its competitors of that traffic." (JOSHUA G. HAZAN, Stop being evil: A proposal for unbiased Google Search, In Michigan Law Review, vol. 111, n. 5, 2013, p. 805). 
do negócio e do número de reviews, e apresenta um resultado alternativo ao do OneBox. ${ }^{695}$ O grande objetivo dessa plataforma é o de simular um método alternativo de apresentação desses resultados, que fosse baseado no princípio de funcionamento do algoritmo de busca orgânica do Google. ${ }^{696-697}$

O experimento realizado pelos autores teve como resultado uma propensão até $40 \%$ maior dos usuários pelo conteúdo gerado pelo FOTUL em comparação com os resultados gerados pelo OneBox. Além disso, em uma comparação direta entre os dois mecanismos, 70 a $80 \%$ dos usuários apontaram preferir o mecanismo do FOTUL. A conclusão que se extrai desse estudo é a de que a aplicação de princípios de busca orgânica do Google no algoritmo de buscas leva a resultados superiores (conforme as preferências dos usuário por melhores resultados) quando comparados com resultados apresentados pelo mecanismo sujeito ao bias implementado pela empresa. ${ }^{698}$

Alguns analistas sustentam que os serviços de busca geral e vertical seriam concorrentes, sendo estes últimos apenas uma especialização do mecanismo de busca geral. ${ }^{699}$ Essa visão considera que os serviços oferecidos pelos mecanismos de busca orgânica e vertical do Google seriam todos integrados por se tratarem de um único serviço. No entanto, esta visões também não parecem ser condizentes com a realidade. Dados

695 Maiores informações sobre o FOTUL podem ser obtidas no site: http://www.focusontheuser.eu/.

696 MICHAEL LUCA; TIMOTHY WU; ET. AL., Does Google degrade Google search? Experimental evidence, 2015, disponível em: http://bit.ly/1NpGX9J, acesso no dia 17, dez., 2015, pp. 23-24.

697 Tal plataforma tem como objetivo implementar principios próximos ao que seria denominado de busca neutra. Conforme MARINA LAO, "In practical terms, search neutrality would not allow Google to return a Google map in response to an address query, for example, unless a Google map is determined, under some "objective" measure of rele- vance and quality, to be better than other maps. Under a neutral search regime, "universal search" displays — a search engine's integration and display of its proprietary content in search results, usually ahead of links to competing websites - would likely be impermissible." (MARINA LAO, Neutral search as a basis for antitrust action, In Harvard Journal of Law \& Technology Occasional Paper Series, July, 2013, disponível em: http://bit.ly/1QT9bgq, acesso no dia 20, dez., 2015, p.2).

698 Para maiores detalhes com relação à metodologia aplicada na análise, bem como aos resultados do experimento, consultar MICHAEL LUCA; TIMOTHY WU; ET. AL., Does Google degrade Google search? Experimental evidence, 2015, disponível em: http://bit.ly/1NpGX9J, acesso no dia 17, dez., 2015, pp. 23-35.

699 "Thus, Google competes not only with other general search engines (and possibly all other forms of advertising) but also with so-called vertical search engines. These are search engines and e-commerce websites with search functionality that specialize in specific content: Amazon in books, music, and other consumer goods; Kayak in travel services; eBay in consumer auctions; WebMD in medical information and products; SourceTool in business-to-business supplies; and many others." (GEOFFREY A. MANNE; JOSHUA D. WRIGHT, Google and the limits of antitrust: The case against the case against Google, In Harvard Journal of Law \& Public Policy, Vol. 34, disponível em: http://bit.ly/1hHH4TR, acesso no dia 17 , ago., 2015, p. 202). 
apontam que a entrada do Google no setor de pesquisa de passagens aéreas e hotéis não alterou de forma significativa os Market-shares de empresas líderes nesse tipo de busca vertical como o Kayak e o Expedia. ${ }^{700}$ A empresa poderia integrar diversos serviços de busca vertical ao seu serviço de busca universal, desde que apresentasse os resultados de busca vertical mais relevantes, e não apenas aqueles oferecidos por seus próprios serviços, ${ }^{701}$ conforme sugestão da plataforma FOTUL.

Os críticos da neutralidade de buscas afirmam ser inviável implementar essa noção por conta de três principais argumentos: (i) a busca é uma atividade subjetiva, ou seja, a definição do que seria um padrão neutro não se mostra consensual; (ii) não é possível identificar uma teoria antitruste de responsabilidade que obrigue a aplicação de uma busca neutra; e (iii) qualquer remédio aplicado tende a ser mais prejudicial do que os possíveis efeitos exclusionários decorrentes do bias do algoritmo. ${ }^{702}$

Mesmo na ausência de qualquer bias é próprio da natureza do ranking gerado pelos buscadores web a exclusão de alguns sites dos primeiros lugares da pesquisa, uma vez que não se mostra possível que todos os sites figurem nas primeiras posições. A escassez natural própria de qualquer ranking faz com que a maior parte dos sites seja excluído das primeiras posições.

A atividade de buscas é subjetiva pois os ranking gerados pelos buscadores refletem o julgamento do mecanismo de buscas sobre o valor e a relevância do conteúdo disponível na web. Dessa forma, não haveria uma métrica objetiva para definir o que seria “correto" e o que seria "enviesado". Além disso, a complexidade associada ao algoritmo da Google faz com que estes sejam difíceis de serem monitorados e analisados. ${ }^{703}$ Por essa

\footnotetext{
700 Conforme dados apresentados por GEOFFREY A. MANNE e WILLIAM RINEHART. Deve-se ressaltar que os autores apresentam estes para afirmar que a conduta da empresa não tem postencial de exclusão, porém, acabam por indicar que estes serviços se mostram distintos (GEOFFREY A. MANNE; WILLIAM RINEHART, The market realities that undermined the FTC's antitrust case against Google, In Harvard Journal of Law and Technology Occasional Paper Series, July, 2013, disponível em: http://bit.ly/1FCV4Ce, Acesso no dia 25, jun. 2015, pp. 5-6).
}

$701 \quad$ JOSHUA G. HAZAN, Stop being evil: A proposal for unbiased Google Search, In Michigan Law Review, vol. 111, n. 5, 2013, pp. 816-817.

702 "Search neutrality could inhibit innovation, product improvements, and the evolution of search engines." (MARINA LAO, Neutral search as a basis for antitrust action, In Harvard Journal of Law \& Technology Occasional Paper Series, July, 2013, disponível em: http://bit.ly/1QT9bgq, acesso no dia 20, dez., 2015, pp. 3-10).

703 "Search algorithms are extraordinarily complex, and whether regulators would have the expertise and competence to effectively (and continually) monitor and evaluate their technical details, including all changes made to them, is questionable." (MARINA LAO, Neutral search as a basis for antitrust action, In 
razão, a simples evidência de bias na pesquisa não seria evidência de exclusão. Para que o fechamento de mercado possa ser sancionado pelo antitruste deve ocorrer fechamento substancial que impeça a escala necessária para um competidor concorrer nesse mercado. ${ }^{704}$

Mecanismos e busca de um modo geral tendem a elevar o bem estar social, uma vez que atuam como plataforma ligando usuários e fornecedores, reduzindo custos de procura neste processo. No entanto, ao manipular o algoritmo, a empresa aumenta os custos de procura diminuindo o bem estar geral. Esta perda acaba sendo dividida entre os usuários e os fornecedores. Podem ser listados diversos possíveis prejuízos associados a tais condutas. Em primeiro lugar, os consumidores acabam não encontrando aquilo que procuram. Em segundo lugar, alguns consumidores devem encontrar os resultados que procuram, porém, incorrendo em maiores custos de procura. Em terceiro lugar, o consumidor pode acabar escolhendo um fornecedor que não seria sua primeira opção. Ou seja, de um modo geral, a busca degradada acabará invariavelmente gerando algum prejuízo por conta desse direcionamento inadequado. ${ }^{705}$

Da mesma forma, as condutas da empresa acabam gerando risco de exclusão de possíveis concorrentes, especialmente nos setores de busca especializada. Isso, da mesma forma, dificulta a entrada de novos concorrentes nesses setores prejudicando a inovação e a eficiência dinâmica.

Além disso, conforme observamos, o oferecimento de serviços gratuitos por empresas como a Google tem como contrapartida a coleta de dados do usuário que serão utilizados pela empresa. Por essa razão, plataformas gratuitas acabam gerando uma série de custos decorrentes da atenção despendida pelo consumidor, das informações coletadas pelas plataformas bem como pela perda da privacidade do usuário, ao permitir que as empresas acessem seus dados de navegação e informações pessoais.

Harvard Journal of Law \& Technology Occasional Paper Series, July, 2013, disponível em: http://bit.ly/1QT9bgq, acesso no dia 20, dez., 2015, p. 4).

704 GEOFFREY A. MANNE; WILLIAM RINEHART, The market realities that undermined the FTC's antitrust case against Google, In Harvard journal of law and technology occasional paper series, July, 2013, disponível em: http://bit.ly/1FCV4Ce, Acesso em 25, jun. 2015, pp. 3-4.

705 MICHAEL LUCA; TIMOTHY WU; ET. AL., Does Google degrade Google search? Experimental evidence, 2015, disponível em: http://bit.ly/1NpGX9J, acesso no dia 17, dez., 2015, pp. 18-19. 
A visão de que os usuários realizam trocas racionais de informações pessoais por serviços gratuitos desconsidera uma série de características dessas trocas. Para que esse mercado funcionasse adequadamente os usuários deveriam ter a capacidade de avaliar corretamente os benefícios que recebem da Google, da mesma forma que os usuários deveriam poder mensurar o valor monetário e o custo de oportunidade das informações ofertadas. Além disso, o resultado final dessas trocas não deveria levar à redução do bem estar de um modo geral. Ainda que se desconsidere os danos não econômicos possivelmente sofridos pelo consumidor, os prejuízos econômicos se mostram relevantes e devem ser objeto do antitruste. ${ }^{706}$

O que notamos é que o usuário superestima o valor adicionado pelos serviços da Google, não se dando conta de que a maior parte do valor dos seus dados pessoais não é compartilhado entre ele e a plataforma. $\mathrm{Na}$ era da Internet o usuário se torna produtor da maior parte do conteúdo, porém, não recebe a maior parte do valor relacionado ao que produz. ${ }^{707}$ Isso ocorre tanto com empresas como Amazon.com (nos quais os reviews dos usuários agregam enorme valor a plataforma de vendas), Facebook (no qual a maior parte do conteúdo é gerado pelos usuários) e Google (que tem como principal função a de buscar conteúdo gerado por terceiros, além de vídeos de sua plataforma YouTube carregados pelos usuários). ${ }^{708}$

O próprio mecanismo do PageRank, a grande inovação do Google, se vale de links criados por outros sites para avaliar e classificar os sites. Da mesma forma a melhoria do algoritmo depende das pesquisas realizadas pelos usuários, que retroalimentam o mecanismo para ele se tornar mais preciso. Outros serviços da Google como o YouTube e o

\footnotetext{
706 Conforme aponta NEWMAN, os prejuízos ao consumidor podem ser decorrentes até mesmo do perfil de crédito, que poderia levar a exploração de marketing predatório direcionado para pessoas em situação de vulnerabilidade: "Online profiling based on user data allows seedier companies, from subprime mortgage lenders to payday lenders, to target the most naïve and vulnerable potential consumers and facilitate new forms of price discrimination even by more legitimate firms that allow those companies to extract the highest potential price for goods and services from each customer" (NATHAN NEWMAN, The Costs of Lost Privacy: Consumer Harm and Rising Economic Inequality in the Age of Google, In William Mitchell Law Review, Vol. 40, n. 2, 2014, p. 857)
}

707 Nesse sentido SIDA VAIDHYANATHAN afirma que: "Google is taking a free ride on the creative content of billions of content creators. But the ride is not free at all. Even though we don't ever negotiate terms of a contract, we essentially agree (by not opting out or actively disagreeing) that search engines mau copy our content and make money from the process of judging, ranking, and connecting people to it in in exchange for the privilege of our content being found." (SIVA VAIDHYANATHAN, The Googlization of everything: (And why we should worry), Berkeley, University of California Press, 2011, p. 30).

708 NATHAN NEWMAN, The Costs of Lost Privacy: Consumer Harm and Rising Economic Inequality in the Age of Google, In William Mitchell Law Review, Vol. 40, n. 2, 2014, p. 858. 
Gmail funcionam sob a mesma dinâmica de dependência de conteúdo gerado pelo usuário. $^{709}$

Considerando que os usuários não recebem qualquer valor monetário pelas informações que fornecem ao Google, fica nítido que estes não recebem o valor que esta informação representa para a empresa. O problema, porém, é que, conforme observamos, a maior parte dos usuários nem mesmo percebe que seus dados pessoais fornecidos ao Google estão sendo compartilhados com terceiros que nem mesmo participam dessa relação. Um estudo realizado com usuários norte-americanos revelou que $73 \%$ dos usuários eram contrários aos uso de seu histórico de navegação pela plataforma de buscas com o objetivo de melhorar os resultados de busca. Além disso, 68\% eram contrários ao uso de seus dados para auxiliar os anunciantes a oferecerem anúncios direcionados. Isso demonstra que os desejos dos usuários de não terem suas informações e dados de navegação rastreados não vem sendo atendidos. O grande problema é que os termos de troca não se mostram claros aos usuários, que muitas vezes não tem real consciência do que está oferecendo em troca dos serviços. Algumas estimativas apontam que a plataforma obtém o valor de até 5 mil dólares, por usuário, por ano, dependendo do tempo e do volume de dados utilizados pelo usuário. ${ }^{710-711}$

Recentemente esta preocupação vem aumentando dentro das escolas norteamericanas, especialmente por conta da entrada da empresa Google no mercado de laptops de baixo custo. Atualmente estima-se que mais de 50 milhões de alunos e professores estejam usando algum dos chamados Chromebooks, laptops fabricados por diferentes empresas que operam quase integralmente com software da Google. Ao oferecer diversos

709 NATHAN NEWMAN, The Costs of Lost Privacy: Consumer Harm and Rising Economic Inequality in the Age of Google, In William Mitchell Law Review, Vol. 40, n. 2, 2014, p. 860.

$710 \quad$ NATHAN NEWMAN, The Costs of Lost Privacy: Consumer Harm and Rising Economic Inequality in the Age of Google, In William Mitchell Law Review, Vol. 40, n. 2, 2014, pp. 865-866.

711 Deve-se ressaltar que nem todo resultado de buscas é monetizável. Conforme apontam MANNE e RINEHART, diferentemente de sites como a Amazon, na maior parte dos casos a empresa não consegue capturar qualquer valor monetizável das buscas realizadas. Estima-se que $70 \%$ das buscas realizadas não geram qualquer interesse comercial, uma vez que se relacionam a buscas de informações ou de dados de navegação. Ao passo que apenas cerca de 10 a $20 \%$ das buscas realizadas na plataforma se relacionem a busca de produtos e serviços. é por essa razão que a empresa vem investindo em outros serviços de busca específicos de produtos e serviços como o Google Shopping (busca de produtos), o Zagat (busca e avaliação de restaurantes e o Flight Search (busca de voos) (GEOFFREY A. MANNE; WILLIAM RINEHART, The market realities that undermined the FTC's antitrust case against Google, In Harvard journal of law and technology occasional paper series, July, 2013, disponível em: http://bit.ly/1FCV4Ce, Acesso em 25, jun. 2015, pp. 11-12). 
serviços como editores de texto e gerenciadores de arquivos, a empresa tem a capacidade de monitorar as atividades desses usuários no meio acadêmico, com o objetivo de oferecer anúncios direcionados ou comercializar estas informações, porém sem o consentimento dos pais com relação a estas informações. $O$ oferecimento de forma gratuita destes softwares às escolas fez com que a empresa tivesse enorme crescimento nesse setor e levantasse novas preocupações com relação aos dados de privacidade dos usuários. ${ }^{712}$

Além da desigualdade na trocas de informações pessoais, outro prejuízo social que surge das práticas da empresa se relacionam ao uso dessa assimetria informacional para a prática de discriminação de preços sem o conhecimento do usuário. Em 2012, diversas lojas como Staples e Home Depot estavam utilizando a localização do usuário para oferecimento de preços distintos. Diversas outras práticas vem sendo utilizadas com o objetivo de confundir o consumidor com relação aos preços, o que faz com que a suposta facilidade de se comparar preços entre diferentes fornecedores não seja efetiva. A posse do Google de enormes quantidades de dados dos usuários poderia permitir que este utilizasse de seu poder de mercado para incorrer em distintas estratégias de discriminação de preços, o que poderiam, da mesma forma, causar prejuízos ao bem estar social. ${ }^{713}$

Devemos ter cautela quanto às conclusões relacionadas a setores dinâmicos como este. Se o Direito Antitruste continuar a ignorar o poder detido por estas empresas talvez voltemos a situação do século XIX quando poucas gigantes de setores de infraestrutura convenceram reguladores e políticos de que sua dominação seria fruto necessário da inovação e que deveriam atuar livremente. Se os reguladores ignorarem a possibilidade de abusos por parte desses agentes podemos ter sério risco de que as inovações permaneçam concentradas em poucas mega-firmas com capacidade de reunir quantidade massiva de dados e promover novos negócios. ${ }^{714}$

712 ANDREA PETERSON, Google is tracking students as it sells more products to schools, privacy advocates warn, In The Washington Post, disponível em: http://wapo.st/1SjMHWP, acesso no dia 12, jan., 2016.

713 "What's unique about Google is that it can use its monopoly power not just to engage in price
discrimination directly in regards to its advertising customers and potentially with users in its own e-
commerce efforts, but also as a vehicle for companies across the economy to engage in such consumer harm
via price discrimination, which should raise the priority for restraining its power in the marketplace."
(NATHAN NEWMAN, The Costs of Lost Privacy: Consumer Harm and Rising Economic Inequality in the
Age of Google, In William Mitchell Law Review, Vol. 40, n. 2, 2014, p. 875).

$714 \quad$ "Regulators should be concerned about Google using its dominance in general purpose search to leverage undue power in other, more specialized fields. We either commit to a $21^{\text {st }}$ century antitrust law capable of detecting and deterring misuses of power online, or we allow centralizing tendencies to 


\section{III.9-Conclusão}

As particularidades presentes nos setores pontocom desafiam cotidianamente analistas de mercado bem como operadores de direito. Conforme observamos, características desses mercados, como a estruturação em plataformas de múltiplos lados, o uso intensivo de software, com a possibilidade de customização sem precedentes da experiência do usuário, a presença de estruturas de preço zero na quase totalidade desses serviços, associados ao intenso dinamismo e a intensa competição entre estes players faz necessária uma adaptação do ferramental baseado em modelos de economia neoclássica.

A realidade dos mercados fez com que fossem necessárias uma série de adaptações a esses modelos, sem que, no entanto, tal paradigma fosse substituído por outros modelos. Assim como tradicionalmente as considerações das falhas de mercado, bem como, modernamente, a economia dos custos de transação e a economia comportamental trouxeram importante relativização de diversos conceitos clássicos de concorrência perfeita, nesses setores notamos que mais uma vez alguns conceitos devem ser adaptados para que os modelos de análise não fiquem distanciados da realidade.

Nesse sentido, a conceituação do poder de mercado e a delimitação do mercado relevante devem sofrer uma nova relativização de seus conceitos e uma adaptação na metodologia aplicada para que não se mostrem inadequados e distanciados da realidade dinâmica e complexa desses mercados. Nesse sentido se faz necessária a substituição da aferição de poder de mercado pela pura e simples análise das participações de mercado e se passem a analisar as restrições competitivas enfrentadas pela empresa para que se tenha melhor noção da real extensão desse poder.

O próprio conceito de mercado relevante material baseado no produto ou serviço oferecido deve sofrer relativização, uma vez que as relações de substituição nesses setores se mostra distinta dos setores tradicionais. Por essa razão o conceito de competição por atenção traz importantes considerações com relação a essa nova definição.

Além disso, a complexidade associada a estas novas condutas, como se constata nos casos das empresas Uber e Google, cria enormes desafios para que a autoridade

concentrate innovation in the few mega-firms capable of gathering critical data and promoting new services on an ever-less-level playing field." (FRANK PASQUALE, Paradoxes of digital antitrust: Why the FTC failed to explain its inaction on search bias, In Harvard journal of law and technology occasional paper series, July, 2013, disponível em http://bit.ly/1FbNQVJ, acesso no dia 11, jun. 2015, pp. 20-21). 
regulatória intervenha sobre estes mercados. A dificuldade de compreensão do funcionamento destas plataformas baseadas em software associada ao uso de algoritmos inteligentes em um mercado em evolução, faz com que diversas medidas possam trazer riscos à eficiência dinâmica e a concorrência nestes setores. A ausência de dados empíricos confiáveis, da mesma forma, dificulta a real compreensão de determinadas condutas como se constata no caso do Google.

Disso decorre a enorme assimetria negocial presente nas relações entre provedores de atenção e os usuários desses sites. A dificuldade do consumidor compreender a real extensão e o valor associado às informações e dados pessoais que estão sendo compartilhados, aliada à imprevisibilidade dos riscos pós-contratuais presentes nessas relações faz com que surjam relevantes falhas negociais nesses setores. Do mesmo modo, a natureza de creedence goods da maior parte desses serviços faz com que o consumidor não consiga muitas vezes avaliar a qualidade do serviço prestado, diminuindo as pressões competitivas sobre a empresa.

Por fim, a análise do caso Google permite a observação de diversas dessas dificuldades, demonstrando a necessidade de consideração dessas características para que não se incorram em falsos positivos ou falsos negativos.

Dessa forma, o que notamos é que ao invés de se tratar de uma área de isenção do direito da concorrência, na qual a liberdade absoluta dos agentes econômicos levaria a um resultado ótimo, o que percebemos é que mais do que nunca o direito antitruste cumpre um papel fundamental nesses setores. Este, porém, deve considerar todas as suas características e complexidades para que a análise não aponte para intervenções equivocadas ou ineficientes. 


\section{BIBLIOGRAFIA}

ABBATE, Janet, Inventing the internet, Cambridge, MIT, 1999, Kindle Edition;

ALBA, Davey The death of the PC has not been greatly exaggerated, disponivel em http://bit.ly/1eNXKr4, acesso no dia 19, nov., 2015;

ANDERSON, Simon P.; GABSZEWICZ, Jean J., The media and advertising: A tale of two-sided markets, 2005, disponível em http://bit.ly/2161rN1, acesso no dia 19, nov., 2015;

ANTON, James; YAO, Dennis, Standard-setting consortia, antitrust, and high technology industries, In Antitrust law journal, vol. 64, n. 1, 1995, 247-265;

ARMSTRONG, Mark, Competition in two-sided markets, In Rand Journal of Economics, 2005 ;

ARROW, Kenneth, Economic Welfare and the Allocation of Resources for Invention, In The Rate and Direction of Inventive Activity: Economic and Social Factors, disponível em: http://bit.ly/1NNRvyg, acesso no dia 24, dez., 2015;

ARTHUR, Brian, Positive feedbacks in the economy, In Scientific American, vol. 262, 1990, pp. 92-99;

ARIELY, Dan, Predictably irrational, New York, Harper Collins, 2009;

AXELROD, Robert, The evolution of cooperation, 1984, versão adaptada disponível em http://stanford.io/20aWHoH, acesso no dia 17, nov., 2015;

BABAIOFF, Moshe; NISAN, Noam; LEME, Renato Paes, Price Competition in Online Combinatorial Markets, disponível em: http://bit.ly/20ESFVM, acesso no dia 8, nov., 2015 ;

BAGNOLI, Vicente, Introdução ao Direito da Concorrência: Brasil, Globalização, União Européia, Mercosul, Alca, São Paulo, Singular, 2005;

BAUMOL, William J., Contestable markets: An uprising in the theory of industry structure, In The American Economic Review, vol. 72, N. 1, 1982; 
BAKER, Jonathan B., Beyond Schumpeter vs. Arrow: How antitrust fosters innovation, 2007, disponível em http://bit.ly/1S9U4xE, acesso no dia 8, nov., 2015;

BENKLER, Yochai, Coase's Penguin, or, Linux and The Nature of the Firm, In The Yale Law Journal, Vol. 112, 2002;

BERGHPP, Roger Van Den, Behavioral antitrust: Not ready for the main stage, In Journal of Competition Law \& Economics, vol. 9 (1), 2013;

BERNSTEIN, Lisa, Opting out of the legal system: Extralegal contractual relations in the diamond industry, In The Journal of Legal Studies, vol. 21, n. 1, 1992, pp. 115-157;

BESEN, Stanley; FARRELL, Joseph, Choosing how to compete: Strategies and tactics in standardization, In Journal of Economic Perspectives, vol. 8, 1994, pp. 117-131;

BLAIR, Roger D.; CARRUTHERS, Celeste K., The economies of monopoly power in antitrust, In KEITH N. HILTON, Antitrust law and economics, Encycplopedia of law and economics, 2 ed., Northhampton, MPG Books, 2010;

BOLIEK, Babette E. L., FCC regulation versus antitrust: How net neutrality is defining the boundaries, In Boston college law review, Vol. 52, 2011, pp. 1627-1686;

BORK, Robert, The antitrust paradox: A policy at war with itself, New York, Free Press, 1993;

; SIDAK, J. Gregory, What does the Chicago School Teach about Internet Search?, In Journal of Competition Law \& Economics, vol. 8, n. 4, 2012, p. 663 700 ;

BRACHA, Oren; PASQUALE, Frank, Federal Search Commission?: Access, Fairness, and Accountability in the Law of Search, In Cornell Law Review, vol. 93, 2008, p. 1180;

BRANCHER, Paulo Marcos Rodrigues, Direito da concorrência e propriedade intelectual - Da inovação tecnológica ao abuso de poder, Tese de doutorado, São Paulo, PUC-SP, 2009; 
CAMPILONGO, Celso Fernandes; ROCHA, Jean Paul C. Veiga da; MATOS, Paulo Todescan Lessa (Coord.), Concorrência e regulação no sistema financeiro, São Paulo, Max Limonad, 2002;

CANDEUB, Adam, Behavioral Economics, Internet Search, and Antitrust, In I/S Journal of Law and Policy for the Information Society, n. 9, v. 407, 2013-2014;

CARTER, Michael; Wright, Julian, Asymmetric network interconnection, In Review of Industrial Organization, vol. 22, 2003, pp. 27-46;

CARVALHO, Nuno T. P., As concentrações de empresas no direito antitruste, São Paulo, Resenha Tributária, 1995;

CARVALHO, Vinícius Marques de; SCHAPIRO, Mário Gomes, Direito Econômico Concorrencial, São Paulo, Saraiva, 2012;

; CORDOVIL, Leonor; BAGNOLI, Vicente e ANDERS, Eduardo Caminati, Nova Lei de Defesa da Concorrência Comentada, São Paulo, Editora Revista dos Tribunais, 2011;

, Poder Econômico e Defesa da Concorrência: reflexões sobre a realidade brasileira, In GUEDES, Jefferson Carús; NEIVA, Juliana Sahione Mayrink (org.), Publicações da Escola da AGU: Debates em Direito da Concorrência, Brasília, Advocacia Geral da União, 2011, pp. 295-315;

CHOU, Chien-Fu; SHY, Oz, Network effects without network externalities, In International Journal of Industrial Organization, vol. 8, 1990, pp. 259-270;

CHURCH, Jeffrey; GANDAL, Neil, Complementary network externalities and technology adoption, In International journal of industrial organization, vol.11, 1993, pp. 239-260;

CLEMENT, Douglas, Creative disruption, In The Region, set., 2008, p. 31-61, disponível em: http://bit.ly/1M0e3xe, acesso no dia 8, nov., 2015;

COHEN, Julie E.; NOLL, Roger G., Intellectual property, antitrust and the new economy, In University of Pittsburgh law review, vol. 62, 2001, pp. 453-473; 
CONSTINE, Josh, RUSSELL, Kyle, Skip Googling With Facebook's New "Add A Link" Mobile Status Search Engine, 9 de Maio de 2015, disponível em http://tcrn.ch/1R1E7xl, acesso no dia 30, Jun. 2015;

CRANE, Daniel A., Search neutrality and referral dominance, In Journal of Competition Law \& Economics, vol. 8, n. 3, 2012;

DAVID, Paul; GREENSTEIN, Shane, The economics of compatibility standards: An introduction to recent research, In Economic innovation and new technology, vol. 1, 1990, pp. 3-41;

DEVINE, Kristine Laudadio, Preserving competition in multi-sided innovative markets: How do you solve a problem like Google?, In North Carolina Journal of Law \& Technology, Vol. 10, n. 1, 2008;

D'IGNAZIO, Alessio; GIOVANETTI, Emanuele, Antitrust Analysis for the Internet Upstream Market - A Border Gateway Protocol Approach, In Journal of Competition Law \& Economics, n. 2, 2006;

DOMINGUES, Juliana Oliveira, Concorrência e defesa comercial, In PEDRO ZANOTTA; PAULO BRANCHER, Desafios atuais do direito da concorrência, São Paulo, Singular, 2008;

DUHIGG, Charles, The power of habit: Why we do what we do in life and business, New York, Random House, 2012;

ECONOMIDES, Nicolas, Antitrust issues in network industries, 2008, disponível em: http://bit.ly/1SC1s5C, acesso no dia 8, nov., 2015,

, Net neutrality, non-discrimination, and digital distribution of content through the Internet, In I/S: A Journal of Law and Policy for the Information Society, disponível em: http://bit.ly/1WK3T6J, acesso no dia 8, nov., 2015;

, Network externalities, complementarities, and invitations to enter, In The European journal of political economy, vol. 12, 1996, pp. 211-232;

, The economics of networks, In International journal of industrial organization, vol. 16, n. 4, 1996, pp. 675-699; 
; FLYER, Fredrick, Compatibility and market structure for network goods, Discussion Paper EC-98-02, Stern School of Business, N.Y.U., 1998, disponível em: http://bit.ly/1MFqtaS, acesso no dia 8, nov., 2015;

; LIANOS, Ioannis, The elusive antitrust standard on bundling in Europe and in the United States at the aftermath of the Microsoft cases, In Antitrust law journal, 2008, disponível em: http://bit.ly/1XXZVd6, acesso no dia 8, nov., 2015;

; TAG, Joacim, Net neutrality on the Internet: A two-sided market analysis, NET Institute Working Paper \#07-14, 2007, disponível em: http://bit.ly/1NCEDyX, acesso no dia 8, nov., 2015;

EDELMAN, Benjamin, Does google leverage market power through tying and bundling?, In Journal of Competition Law and Economics, vol. 11, n. 2, 2015, pp. 365-400;

EDLIN, Aaron S.; HARRIS, Robert G., The role of switching costs in antitrust analysis: A comparison of Microsoft and Google, In Yale Journal of Law \& Technology, n. 169, v. 15, 2013;

EINAV, Liran; KUCHLER, Theresa; LEVIN, Jonathan; SUNDARESAN, Neel, Learning from seller experiments in online markets, 2011, disponível em: http://bit.ly/1OoMP2f, acesso no dia 24/06/2014;

ETRO, Federico, Competition, innovation, and antitrust - A theory of market leaders and its policy implications, Berlin, Springer, 2007;

, Leadership in Multisided Markets, University Ca' Foscari of Venice, Dept. of Economics Research Paper Series No. 19, disponível em http://bit.ly/1PEcYMy, acesso em 21, ago., 2015;

, The theory of market leaders, antitrust policy and the Microsoft case,

Working Paper n. ${ }^{\circ}$ 99, Facoltà di Economia Università degli Studi di Milano, 2006, disponível em http://bit.ly/1mUlDlw, acesso no dia 8 out. 2010;

EVANS, David S., Antitrust issues raised by the emerging global internet economy, In Northwestern University Law Review, vol. 102, n.4, 2008; 
, Attention rivalry among online platforms, In Journal of Competition Law \& Economics, 9 (2), 2013;

, Lightening Up on Market Definition, 2010, disponível em http://bit.ly/1P15q44, acesso no dia 9, nov., 2015;

, Rivals for attention: How competition for scarce time drove the web revolution, what it means for the mobile revolution, and the future of advertising, 2014, disponível em http://bit.ly/1WZhJHL, acesso no dia 18, nov., 2015;

, The antitrust economics of free, 2011, disponível em http://bit.ly/1GhLjB0, acesso no dia 21, out., 2015;

, The antitrust economics of multi-sided platform markets, In Yale journal on regulation, vol. 20, n. 2, 2003;

, The economics of online advertising industry, disponível em: http://bit.ly/1Sg7wDy, acesso no dia 24/06/2014;

; KATZ, Michael L., The effects of antitrust and intellectual property law on compatibility and innovation, In Antitrust bulletin, vol. 43, 1998, pp. 609-650;

; KLEMPERER, Paul, Coordination and lock-in: Competition with switching costs and network effects, In Schmalensee R.; Willig, R., Handbook of Industrial Organization 3, Amsterdam, North Holland;

; MARISCAL, Elisa V., Market Definition Analysis in Latin America with Applications to Internet-Based Industries, 2013, disponível em http://bit.ly/1Qkz0He, acesso no dia 12, nov., 2015;

; SALONER, Garth, Installed base and compatibility: Innovation, product preannouncements, and predation, In The American economic review, vol. 76, pp. 940-55; , Standardization, compatibility and innovation, In RAND Journal of Economics, vol. 16, 1995, pp. 70-83; 
; SCHMALENSEE, Richard, A guide to antitrust economics of networks, In Antitrust, vol. 10, n. 36, 1995-1996; ; , The antitrust analysis of multi-sided platform businesses, disponível em: http://bit.ly/1KhV5mT, acesso no dia 19, mai, 2015;

EZRACHI, Ariel; STUCKE, Maurice E., Artificial Intelligence \& Collusion: When Computers Inhibit Competition, 2015, disponível em: http://bit.ly/1MXhdC3, acesso em 06, out., 2015;

FARINA, Elizabeth M. M. Q.; Et. al., Competitividade: Mercado, Estado e organizações, São Paulo, Singular, 1997;

FAGUNDES, Jorge, Fundamentos econômicos das políticas de defesa da concorrência Eficiência econômica e distribuição de renda em análises antitruste, São Paulo, Singular, 2003;

FIDELIS, Andressa Lin, Entre o "laissez-faire" americano e o "intervencionismo" europeu: para qual direção aponta a atual investigação do CADE sobre o mecanismo de busca do Google, In Revista de defesa da Concorrência, vol. 3, n. 2, 2015;

FORGIONI, Paula A., Análise Econômica Do Direito (AED): Paranóia Ou Mistificação?, In Revista de direito mercantil, industrial, econômico e financeiro, n. ${ }^{\circ}$ 139, São Paulo, Malheiros, jul/set, 2005, pp. 242-256;

, Direito concorrencial e restrições verticais, São Paulo, Revista dos Tribunais, 2007;

, Evolução do Direito Comercial Brasileiro - Da mercancia ao mercado, São Paulo, Revista dos Tribunais, 2009;

, Importações paralelas no Brasil: A propriedade industrial nos quadrantes dos princípios constitucionais, In Revista de direito mercantil, industrial, econômico e financeiro, n. ${ }^{\circ}$ 149/150, São Paulo, Malheiros, jan./dez., 2008, pp. 187-200;

, Os fundamentos do antitruste, $6^{\mathrm{a}}$ ed., São Paulo, Revista dos Tribunais, 2013; 
FRANCESCHINI, Ana Carolina Trousdell; FERREIRA, Diogo Conque Seco, Economia Comportamental: uma introdução para analistas do comportamento, In Revista interamericana de psicologia, Vol. 46, n. 2, 2012;

FUDENBERG, Drew; VILlAS-BOAS, J. Miguel, Price Discrimination in the Digital Economy, In PEITZ, Martin; WALDFOGEL, Joel, The Oxford Handbook of the Digital Economy, Oxford, Oxford University, 2012;

GAL, Michal S.; RUBINFELD, Daniel L., The hidden costs of free goods: Implications for Antitrust enforcement, New York University Law and Economics Working Papers, disponível em http://bit.ly/1Qg96Ds, acesso no dia 05, nov., 2015;

GIBBONS, Michael, Innovation and the Developing System of Knowledge Production, disponível em http://bit.ly/1mSNAtf, acesso no dia 23 ou. 2010;

GICO JUNIOR, Ivo Teixeira, Cartel - Teoria unificada da colusão, São Paulo, Lex Editora, 2007;

GIL-MOLTÓ, Maria J., Economic aspects of the Microsoft Case: Networks, interoperability and competition, disponível em http://bit.ly/1OfXL4k, acesso no dia 24 mai. 2009;

GOLDMAN, Eric, Revisiting search engine bias, In William Mitchell Law Review, Vol. 38, n. 1, 2011, pp. 96-110;

GRAU, Eros Roberto, A ordem econômica na constituição de 1988, 13ª ed., São Paulo, Malheiros, 2008;

GRAU-KUNTZ, Karin, Ainda sobre a questão das peças de reposição, In Revista eletrônica do IBPI - Edição especial sobre a questão das peças de reposição must-match, 2010, disponível em http://bit.ly/1MFwRz7, acesso no dia 8, nov., 2015;

, O desenho industrial como instrumento de controle econômico do mercado secundário de peças de reposição de automóveis - Uma análise crítica a recente decisão da Secretaria de Direito Econômico (SDE), In Revista de Direito Mercantil Industrial, Econômico e Financeiro, vol. 145, 2007, p. 148-184; 
GRIMMELMANN, James, Some skepticism about search neutrality, In SZOKA, Berin; MARCUS, Adam, The next digital age: Essays on the future of the Internet, Washington, Tech Freedom, 2010;

GUIMARÃES, Bernardo; GONÇALVES, Carlos Eduardo, Introdução à economia, Rio de Janeiro, Elsevier, 2010;

HAZAN, Joshua G., Stop being evil: A proposal for unbiased Google Search, In Michigan Law Review, vol. 111, n. 5, 2013;

HOBSBAWM, Eric, Era dos extremos: O breve século XX, São Paulo, Companhia das Letras, 1995;

HOOFNAGLE, Chris J.; WHITTINGTON, Jan, Free - Accounting for the costs of the Internet's most popular price, In UCLA Law Review, n. 61, vol. 3, 2014;

HOVENKAMP, Herbert, Federal antitrust policy: The law of competition and its practice, $2^{\text {nd }}$ ed., St. Paul, West Pub. Co, 1999;

, Federal antitrust policy: The law of competition and its practice, $5^{\text {th }}$ ed., St. Paul, West Pub. Co, 2015;

, The antitrust enterprise: Principle and execution, Cambridge, Harvard University, 2005;

, The intellectual property-antitrust interface, In Issues in competition law and policy, n. ${ }^{\circ}$ 1979, ABA section of antitrust law, 2008, pp. 1979-2007;

HUNT, E. K., História do pensamento econômico - Uma perspectiva crítica, tradução da 2 ed., Rio de Janeiro, Elsevier, 2005;

JARVIS, Jeff, What would google do?, New York, Harper Collins, 2009;

KAGAN, Jared, Bricks, Mortar, and Google - Defining the Relevant Antitrust Market for Internet-Based Companies, In New York Law School Law Review, v. 55, 2010/2011;

KAHNEMAN, Daniel, Thinking, fast and slow, New York, Farrar, Straus and Giroux, 2011; 
KAPLOW, Louis, Why (ever) define markets?, in Harvard Law Review, Vol. 124, n. 2, 2010 ;

KATZ, Michael L.; ROGERSON, William P., The applications barrier to entry and its implications for the Microsoft remedies: Comment on Iansiti and Richards, In Antitrust law journal, Vol. 75, 2008-2009, pp. 723-738;

; SHAPIRO, Carl, Antitrust in software markets, In JEFFREY A EISENACH; Thomas M. Lenard (Ed.), Competition, innovation and the Microsoft monopoly: Antitrust in the digital marketplace, Kluwer Academic Publishers, 1998, pp. 29-81

; $\longrightarrow$ Network externalities, competition and compatibility, In The american economic review, vol. 75, n. ${ }^{\circ} 3,1985$, pp. 424-440; , Systems competition and network effects, In Journal of economic perspectives, vol. 8, n. ${ }^{\circ}$ 2, 1994, pp. 93-115;

; SHAPIRO, Carl, Technology adoption in the presence of network externalities, In Journal of political economy, vol. 94, n. 4, 1986;

KATZ, Michael L.; SHELANSKI, Howard A, Schumpeterian competition in high-tech markets, disponível em: http://bit.ly/1NqgTMw, acesso no dia: 16, jul, 2014;

KEEN, Andrew, O culto do amador: Como blogs MySpace, Youtube e a pirataria digital estão destruindo nossa economia, cultura e valores, tradução de Maria Luiza X. de A. Borges, Rio de Janeiro, Zahar, 2009;

KERR, Macaulay Duff, Web 2.0, dilemmas 1.0 - Essay on an evolving market, Dissertação de Mestrado, Escola de Administração de Empresas da Fundação Getúlio Vargas, Rio de Janeiro, 2007;

KNIEPS, Günter, Network neutrality and the Evolution of the Internet, 2010, disponível em: http://bit.ly/1QqMvG2, acesso no dia: 25, jun., 2014;

KWOKA JR., John E.; WHITE, Lawrence J., The antitrust revolution: Economics, competition, and policy, $5^{\text {th }}$ ed., New York, Oxford University Press, 2009; 
LAO, Marina, Neutral search as a basis for antitrust action, In Harvard Journal of Law \& Technology Occasional Paper Series, July, 2013, disponível em: http://bit.ly/1QT9bgq, acesso no dia 20, dez., 2015;

LEAL, Ana Luiza; AMORIM, Lucas, Bolha.com.br? Lojas online crescem, mas não lucram, In Revista Exame, ed. 1062, abr., 2014, disponível em: http://abr.ai/1PjiK9c, acesso no dia 8, nov., 2015;

LEE, Yoon-Ho Alex; BROWN, Donald J., Competition, consumer welfare, and the social cost of monopoly, In Yale Law School legal scholarship repository, disponível em http://bit.ly/20EUPEX, acesso no dia 8, nov., 2015;

LEINER, Barry M.; Et. Al., Brief history of the Internet, Internet Society, 2012, disponível em: http://bit.ly/1S9Zoks, acesso no dia 8, nov., 2015;

LEMOS, Ronaldo, WhatsApp e a fragilidade da rede, In Folha de São Paulo, 21, dez., 2015, disponível em: http://bit.ly/1QYTfsZ, acesso no dia 24, dez., 2015;

LEMLEY, Mark A., A new balance between IP and antitrust, Stanford Law and Economics Olin Working Paper, n. ${ }^{\circ}$ 340, 2007, disponível em: http://bit.ly/1TQy4bT, acesso no dia 6, ago., 2010;

, Intellectual property rights and standard-setting organizations, In California Law Review, vol. 90, 2002, pp. 1889-1980;

, Property, intellectual property and free riding, In Texas Law Review, vol. 83, 2004-2005, pp. 1031-1075;

; LESSIG, Lawrence, Open access to cable modems, In Whittier Law Review, vol. 22, n. ${ }^{\circ}$ 1, 2000, p. 3-34;

; MCGOWAN, David, Legal implications of network economic effects, In California Law Review, vol. 86, 1998, pp. 479-612;

LEONARDI, Marcel, Responsabilidade civil dos provedores de serviços de Internet, São Paulo, Juarez de Oliveira, 2005; 
LESSIG, Lawrence, The end of end-to-end: Preserving the architecture of the Internet in the broadband era, In UCLA Law Review, n. 48, vol. 925, 2001;

LEVIN, Jonathan, The economics of Internet markets, 2010, disponível em: http://bit.ly/1GRkYde, acesso no dia 8, nov., 2015;

LIANOS, Ioannis; MOTCHENKOVA, Evgenia; BARTELSMAN, Eric, Market dominance and quality of search results in the search engine market, disponível em: http://bit.ly/11QEehV, acesso no dia 24, jun., 2014;

LIEBOWITZ, Stan J.; MARGOLIS, Stephen E., Dismal science fictions: Network effects, Microsoft, and antitrust speculation, In Policy analysis, n. 324, 1998

; , Network externality: An uncommon tragedy, In The Journal of Economic Perspectives, vol. 8, n. ${ }^{\circ}$ 2, 1994, pp. 133-150;

, The fable of the keys, In Journal of Law and

Economics, vol. 30, n. ${ }^{\circ} 1,1990$, pp. 1-26;

LIPSKY JR., Abbot B.; SIDAK, Gregory, Essential facilities, In Stanford Law Review, vol. 51, n. ${ }^{\circ}$ 5, 1999, pp. 1187-1248;

LUCA, Michael; WU, Timothy; ET. AL., Does Google degrade Google search? Experimental evidence, 2015, disponível em: http://bit.ly/1NpGX9J, acesso no dia 17, dez., 2015;

LUCHETTA, Giacomo, Is the Google platform a two-sided market?, disponível em: http://bit.ly/1TRQw8o, acesso no dia 18, ago., 2015;

MACERA, Andréa Pereira; MONTEIRO, Carmen Diva Beltrão, Antitruste versus Antidumping: reconciliando políticas através da Cláusula do Interesse Nacional, In Revista de Políticas Públicas e Gestão Governamental, vol. 7, n. 1, 2008;

MANNE, Geoffrey A.; RINEHART, William, The market realities that undermined the FTC's antitrust case against Google, In Harvard journal of law and technology occasional paper series, July, 2013, disponível em: http://bit.ly/1FCV4Ce, Acesso no dia 25, jun. 2015; 
; WRIGHT, Joshua D., Google and the limits of antitrust: The case against the case against Google, In Harvard Journal of Law \& Public Policy, vol. 34, disponível em: http://bit.ly/1hHH4TR, acesso em 17, ago., 2015;

MARKOVITS, Richard S., Why one should never define markets or use market-oriented approaches to analyze the legality of business conduct under U.S. antitrust law, University of Texas Law, Law and Econ Research Paper n. 228, disponível em: http://bit.ly/1Ngveba, acesso no dia 29, nov., 2015;

MARTINS, Amanda Athayde Linhares, Prova indireta de cartel no âmbito das associações: comportamento paralelo e plus factors, In Economic Analysis of Law Review, Vol. 2, n. 1, 2011;

MEHRA, Salil K., Antitrust and the Robo-Seller: Competition in the time of algorithms, disponível em: http://bit.ly/1kZQtrk, acesso no dia 16, nov., 2015;

MELAMED, A. Douglas, Network industries and antitrust, disponível em http://1.usa.gov/1NCT7yx, acesso no dia 8, nov., 2015;

MENGER, Carl, On the origins of money, Ludwig von Mises Institute, disponível em: http://bit.ly/1QLweLz, acesso no dia 23, dez., 2015;

MONCADA, Luís S. Cabral de, Direito económico, $3^{\mathrm{a}}$ ed., Coimbra, Coimbra Editora, 2000 ;

MOWERY, David C.; SIMCOE, Timothy, Is the Internet a U.S. invention? - An economic and technological history of computer networking, In Research Policy, n. 31, Elsevier, 2002;

NEWBERG, Joshua A., Antitrust for the economy of ideas: the logic of technology markets, In Harvard journal of law \& technology, vol. 14, n. ${ }^{\circ}$ 1, 2000, pp. 83-137;

NEWMAN, John M., Antitrust in zero-price markets: Foundations, In University of Pennsylvania Law Review, Vol. 164, 2014, disponível em: http://bit.ly/1jEUMaX, acesso no dia 15 , out., 2015 ;

NEWMAN, Nathan, The Costs of Lost Privacy: Consumer Harm and Rising Economic Inequality in the Age of Google, In William Mitchell Law Review, Vol. 40, n. 2, 2014; 
OLIVEIRA, Gesner; RODAS, João Grandino, Direito e economia da concorrência, 2a ed., São Paulo, Revista dos Tribunais, 2013;

PASQUALE, Frank, Paradoxes of digital antitrust: Why the FTC failed to explain its inaction on Search Bias, In Harvard Journal of Lwa \& Technology Occasional Paper Series, July, 2013, disponível em: http://bit.ly/1FbNQVJ, acesso no dia 21, dez., 2015;

PATTERSON, Mark R., Google and search-engine market power, In Harvard Journal of Law \& Technology Occasional Paper Series, jul. 2013, disponível em: http://bit.ly/1kQlVZw, acesso no dia 23, nov., 2015;

PETERSON, Andrea, Google is tracking students as it sells more products to schools, privacy advocates warn, In The Washington Post, disponível em: http://wapo.st/1SjMHWP, acesso no dia 12, jan., 2016;

PITOFSKY, Robert, Challenges of the new economy: Issues at the intersection of antitrust and intellectual property, In Antitrust law journal, vol. 68, 2000-2001, pp. 913-924;

, How the Chicago school overshot the mark - The effect of conservative economic analysis on U.S. antitrust, Oxford University Press, 2008;

; Patterson, Donna; HOOKS, Jonathan, The essential facilities doctrine under U.S. antitrust law, In Antitrust law journal, vol. 70, n. . 2, 2002, pp. 443-462;

POSNER, Richard A., Antitrust in the new economy, In Antitrust law journal, vol. 68, 2000-2001, pp. 925-943;

, Antitrust law, 2nd edition, Chicago, The University of Chicago Press, 2001;

PRIEST, George L., Rethinking antitrust Law in age of networks, Yale Law \& Economics Research Paper No. 352, disponível em: http://bit.ly/1MiDyYy, acesso no dia 8, nov., 2015;

PROENÇA, José Marcelo Martins, Concentração empresarial e o direito da concorrência, São Paulo, Saraiva, 2001; 
RATLIFF, James D.; RUBINFELD, Daniel L., Is there a Market for organic search engine results and can their manipulation give rise to antitruste liability?, In Journal of Competition Law \& Economics, vol. 10, n. 3, 2014;

REEVES, Amanda P., Behavioral antitrust: Unanswered questions on the horizon, In The antitrust source, jun., 2010;

ROCHET, Jean-Charles; TIROLE, Jean, Platform competition in two-sided markets, In Journal of the European Economic Association, MIT Press, vol. 1, 2003;

, Two-Sided Markets: A Progress Report, In The RAND Journal of Economics, Vol. 37, N. 3, 2006;

SAITO, Leandro, A “propriedade” intelectual como barreira à entrada de novos players no mercado de softwares, IBPI, 2010, disponível em: http://bit.ly/1MQEGIp, acesso no dia 8, nov., 2015;

, Desafios da intervenção antitruste em indústrias de rede, In Revista de defesa da concorrência, n. 1, 2013;

SALOMÃO FILHO, Calixto, A paralisia do antitruste, In GABAN, Eduardo Molan; DOMINGUES, Juliana Oliveira (coord.), Estudos de direito econômico e economia da concorrência em homenagem ao Prof. Dr. Fábio Nusdeo, Curitiba, Juruá, 2009, pp. 15-31; , Calixto, Direito concorrencial - As condutas, São Paulo, Malheiros, 2003;

, Calixto, Direito concorrencial - As estruturas, 3a Ed., São Paulo, Malheiros, 2007;

, Calixto, Direito concorrencial, São Paulo, Malheiros, 2013;

SAMUELSON, Pamela, Are patents on interfaces impeding interoperability?, In Minnesota Law Review, vol. 93, n. ${ }^{\circ}$ 6, 2009, pp. 1943-2019;

, The strange odyssey of software interfaces and intellectual property law, UC Berkeley Public Law Research Paper n. ${ }^{\circ}$ 1.323.818, 2008, disponível em http://bit.ly/1ZcIMwW, acesso no dia 2, out., 2010; 
SANTOS, Manoel Joaquim Pereira dos, A proteção autoral de programas de computador, Rio de Janeiro, Lumen Iuris, 2008;

SCHEWICK, Barbara Van, Internet archtecture and innovation, Massachussets, MIT Press, 2010;

SCHUARTZ, Luiz Fernando, Mercados de Novas Tecnologias - Crise Anunciada do Direito da Concorrência?, In GRECO, Marco Aurélio; MARTINS, Ives Gandra da Silva (Org.), Direito e Internet - Relações Jurídicas na Sociedade Informatizada, São Paulo, Revistas dos Tribunais, 2001;

SCHUMPETER, Joseph A., Capitalism, socialism, and democracy, New York, Harper Perennial Modern Though, 1975;

SCOTT-MORTON, Fiona, Antitrust Enforcement in High-Technology Industries: Protecting Innovation and Competition, 2012, disponível em: http://1.usa.gov/1QNjSRN, acesso no dia 24, jun., 2014;

SMITH, Adam, An inquiry into the nature and causes of the wealth of nations, edição eletrônica, disponível em: http://bit.ly/1dPsCAF, acesso no dia 8, nov., 2015;

SPIEGEL, Uriel; BENZION, Uri; SHAVIT, Tal, Free product as a complement or substitute for a purchased product-Does it matter?, In Modern Economy, disponível em: http://bit.ly/1015UI0, acesso no dia 22, dez., 2015, 2011;

SHAPIRO, Carl, Antitrust in network industries, disponível em http://1.usa.gov/1kDLjkC, acesso no dia 8, nov., 2015;

, Declaration of Carl Shapiro before the United States District Court for the District of Columbia (United States of America v. Microsoft Corporation), disponível em: http://1.usa.gov/1RpdOAe, acesso no dia 18, out., 2010;

, Exclusivity in network industries, In George Mason law review, vol. 7,

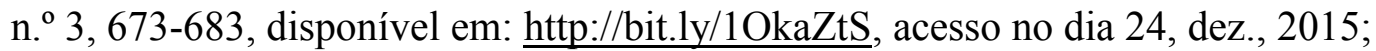

, Microsoft: A remedial failure, In Antitrust law journal, vol. 75, 2008-

2009, pp. 739-772; 
; VARIAN, Hal R., Information rules: A strategic guide to the network economy, Harvard Business Press, 1998;

SHELANSKI, Howard A., Information, Innovation, and Competition Policy for the Internet, In University of Pennsylvania Law Review, n. 161, v. 1663, 2012-2013;

SHY, Oz, The economics of network industries, Cambridge University Press, 2001;

SNYDER, Christopher; NICHOLSON, Walter, Microeconomic theory: Basic principles and extensions, 11 ed., Cengage Learning, 2012;

SPULBER, Daniel F., Unlocking Technology: Antitrust and Innovation, In Journal of Competition Law and Economics, disponível em: http://bit.ly/1m7M8Ua, acesso no dia 24, dez., 2015;

STUART, Keith; ARTHUR, Charles, PlayStation Network hack: why it took Sony seven days to tell the world, In The Guardian, 27, abr., 2011, disponível em http://bit.ly/1P7rgIo, acesso no dia 3, nov., 2015;

TECH DESK, Facebook testing 'in-app' search engine, wants users to skip Google: report, disponível em http://bit.ly/1BTSs84, acesso no dia 30, jun. 2015;

TEREPINS, Sandra, Neutralidade de rede: uma análise concorrencial da discriminação de conteúdo e aplicativos pelo detentor de rede de internet banda larga, Monografia, Prêmio SEAE, 2010, disponível em: http://bit.ly/1T2dqph, acesso no dia 25, jun., 2014;

TOR, Avishalom, The fable of entry - Bounded rationality, market discipline, and legal policy., In Michigan Law Review, Vol. 101, 2002;

THALER, Richard H., SUNSTEIN, Cass R., Nudge: Improving decisions about health, wealth, and happiness, London, Penguin Books, 2008;

VAIDHYANATHAN, Siva, The Googlization of everything: (And why we should worry), Berkeley, University of California Press, 2011;

VARIAN, Hal. R, Computer-mediated transactions, In SZOKA, Berin; MARCUS, Adam, The next digital age: Essays on the future of the Internet, Washington, Tech Freedom, 2010; 
, Intermediate Microeconomics, 8th Ed., 2009, traduzido por SERGIO

DA SILVA, disponível em: http://bit.ly/1IV5Egr, acesso no dia 19, out., 2011;

, Microeconomia - Princípios básicos, $7^{\mathrm{a}}$ ed., São Paulo, Campus, 2006;

; FARRELL, Joseph; SHAPIRO, Carl, The economics of information technology: An introduction, Cambridge University Press, 2005;

WEISER, Philip J., The Internet, innovation, and intellectual property policy, In Columbia law review, vol. 103, 2003, pp. 534- 613;

WEISMAN, Aly, Jerry Seinfeld's Wife Spent \$415 During Uber's Surge Pricing To Make Sure Her Kid Got To A Sleepover, disponível em: http://read.bi/1WNDu9Y, acesso em 07, out., 2015;

WERDEN, Gregory J., The law and economics of the essential facility doctrine, In Saint Louis university law journal, vol. 32, n. ${ }^{\circ}$ 2, 1987, pp. 433-480;

, Why (ever) define markets? An answer to Professor Kaplow, 2012, disponível em: http://bit.ly/1106TAF, acesso no dia 29, nov., 2015;

WILLIAMSON, Oliver E., Mechanisms of Governance, New York, Oxford University Press, 1996;

WOOD, David, EU Competition Law and the Internet - Present and past, In Competition Law International, n. 7, 2011;

WRIGHT, Joshua D., Broadband policy \& consumer welfare: The case for an antitrust approach to net neutrality issues, Remarks at the Information Economy Project's Conference on US Broadband Markets in 2013, disponível em http://1.usa.gov/1WHeOUb, acesso no dia 8, nov., 2015;

, Defining and measuring search bias: Some preliminary evidence, George Mason University Law and Economics Research Paper Series, 2011, disponível em: http://bit.ly/1Lxa90i, acesso no dia 25, nov., 2015;

WU, Tim, Impérios da comunicação: Do telefone à internet, da AT\&T ao Google, Rio de Janeiro, Zahar, 2012; 
YOO, Christopher S., Beyond network neutrality, In Harvard journal of law \& technology, Vol. 19, 2005, pp. 1-77;

ZITTRAIN, Jonathan, Facebook could decide an election without anyone ever finding out, Disponível em http://bit.ly/1m3tA3e, acesso no dia 05, out., 2015;

, The Future of the Internet - And How to Stop It, New Haven, Yale University, 2008. 